


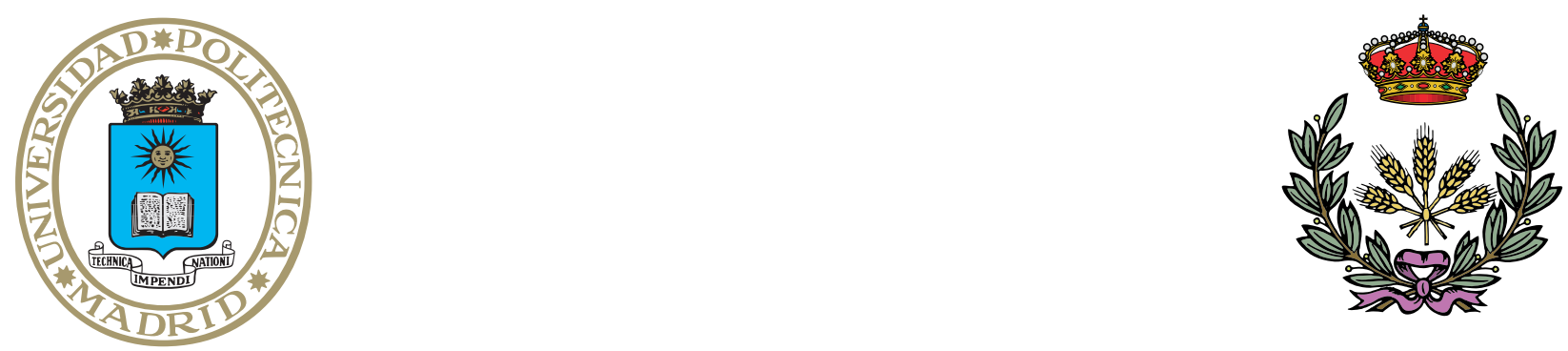

UNIVERSIDAD POLITÉCNICA DE MADRID

Escuela Técnica Superior de Ingeniería Agronómica,

Alimentaria y de Biosistemas

\title{
Caracterización e influencia del terroir sobre la composición de la uva y los componentes vegeto-productivos de la vid (Vitis vinifera L.) en la DOCa Rioja
}

\author{
TESIS DOCTORAL
}

ÁLVARO MARTÍNEZ HERNÁNDEZ

Máster en Tecnología Agroambiental para una Agricultura Sostenible

Madrid, 2020 





\title{
DEPARTAMENTO DE PRODUCCIÓN AGRARIA
}

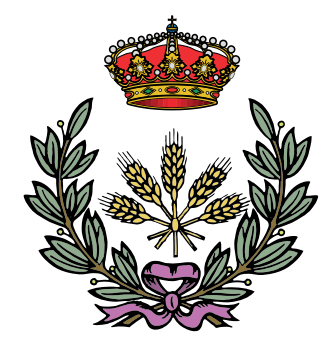

Escuela Técnica Superior de Ingeniería Agronómica,

Alimentaria y de Biosistemas

UNIVERSIDAD POLITÉCNICA DE MADRID

\section{Caracterización e influencia del terroir sobre la composición de la uva y los componentes vegeto-productivos de la vid (Vitis vinifera $\mathrm{L}$. en la DOCa Rioja}

\author{
TESIS DOCTORAL
}

Autor:

ÁLVARO MARTÍNEZ HERNÁNDEZ

Máster en Tecnología Agroambiental para una Agricultura Sostenible

Director:

VICENTE GÓMEZ MIGUEL

Doctor Ingeniero Agrónomo

Madrid, 2020 

«iMuchacho, muchacho, no sigas! Como azotado por espíritus invisibles, los caballos solares del tiempo se precipitan con el carro ligero de nuestro destino y no nos queda más que agarrar fuertemente las riendas y apartar las ruedas a izquierda y derecha de esta piedra o de aquella caída. ¿Quién sabe adónde vamos? Si a duras penas recuerda nadie de dónde viene...»

LIBRO XX, POESÍA Y VERDAD, J.W. VON GOETHE.

A mis padres, Ángel (in memoriam) y Sonsoles. 



\section{Agradecimientos.}

Las siguientes personas e instituciones han participado activa y positivamente en la ejecución de esta tesis doctoral, por lo que expreso mi agradecimiento a:

Profesor Vicente Gómez, por darme la oportunidad de realizar este trabajo bajo su exigente dirección y por compartir sus profundos conocimientos edafológicos, su originalidad y su rigurosidad científica durante el desarrollo del mismo.

Profesores María Luisa González, Alberto Masaguer y Rafael Espejo, por su disponibilidad y aportaciones que han mejorado el documento final.

Departamento de Edafología de la UPM, actual Departamento de Producción Agraria, por prestar sus instalaciones y recursos cuando fueron necesarios y, en particular, Joaquín Cámara por su ayuda en la apertura y descripción en campo de las calicatas y Carmen Diéguez por su asesoramiento en los aspectos burocráticos.

Estación Enológica de Haro, especialmente Montserrat Iñiguez y Elena Meléndez, por su colaboración desinteresada en los análisis anuales de las muestras de uva.

Bodegas de los Herederos del Marqués de Riscal, en particular Luis Hurtado de Amézaga, por permitir compaginar mi labor profesional con el desarrollo de esta tesis.

Instituto Geográfico Nacional, que a través del Plan Nacional de Teledetección (PNT), ha posibilitado y facilitado el acceso a imágines multiespectrales SPOT 5.

Área de Teledetección del Instituto Nacional de Técnica Aeroespacial (INTA), especialmente Manuel Simón, por su asesoramiento y gestión en la adquisición de escenas multiespectrales Pléiades.

Jorge Elías, por su inestimable ayuda en la maquetación del documento.

María Eugenia Mugaburu, por tu imprescindible ayuda en la toma de las muestras en campo y por tu alentador e incondicional apoyo, sin el cual dudo que esta empresa hubiera llegado a buen término. 


\section{Resumen.}

Los factores naturales que definen el terroir son responsables de la variabilidad observada entre plantas de una misma parcela (variabilidad intraparcela) o de distintas fincas (variabilidad interparcela). En el presente trabajo se propone una microzonificación integrada del terroir (mapa ejecutivo 1:2.500) en cuatro viñedos de la Denominación de Origen Calificada Rioja (DOCa Rioja) a partir de una macrozonificación previa (mapa de gestión 1:50.000) integrando el uso de la teledetección posibilitando reducir el número de observaciones.

La zonificación de los elementos del medio se ha llevado a cabo a partir de la fotointerpretación aérea (FIA), del estudio edafológico y del índice de vegetación de diferencia normalizada (NDVI). La FIA se realizada sobre un histórico de ortofotografías aéreas, el estudio edafológico mediante la descripción, análisis y clasificación de los perfiles del suelo y la representación gráfica del NDVI se efectúa partiendo de imágenes multiespectrales capturadas por los satélites Pleiades y SPOT de 0,5 y 2,5 metros de resolución espacial, respectivamente. Comparando los datos vegeto-productivos y de composición de la uva obtenidos en sectores diferenciados por la metodología propuesta se ha observado que existen sectores con tendencia a ser más vigorosos, más productivos y con uvas con un menor contenido fenólico y de mayor acidez.

En la microzonificación propuesta se ha utilizado un modelo paramétrico (el mismo que se utilizó en el mapa de gestión de referencia) basado en el índice de calidad del suelo (ICA) para la integración de resultados, así como los resultados vegeto-productivos y de composición de la uva para la validación de la misma. Esta validación ha sido positiva encontrando relaciones significativas entre los parámetros determinantes del medio y variables relacionadas con el mosto como el GAP, la acidez y el contenido polifenólico.

La extrapolación de los resultados a la DOCa Rioja, realizada a través del NDVI, representa una aportación metodológica que mejora notablemente la definición de las unidades del mapa de gestión de referencia, permitiendo de este modo el uso del mapa original como un mapa de mayor detalle susceptible de ser utilizado en Viticultura de Precisión, permitiendo realizar una viticultura personalizada y sostenible. 


\section{Abstract.}

The natural factors that define the terroir are responsible for the variability observed between plants of the same plot (intra-plot variability) or of different farms (inter-plot variability). In the present work, an integrated microzonification of the terroir (executive map 1:2,500) is proposed in four vineyards of the Rioja Qualified Denomination of Origin (DOCa Rioja) from a previous macrozonification (management map 1: 50,000) integrating the use of remote sensing making it possible to reduce the number of observations.

The zoning of the elements of the environment has been carried out based on aerial photointerpretation (FIA), the edaphological study and the standardized difference vegetation index (NDVI). The FIA is carried out on a history of aerial orthophotographs, the edaphological study by means of the description, analysis and classification of the soil profiles and the graphic representation of the NDVI is made based on multispectral images captured by the Pleiades and SPOT satellites of 0.5 and 2.5 meters of spatial resolution, respectively. Comparing the vegeto-productive and grape composition data obtained in sectors differentiated by the proposed methodology, it has been observed that there are sectors with a tendency to be more vigorous, more productive and with grapes with a lower phenolic content and greater acidity.

In the proposed microzonation, a parametric model (the same one that was used in the reference management map) based on the soil quality index (ICA) has been used for the integration of results, as well as the vegetative and productive results of grape composition for the validation of it. This validation has been positive finding significant relationships between the determining parameters of the environment and variables related to the must such as GAP, acidity and polyphenolic content.

The extrapolation of the results to DOCa Rioja, carried out through the NDVI, represents a methodological contribution that significantly improves the definition of the units of the reference management map, thus allowing the use of the original map as a map of greater detail capable of being used in Precision Viticulture, allowing a personalized and sustainable viticulture. 



\section{Índice general.}

Abreviaturas, Acrónimos y Observaciones ............................................ V

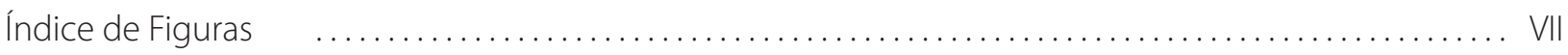

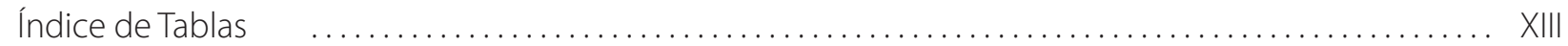

Capítulo 1. INTRODUCCIÓN......................................................... 1

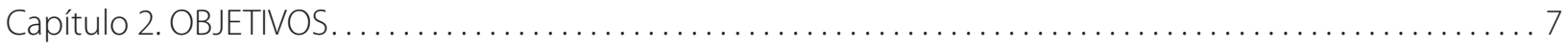

Capítulo 3. ANTECEDENTES. .................................................... 11

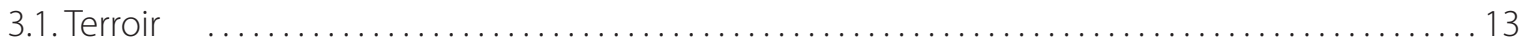

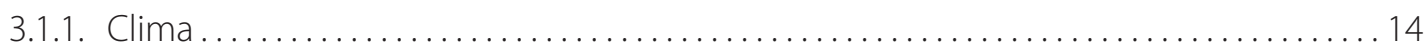

3.1.1.1. Luz Solar .................................................... 15

3.1.1.2. Temperatura.............................................. 16

3.1.1.3. Precipitación .................................................... 18

3.1.1.4. Humedad Relativa.............................................. 19

3.1.1.5. Vid, viñedo y cambio climático................................ 20

3.1.2. Geología, geomorfología y geografía................................. 21

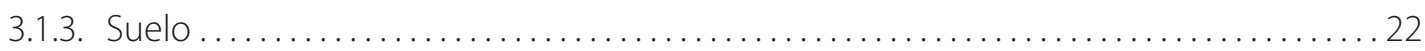

3.1.3.1. Propiedades Físicas ................................................. 22

3.1.3.2. Propiedades Químicas ............................................ 23

3.1.3.3. Propiedades Biológicas............................................... 26

3.1.4. Material vegetal ................................................... 26

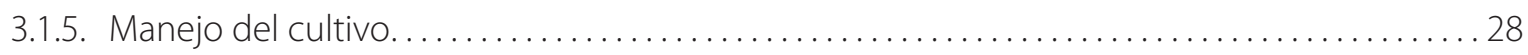

3.2. Variabilidad vitícola....................................................... 31

3.3. Zonificación vitícola........................................................ 34

3.3.1. Límites preexistentes ................................................. 35

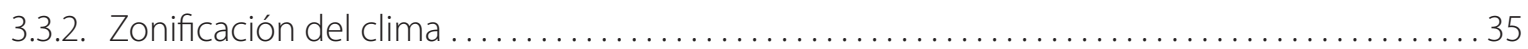

3.3.3. Zonificación del medio ....................................................... 36

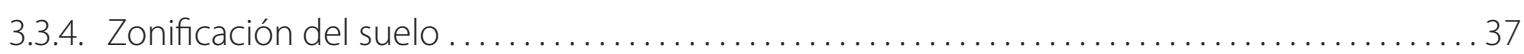

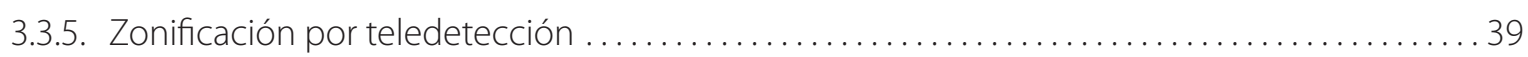

3.3.6. Zonificación Integrada del Terroir .......................................... 40

3.4. Conclusión........................................................... 41 


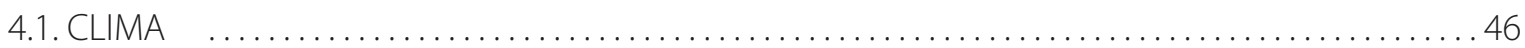

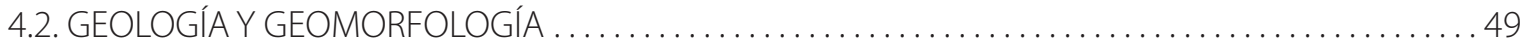

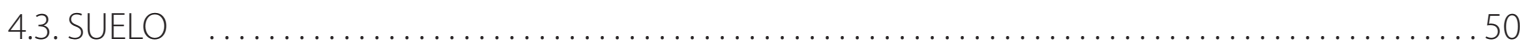

4.4. VEGETACIÓN Y CULTIVO ................................................... 54

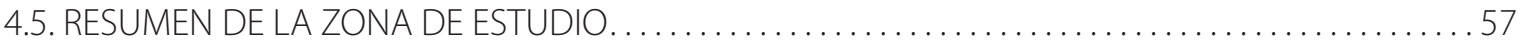

Capítulo 5. MATERIAL Y MÉTODOS ................................................... 59

5.1. Diseño experimental .................................................. 61

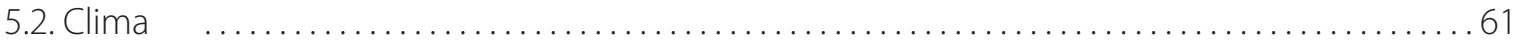

5.3. Litología y geomorfología .................................................. 62

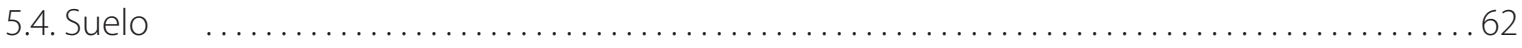

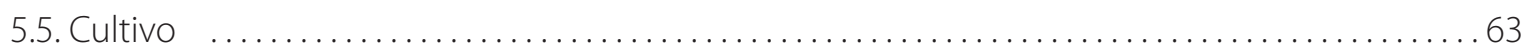

5.5.1. Mantenimiento del suelo .......................................... 64

5.5.2. Tratamientos fitosanitarios ............................................ 64

5.5.3. Técnicas de cultivo y fenología .......................................... 65

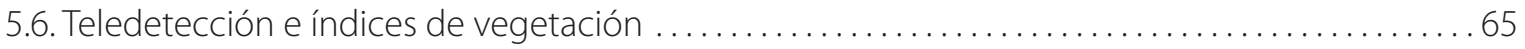

5.7. Agronomía y producción. ................................................... 66

5.8. Composición y características físicoquímicas de la uva............................ 67

5.9. Zonificación integrada del terroir ........................................ 68

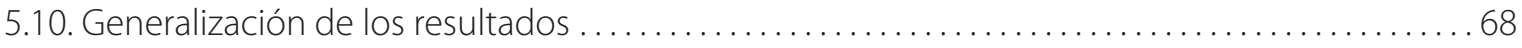

5.11. Análisis estadístico ........................................................ 68

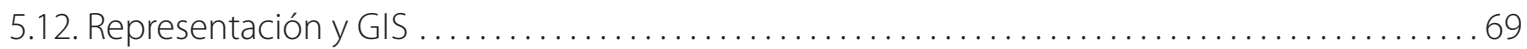




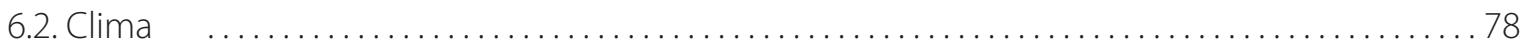

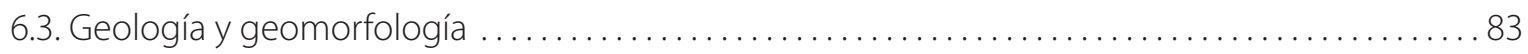

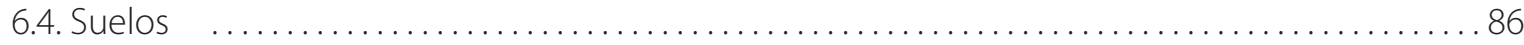

6.4.1. Edafoclima.................................................... 87

6.4.2. Clasificación y correlación............................................... 99

6.5. Zonificación Integrada del Terroir (ZIT) . ..................................... 104

6.5.1. Teledetección: ajuste y precisión de los límites ............................. 104

6.5.2. Componentes vegeto-productivos .................................... 113

6.5.2.1. Número de racimos ............................................ 116

6.5.2.2. Peso del racimo y producción ................................... 119

6.5.2.3. Longitud y calibre del sarmiento ................................. 119

6.5.2.4. Peso de madera de poda ........................................... 119

6.5.2.5. Índice de ravaz. Equilibrio vegeto-productivo ......................... 119

6.5.3. Composición de la uva............................................... 120

6.5.3.1. Grado alcohólico probable ....................................... 123

6.5.3.2. Acidez total. .............................................. 124

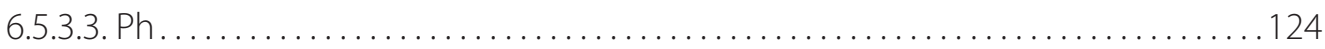

6.5.3.4. Ácido málico ..................................................... 124

6.5.3.5. Intensidad de color ........................................... 127

6.5.3.6. Índice de polifenoles totales .................................... 127

6.5.3.7. Antocianos .................................................... 127

6.5.3.8. Potasio ........................................................ 128

6.5.3.9. Ácido tartárico ........................................... 128

6.5.3.10. Peso de 100 bayas......................................... 128

6.5.4. Relación entre parámetros del suelo y vitícolas ............................. 128

6.6. Mapa de Zonificación Integrada del Terroir (ZIT) . ................................. 146

6.7. Extrapolación a la DO CA Rioja ................................................... 165

6.8. Conclusión............................................................ 167

Capítulo 7. CONCLUSIONES ....................................................... 169

Capítulo 8. BIBLIOGRAFÍA ........................................................... 173 


$$
\text { . }
$$




\section{Abreviaturas, acrónimos y observaciones.}

Abreviaturas

\begin{tabular}{|c|c|c|c|}
\hline${ }^{\circ} \mathrm{C}:$ & grado Celsius & km: & kilómetro \\
\hline$A C:$ & Acidez de Cambio & $\mathrm{nm}:$ & nanómetros \\
\hline$A C P$ : & Análisis de Componentes Principales & $\mathrm{m}:$ & metro \\
\hline AJC: & Análisis Jerárquico Cluster & $\mathrm{m} 2:$ & metro cuadrado \\
\hline \multirow[t]{2}{*}{ BTU: } & Unidad Base de Terroir (del inglés: & MC: & Media Cuadrática \\
\hline & Basic Terroir Unit) & MCCS: & Sistema de Clasificación Climática \\
\hline CE: & Conductividad Eléctrica & & Multicriterio (del inglés: Multicriteria \\
\hline \multirow[t]{2}{*}{ CE1:5: } & Conductividad Eléctrica en extracto & & Climatic Classification System) \\
\hline & acuoso 1:5 & MDT: & Mapa Digital del Terreno \\
\hline cmol: & centimol & mg: & miligramo \\
\hline CV: & Coeficiente de Variación & mm: & milímetros \\
\hline dS: & decisiemens & mo: & materia orgánica \\
\hline ETP: & Evapotranspiración Potencial, mm & msnm: & metros sobre el nivel del mar \\
\hline \multirow[t]{2}{*}{ ETPTH: } & Evapotranspiración potencial Thor- & NIR: & Absorbancia del Infrarojo Cercano \\
\hline & nwaite, mm & Ol: & Índice de Oportunidad (del inglés: \\
\hline \multirow[t]{2}{*}{ ETPB-C: } & Evapotranspiración FAO-Blaney-Cri- & & Opportunity Index) \\
\hline & ddle, mm & $P:$ & Producción \\
\hline g: & gramo & $\mathrm{PH}:$ & Producto Heliotérmico de Branas \\
\hline h: & hora & PRE: & Precipitación media anual, mm \\
\hline ha: & hectárea & PSI: & Porcentaje de Sodio Intercambiable \\
\hline$H X:$ & Índice Heliotérmico de Branas & $P V:$ & Viticultura de Precisión (del inglés: \\
\hline HR: & Humedad Relativa & & Precision Viticulture) \\
\hline Ic: & Índice de Cambardella & $\mathrm{R}:$ & Absorbancia del Rojo \\
\hline $\mathrm{IC}$ & Índice de Color & SB: & Suma de Cationes o Bases \\
\hline ICA: & Índice de Calidad & SFE: & Superficie Foliar Expuesta \\
\hline $\mathrm{IF}:$ & Índice de Frío Nocturno & Sig.: & grado de significación \\
\hline \multirow[t]{2}{*}{$\mathrm{HC}:$} & Índice Heliohidrotérmico de Cons- & SS: & Suma de Cuadrados \\
\hline & tantinescu & TM: & Temperatura Media, ${ }^{\circ} \mathrm{C}$ \\
\hline $\mathrm{H}$ : & Índice Heliotérmico de Huglin & $P C:$ & porcentaje \\
\hline IS: & Índice de Sequía & PRE: & Precipitación \\
\hline IPT: & Índice de Polifenoles Totales & TOi: & Índice de Oportunidad Técnica (del \\
\hline \multirow[t]{2}{*}{ ITE: } & Integral Térmica Eficaz (Índice de & & inglés: Technical Opportunity Index) \\
\hline & Winkler) & UHM: & Unidad Homogénea del Medio \\
\hline 川 & Índices de Vegetación & UHT: & Unidad Homogénea del Terroir \\
\hline IW: & Índice de Winkler & $V:$ & Porcentaje de Saturación de Bases \\
\hline & kilogramo & W & vatio \\
\hline
\end{tabular}




\section{Acrónimos}

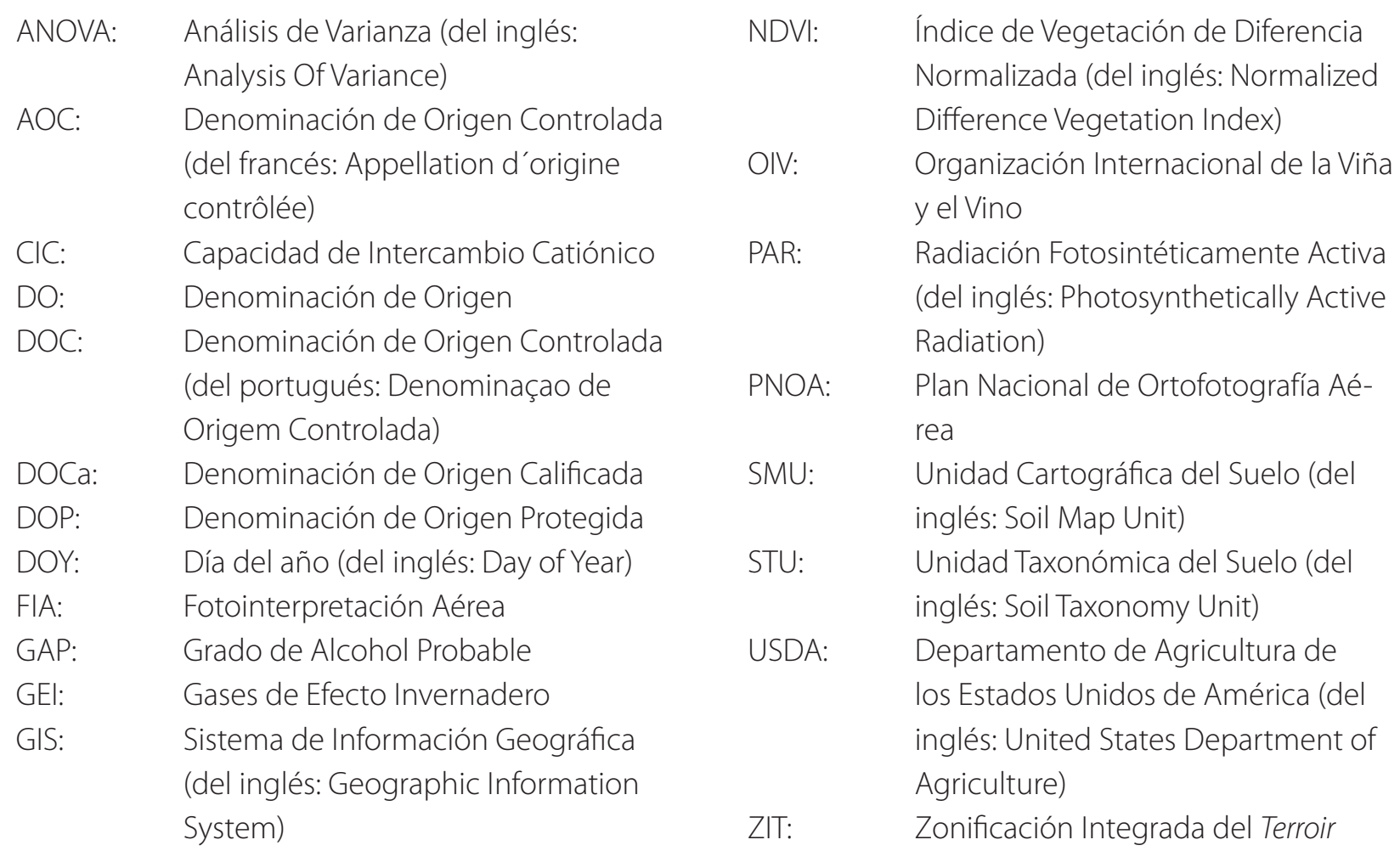

Por último, algunas aclaraciones generales relacionadas con la lectura del texto:

- Siempre que se hace referencia a uva, si no se indica lo contrario, debe entenderse uva tinta,

- En determinadas ocasiones se hace referencia a producción de uva y a producción de vino de forma indiferenciada ya que el estudio trata exclusivamente de uva de vinificación,

- Cuando se hace referencia a la situación geográfica de un viñedo se sobrentiende que está situado en el hemisferio norte, excepto si se indica lo contrario de forma explícita.

- Cuando se habla de figuras de protección, particularmente de Denominaciones de Origen, se hace referencia al vino a no ser que se especifique el producto agroalimentario del que se trata. 


\section{Índice de figuras.}

Figura 1. Histórico de publicaciones indexadas en Web of Science sobre la temática del terroir ........ 4

Figura 2. Factores y elementos del terroir (Gómez-Miguel, 2011) ......................... 13

Figura 3. Temperatura media $\left({ }^{\circ} \mathrm{C}\right)$ y precipitación $(\mathrm{mm})$ en 6 zonas de producción de vino de calidad. Datos de Mendoza y Adelaida con un desfase de 6 meses. Elaboración propia a partir de Tonietto (2017) .............................................. 15

Figura 4. Concentraciones atmosféricas de CO2 en los últimos 22.000 años (a) y en el período 1960-2018 (b), (aemet, 2019)

Figura 5. Propiedades del medio sobre las que afecta la interacción entre geología y clima, (Selley, 2004 en Hancock, 2005)

Figura 6. pH y propiedades del suelo relacionadas con la nutrición de la vid (Gómez-Miguel, 2011). . . . . 25

Figura 7. Plasticidad térmica de varios cultivares de vid en función de la temperatura media durante el ciclo vegetativo (Jones, 2006) ................................... 27

Figura 8. Operaciones de cultivo en relación con el medio físico y la vid

Figura 9. Zonificación (macrozonificación y microzonificación): escala de trabajo y niveles de producción (Gómez-Miguel, 2011) ........................................... 32

Figura 10. Criterios de zonificación incluidos en la zonificación integrada del terroir 34

Figura 11. Esquema metodológico de la zonificación del Geositio: Geomorfología, Litología y Vegetación (Gómez-Miguel \& Sotes, 2003).

Figura 12. Representación de: (A) estado hídrico evaluado por la medida del C13 sobre el azúcar de la uva; (B) resistividad eléctrica del suelo (van Leeuwen et al., 2009)

Figura 13. Situación de los viñedos (Ricio, Naval, Campillo y Majadahonda) objeto de estudio. A: en la DOCa Rioja; B: como transición entre Rioja Alta y Rioja Oriental; C: en relación con el centro urbano de Oyón

Figura 14. Zonas climáticas en la DOCa Rioja y detalle del término Municipal de Oyón ubicado principalmente en la zona 3. Elaboración propia a partir de Gómez-Miguel y Sotés (1990-2017) . . . . 
Figura 15. Zonas litológicas en la DOCa Rioja y detalle del término Municipal de Oyón ubicado principalmente en la zona 10: Formaciones Haro y Transición. Elaboración propia a partir de Gómez-Miguel y Sotés $(1990-2017)$....................................... 50

Figura 16. Mapa de suelos de la DOCa Rioja y detalle del término Municipal de Oyón. Elaboración propia a partir de Gómez-Miguel y Sotés (1990-2017). ............................ 51

Figura 17. Distribución parcelaria del viñedo (2017) en la DOCa Rioja y detalle del término Municipal de Oyón. Elaboración propia a partir de datos del Registro Vitícola de 2017 56

Figura 18. Características y situación de la Estación meteorológica de Viana respecto a las parcelas del ensayo.

Figura 19. Parcela Ricio. Representación gráfica de: 1. Imagen satelital Pléiades; 2. NDVI calculado pixel a pixel; 3. NDVI calculando cada pixel como media de $6 \times 6$ píxeles (9m2); 4 . Segementación supervisada de NDVI

Figura 20. Resultado de la sectorización y muestreo de las parcelas A: NAVAL; B: RICIO; C: CAMPILLO y D: MAJADAHONDA con la referencia de los perfiles y la codificación utilizada en este trabajo.

Figura 21. Sectorización y muestreo de la parcela NAVAL a partir de ortofotos procedentes de diferentes vuelos del IGN. Elaboración propia a partir de georreferenciación del IGN

Figura 22. Sectorización y muestreo de la parcela RIClO a partir de ortofotos procedentes de diferentes vuelos del IGN. Elaboración propia a partir de georreferenciación del IGN . . . . . . 75

Figura 23. Sectorización y muestreo de la parcela CAMPILLO a partir de ortofotos procedentes de diferentes vuelos del IGN. Elaboración propia a partir de georreferenciación del IGN

Figura 24. Sectorización y muestreo de la parcela MAJADAHONDA a partir de ortofotos procedentes de diferentes vuelos del IGN. Elaboración propia a partir de georreferenciación del IGN.

Figura 25. Temperatura media mensual de los años del ensayo y de la serie histórica. Estación meteorológica de Viana (Gobierno de Navarra, 2019). ...

Figura 26. Precipitación mensual de los años del ensayo y de la serie histórica. Estación meteorológica de Viana (Gobierno de Navarra, 2019)

Figura 27. Comparación del año medio (rosa, morado, amarillo) con los años del ensayo [flechas: años 2012 (rojo); 2013 (verde); 2014 (marrón); 2015 (azul)] conforme a la metodología MCCS (Tonietto \& Carbonneau, 2004). 
Figura 28. Distribución espacial de la formación F. de Haro (W) del Terciario y las formaciones aluviales del cuaternario asociadas a ella (FW) en la DOCa Rioja. Elaboración propia a partir de Gómez-Miguel y Sotés, 1990-2017

Figura 29. Detalle de la formación Facies de Haro en las parcelas del ensayo (A. NAVAL; B. RICIO; C. CAMPILLO; D. MAJADAHONDA) y su relación con los sectores realizados en el § 5.1. La falta de ajuste de los límites se debe a la gran diferencia entre las escalas de trabajo (1:2.500 versus $1: 50.000)$

Figura 30. Representación gráfica 3D (a partir de MDT de 5m de resolución) junto con la FIA cartografiada sobre las parcelas de ensayo

Figura 31. Reserva acumulada de agua $(\mathrm{mm})$ calculada de los 20 perfiles estudiados 88

Figura 32. Representación gráfica de la reserva de agua del suelo $(\mathrm{mm})$ durante el año 2012 en los diferentes perfiles del ensayo

Figura 33. Representación gráfica de la reserva de agua del suelo $(\mathrm{mm})$ durante el año 2013 en los diferentes perfiles del ensayo

Figura 34. Representación gráfica de la reserva de agua del suelo $(\mathrm{mm})$ durante el año 2014 en los diferentes perfiles del ensayo7.

Figura 35. Representación gráfica de la reserva de agua del suelo $(\mathrm{mm})$ durante el año 2015 en los diferentes perfiles del ensayo

Figura 36. Representación de la reserva de agua $(\mathrm{mm})$ de los diferentes perfiles en la parcela NAVAL para cada uno de los años de ensayo. En la columna A se representa la reserva de agua del suelo del mes de mayo y en la columna B se recoge la reserva anual como suma de las reservas mensuales, aunque no es un valor físicamente justificable, si es un buen indicativo del agua disponible para el cultivo. En la figura 2012B también se incluye el símbolo de la STU del mapa de la DOCa Rioja (ver Tabla 25)

Figura 37. Representación de la reserva de agua $(\mathrm{mm})$ de los diferentes perfiles en la parcela RIClO para cada uno de los años de ensayo. En la columna A se representa la reserva de agua del suelo del mes de mayo y en la columna B se recoge la reserva anual como suma de las reservas mensuales, aunque no es un valor físicamente justificable, si es un buen indicativo del agua disponible para el cultivo. En la figura 2012B también se incluye el símbolo de la STU del mapa de la DOCa Rioja (ver Tabla 25) .................. 96 
Figura 38. Representación de la reserva de agua $(\mathrm{mm})$ de los diferentes perfiles en la parcela CAMPILLO para cada uno de los años de ensayo. En la columna A se representa la reserva de agua del suelo del mes de mayo y en la columna B se recoge la reserva anual como suma de las reservas mensuales, aunque no es un valor físicamente justificable, si es un buen indicativo del agua disponible para el cultivo. En la figura 2012B también se incluye el símbolo de la STU del mapa de la DOCa Rioja (ver Tabla 25). ...

Figura 39. Representación de la reserva de agua $(\mathrm{mm})$ de los diferentes perfiles en la parcela MAJADAHONDA para cada uno de los años de ensayo. En la columna A se representa la reserva de agua del suelo del mes de mayo y en la columna B se recoge la reserva anual como suma de las reservas mensuales, aunque no es un valor físicamente justificable, si es un buen indicativo del agua disponible para el cultivo. En la figura 2012B también se incluye el símbolo de la STU del mapa de la DOCa Rioja (ver Tabla 25). ...

Figura 40. Dendrograma del análisis jerárquico cluster (AJC) de las variables del suelo analizadas . . . 100

Figura 41. Regresión lineal entre la materia orgánica (mo) y la capacidad de intercambio catiónico $(\mathrm{ClC})$

Figura 42. Representación de los sectores obtenidos por la FIA sobre el NDVI para la parcela NAVAL y para los diferentes años con dos métodos distintos: en la columna A se ha utilizado como universo todas las parcelas en su conjunto y en la B únicamente cada parcela.

Figura 43. Representación de los sectores obtenidos por la FIA sobre el NDVI para la parcela RICIO y para los diferentes años con dos métodos distintos: en la columna A se ha utilizado como universo todas las parcelas en su conjunto y en la B únicamente cada parcela. . .

Figura 44. Representación de los sectores obtenidos por la FIA sobre el NDVI para la parcela CAMPILLO y para los diferentes años con dos métodos distintos: en la columna A se ha utilizado como universo todas las parcelas en su conjunto y en la B únicamente cada parcela

Figura 45. Representación de los sectores obtenidos por la FIA sobre el NDVI para la parcela MAJADAHONDA y para los diferentes años con dos métodos distintos: en la columna A se ha utilizado como universo todas las parcelas en su conjunto y en la B únicamente cada parcela

Figura 46. FIA y clasificación del NDVI, calculado pixel a pixel, para las cuatro parcelas experimentales y los cuatro años de estudio.

Figura 47. Sectorización definitiva de las parcelas del ensayo, incluyendo: Columna A, generalización de los perfiles del ensayo; Columna B, equivalencia con STU de Gómez-Miguel y Sotés (1997) 
Figura 48. Representación de las variables vegeto-productivas estudiadas por sectores: C1, C2 y C3: CAMPILLO; M1 Y M2: MAJADAHONDA; N1 Y N2: NAVAL; R1, R2 Y R3: RICIO. . .

Figura 49. Representación de las variables vegeto-productivas estudiadas durante los cuatro años de ensayo

Figura 50. Representación de las variables relacionadas con la uva por sectores

Figura 51. Representación de las variables relacionadas con la uva durante los cuatro años de ensayo, cuando hubo diferencias significativas en el análisis ANOVA ...

Figura 52. Gráfico Biplot con la distribución de observaciones (10 sectores) y variables (Tabla 36) del Análisis de Componentes Principales según los factores 1 (eje F1: abscisas) y 2 (eje F2: ordenadas)

Figura 53. Gráfico Biplot con la distribución de observaciones (20 sectores) y variables (Tabla 37) del Análisis de Componentes Principales según los factores 1 (eje F1: abscisas) y 2 (eje F2: ordenadas) ....

Figura 54. Zonificación Integrada del Terroir (ZIT): en la columna A se representa la agrupación del índice de calidad (ICA) por clases y en la columna B su distribución en porcentajes distribuidos de forma aleatoria en 10 clases...

Figura 55. Superficie (ha, \%) por clases como resultado de la Zonificación Integrada del Terroir (ZIT) en las parcelas del ensayo.

Figura 56. Gráfico Biplot con la distribución de observaciones (20 sectores) y variables (Tabla 43) del Análisis de Componentes Principales según los factores 1 (eje F1: abscisas) y 2 (eje F2: ordenadas) ....

Figura 57. Distribución geográfica del ácido tartárico (TH2, g/l) en las cuatro parcelas del ensayo y durante los cuatro años (etiquetas) en relación con las clases (colores) procedentes de la ZIT (compárese con la Figura 54).

Figura 58. Distribución geográfica del contenido en antocianos (ANTO, mg/l) en las cuatro parcelas del ensayo y durante los cuatro años (etiquetas) en relación con las clases (colores) procedentes de la ZIT (compárese con la Figura 54)

Figura 59. Distribución geográfica del Índice de Polifenoles Totales (IPT) en las cuatro parcelas del ensayo y durante los cuatro años (etiquetas) en relación con las clases (colores) procedentes de la ZIT (compárese con la Figura 54)

Figura 60. Distribución geográfica de las unidades de la DOCa Rioja a las que es posible realizar la extrapolación de los resultados del ensayo. Se destaca la zona extrapolada en la Figura 61. Elaboración propia a partir de Gómez-Miguel y Sotés (1997). 
Figura 61. ZIT de la zona geográfica de la DOCa Rioja a la que se han extrapolado los resultados del ensayo: ver la Figura 60. Se incluye la situación de las parcelas de ensayo. ...

Figura 62. Comparación de la ZIT de la zona geográfica de la DOCa Rioja procedente del resultado de la extrapolación de los datos del ensayo (A) con del estudio a escala original 1:50.000 (B) 


\section{Índice de tablas.}

Tabla 1. Niveles de referencia de materia orgánica (MO), P, K y Mg en los primeros $30 \mathrm{~cm}$ de suelo en viñedos de Rioja Alavesa según la Diputación Foral de Álava (Unamunzaga, 2010).......................................................... 26

Tabla 2. Variabilidad interanual de la producción (\%) en función de los componentes del rendimiento. Elaboración propia a partir de Clingeleffer et al, (2001). . .

Tabla 3. Variables climáticas los centros de gravedad (CDG) de las seis Zonas Climáticas de la DOCa Rioja y detalle del centro de gravedad de la ZC 3 (Fernández, 1999) y de la Estación Meteorológica de Viana (Gobierno de Navarra, 2019)

Tabla 4. Aplicación de MCCS sobre datos de la serie histórica (1982-2015) de la Estación meteorológica de Viana. Elaboración propia a partir de datos de Gobierno de Navarra (2019) ................................................. 48

Tabla 5. Descripción de las SMU en términos de STU incluyendo su litología, su clase (vocación vitícola) y el porcentaje (PC), el Índice de Calidad (ICA) y la clasificación (subgrupo, USDA, 1975) de las STU principal y secundaria en el término Municipal de Oyón. Elaboración propia a partir de Gómez-Miguel y Sotés (1990-2017) .

Tabla 6. Distribución del viñedo en producción por subzonas y color de la variedad (CRDOCa Rioja, 2016)....................................................... 54

Tabla 7. Superficie (ha) ocupada por variedades blancas en la DOCa Rioja (CRDOCa Rioja, 2016)....... 55

Tabla 8. $\quad$ Superficie (ha) ocupada por variedades tintas en la DOCa Rioja (CRDOCa Rioja, 2016) ...... 55

Tabla 9. Determinaciones analíticas realizadas sobre las muestras de tierra, correspondientes a las 20 calicatas abiertas

Tabla 10. Ecuación para el cálculo del NDVI. NIR: Absorbancia del Infrarrojo cercano y R: Absorbancia del Rojo

Tabla 11. Medidas realizadas sobre todos los individuos de las 20 repeticiones

Tabla 12. Determinaciones analíticas realizadas sobre el procesado de 100 bayas

Tabla 13. Resumen de algunos elementos e índices climáticos de los años de estudio y de la serie histórica. Estación meteorológica de Viana (Gobierno de Navarra, 2019). . . . 78 
Tabla 14. Comparación de Índice de Constantinescu (IHC) y de evapotranspiración potencial FAO-Blaney-Criddle (ETPB-C) de los años de ensayo y de las zonas climáticas de la DOCa Rioja.

Tabla 15. MCCS (Tonietto \& Carbonneau, 2004) aplicado a los años de ensayo y a la serie histórica. Estación meteorológica de Viana. Fuente de datos: www.meteo.navarra.es ... 80

Tabla 16. Cantidad de agua empleada por parcela durante el año 2012

Tabla 17. Estados fenológicos mayores (Coombe, 1995) para las cuatro parcelas y los cuatro años de estudio.

Tabla 18. Días transcurridos entre algunos de los estados fenológicos mayores. DS: Desviación Estándar

Tabla 19. Densidad de observaciones consideradas por diferentes metodologías (obs/cm2 de mapa), el número de observaciones por ha para un mapa a escala 1:2.500 y las observaciones necesarias para las parcelas del ensayo. El porcentaje de ahorro en el ensayo es proporcional al número de observaciones. .

Tabla 20. Reserva de agua ( $\mathrm{mm}$ ) mensual y anual del suelo durante el año 2012 en los diferentes perfiles del ensayo.

Tabla 21. Reserva de agua ( $\mathrm{mm}$ ) mensual y anual del suelo durante el año 2013 en los diferentes perfiles del ensayo.

Tabla 22. Reserva de agua $(\mathrm{mm})$ mensual y anual del suelo durante el año 2014 en los diferentes perfiles del ensayo

Tabla 23. Reserva de agua ( $\mathrm{mm}$ ) mensual y anual del suelo durante el año 2015 en los diferentes perfiles del ensayo.

Tabla 24. Algunas peculiaridades comparativas de los perfiles descritos

Tabla 25. Relación entre las STU en la DOCa Rioja de las formaciones del Cuaternario (FW) y del Terciario de F. Haro-Transición (W) y los perfiles del ensayo

Tabla 26. Valores geoestadísticos de las distribuciones NDVI. NMI: Índice de Morans, Z-Value, valores del semivariograma (CO y C1) e Ic: Índice de Cambardella

Tabla 27. Análisis de varianza (ANOVA) por sectores, años y la interacción Año*Sector para Número de racimos, Peso del racimo, Producción, Número de sarmientos, Calibre del sarmiento, Peso de poda y Longitud del sarmiento; gl: grados de libertad, SS: Suma de cuadrados; MC: Media cuadrática, Sig: grado de significación para un nivel de probabilidad $p<0,05\left({ }^{*}\right), p<0,01\left(^{* *}\right), p<0,001\left(^{* *}\right)$ y no significativo (ns). 
Tabla 28. Valores separados por sectores de comparación de medias y sus agrupaciones mediante el test de Duncan, así como su significación (sg) para un nivel de probabilidad $p<0,001\left(^{* *}\right) ; p<0,01\left(^{* *}\right) ; p<0,05\left(^{*}\right)$ y ns (no significativo) para: NRAC (№ de Racimos), PROD (Racimos*PRacimo), PRAC (Peso del racimo, gr), LONG (Longitud del sarmiento, cm), CAL (Calibre del sarmiento, cm), PESOMAD (Peso de madera de poda, gr) y RAVAZ (Índice de Ravaz: Pesomad/Producción). Resultados para cada uno de los años de estudio ........................................................ 115

Tabla 29. Valores separados por sectores de comparación de medias y sus agrupaciones mediante el test de Duncan, así como su significación (sg) para un nivel de probabilidad $p<0,001\left(^{* *}\right) ; p<0,01\left(^{* *}\right) ; p<0,05\left(^{*}\right)$ y ns (no significativo) para: NRAC (№ de Racimos), PROD (Racimos*PRacimo), PRAC (Peso del racimo, gr), NPAMP (№ de Pámpanos), LONG (Longitud del sarmiento, $\mathrm{cm}$ ), CAL (Calibre del sarmiento, $\mathrm{cm}$ ), PESOMAD (Peso de madera de poda, gr) y RAVAZ (Índice de Ravaz: Pesomad/Producción). Resultados para la media de los cuatro años de ensayo .

Tabla 30. Valores separados por años de comparación de medias y sus agrupaciones mediante el test de Duncan, así como su significación (sg) para un nivel de probabilidad $p<0,001\left(^{* *}\right) ; p<0,01\left(^{* *}\right) ; p<0,05\left(^{*}\right)$ y ns (no significativo) para: NRAC (No de Racimos), PROD (Racimos*PRacimo), PRAC (Peso del racimo, gr), NPAMP (№ de Pámpanos), LONG (Longitud del sarmiento, $\mathrm{cm}$ ), CAL (Calibre del sarmiento, $\mathrm{cm}$ ), PESOMAD (Peso de madera de poda, gr) y RAVAZ (Índice de Ravaz: Pesomad/Producción). ...

Tabla 31. Análisis de varianza (ANOVA) por sectores, años y la interacción Año*Sector para Grado de Alcohol Probable, Acidez Total, pH, Ácido Málico, Índice de Color, Índice de Polifenoles Totales, Antocianos, Peso de 100 bayas, Potasio y Ácido Tartárico; gl: grados de libertad, SS: Suma de cuadrados; MC: Media cuadrática, Sig: grado de significación para un nivel de probabilidad $p<0,05(*), p<0,01\left(^{* *}\right), p<0,001\left(^{* *}\right)$ y no significativo (ns).

Tabla 32. Valores separados por sectores de comparación de medias y sus agrupaciones mediante el test de Duncan, así como su significación (sg) para un nivel de probabilidad $p<0,05$ $\left({ }^{*}\right), p<0,01\left(^{* *}\right)$ y $p<0,001{ }^{* * *}$ ) para: GAP (Grado de Alcohol Probable, \% volúmen), ATOTAL (Acidez Total, gr/l de Ácido Tartárico), MH2 (Ácido Málico, gr/l), IC (Índice de Color), IPT (Índice de Polifenoles Totales), ANTO (Antocianos, mg/l), P100B (peso de 100 bayas, gr), K (potasio, mg/l) y TH2 (Ácido Tartárico, gr/l). Resultados para cada uno de los cuatro años de estudio

Tabla 33. Valores separados por sectores de comparación de medias y sus agrupaciones mediante el test de Duncan, así como su significación (sg) para un nivel de probabilidad $p<0,001\left(^{* *}\right) ; p<0,01\left(^{* *}\right) ; p<0,05\left(^{*}\right)$ y ns (no significativo) para: GAP (Grado de Alcohol Probable, \% volúmen), ATOTAL (Acidez Total, gr/l de Ácido Tartárico), MH2 (Ácido Málico, gr/l), IC (Índice de Color), IPT (Índice de Polifenoles Totales), ANTO (Antocianos, mg/l), P100B (peso de 100 bayas, gr), K (potasio, mg/l) y TH2 (Ácido Tartárico, gr/l). Resultados para la media de los cuatro años de ensayo. 
Tabla 34. Valores separados por años de comparación de medias y sus agrupaciones mediante el test de Duncan, así como su significación ( $\mathrm{sg}$ ) para un nivel de probabilidad $p<0,001\left(^{* * *}\right) ; p<0,01\left(^{* *}\right) ; p<0,05\left(^{*}\right)$ y ns (no significativo) para: GAP (Grado de Alcohol Probable, \% volúmen), ATOTAL (Acidez Total, gr/l de Ácido Tartárico), MH2 (Ácido Málico, gr/l), IC (Índice de Color), IPT (Índice de Polifenoles Totales), ANTO (Antocianos, mg/l), P100B (peso de 100 bayas, gr), K (potasio, mg/l) y TH2 (Ácido Tartárico, gr/l) ...

Tabla 35. Parámetros y simbología utilizada en este apartado y en los siguientes. Nótese que algunos tienen varios símbolos por exigencias de los programas informáticos utilizados ....................................................... 129

Tabla 36. Matriz de correlaciones (Pearson) de los parámetros analizados relacionados con la vid (datos medios 2012-2015) y con el suelo (G1, G2, G3), según la primera sectorización propuesta (10 sectores) .

Tabla 37. Matriz de correlaciones (Pearson) de los principales parámetros analizados relacionados con la vid (datos medios 2012-2015) y con el suelo (G1, G2, G3), según la ZIT definitiva (20 sectores)

Tabla 38. Matriz de correlaciones (Pearson) de los principales parámetros analizados relacionados con la vid (año 2012) y con el suelo (G1, G2, G3), según la ZIT definitiva (20 sectores).

Tabla 39. Matriz de correlaciones (Pearson) de los principales parámetros analizados relacionados con la vid (año 2013) y con el suelo (G1, G2, G3), según la ZIT definitiva (20 sectores) .......................................................... 138

Tabla 40. Matriz de correlaciones (Pearson) de los principales parámetros analizados relacionados con la vid (año 2014) y con el suelo (G1, G2, G3), según la ZIT definitiva (20 sectores)

Tabla 41. Matriz de correlaciones (Pearson) de los principales parámetros analizados relacionados con la vid (año 2015) y con el suelo (G1, G2, G3), según la ZIT definitiva (20 sectores).

Tabla 42. Z ZIT: índice de calidad (ICA) y clasificación de los sectores según la ZIT propuesta (Figura 47).

Tabla 43. Matriz de correlación (Pearson) de los parámetros relacionados con la vid (componentes vegeto-productivos y composición de la uva) de la media de años 2012-2015 y el Índice de Calidad (ICA), según la ZIT definitiva (20 sectores).

Tabla 44. Matriz de correlación (Pearson) de los principales parámetros relacionados con la vid (componentes vegeto-productivos y composición de la uva) del año 2012 y el Índice de Calidad (ICA), según la ZIT definitiva (20 sectores) 
Tabla 45. Matriz de correlación (Pearson) de los principales parámetros relacionados con la vid (componentes vegeto-productivos y composición de la uva) del año 2013 y el Índice de Calidad (ICA)....

Tabla 46. Matriz de correlación (Pearson) de los principales parámetros relacionados con la vid (componentes vegeto-productivos y composición de la uva) del año 2014 y el Índice de Calidad (ICA)....

Tabla 47. Matriz de correlación (Pearson) de los principales parámetros relacionados con la vid (componentes vegeto-productivos y composición de la uva) del año 2015 y el Índice de Calidad (ICA)... 


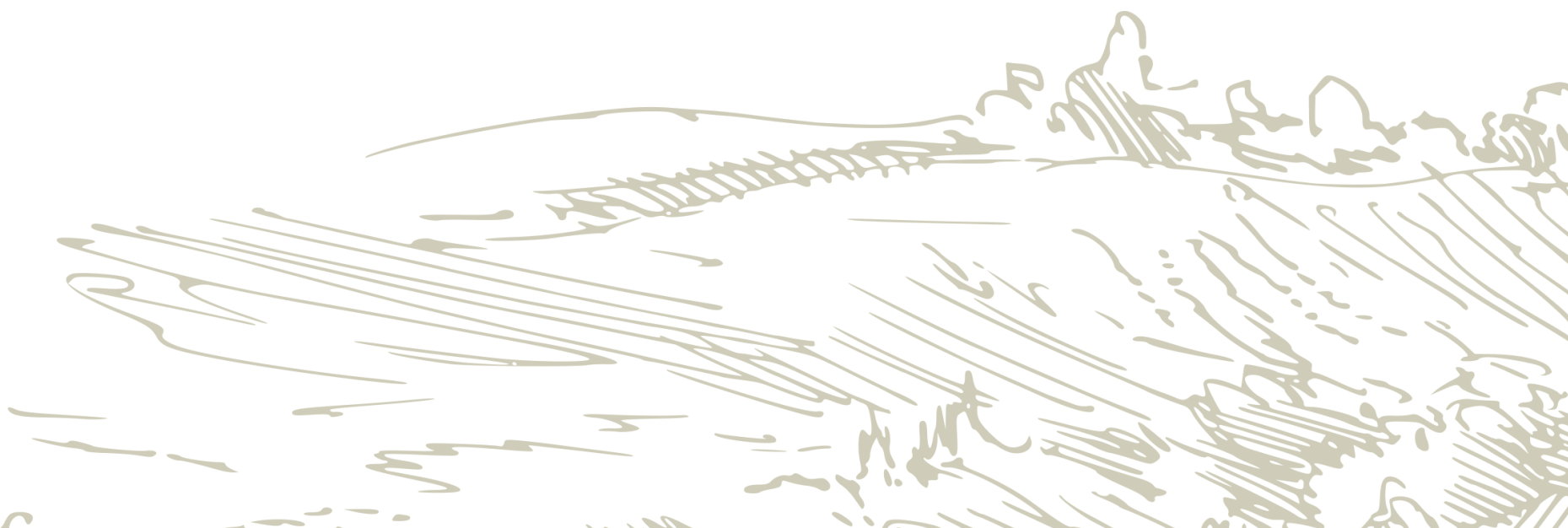

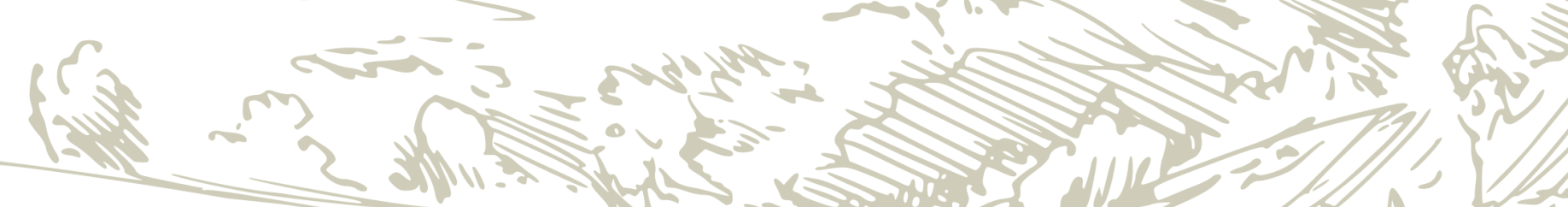




\section{CAPÍTULO 1 \\ Introducción}

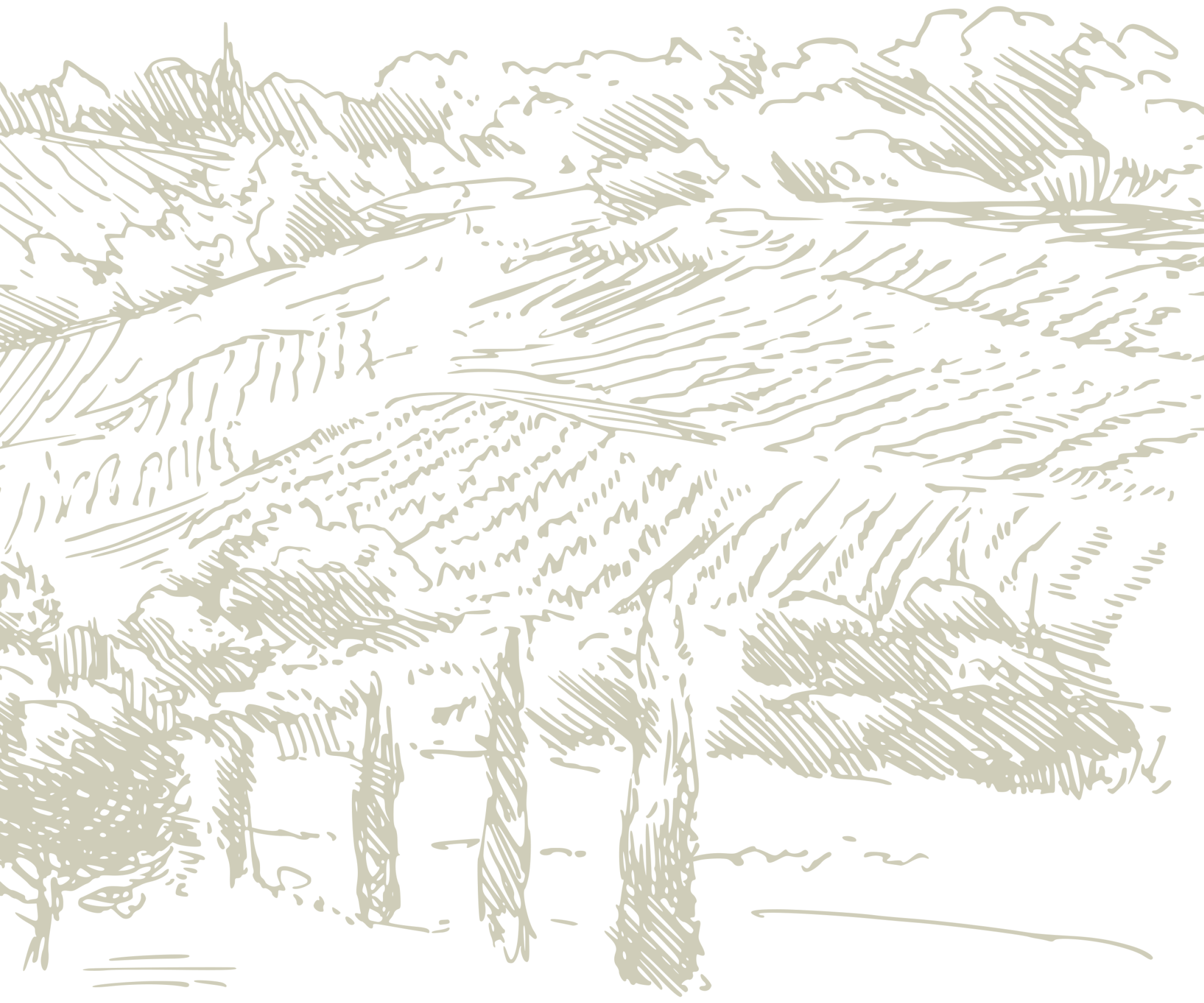



Los primeros estudios científicos relacionados con los elementos del medio vitícola y sus interacciones se llevan a cabo en el último cuarto del siglo XX, pudiendo considerarse la tesis doctoral del profesor René Morlat (Morlat, 1989) uno de los estudios pioneros sobre la zonificación del terroir vitícola en el sentido moderno del término. El citado trabajo se desarrolla en la zona media del valle del Loira, siendo los países europeos los que tradicionalmente más importancia han otorgado a los elementos del medio en la caracterización de los vinos, protegiendo así el origen de los mismos. Dos ejemplos de esta tradición son la clasificación actual de vinos de Burdeos, que prácticamente no ha sufrido modificaciones desde su creación en 1855 y la clasificación de vinos de Oporto que tiene su origen en la delimitación de 1758 (actualmente esa zonificación se ha visto ampliada) Ilevada a cabo por la Companhia Geral da Agricultura das Vinhas do Alto Douro (empresa similar a los actuales Consejos Reguladores) a propuesta del Marqués de Pombal.

En nuestro país, los primeros estudios de este tipo relacionados con la zonificación del medio vitícola se llevan a cabo por los profesores Vicente Gómez Miguel y Vicente Sotés Ruíz, en los años ochenta del pasado siglo. En el año 1997 estos autores realizan la zonificación a media escala (macrozonificación) de la Denominación de Origen Calificada Rioja (en adelante, DOCa Rioja) que puede considerarse como un antecedente inmediato de la tesis doctoral "Caracterización e influencia del terroir sobre la composición de la uva y los componentes vegeto-productivos de la vid (Vitis vinífera L.) en la DOCa Rioja", que ahora ve la luz, y en la que se lleva a cabo una zonificación más detallada (microzonificación), por tratarse de parcelas de pequeño tamaño (1,5-2 ha), por lo demás habitual en la DOCa Rioja (ver Capítulo 4).

El interés creciente por los estudios relacionados con el terroir se pone de manifiesto al observar el incremento de publicaciones relacionadas con este tema (Figura 1). En los últimos 20 años se ha pasado de siete publicaciones en el año 2.000 a 114 en 2.019, es decir, un incremento de más de un 1.300\% de publicaciones anuales. Incluso analizando un periodo de tiempo más corto se aprecia un notable aumento en este número de publicaciones. Así, observando el período 2014-2018, se produjo un crecimiento del 54 \% en el número de publicaciones anuales.

La clasificación de los vinos en el marco de la DOCa Rioja data de 1970 y está basada en el envejecimiento de los mismos, existiendo las clases Garantía de Origen (o Genérico), Crianza, Reserva y Gran Reserva. En los últimos años el Consejo Regulador de la DOCa Rioja ha aprobado nuevas figuras de protección complementarias a las ya existentes. Recientemente, en julio de 2019, se han reconocido 84 parajes vitícolas amparados como "Viñedo Singular", que, entre otros aspectos, son viñedos que se caracterizan por poseer una delimitación natural técnicamente justificable, una edad de las plantas superior a los 35 años, y un rendimiento más de un 20 \% inferior al autorizado para el conjunto de la DO. Para una adecuada incorporación tanto de esta nueva protección como de hipotéticas nuevas figuras relacionadas con los elementos del medio parece necesario el uso de metodologías de zonificación rigurosas y objetivas que permitan clasificar los diferentes terroir de la DO, huyendo de potenciales métodos de caracterización subjetivos y poco exhaustivos que pondrían en riesgo su éxito. 


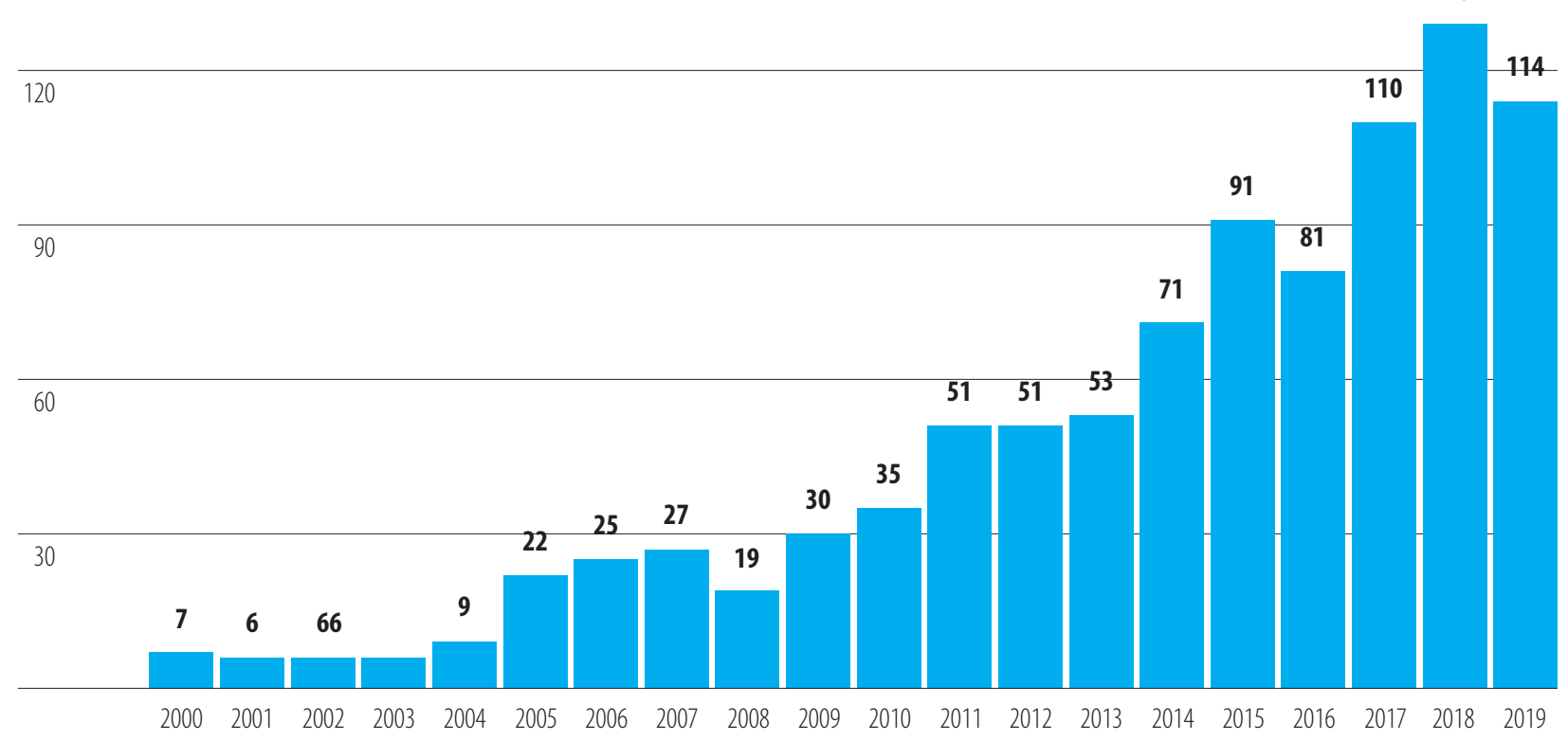

Figura 1. Histórico de publicaciones indexadas en Web of Science sobre la temática del terroir.

El concepto de terroir incluye, además de los elementos del medio vitícola, un factor enológico y un factor humano, presente en los dos anteriores (OIV, 2010). Después de la vendimia, el manejo de la cosecha queda subordinado a la enología, cuyos procesos han evolucionado notablemente en España desde los años 70 del siglo XX (Pan-Montojo, 2005), mejorándose, entre otros aspectos, la higiene de las bodegas o el control de los procesos microbiológicos, térmicos, de envejecimiento, etc. Tomando, por lo tanto, el momento de la vendimia como punto de inflexión, podemos diferenciar entre un aspecto vitícola y otro vinícola dentro del terroir vitivinícola, sobre el primero gravita este documento.

Después de esta Introducción (Capítulo 1) y del planteamiento de los Objetivos (Capítulo 2), en el Capítulo 3 (Antecedentes) se lleva a cabo una revisión bibliográfica en relación con el terroir y la variabilidad y la zonificación vitícola. La Zona de Estudio queda definida en el Capítulo 4, describiéndose las características climáticas, geológicas, geomorfológicas, edafológicas y de vegetación y cultivo del viñedo. Como complemento a la descripción de estos elementos del medio del municipio de Oyón es recomendable consultar el texto publicado durante el desarrollo de esta tesis: "Vegetation Index cartography as a metodology complement to the terroir zoning for its use in Precision Viticulture" (Martínez \& Gómez-Miguel, 2017). En el Capítulo 5 (Material y Métodos) se presenta la metodología seguida, los materiales empleados y los análisis realizados. En el apartado Resultados y Discusión (Capítulo 6) se muestran los resultados obtenidos, discutiendo su significación así como sus posibles analogías con trabajos de otros autores. Además de estos resultados directos, se propone una metodología que permite integrar la zonificación realizada a escalas grandes en los estudios de zonificación convencional a escalas medias en la que se definen Unidades Homogéneas del Medio (UHM). En el Capítulo 7 (Conclusiones) se presentan las conclusiones generales y en el Capítulo 8 (Bibliografía) se detallan los textos consultados en la redacción del texto.

En varios apartados del Capítulo 3, se hace referencia a la calidad de la uva a partir de las opiniones de diferentes autores. La calidad de la uva (y del vino) es fuente de debates y está sujeta, entre otras coyunturas, al momento histórico en que se defina. En las citadas ocasiones en las que se califica la uva como de calidad, 
ésta debe entenderse como la materia prima con la que se producen vinos que técnicos y consumidores otorgan unas cualidades organolépticas por encima de unos estándares, también difíciles de definir, y que su estudio excede los límites del presente documento. En el resto de los capítulos, fundamentalmente en el Capítulo 6, se ha tratado de evitar hacer mención de uvas o vinos de calidad, optando por tomar posiciones más objetivas o menos controvertidas, poniendo de relieve exclusivamente las características cuantitativas de las uvas.

Por último, cabe destacar que durante la redacción del presente manuscrito se han producido varias propuestas (o incluso cambios) en el seno de la DOCa Rioja relacionados con las figuras de protección y la zonificación. Por este motivo, la aportación de estudios como el presente podrían servir de apoyo para encontrar una dirección técnica y objetiva en los próximos años, en esta y/o en otra de las diferentes DO o regiones protegidas existentes en el país. 


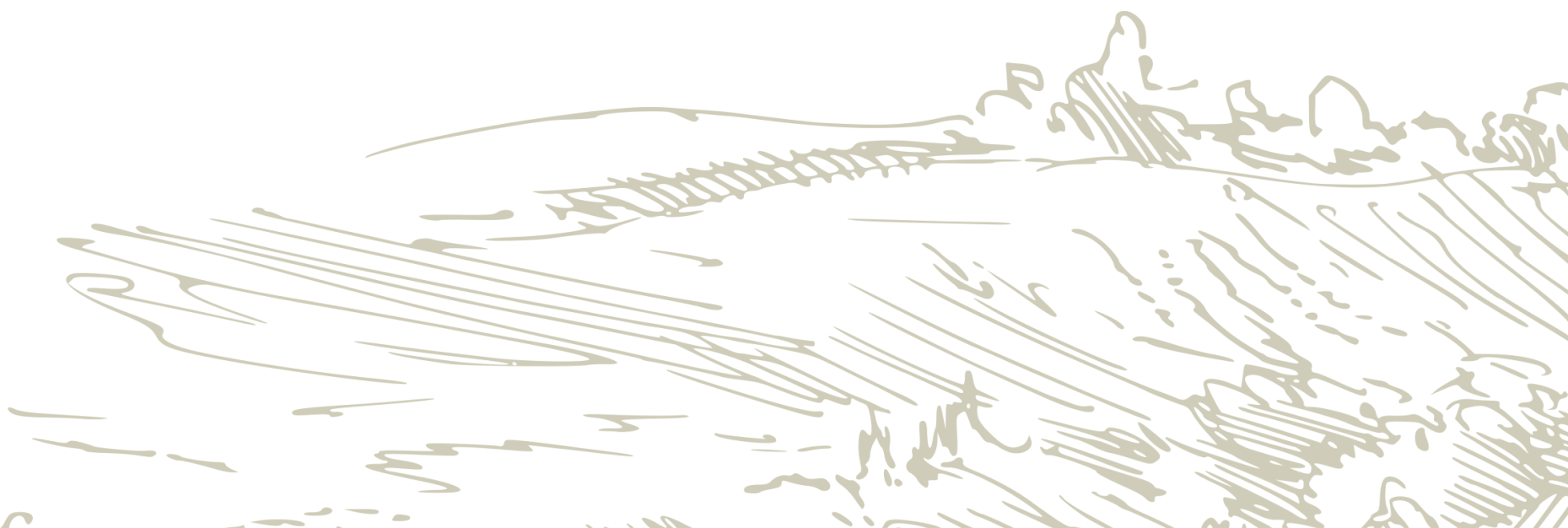

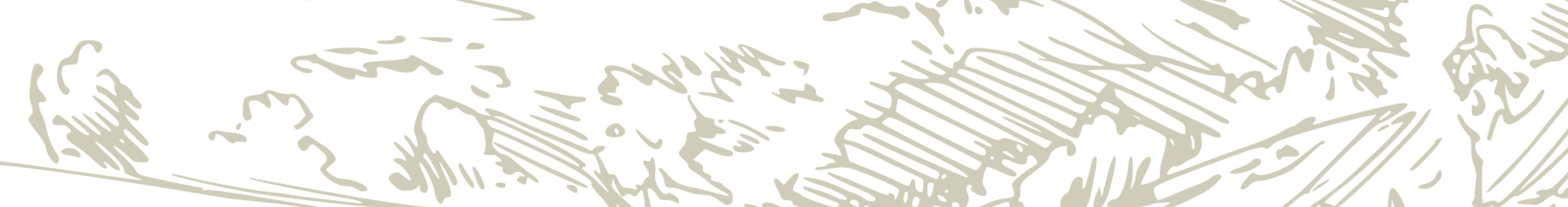




\section{CAPÍTulO 2 \\ Objetivos}

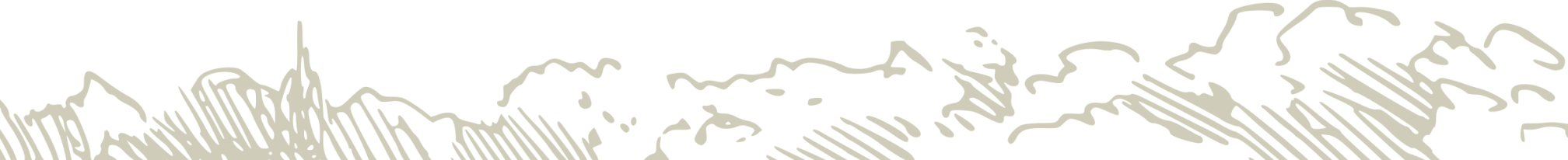
on
(1)
axe $y$, Ino.
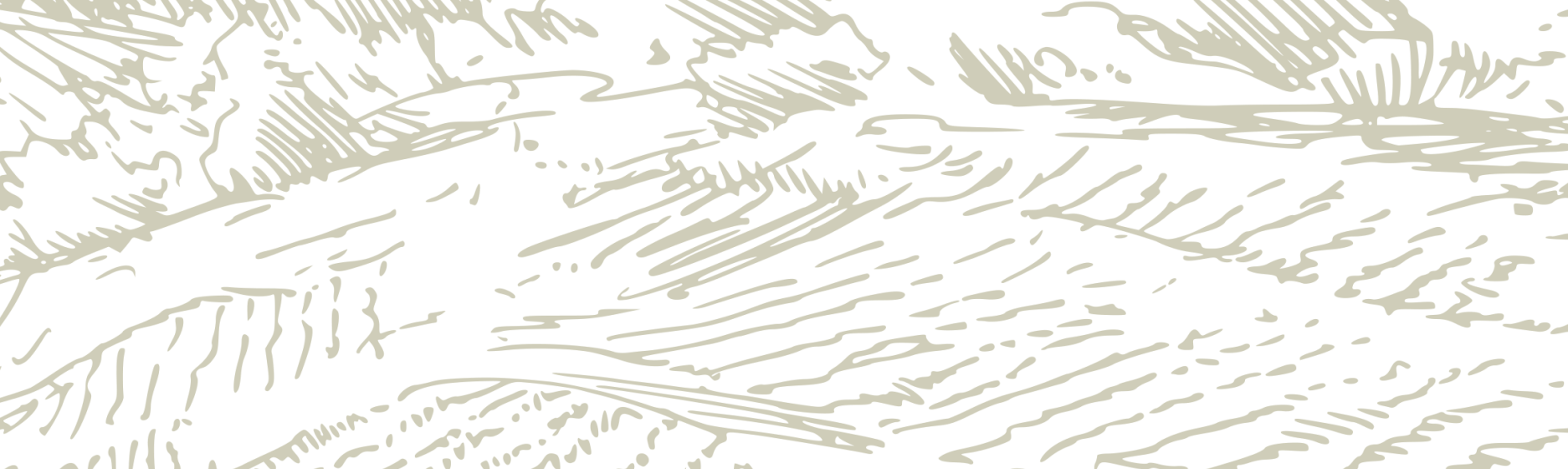

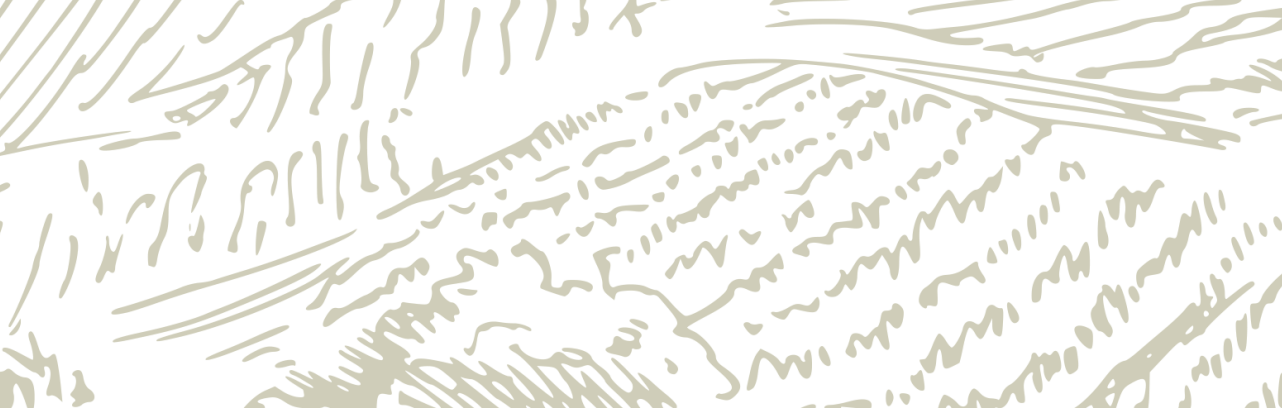

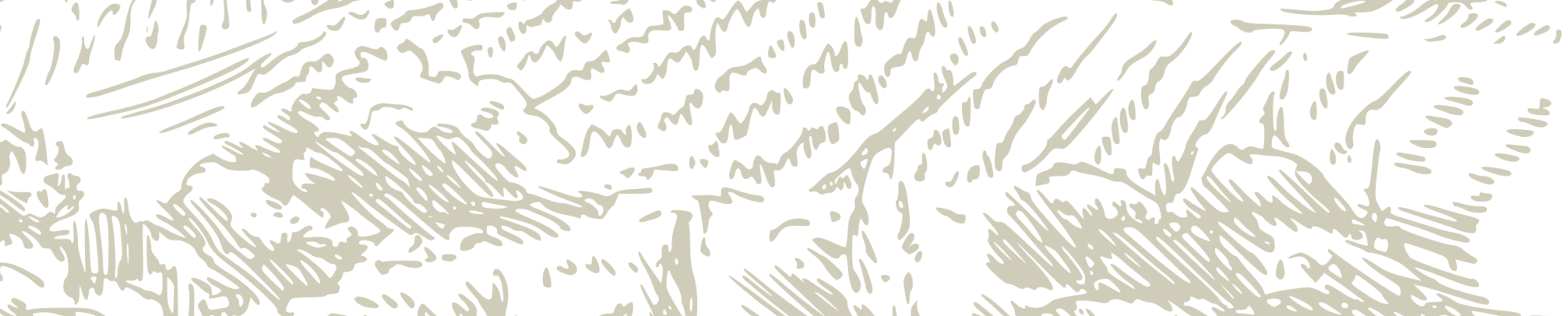

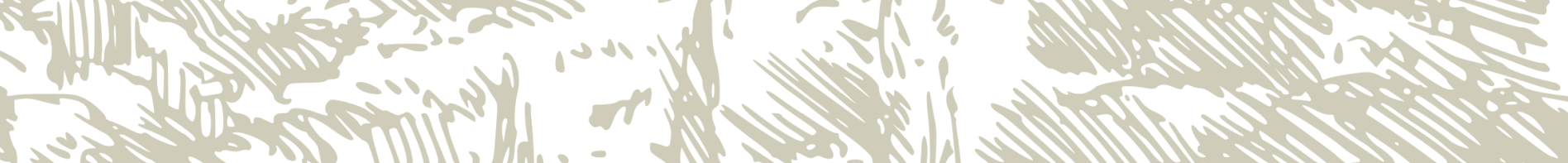
con Sis 

El objetivo general de la tesis doctoral es:

Desarrollar una metodología que permita la realización de mapas de microzonificación integrada del terroir (mapas ejecutivos, escala 1:2.500 de orden 1según USDA, 2017) utilizables en Viticultura de Precisión optimizando el uso de los mapas de macrozonificación (mapas de gestión, escala 1:50.000 de orden 3 según USDA, 2017) y minimizando costes.

Con la finalidad de alcanzar el citado objetivo general, se plantean los siguientes objetivos específicos:

1 Describir y caracterizar el clima, la geología y la geomorfología de la zona en relación con los de la DOCa Rioja.

2 Describir y caracterizar los suelos de la zona de estudio y cuantificar sus propiedades, analizando la variabilidad edáfica entre e intraparcela y delimitando diferentes sectores o bloques según su homogeneidad.

3 Estudiar la respuesta de la vid, analizando el crecimiento vegetativo de la planta, la producción y la composición de la uva, en relación con las características del medio en el que se desarrolla la planta y con un determinado manejo.

4 Evaluar el uso de la teledetección, obteniendo Índices de Vegetación a partir de imágenes multiespectrales, como herramienta complementaria a la zonificación vitícola clásica. 


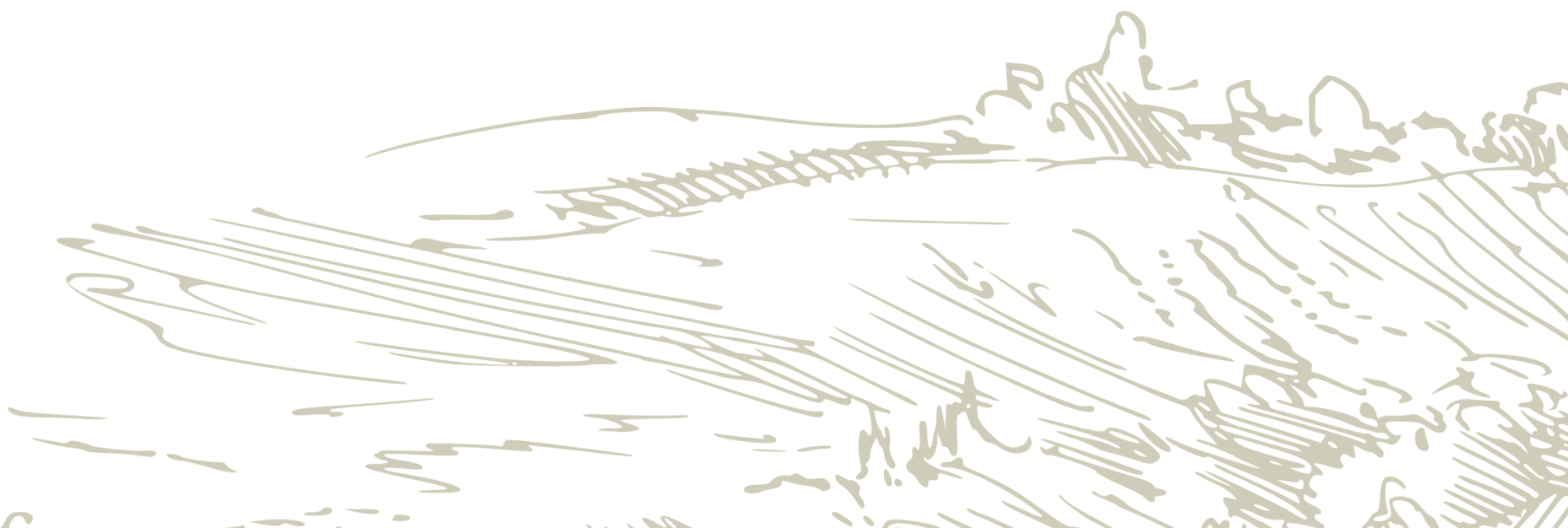

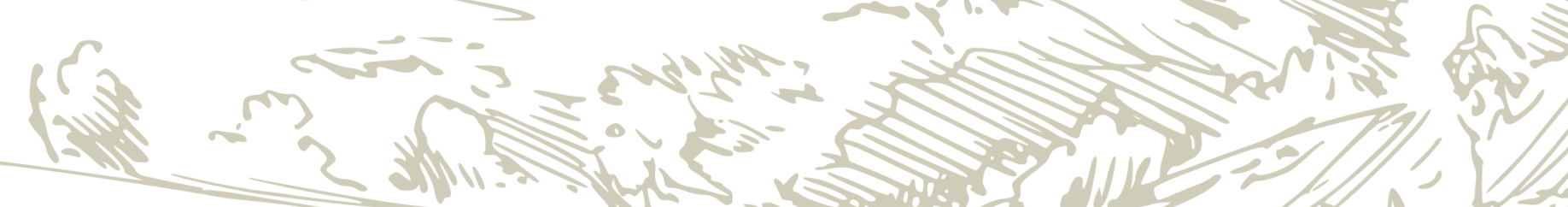


CAPÍTULO 3

\section{Antecedentes}

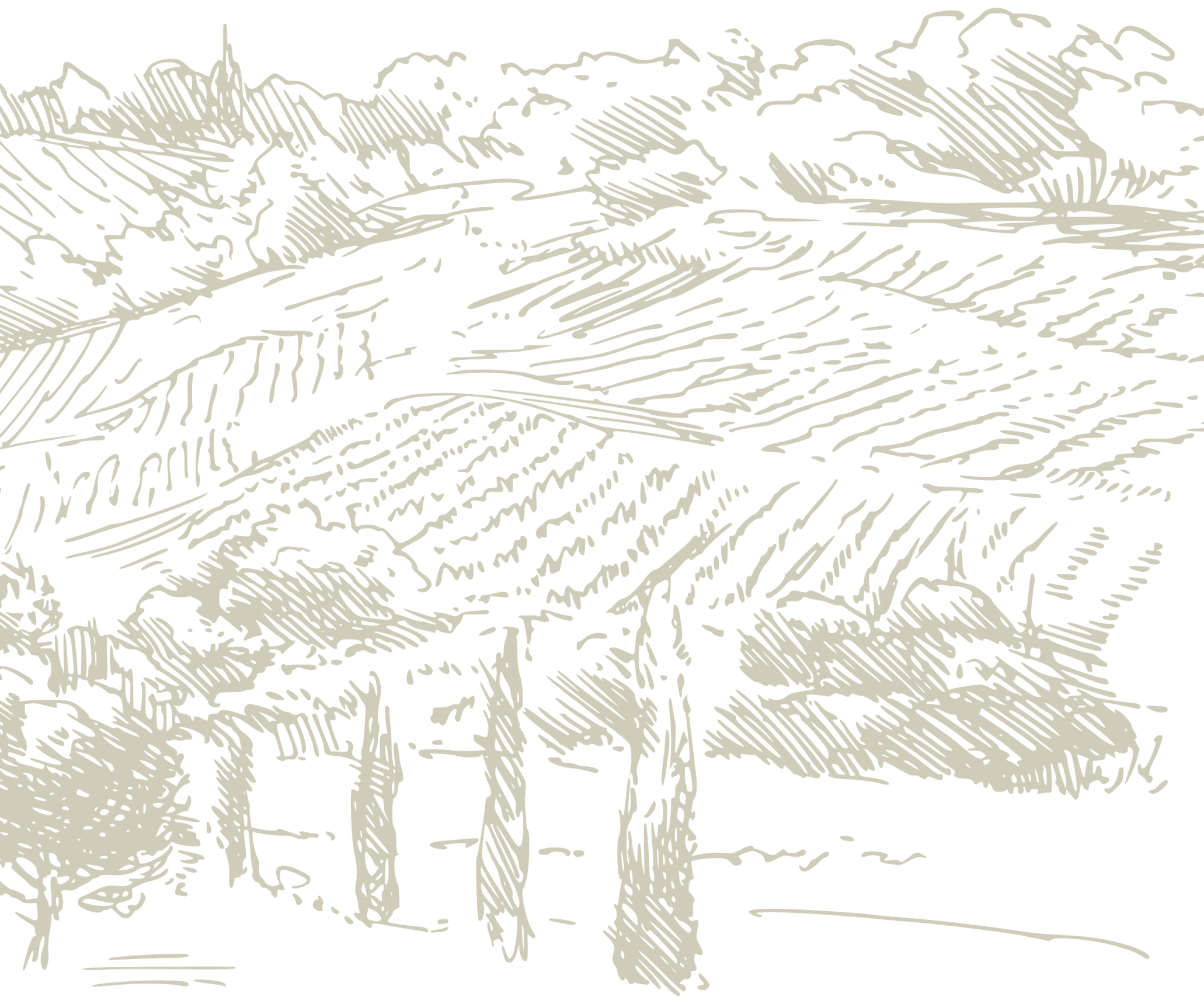





\subsection{TERROIR}

Desde los sumerios hasta nuestros días, pasando por egipcios, fenicios, griegos, romanos, Edad Media, etc., se ha relacionado el vino de calidad con determinadas regiones. Este interés por el origen geográfico de los vinos justifica la existencia del concepto terroir y que permanezca su uso en el sentir general tanto popular y de mercado como científico. La Organización Internacional de la Viña y el Vino (OIV) en su Resolución VITI 333/2010 (OIV, 2010) recoge esta idea y define el terroir como sigue:

«El terroir vitivinícola es un concepto que se refiere a un espacio sobre el cual se desarrolla un saber colectivo de las interacciones entre un medio físico y biológico identificable y las prácticas vitivinícolas aplicadas, que confieren unas características distintivas a los productos originarios de este espacio».

Por lo tanto, el terroir incluye características específicas del clima, de la geología, de la topografía y del paisaje, del suelo, de la flora y fauna y de la biodiversidad, pero también de la vid y de las prácticas de manejo del medio y de las prácticas y tecnología enológicas sobre los productos. Y muchos autores añaden la tradición y la conciencia del terroir (Figura 2).

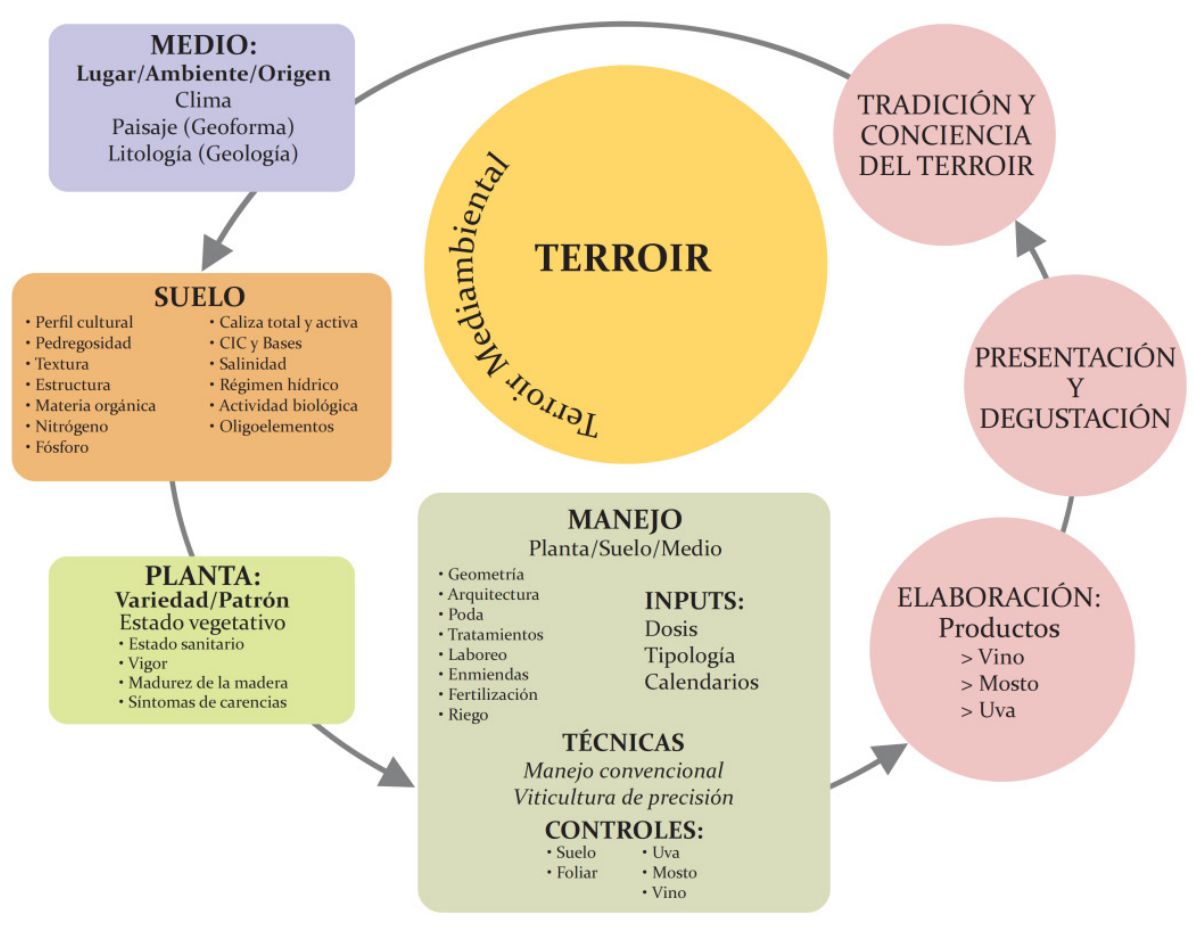

Figura 2. Factores y elementos del terroir (Gómez-Miguel, 2011)

No todas las variables incluidas en esta descripción son fácilmente medibles, georreferenciables y cartografiables. En esta tesis nos referiremos principalmente a ellas con el fin de hacer comparaciones no sólo puntuales, sino también (geo)gráficas. 
El concepto de terroir se empezó a emplear para algunas propiedades de la producción de vinos de alta calidad de Côte d'Or, Borgoña (Wilson, 2001), siendo complejo definir los factores ideales que componen el terroir debido a la interacción que existe entre ellos (van Leeuwen \& Seguin, 2006). Esta dificultad de análisis individual de los factores naturales, particularmente del suelo, se ve poco a poco superada con la ayuda de nuevas herramientas de detección, gestión y análisis. En cualquier caso, aunque no se conozcan con total exactitud las interacciones físicas y químicas que afectan al cultivo, la difusión del término terroir está fomentando un mejor conocimiento y uso de la geología, el suelo, el clima y la cultura vitivinícola para la producción de mejores vinos (Wilson, 2001).

La globalización del comercio internacional del vino ha llevado a aumentar la producción, especialmente en nuevos países, de vinos varietales y de marca, y a la adopción de técnicas de bajos insumos, ejerciendo una presión significativa sobre los productores tradicionales de vino de terroir (Clingeleffer, 2014).

En los apartados siguientes analizaremos la influencia específica de cada uno de los elementos que influyen y caracterizan el terroir y en las interacciones entre ellos, haciendo especial hincapié en su estabilidad temporal, su variabilidad y la posibilidad de modificaciones a partir del manejo.

\subsubsection{Clima}

El clima es un factor de gran importancia en la calificación de una región o zona en relación con la aptitud para producir uvas de calidad, siendo sus efectos notables en el nivel de maduración de una determinada variedad y en la tipicidad y la calidad del vino obtenido (Tonietto \& Carbonneau, 2004; Jones, 2006). También se puede considerar que el clima es el factor principal que justifica la utilización de la añada como indicador de la mayor o menor calidad de la cosecha de un determinado año dentro de una región determinada.

Existen diferencias en los elementos del clima (temperatura, precipitación, radiación solar, etc.) entre las distintas zonas de producción de vino (Figura 3), lo que proporciona a cada región tipicidad, elaborándose en todas ellas productos de calidad.

Para estudiar la influencia del clima en el viñedo es tradicional distinguir entre macroclima, mesoclima y microclima en función de la escala. El primero hace referencia al clima de una región y es el principal factor limitante para el cultivo de la vid (Gómez-Miguel, 2011), mientras que el mesoclima es característico de una ubicación topográfica y paisajística determinada y afecta a un conjunto de plantas por igual en una determinada unidad geomorfológica. Por último, el microclima se refiere al de la propia planta, rodea a hojas y racimos y tiene una gran influencia en el ciclo biológico (por ejemplo, es de gran importancia en el periodo de maduración de la uva), pudiéndose modificar, además, a través del manejo del cultivo.

A continuación se resume el concepto y la influencia de los distintos elementos del clima sobre el comportamiento de la vid, prestando especial atención al período de maduración de la uva. 

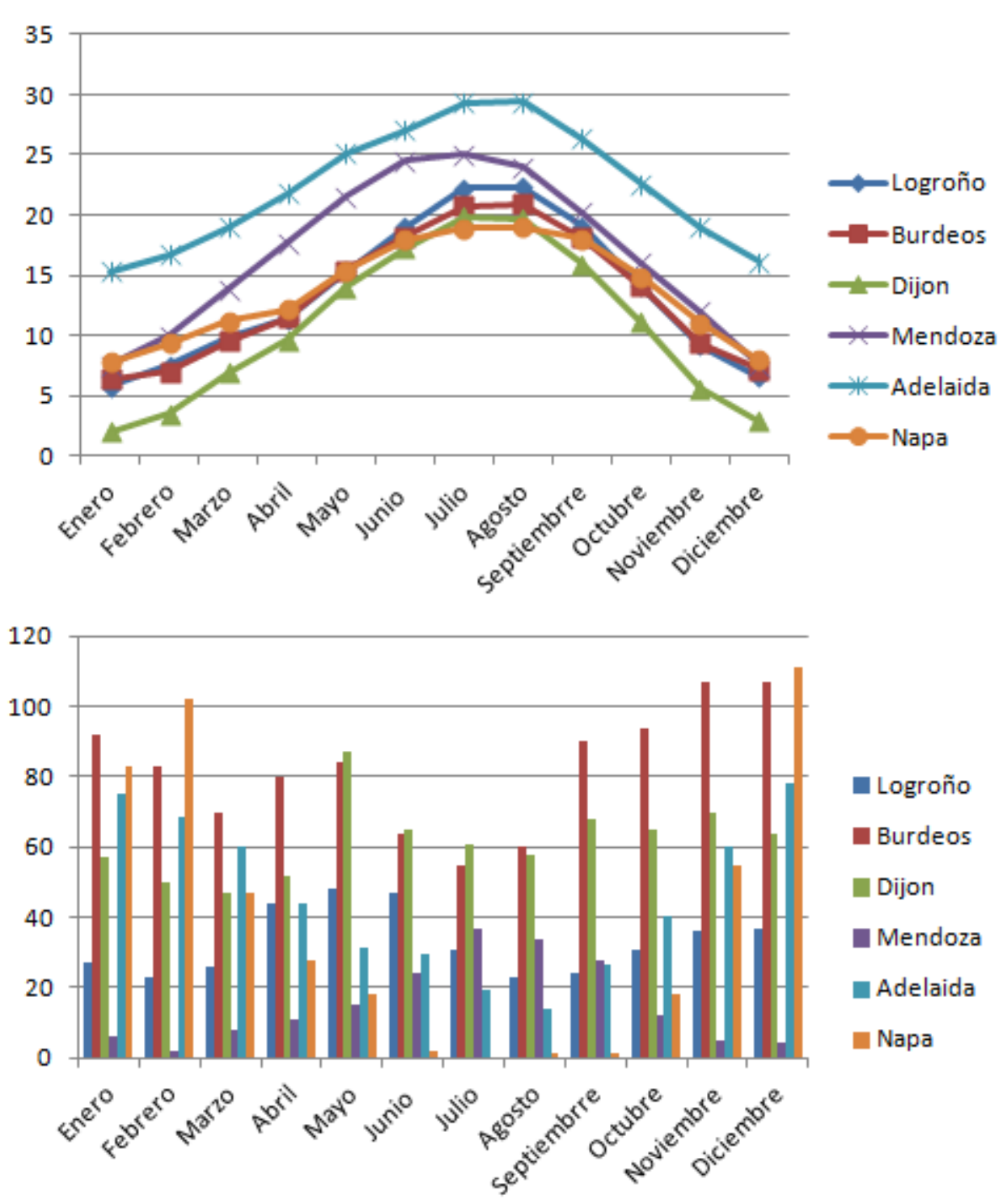

Figura 3. Temperatura media $\left({ }^{\circ} \mathrm{C}\right)$ y precipitación $(\mathrm{mm})$ en 6 zonas de producción de vino de calidad. Datos de Mendoza y Adelaida con un desfase de 6 meses. Elaboración propia a partir de Tonietto (2017).

\subsubsection{Luz Solar}

La radiación solar es el conjunto de radiaciones electromagnéticas que emite el Sol, siendo su unidad de medida el W/m2. A su vez, las radiaciones electromagnéticas tienen diferentes longitudes de onda, que se miden en nanómetros $(\mathrm{nm})$. La luz solar o iluminación es la porción de la radiación solar que alcanza la superficie de la Tierra. 
La iluminación es un elemento del clima necesario durante todo el desarrollo vegetativo de la vid, debido a que es un factor imprescindible para la realización de la fotosíntesis por parte de las hojas. De todo el espectro de radiación recibida por el aparato fotosintético, solamente la Radiación Fotosintéticamente Activa (PAR), entre 400 y 700 nm, es utilizada para producir fotoasimilados que según el momento del ciclo son traslocados hacia unos órganos u otros, en función de las necesidades de la planta.

Becker (1977) no encontró en Europa viñedos que recibieran menos de 1250 horas de sol durante el periodo activo de crecimiento (de Abril a Octubre en el hemisferio norte), concluyendo que las zonas que no reciben esta cantidad de insolación no cuentan con suficiente temperatura para el cultivo de la vid. Gladstones (1992) indica que durante el ciclo vegetativo son necesarias al menos 1200 horas de radiación solar para los cultivares más tempranos, existiendo a partir de esa insolación una interacción entre las horas de radiación y el clima térmico (cálido o fresco) que determina la calidad de la cosecha.

Esta iluminación junto con la temperatura (ver § 3.1.1.2), son los elementos climáticos más importantes en la inducción y la diferenciación floral. La exposición del pámpano a la luz está positivamente correlacionada con el número y el tamaño de las inflorescencias (Sanchez \& Dokoozlian, 2005).

Respecto a la influencia del fotoperiodo (número de horas de iluminación diarias) sobre la floración, la vid no es dependiente de unas horas de luz determinadas por día, y puede tener lugar la iniciación de las inflorescencias independientemente de la longitud del día, pero con días largos tiende a formar más inflorescencias. En esta línea, un incremento en la interceptación de energía solar por las hojas, tanto si es por aumento de la intensidad de la luz como si es por el tiempo de exposición, da lugar a una mayor fotosíntesis y a una mayor disponibilidad de carbohidratos para la iniciación de las inflorescencias (Bennet, 2002).

Para una correcta maduración, en cantidad y composición, el aparato fotosintético debe ser eficiente (plenamente desarrollado, equilibrado y sano) en la interceptación de radiación solar con el fin de producir fotoasimilados en cantidad suficiente para distribuirlos hacia las bayas. La saturación luminosa se alcanza a niveles muy bajos, dándose los valores máximos de fotosíntesis a 1/2 y 1/3 de la iluminación a pleno sol (Sánchez de Miguel, 2007). Por encima de estos niveles de intensidad, la fotosíntesis puede inhibirse, más aún si va acompañada de altas temperaturas. Por esta razón, la luz solar de baja intensidad o intermitente puede producir la misma fotosíntesis o incluso más que exposiciones continuas y de alta intensidad (Gladstones, 2011).

Además, durante el envero y la maduración de la uva en climas cálidos, cierta nubosidad ayuda a disminuir la temperatura de la uva y posibles pérdidas de aromas y pigmentos por sobreexposición a la radiación solar (Gladstones, 2011).

\subsubsection{Temperatura}

La temperatura es una magnitud física que expresa el grado o nivel de calor de los cuerpos o del ambiente, cuya unidad de medida habitual es el grado Celsius $\left({ }^{\circ} \mathrm{C}\right)$ y se mide con ayuda de un termómetro. La temperatura del aire durante el ciclo vegetativo de la vid se considera como uno de los factores más importantes en la producción de uvas de calidad (Hall \& Jones, 2010). 
Con el objeto de caracterizar climáticamente una región vitícola se han empleado distintos índices vitícolas bioclimáticos basados en la temperatura durante el ciclo vegetativo de la vid. Así, uno de los primeros en aparecer es el Índice de Winkler (Amerine \& Winkler, 1944) basado en las observaciones realizadas en el siglo XIX por A.P. de Candolle (Jones et al. 2012). Otros índices que han sido empleados con frecuencia son el Índice Heliotérmico de Branas (Branas, 1946) y el Índice Heliotérmico de Huglin (Huglin, 1978). Más recientemente, se creó el Sistema de Clasificación Climática Multicriterio (Tonietto, 1999; Tonietto \& Carbonneau, 2004) que combina tres índices bioclimáticos, estando dos de ellos relacionados con la temperatura.

La temperatura determina el inicio y el final del ciclo vegetativo e influye en el ritmo de crecimiento siendo un factor determinante, junto con la iluminación, en la actividad fotosintética. También afecta al ciclo reproductor durante la iniciación y diferenciación floral (lo que se reflejará en el rendimiento) y durante la maduración de la uva.

Cada año, en la vida de un viñedo, se inicia el ciclo vegetativo cuando en primavera la temperatura ambiental media diaria alcanza los $10^{\circ} \mathrm{C}$ (cero de vegetación de la vid) aproximadamente, iniciándose la actividad celular de las yemas latentes (Reynier, 2012). A continuación tiene lugar el desarrollo del pámpano, cuyo crecimiento se ve influenciado por la temperatura, situándose el óptimo en torno a $25^{\circ} \mathrm{C}$ (Buttrose, 1968; Wilson, 1998).

El óptimo térmico en el proceso fotosintético depende, en gran medida, del régimen de temperaturas en el que se ha desarrollado la hoja, pues existe una aclimatación a las condiciones en las que ha transcurrido su crecimiento (Sánchez de Miguel, 2007). Generalizando, varios autores sitúan la temperatura óptima, fotosintéticamente hablando, entre $25^{\circ} \mathrm{C}$ y $30^{\circ} \mathrm{C}$.

Respecto al ciclo reproductor, durante la brotación el tiempo cálido favorece una mayor diferenciación de las inflorescencias, lo que se traduce en un mayor número de racimos por pámpano, mientras que el tiempo fresco favorece la diferenciación de más flores por racimo y menos racimos por pámpano. A continuación, las altas temperaturas estimulan la floración, mientras que el tiempo fresco dificulta el cuajado (Vasconcelos et al. 2009).

La temperatura de la baya, es probablemente el factor ambiental más importante durante su desarrollo y maduración y tiene efectos en la composición (sólidos solubles, acidez o pH) y en el tamaño de la uva (Baeza, 1994). Las noches frescas durante la maduración favorecen la coloración de las bayas, mientras que la temperatura diaria no afecta en gran medida a esta característica (relacionada con el contenido en antocianos) (Kliewer \& Torres, 1972).

A pesar de las grandes diferencias climáticas existentes entre las zonas tradicionalmente vitícolas de Europa, la vendimia en muchas de ellas se lleva a cabo entre el 10 de septiembre y el 10 de octubre. A este tipo de viticultura también se le conoce como "viticultura de zonas frescas" (cool climate viticulture en inglés), no necesariamente porque el clima sea particularmente frío, sino porque la madurez de las uvas tiene lugar en condiciones frescas, al final del verano o principio del otoño. Las uvas cosechadas en estas condiciones tienen la máxima expresión del terroir (van Leeuwen, 2010). 
La relación existente entre la temperatura y la maduración de la uva es muy estrecha, Chuiene et al. (2004) utilizan la fecha de vendimia de la variedad Pinot Noir en Borgoña desde el año 1370 hasta 2003 para recuperar las temperaturas anuales de primavera-verano durante más de seis siglos.

En un estudio llevado a cabo en Burdeos entre 1954 y 1997 (Jones \& Davis, 2000) se concluye que las últimas dos décadas del ensayo fueron más cálidas, obteniéndose mostos de las variedades Merlot y Cabernet Sauvignon con más concentración de azúcar y menor acidez.

\subsubsection{Precipitación}

La pluviometría mide y estudia la cantidad, la intensidad y la regularidad de las precipitaciones en un espacio geográfico y en un tiempo determinado.

Como se ha comentado más arriba, el inicio del ciclo vegetativo se inicia cuando la temperatura media ambiental en primavera está en torno a $10^{\circ} \mathrm{C}$. Previamente, las raíces ya han iniciado su actividad, debido a que esa temperatura se alcanza antes en el suelo, empezando a tomar agua del mismo.

Durante el invierno y la primavera es recomendable suficiente cantidad de lluvia o nieve para reponer las reservas de agua en todo el perfil del suelo sin que se produzcan encharcamientos (Gladstones, 2011).

La lluvia durante el cuajado obstaculiza la fecundación, y por tanto la producción final afectando al número de bayas por racimo (Vasconcelos et al., 2009). Después de dicho estado y hasta el envero el estrés hídrico reduce el tamaño de las bayas, más que en el periodo de maduración (Ojeda et al., 2001). Además, un estrés en pre-envero aumenta la concentración de sustancias fenólicas (Intrigliolo \& Castel, 2010).

La parada de crecimiento vegetativo tiene lugar cuando las uvas empiezan a madurar, está asociada al estrés hídrico y es necesaria para que este proceso de maduración se lleve a cabo de forma adecuada en variedades tintas (Martínez de Toda, 2011), evitando competencias entre el crecimiento vegetativo y dicha maduración. Además, las lluvias después del envero pueden favorecer la aparición de enfermedades fúngicas (por ejemplo Botrytis cinerea) disminuyendo la calidad de la cosecha (Jackson \& Lombard, 1993).

Después de la vendimia, es recomendable suficiente humedad en el suelo para mantener la actividad de las hojas hasta el final del ciclo, facilitando la acumulación de reservas y una adecuada formación de los sarmientos y de las yemas (Gladstones, 2011).

van Leeuwen et al. (2004) estudiando simultáneamente los tres parámetros fundamentales del terroir (clima, suelo y variedad) durante 4 años en Burdeos, encontraron que los efectos del clima y el suelo sobre el crecimiento vegetativo y sobre la composición de la uva pueden ser explicados en gran medida a través de su influencia en el estado hídrico de la planta. Este estudio concluye que las mejores añadas fueron aquellas en las que el balance hídrico en el periodo floración-vendimia fue más negativo.

La precipitación no es el único elemento que determina la disponibilidad de agua para la

planta. Influyen otros factores como la evapotranspiración potencial (ETP), que junto con la precipitación forma parte de las pérdidas y ganancias en el balance hídrico (Gómez-Miguel, 2011). Evidentemente su 
valor es muy limitado porque es muy modificado por el relieve y por el suelo. Además, las variaciones en la reserva de agua disponible dependen de la escorrentía y de la capacidad de retención de agua del suelo (Deloire et al. 2004).

En situaciones en las que la disponibilidad hídrica no sea suficiente para cubrir las necesidades demandadas por la planta se producirá estrés hídrico. Por lo tanto, el estado hídrico de la vid tiene una importancia capital en su fisiología y en algunos estados fenológicos es preferible que esté por debajo del óptimo (van Leeuwen et al., 2009).

La técnica del riego permite modificar el régimen hídrico, siendo una herramienta de gran utilidad en las zonas en las que es posible su implantación. En el manejo del riego, es importante tener en consideración lo apuntado en el párrafo anterior, ya que aportaciones excesivas de agua durante algunos estados fenológicos pueden derivar en una disminución de la calidad de la uva.

\subsubsection{Humedad Relativa}

La humedad relativa (HR), medida como porcentaje de vapor de agua en el aire, es un elemento que influye en la respuesta fotosintética a través de la abertura estomática. (Sánchez de Miguel, 2007) apunta que el óptimo higrométrico se sitúa entre el 60 y el 70 \%, encontrando que las hojas con HR limitante $(H R<30 \%)$ presentan diferencias globales muy significativas en su respuesta fotosintética a la luz respecto a HR no limitante $(H R>60 \%)$, aunque no se observaron estas diferencias con bajas intensidades lumínicas.

El desarrollo de algunas enfermedades fúngicas puede verse favorecido por una HR alta. También la aparición de rocío sobre la hoja, fenómeno físico que provoca la condensación de vapor de agua contenido en el aire sobre la superficie de la hoja, causado por un descenso importante de la temperatura del aire, puede favorecer la aparición de enfermedades criptogámicas. La aparición de este rocío sobre la superficie del suelo puede considerarse como un aporte hídrico natural.

Viento

El viento se describe por su dirección, según el punto cardinal del que proceda respecto a un lugar determinado, y por su velocidad medida en $\mathrm{km} / \mathrm{h}$.

La influencia del viento sobre el comportamiento de la vid es indirecta a través de la humedad relativa, renovando el aire en contacto con la superficie foliar; de tal forma que vientos leves permiten que la capa límite se sature gradualmente por la transpiración y la tasa de evaporación sea menor, pero los vientos fuertes renuevan constantemente la capa límite saturada por una más seca (Sánchez de Miguel, 2007) aumentando, por tanto, las necesidades hídricas.

Por otro lado, la presencia de viento durante el ciclo biológico de la vid es considerada como un elemento útil en la lucha contra enfermedades criptogámicas. Un ejemplo es el cierzo, viento fresco de componente noroeste característico de la DOCa Rioja o de la DO Campo de Borja, que dificulta la aparición y/o el desarrollo de podredumbres durante la maduración de la uva. 


\subsubsection{Vid, viñedo y cambio climático}

El incremento en la emisión de gases de efecto invernadero (GEI) producido por el crecimiento de la población mundial y del consumo individual en los últimos dos siglos ha contribuido a un calentamiento totalmente inusual de nuestro planeta (IPCC, 2014; Resco, 2015). Los GEl que más preocupan son el metano (CH4), el óxido nitroso (N2O) y el dióxido de carbono (CO2), la evolución temporal en la concentración de este último puede verse en la Figura 4.

Otros efectos del Cambio Climático, producidos por los GEl, son el aumento de superficies afectadas por la sequía y de fenómenos climáticos extremos como olas de calor o precipitaciones intensas (Resco, 2015), o el incremento de la radiación ultravioleta y de la evapotranspiración (Taylor, 2004).

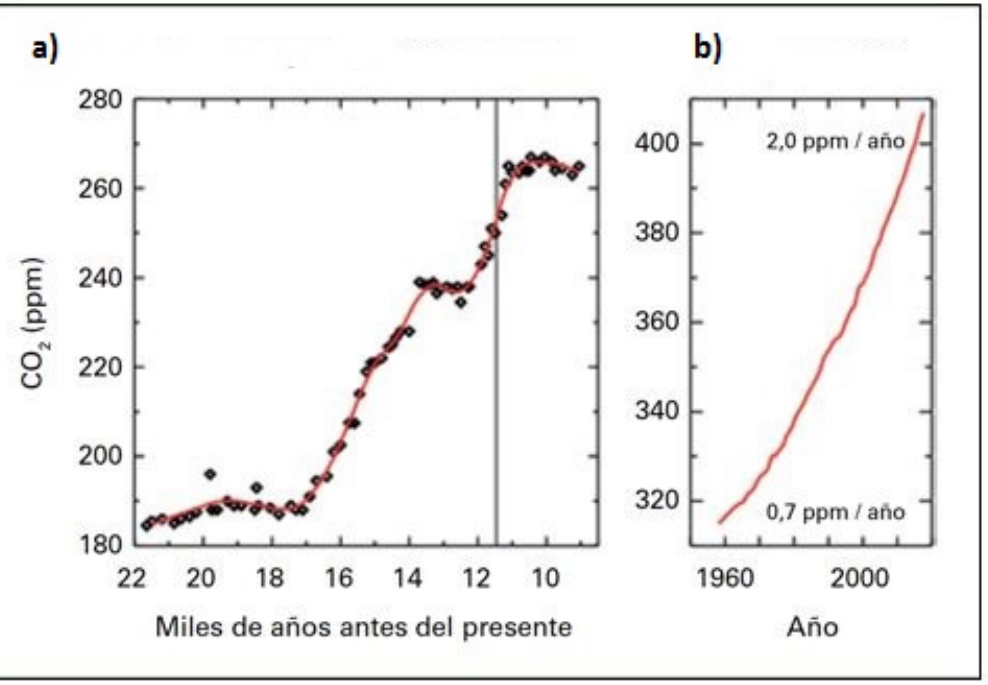

Figura 4. Concentraciones atmosféricas de CO2 en los últimos 22.000 años (a) y en el período 1960-2018 (b), (aemet, 2019).

Respecto a la respuesta de la vid al Cambio Climático, un aumento en la concentración de CO2 atmosférico puede suponer un aumento en el rendimiento y en el contenido en azúcar, una mayor resistencia a temperaturas extremas y a la sequía y una mejora de la eficiencia en el consumo de agua por la planta (Gladstones, 2011). Además, es posible que la fotosíntesis no se vea disminuida durante el período de maduración, en un momento en que hay poca disponibilidad hídrica en el suelo y la absorción de nitrógeno se ve dificultada o impedida (Gladstones, 2011).

Un estudio (Cook \& Wolkovich, 2016) que investiga la relación entre la fecha de vendimia y datos climáticos durante cuatro siglos (1600-2007), concluye que en los últimos 30 años de estudio la fecha de vendimia se ha visto adelantada con respecto a la media en 10,2 días. Este adelanto fenológico en el período 1980-2007 es debido a un aumento de la temperatura, dejando de influir la sequía en la precocidad fenológica, tal y como sucedía en los años previos.

Tal y como se comentó previamente, es primordial que el momento de la vendimia tenga lugar en condiciones frescas para conseguir la máxima expresión de un determinado terroir. Al estar sometidas las regiones vitícolas al calentamiento global, es posible que en el futuro se vea modificada la geodistribución actual de variedades. 


\subsubsection{Geología, geomorfología y geografía}

Al igual que sucede con el clima, se producen vinos de alta calidad a partir de uvas cultivadas sobre geologías (estratigrafía y litología) diferentes. Wilson (1998) apunta que los límites de la clasificación de vinos francesa (Grand Cru, Premier Cru y vino común) coinciden con los límites geológicos: Grand Cru con margas calizas, Premier Cru con losas calizas y el vino común con mezclas de calizas y margas.

Para Hancock (2005) la geología influye en tres factores que afectan a la calidad del vino: (i) modificando la temperatura alrededor de la planta y de los racimos; (ii) controlando el suministro de humedad y la velocidad en la toma de nutrientes; (iii) determinando la disponibilidad de nutrientes en el suelo (Figura 5). Respecto a este último punto, la geología es un factor importante en el control de la nutrición potásica de la vid (Hancock, 2005).

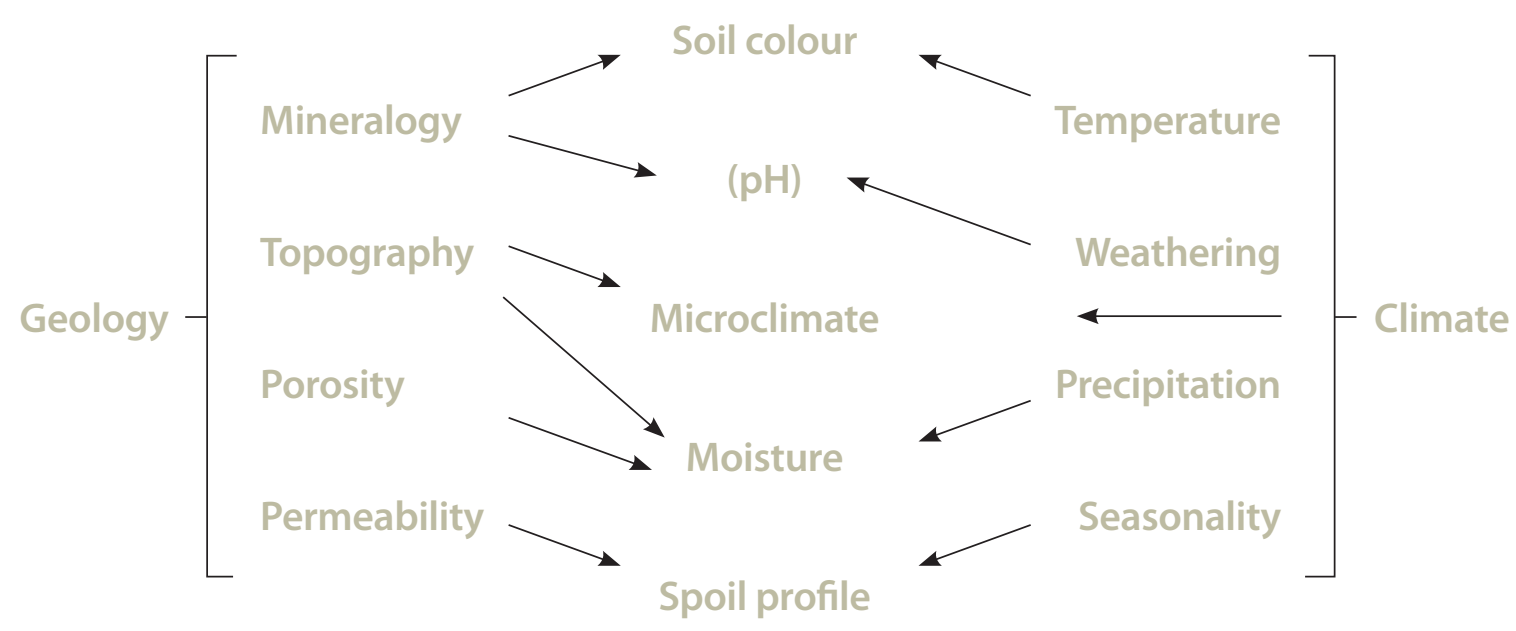

Figura 5. Propiedades del medio sobre las que afecta la interacción entre geología y clima, (Selley, 2004 en Hancock, 2005).

Huggett (2006) apunta que la influencia directa de la geología sobre el viñedo es mínima en suelos profundos, afectando de forma indirecta en suelos superficiales, a través de la composición del suelo, la geomorfología y la capacidad de retención de agua (Figura 5). También señala, al igual que en un trabajo previo (Hancock, 2005), que la roca caliza proporciona la porosidad y permeabilidad ideales para el cultivo de la vid, además las calizas moderadamente cementadas o fracturadas, areniscas, conglomerados, así como granitos o esquistos profundamente degradados y fracturados pueden aportar un balance hídrico ideal.

El efecto de la geomorfología sobre el terroir es indirecto, a través de la altitud, la pendiente y la orientación o exposición (Bramley, 2010; van Leeuwen, 2010). Esta última afecta al balance de radiación y por consiguiente a la temperatura (Bramley, 2010). 
La influencia de la orientación del viñedo en la temperatura efectiva tiene lugar de forma conjunta con la latitud, la inclinación de la pendiente, la hora del día y el momento del año. Por otro lado, las laderas también tienen la ventaja de favorecer el drenaje de aire frío (Taylor, 2004; Huggett, 2006; White, 2009) e hídrico y reducen el riesgo de encharcamiento (Gladstones, 2011).

En viñedos situados en latitudes altas, la cantidad de radiación solar recibida es en gran medida función de la pendiente y de la orientación. Estas regiones se corresponden con climas frescos por lo que suelen recomendarse laderas con exposición sur (White, 2009; Gladstones, 2011).

La diferencia de latitud afecta a la iluminación y en menor medida al régimen de temperatura, de manera que en los viñedos más septentrionales los días son más largos en verano pero la radiación solar es menor. En dichas regiones, se producen vinos delicados, aromáticos y con un grado alcohólico de bajo a moderado, aunque no todos los años se consigue una maduración adecuada (Gladstones, 2011).

La altitud hace que el clima se vea modificado, de modo que por cada 100 metros que aumenta la altitud disminuye la temperatura media alrededor de 0,65C (Gómez-Miguel, 2011). Generalizando, es más

fácil conseguir el régimen de temperaturas ideal para una correcta maduración en zonas de altitud baja y latitud alta frente a zonas de altitud elevada y más meridionales (Gladstones, 2011).

\subsubsection{Suelo}

Una concepción tradicional del suelo permite considerarlo como el resultado de la interacción del clima y de los seres vivos, como factores activos, sobre el tipo de roca y el relieve, como factores pasivos, durante un tiempo de actuación determinado. Desde un punto de vista vitícola, el suelo es el sustentáculo de las plantas, el almacén de agua y nutrientes que estas utilizan y el regulador de los elementos del clima (temperatura y precipitación, por ejemplo) que actúan sobre ellas (Gómez-Miguel, 2011).

La descripción de suelos cultivados con viñedo ha estado durante mucho tiempo reducida a los tipos de textura, pero, por ejemplo, un mismo contenido en arcilla no tiene las mismas propiedades, ya que éstas dependen de la naturaleza mineralógica de la arcilla en cuestión. Así, las convicciones basadas en el empirismo popular se revelan a veces contradictorias debido a su carácter simplista (Vaudour, 2010). Por el contrario, el uso de metodologías rigurosas y universales de clasificación de suelos permitirá comparar los mismos con garantías de éxito.

De igual manera que sucede con el clima, y lógicamente con la geología, se elaboran vinos de alta calidad a partir de uvas producidas sobre una gran diversidad de suelos, siendo imposible definir los mejores suelos en términos de pedregosidad, contenido en arcilla o limo, profundidad de suelo o contenido mineral (Bramley, 2010). Desde una perspectiva general, las propiedades del suelo que afectan a la composición de la uva, directa o indirectamente, son las que se relacionan con la alimentación hídrica y mineral de la vid y las que influyen en el mesoclima del viñedo y en el microclima de la planta. Así, los mejores suelos para la producción de uvas tintas de vinificación son los que aportan un rendimiento y un vigor limitados, controlando la disponibilidad de agua y/o de nitrógeno (Bramley, 2010).

No hay que olvidar que el suelo está en continuo cambio, por la actuación del hombre y por las interacciones existentes con el clima. Estas modificaciones realizadas por el clima se relacionan principalmente 
con los procesos de alteración y lavado: en el perfil (profundidad efectiva y diferenciación de horizontes, contrastes,...), en las propiedades físicas (formación de estructura, porosidad, color,...), en la materia orgánica (acumulación, humificación, mineralización), en la solución del suelo (dilución-concentración), en el pH y en el complejo de cambio (cambios en la fertilidad actual y potencial...) (Gómez-Miguel, 2011).

\subsubsection{Propiedades Físicas}

Respecto a la granulometría, Gómez-Miguel (2011) indica que la pedregosidad (tamaños iguales o superiores a gravas y cantos) disminuye el vigor y el rendimiento mientras que la distribución de la fracción fina o textura (partículas inferiores a $2 \mathrm{~mm}$ ) es la principal propiedad del suelo que afecta a la capacidad de retención de agua (Taylor, 2004). Efectivamente, es sobradamente conocida la mayor capacidad de retención de agua por la arcilla frente a la arena.

La estructura influye directamente en la distribución del sistema radicular de la viña, existiendo dificultades de enraizamiento con formas prismáticas o laminares bien desarrolladas. Además, el deterioro relativo de la estructura del horizonte superior y la pérdida de materia orgánica está relacionada con la formación de la costra superficial que dificulta la infiltración y la aireación (Gómez-Miguel, 2011).

Coipel et al. (2006) estudian la respuesta del cultivar Garnacha en cinco tipos de suelo de Côtes du Rhône encontrando que en los suelos de menor profundidad los valores del potencial hídrico en hoja son más bajos y el contenido en nitrógeno de la planta es inferior, lo que se refleja en una parada temprana del crecimiento de los pámpanos y en un rendimiento moderado, así como en altos niveles de azúcar y antocianos. En dicho trabajo, las uvas con mayor potencial enológico se obtuvieron en los suelos con menor capacidad de retención de agua.

El balance hídrico de un suelo permite conocer la capacidad de retención de agua del mismo, pudiéndose apreciar diferencias notables entre suelos de una misma zona (ver § 6.4.1).

El calor absorbido por los suelos pedregosos durante el día es liberado por la noche favoreciendo la maduración en zonas de noches demasiado frías, como sucede con el cultivar Riesling en el valle del Mosel. También el color de la superficie del suelo es un factor importante en el balance de energía entre suelo y atmósfera, comportándose los suelos oscuros, en este sentido, de manera similar a los suelos pedregosos (Gladstones, 2011).

\subsubsection{Propiedades Químicas}

Existe divergencia de opiniones en cuánto a la manera en que las propiedades químicas del suelo influyen en la calidad del mosto y del vino (Taylor, 2004).

Durante el ciclo anual, la vid puede sufrir desequilibrios minerales que perjudican la fisiología de la planta y que pueden ser debidos a un exceso de vigor, a la composición del suelo o a las condiciones meteorológicas. Las deficiencias nutricionales pueden afectar a la forma, el color, la composición química, el rendimiento y la edad alcanzable de los distintos órganos de la vid, siendo la consecuencia de la deficiencia uno 
o más nutrientes. Los síntomas visibles proporcionan pistas sobre su causa, pero los análisis del suelo y de las hojas (hojas o peciolos) pueden confirmar el desequilibrio de nutrientes (Bavaresco et al. 2010). A partir de los datos analíticos del suelo, hay que tener en cuenta que es tan importante la cantidad del elemento que se encuentra disponible para las raíces como la relación relativa que se encuentra de uno u otro elemento (el porcentaje). Los bajos contenidos en las capas superficiales del suelo favorecen la extensión de las raíces en profundidad y este enraizamiento profundo permite una mayor regularidad en la alimentación de agua de la viña y, desde este punto de vista, puede considerarse como un factor de calidad (Gómez-Miguel, 2011).

Una gran parte de los suelos vitícolas peninsulares son calizos y en ellos el humus, estabilizado por la caliza activa, es difícil de mineralizar por las bacterias, siendo la tasa anual de mineralización dos veces más débil que en los demás suelos, por lo que este tipo de suelo necesita contenidos en N total dos veces más elevados para obtener una nutrición nitrogenada equivalente. Aunque por diferentes motivos, en los suelos ácidos sucede algo comparable en relación con el problema de la nitrificación (Gómez-Miguel, 2011).

La disponibilidad de nutrientes en el suelo está regulada por el llamado equilibrio iónico del suelo, que se lleva a cabo entre la solución interna (complejo de cambio o arcillo-húmico) y la solución externa (solución del suelo). En este complejo se mide la fertilidad potencial con la capacidad de intercambio catiónico (CIC), que está constituida por la suma de cationes o bases (SB) y por la acidez de cambio (AC); la fertilidad actual se mide por el porcentaje de saturación de bases (V), que relaciona estas (SB) y la CIC; y la alcalinidad se evalúa con el porcentaje de sodio intercambiable (PSI), que es la relación entre el sodio de cambio (Na) y la CIC (Gómez-Miguel, 2011).

La mayoría de los viñedos que producen vinos tintos de alta calidad son pobres en elementos minerales y materia orgánica (Vaudour, 2010) y se fertilizan poco o nada con nitrógeno (van Leeuwen, 2010). En caso de realizarse este tipo de fertilización, los viñedos con aportes de nitrógeno han mostrado un mayor peso de las bayas, un mayor contenido en ácido málico (y en acidez total) y mayor peso en la madera de poda sobre variedades blancas (Chone et al., 2006) y tintas (Chone et al., 2001).

El potasio es un elemento importante en la determinación de la calidad del mosto (Taylor, 2004). En un estudio llevado a cabo sobre la variedad Tempranillo en la DO Ribera del Duero, Delgado et al. (2004) encontraron que aportes altos de potasio al suelo (240 g/cepa de K2SO4, es decir, 120 g/cepa de K2O) provocan una disminución en la acidez total de las uvas sin afectar a las características cromáticas del mosto. Con aportes bajos de potasio la absorción no se ve influenciada por el cultivar, algo que si ocurre cuando los aportes son elevados (Ruhl, 2000).

Los antagonismos que existen entre el calcio, el magnesio y el potasio en la nutrición de la planta sugieren que en los suelos calcáreos se puede reducir la toma de potasio durante la maduración, reduciéndose el pH del mosto (Gladstones, 2011).

El fósforo es fundamental en muchos procesos de la planta, reflejándose su deficiencia en un crecimiento reducido, pero con pocos síntomas específicos. Esta carencia es habitual en suelos con alto contenido en hierro, que combina fuertemente con el fosfato, fijándolo en formas no disponibles para la planta (Gladstones, 2011). 
Mackenzie y Christy (2005) relacionan el contenido de ciertos cationes como $\mathrm{Na}$, Si, Ca, Sr con el contenido en acidez total (positivamente) y en azúcar (negativamente), sobre uvas de la variedad Riesling cultivadas en Australia. También apuntan que podría ser que Ca principalmente, pero también Sr, Ba y Pb tengan influencia en las reacciones celulares (como en la formación de azúcares) afectando a los procesos de intercambio de la membrana celular así como a reacciones enzimáticas.

El pH del suelo (ver Figrua 6) se relaciona con importantes elementos como la estructura y la nitrificación, con determinados equilibrios nutricionales y con distintas deficiencias y toxicidades y a través de ellos tiene una gran influencia en la calidad del vino (Gómez-Miguel, 2011).

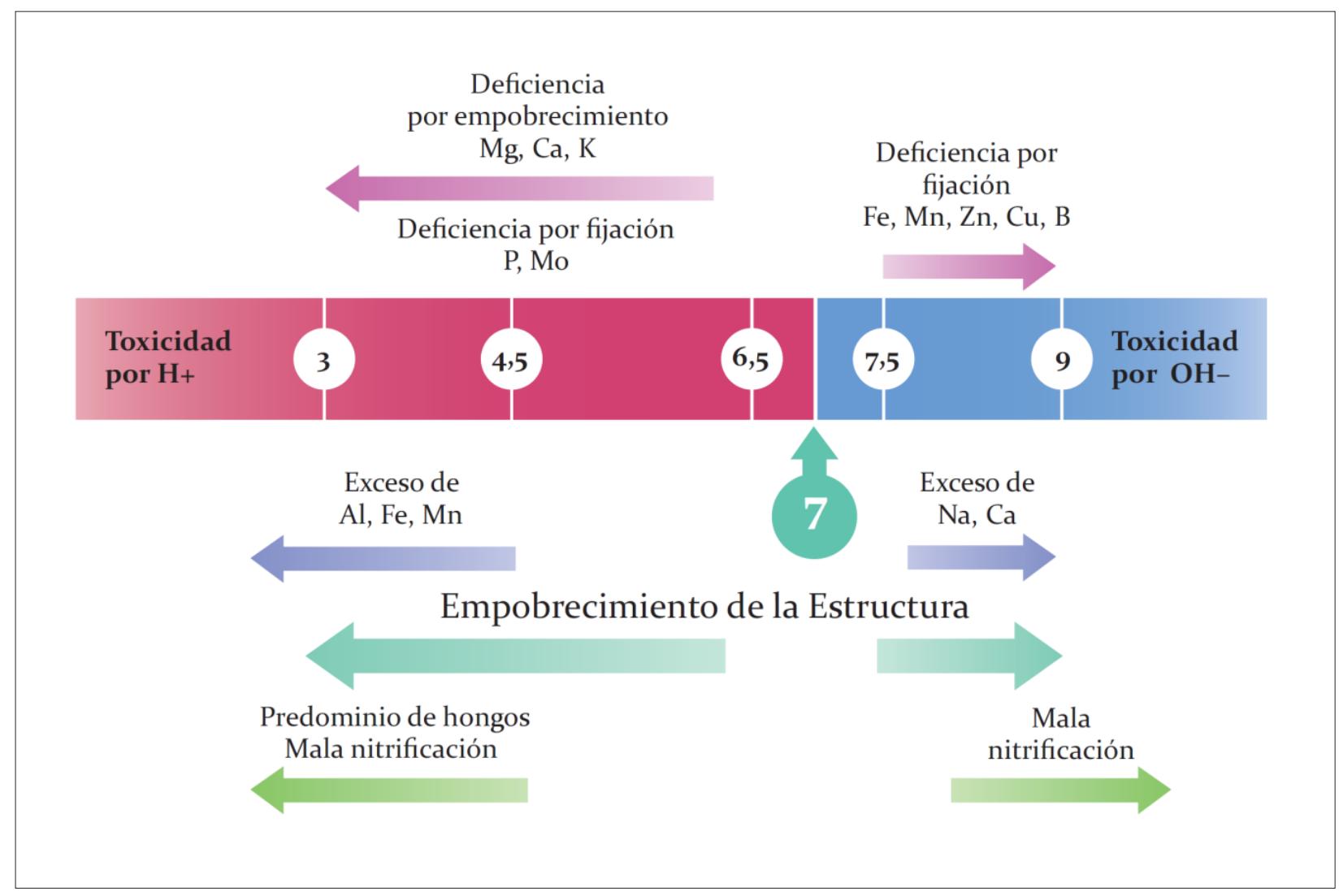

Figura 6. pH y propiedades del suelo relacionadas con la nutrición de la vid (Gómez-Miguel, 2011).

La salinidad del suelo afecta tanto al rendimiento de la vid, reduciendo el número de racimos y el peso de las bayas, como a la calidad de la uva, aumentando el pH. Con valores de conductividad eléctrica del extracto saturado 1:5 (CE1:5) inferiores a $2 \mathrm{dS} / \mathrm{m}$ la vid no es sensible, por encima de este valor las plantaciones sobre pie franco empiezan a ser afectadas ya que son más sensibles a la salinidad que las plantaciones sobre portainjerto. Por encima de 16 dS/m de CE1:5 la vid no puede vivir (Taylor, 2004).

En la Tabla 1 se muestran los valores de referencia de materia orgánica, de P, de Ky de Mg en los suelos de Rioja Alavesa, fijados por el Servicio de Enología de la Diputación Foral de Álava. 
Tabla 1. Niveles de referencia de materia orgánica (MO), P, Ky Mg en los primeros $30 \mathrm{~cm}$ de suelo en viñedos de Rioja Alavesa según la Diputación Foral de Álava (Unamunzaga, 2010).

\begin{tabular}{|c|c|c|c|c|c|c|}
\hline & Muy bajo & Bajo & Normal & Alto & Muy alto & Extremo \\
\hline MO (g/kg) & $0-5$ & $5-10$ & $10-15$ & $15-20$ & $20-25$ & $>50$ \\
\hline$P(\mathrm{mg} / \mathrm{kg})$ & $0-6$ & $6-12$ & $12-18$ & $18-30$ & $30-150$ & $>150$ \\
\hline $\mathrm{K}(\mathrm{mg} / \mathrm{kg})$ & $0-80$ & $80-160$ & $160-240$ & $240-400$ & $400-1500$ & $>1500$ \\
\hline $\mathrm{Mg}(\mathrm{mg} / \mathrm{kg})$ & $0-192$ & $192-360$ & $360-552$ & $552-720$ & $720-960$ & $>960$ \\
\hline
\end{tabular}

\subsubsection{Propiedades Biológicas}

Un suelo ideal tiene una diversidad de organismos, desde bacterias y hongos hasta artrópodos y lombrices que interactivamente descomponen los residuos orgánicos. La mayoría de estos organismos son saprófitos, es decir, se alimentan de materia orgánica muerta, y son, por tanto, cruciales para el ciclo de los nutrientes (White, 2009).

van Leeuwen (2010) apunta que no existe evidencia científica de influencia directa de los microorganismos del suelo sobre la calidad del vino o sobre la expresión del terroir, aunque debido a que para la producción de vinos de calidad no es deseable una alta disponibilidad de nitrógeno en el suelo, es lógico pensar que no es recomendable una alta mineralziación en los suelos cultivados con viñedo.

Steenwerth et al. (2008) estudian la distribución microbiana en distintos suelos de una ladera cultivada con Pinot Noir en California, sugiriendo que el carbono del suelo juega un papel más importante en la composición microbiológica que la humedad o los factores físicos (como la textura o la densidad aparente). Estos mismos autores, encuentran una carga microbiológica similar en el horizonte superficial (Ap), mientras que existen mayores diferencias en los horizontes subsuperficiales, siendo las zonas con raíces las más ricas, biológicamente hablando.

\subsubsection{Material vegetal}

La elección del portainjerto a utilizar y de la variedad a cultivar debe tomarse considerando las condiciones del medio en el que se implantará el viñedo, con el principal objetivo de conseguir una madurez adecuada de la uva. Jackson y Lombard (1993), en función de la temperatura media en el momento de la madurez de una determinada variedad, clasifican las zonas vitícolas como alfa (entre $9^{\circ} \mathrm{C}$ y $15^{\circ} \mathrm{C}$ ) o beta $\left(16^{\circ} \mathrm{C}\right.$ o más), ver § 3.3.2; mientras que para van Leeuwen y Seguin (2006) la madurez ideal tiene lugar cuando la vendimia se realiza entre el 10 de septiembre y el 10 de octubre (viticultura de clima fresco). Gladstones (2011) define nueve grupos de maduración con un intervalo entre el grupo más temprano y el más tardío de 54 días e índica para cada grupo las variedades recomendadas. Jones (2006) aconseja un cultivar u otro en función de la temperatura media durante el período de vegetación (Figura 7). 
Entre los portainjertos autorizados para su uso en España, la elección de uno u otro será función de posibles condiciones limitantes para el cultivo como la caliza activa, la salinidad o la sequía y de su influencia sobre aspectos vegeto-productivos como el vigor, la fenología o la afinidad con la variedad.

Respecto a la procedencia del material vegetal que conforma la variedad, este puede proceder de selecciones clonales o masales. Las primeras se realizan a partir de un único ejemplar (cabeza de clon) mientras que las segundas multiplican un conjunto de individuos previamente seleccionados, aportando cierta heterogeneidad a la nueva plantación.

Para una determinada variedad cultivada en una zona concreta, los períodos floración/envero y envero/madurez son bastante constantes (Reynier, 2012) y tienen poca variación en función del clima, pudiendo concluir que conociendo la fecha de floración se puede estimar la fecha de vendimia, ver Tabla 18 de § 6.2).

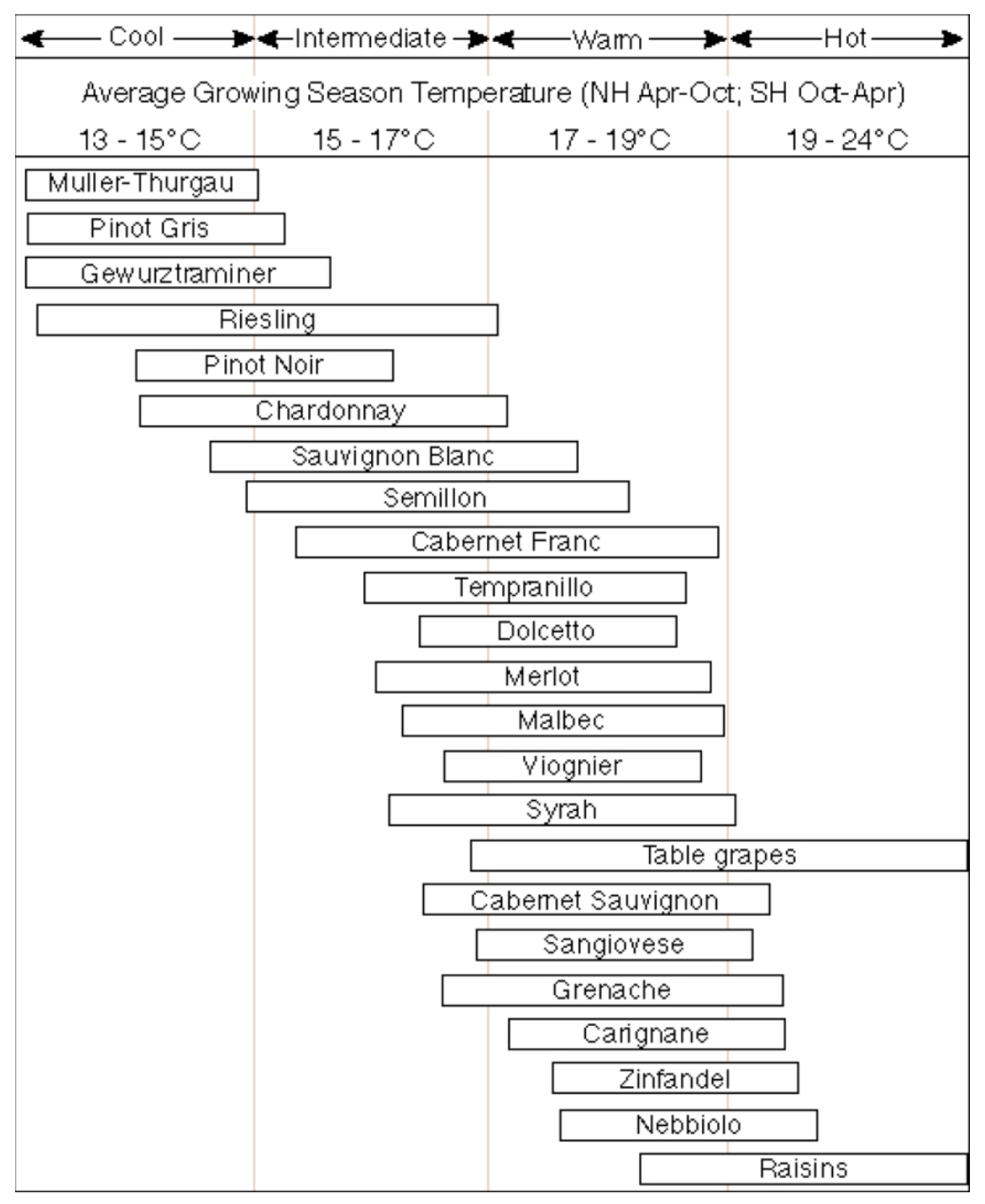

Figura 7. Plasticidad térmica de varios cultivares de vid en función de la temperatura media durante el ciclo vegetativo (Jones, 2006). 


\subsubsection{Manejo del cultivo}

Las distintas técnicas utilizadas para el cultivo de la vid y su influencia en la respuesta de la planta han sido, y son, objeto de numerosos estudios. Sin duda, las operaciones culturales afectan, en distinta medida, al rendimiento de la cosecha y a la composición de la uva.

Pérez (2002) estudiando dos marcos de plantación, encontró que el de mayor densidad (3.953 cepas/ ha frente a 2.645 cepas/ha) produjo más materia seca por metro cuadrado de suelo, así como un rendimiento ligeramente superior y una acidez más baja. En el trabajo de Junquera (2011) se estudia la influencia de la distancia entre filas y de la densidad de pámpanos, apuntado que al aumentar la distancia entre filas aumenta el peso de la madera de poda por metro de fila sin afectar claramente al rendimiento ni a la composición de la uva. Por otro lado, al reducir la densidad de pámpanos aumentó la concentración de azúcares, el pH y el contenido fenólico.

La orientación de las filas afecta a la interceptación de la radiación solar por la vegetación, aunque en sistemas de conducción horizontales su efecto no es tan importante. La elección de una orientación u otra debe decidirse atendiendo a las necesidades hídricas, el tipo de suelo, la topografía, los riesgos de erosión y el viento dominante (Reynier, 2012). En climas cálidos, es recomendable una orientación que permita una iluminación directa por la mañana y por la tarde cuando la temperatura del aire es moderada para una mejor bioquímica de la maduración (Gladstones, 2011).

A pesar de que algunos sistemas de conducción pueden reconvertirse en otros, la elección del mismo se ha considerado una operación permanente (Figura 8), ya que tradicionalmente el sistema de conducción elegido en la plantación es el que se mantiene durante toda la vida del viñedo. Baeza (1994) comparando en Madrid cuatro sistemas de conducción (cortina, espaldera, vaso bajo y vaso alto) concluye que la espaldera obtiene mayor superficie foliar externa, un microclima de racimos menos iluminado y producciones de materia seca y de cosecha superiores.

El deshojado precoz es la técnica de cultivo más reciente de las tratadas en este apartado. Orio (2010) encuentra que el deshojado precoz (realizado entre floración y cuajado) reduce el peso del racimo y su compacidad, sin verse modificada la relación Superficie Foliar Expuesta (SFE)/Producción (P) en el momento de vendimia y aumentando el grado de alcohol probable de la uva.

La técnica del deshojado (tradicional) de la zona de racimos mejora la exposición de estos. Smart (1998) aconseja eliminar una o dos hojas por sarmiento algunas semanas antes del envero, consiguiendo una reducción del ácido málico y aumento del pH, así como mayor contenido fenólico y sacarimétrico, pudiendo incrementar ligeramente el rendimiento. Al practicar esta técnica, habría que contemplar la posibilidad de que se produzcan pérdida de aromas por sobreexposición de los racimos en climas cálidos.

La poda en verde (despampanado, desnietado y despunte) es utilizada para controlar el canopy durante el ciclo vegetativo y en función del momento de realización y del número y la intensidad de tratamientos se obtienen resultados distintos. (Smart, 1998) recomienda realizar despuntes que dejen al menos 10-12 nudos, así como despampanados con brotes de menos de 15-20 cm. En cualquier caso, la poda en verde dependerá en gran medida del vigor del viñedo. 
En general, el canopy condiciona el microclima de la planta afectando sobre todo a la radiación, evaporación y velocidad del viento, y en menor medida, a la humedad y la temperatura. Estas condiciones microclimáticas influyen en aspectos tan importantes como la fotosíntesis, la respiración, el crecimiento de los pámpanos y bayas, la iniciación floral y la maduración (Sánchez de Miguel, 2007).

Rubio (2002) muestra que un aclareo de racimos del 40\% en el envero no tiene influencia sobre los aspectos fisiológicos de la vid, afectando de forma decisiva en la reducción del rendimiento y aumentando la concentración de azúcar en las bayas de cepas aclareadas.

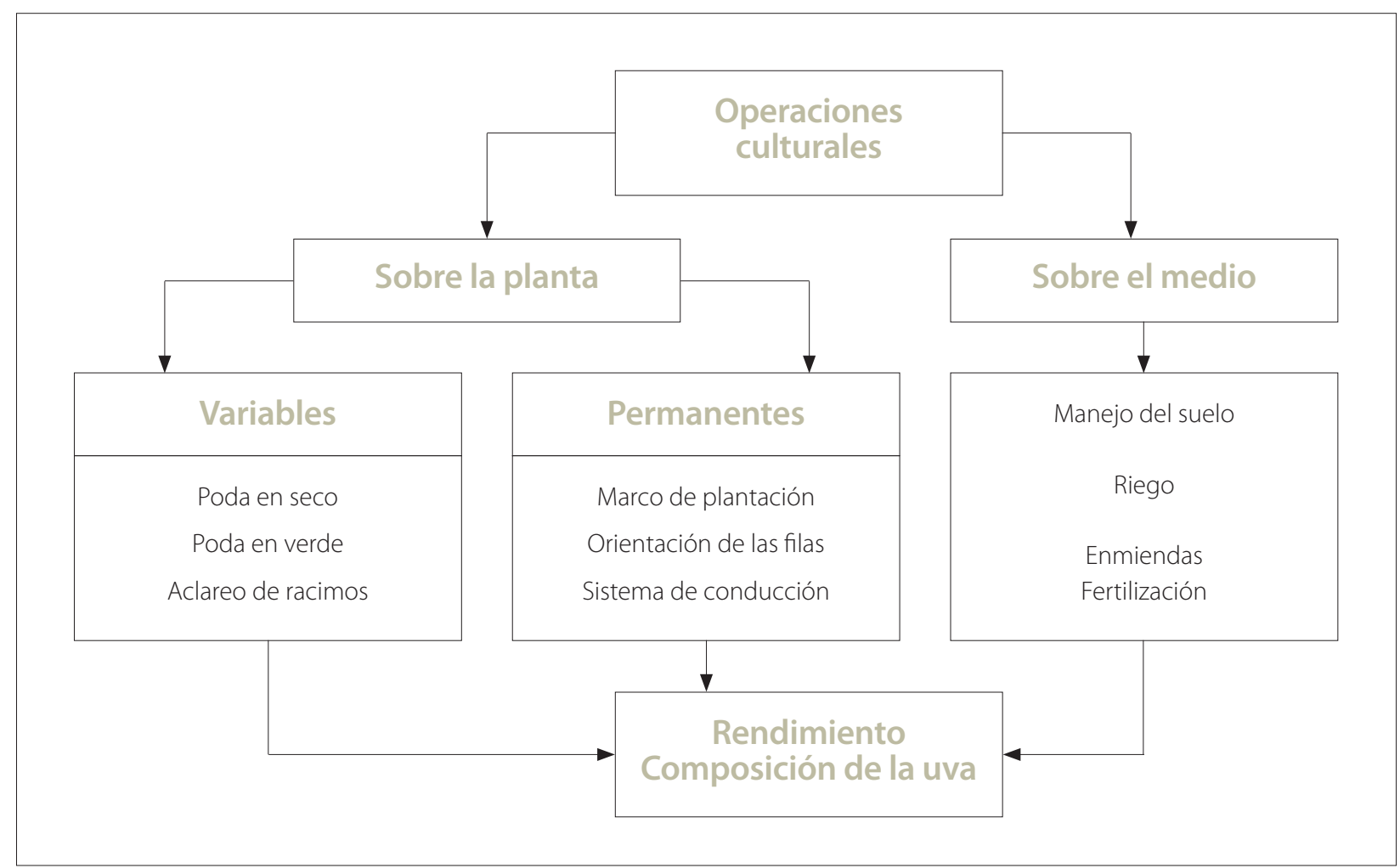

Figura 8. Operaciones de cultivo en relación con el medio físico y la vid.

Las dificultades para predecir el estado hídrico de la planta en base a datos climáticos (ETP) o edáficos (humedad del suelo) aconsejan decidir la aplicación del riego en base al estado fisiológico de la planta, y en este sentido se han desarrollado diferentes "indicadores" que permiten la determinación del momento y la dosis de riego con mayor precisión (Medrano et al., 2007).

Las estrategias de riego que conduzcan a una producción excesiva, a una importante estimulación del vigor, a un desequilibrio entre la expresión vegetativa y productiva, y a una degradación del microclima de hojas y racimos (nivel elevado de solapamiento y pérdida de adecuada disposición), aportarán una valoración negativa de esta técnica de cultivo. Por ello, la utilización del riego pasa por una contención lo más eficaz posible del rendimiento, y sobre todo, del vigor de la planta (García-Escudero, 2007).

Ibáñez (2013) compara el manejo de suelo mediante laboreo frente a cubiertas vegetales, concluyendo que el uso de estas disminuyen el peso de madera de poda, la superficie foliar y el rendimiento. Además, los tratamientos con cubierta manifestaron antes el estrés hídrico, tanto diario como estacional. 


\subsection{VARIABILIDAD VITÍCOLA}

Columela titula el capítulo primero del Libro III de De Re Rustica (Columela, 2008):"Que especie de vid convenga a cada terreno y a cada clima", donde habla de la versatilidad de la vid para adaptarse a distintos climas y suelos, y se dan indicaciones para elegir la variedad de vid adecuada según las características de estos dos factores. Las diferencias entre los factores naturales darán lugar a una variabilidad en las características del cultivo.

Haciendo referencia a la variabilidad entre parcelas, Ribereau Gayon y Peynaud en Larrea (1979) apuntan:

"Es difícil explicar de un modo satisfactorio las diferencias que se observan entre los vinos producidos en una misma comarca, porque el pago de gran calidad es un todo complejo, resultante de varios factores, entre los cuales no se ha de olvidar la labor del hombre".

Los factores del medio que pueden ser responsables de estas diferencias son el clima y el suelo (Seguin, 1986; van Leeuwen et al., 2004), la altitud, la pendiente y su orientación (Santesteban et al., 2013) y/o la geología (Seguin, 1986; Witze, 2005; Huggett, 2006). En un estudio llevado a cabo en el municipio de Oyón, dentro de la DOCa Rioja, Martínez y Gómez-Miguel (2017) considerando el clima constante, encuentran como elementos del medio responsables de la variabilidad interparcela la altitud, la geología, el suelo, la pendiente y la orientación.

Por otro lado, también es conocida la variabilidad existente en la maduración de las uvas dentro de la misma parcela (variabilidad intraparcela), así Abela (1885) en El Libro del Viticultor hablando sobre la vendimia señala:

"Es mala práctica la de coger sistemáticamente de una sola vez los racimos, más o menos agraces o maduros; conviene ir cortando sólo los que se hallen en sazón adecuada, con arreglo al objeto que se desea, según los resultados obtenidos de la experiencia; se concluye de este modo una vuelta completa a la viña, y después procede dar otra u otras, para vendimiar lo restante cuando vaya llegando al oportuno grado de madurez".

Algo que coincide con lo escrito por Cadet-de-Vaux (1803):

"...nunca se hará buen vino sin dos vendimias, porque nunca puede madurar igualmente el fruto".

Más recientemente, Tisseyre et al. (2007) señalan que actualmente con ayuda de la Viticultura de Precisión (PV) se están realizando vendimias bien separando la uva cosechada el mismo día en diferentes lotes, o bien vendimiando en días distintos cada zona de la parcela con el objetivo de obtener el mayor grado de calidad en cada bloque. Bramley et al. (2011) apunta que este tipo de vendimia es viable a distintas escalas de producción, desde pequeños hasta grandes elaboradores. 
La variabilidad intraparcela puede deberse a la variación de los siguientes factores del medio: (i) la topografía (Bramley \& Hamilton, 2007; Bramley, 2010); (ii) la profundidad del suelo (Lamb et al., 2004); (iii) la capacidad de rentención de agua del suelo (Tisseyre et al., 2007; van Leeuwen et al., 2009) y/o (iv) el contenido en nitrógeno del suelo (Chone et al., 2001; Chone et al., 2006). Además, la variabilidad tiene efectos tanto en el rendimiento (Bramley \& Hamilton, 2004) como en la calidad de la uva (Bramley, 2005), siguiendo (en estos dos últimos ensayos) un patrón parecido año tras año.

En resumen, los factores naturales que definen el terroir son también responsables, en distinta medida, de la variabilidad observada entre plantas de una misma parcela (variabilidad intraparcela) o de distintas fincas (variabilidad entre parcelas).

Con el propósito de delimitar las distintas zonas con características comunes se realizan zonificaciones atendiendo a los distintos factores ambientales que afectan a la producción de uva. Es habitual realizar una zonificación climática, una zonificación de la geosituación y una zonificación edáfica para la caracterización ecológica de un viñedo o de una región vitícola. La zonificación integrada del terroir (ZIT) puede considerarse como la combinación y comparación de distintas zonificaciones y se representa de forma gráfica mediante la cartografía (Gómez-Miguel, 2011). Por lo tanto, la ZIT permite conocer la posición de cada una de las zonas con características comunes, que se denominan Unidades Homogéneas del Medio (UHM).

En función de la superficie ocupada por la zona de estudio se llevan a cabo zonificaciones con mayor o menor detalle, de forma que se emplearán escalas de representación gráfica pequeñas cuando el área a zonificar sea grande y viceversa (Figura 9).

En función de esta escala de estudio empleada, puede variar la importancia de los factores que influyen sobre el terroir. Así, el clima es el factor dominante en zonificaciones de grandes superficies (por ejemplo un país), mientras que dentro de una región la geología, la geomorfología y sus efectos mesoclimáticos son los factores principales que explican las diferencias en el desarrollo de la viña y en la composición de la uva. Por último, a escala de parcela la variabilidad puede relacionarse con el tipo de suelo y su profundidad (van Leeuwen, 2010).

Para algunos autores, la influencia del terroir sólo puede estudiarse satisfactoriamente en superficies pequeñas cartografiadas a escalas grandes (Bramley \& Hamilton, 2007; White, 2009). Con un espíritu más integrador, se puede considerar que macro y microzonificación son complementarias, utilizando la primera como base de definición de las UHM, permitiendo el análisis de sus elementos y las relaciones con parámetros de calidad en estudios más detallados (microzonificación), en los que se asignará a cada unidad cartográfica un único terroir (Gómez-Miguel, 2011). 


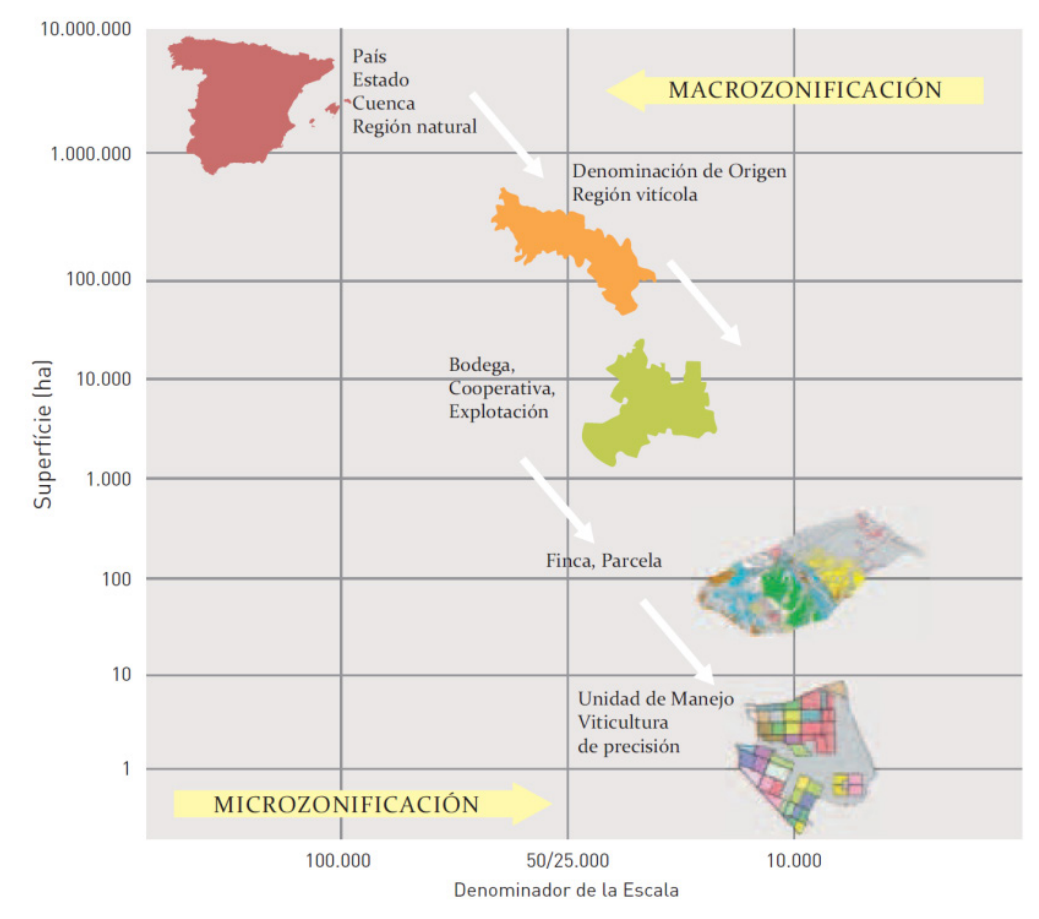

Figura 9. Zonificación (macrozonificación y microzonificación): escala de trabajo y niveles de producción (Gómez-Miguel, 2011).

En función del clima anual se observan diferencias en el rendimiento (Tisseyre et al., 2007), en el vigor o en el estado hídrico de la planta (Acevedo-Opazo et al., 2008) en valores absolutos y a nivel intraparcela. Estos valores absolutos (de distintos años) se pueden normalizar, incluyéndolos en clases, con el objeto de observar la existencia de una estabilidad temporal de la variabilidad espacial.

En un viñedo pueden darse fluctuaciones interanuales respecto a la producción superiores al 35 \% (Carmona et al., 2008), lo que se explica, en distinta proporción, a través de la variación en los componentes del rendimiento, siendo el principal motivo de la variabilidad el número de racimos por cepa (Tabla 2). Este factor, así como el resto de los componentes del rendimiento, se ve a su vez influenciado por las técnicas de cultivo y los factores naturales del medio.

En un ensayo llevado a cabo en tres viñedos de Saint-Emilion durante 5 años por van Leeuwen et al. (2004) se comparó la influencia del clima, el suelo y la variedad en la variabilidad temporal de los parámetros vegetativos, productivos y de composición de la uva, concluyendo que el clima tiene la mayor influencia sobre la mayoría de los parámetros, seguido por el suelo y la variedad.

Ha sido puesta de manifiesto la estabilidad en el tiempo del patrón de variabilidad intraparcela del rendimiento (Bramley \& Hamilton, 2004), de la composición de la uva (Lamb et al., 2004; Bramley, 2005), del diámetro del tronco (Tisseyre et al., 2007), del peso de la madera de poda (Dobrowski et al., 2003) o del estado hídrico de la planta (Ojeda et al., 2005). La estabilidad temporal de la variabilidad puede relacionarse con las características del suelo, la altitud y la disponibilidad de agua en el suelo (Lamb et al., 2004; Taylor, 2004; Tisseyre et al., 2007; Acevedo-Opazo et al., 2008). Tal y como se ha dicho anteriormente, es de esperar que los factores naturales que afectan al terroir sean los responsables de aquellas variabilidades. 
Tabla 2. Variabilidad interanual de la producción (\%) en función de los componentes del rendimiento. Elaboración propia a partir de Clingeleffer et al, (2001).

\begin{tabular}{|c|c|c|}
\hline COMPONENTEDEL RENDIMIENTO & FACTOR CONDICIONANTE & VARIABILIDAD INTERANUAL \\
\hline Yemas/Cepa & Carga en la Poda & \multirow{3}{*}{ 60\% (Racimos/Cepa) } \\
\hline Brotes/Yema & \% Brotación & \\
\hline Racimos/Brote & Iniciación + Diferenciación de inflorescencias & \\
\hline Bayas/Racimo & Diferenciación de flores + Tasa de Cuajado & 30\% (Bayas/Racimo) \\
\hline Gramos/Baya & Floración + Maduración & 10\% (Peso Racimo) \\
\hline
\end{tabular}

El agrupamiento k-means es un método no jerárquico de agregación de datos que maximiza la distancia euclidiana entre los grupos y minimiza las distancias dentro de los mismos y ha sido utilizado con éxito para demostrar la estabilidad temporal en los patrones de variabilidad espacial del rendimiento (Bramley \& Hamilton, 2004; Bramley, 2005). Por otro lado, Tisseyre et al. (2007) no encontraron estabilidad temporal en la variabilidad intraparcela en las propiedades de la uva estudiadas ( ${ }^{B} \mathrm{Brix}, \mathrm{pH}$, acidez total, contenido fenólico y antocianos) sobre viñedos manejados en secano, no pudiendo, por tanto, utilizar mapas de calidad de años anteriores como una herramienta para manejar o prever la calidad en futuros años. Aunque en este último trabajo se concluye que existe estabilidad temporal en la variabilidad del rendimiento, del estado hídrico o del vigor, parámetros relacionados con el suelo y el medio, particularmente con la disponibilidad de agua (Tisseyre et al., 2007).

También es necesario definir la magnitud y la estructura espacial de la variabilidad con la finalidad de determinar si es viable (económica y técnicamente) un manejo diferenciado por bloques o subparcelas. El coeficiente de variación (CV) es un estadístico descriptivo (calculado dividiendo la desviación estándar entre la media) que ha sido utilizado para cuantificar la magnitud de la variabilidad (Taylor, 2004), pero la estadística clásica no ofrece información sobre la naturaleza espacial de la variabilidad.

Sin embargo, la geoestadística se ocupa de la correlación espacial de un conjunto de datos. Cambardella et al. (1994) estudian la variabilidad espacial de las propiedades del suelo a partir de semivariogramas, particularmente a partir de dos de sus parámetros (nugget y semivarianza total), definiendo el índice de Cambardella (Ic), con tres niveles de dependencia espacial (fuerte, moderada y débil) en la distribución de los datos. Otro indicador propuesto por Pringle et al. (2003), es el índice de Oportunidad (OI), que da idea de lo recomendable que puede ser el manejo por bloques en una determinada parcela, evaluando la magnitud de la variabilidad mediante el Coeficiente de Variación superficial (CVa), la superficie media de los bloques donde el rendimiento está autocorrelacionado y el beneficio económico y ambiental de un manejo por bloques frente a la gestión uniforme de la parcela.

El índice de Oportunidad Técnica (TOi) también persigue discriminar si la variabilidad espacial en un determinado viñedo es técnicamente manejable, a partir de información obtenida dentro de la parcela y un algoritmo matemático (Tisseyre \& McBratney, 2008). 


\subsection{ZONIFICACIÓN VITÍCOLA}

Tanto si se trata de una viticultura secular como de una viticultura pionera, todo espacio vitícola está caracterizado por unos límites (Vaudour, 2010). Ciertas delimitaciones están preestablecidas y otras hay que establecerlas. La realización de zonificaciones se debe a diferentes objetivos y necesidades y su demanda no deja de crecer.

Como se aprecia en la Figura 10 la zonificación vitícola puede llevarse a cabo desde distintos puntos de vista. La combinación parcial de varios de estos criterios da lugar a modelos complejos como la Zonificación Integrada del Terroir (ZIT), ya citada en el apartado anterior y que incluye la validación de los resultados.

La disponibilidad de datos publicados por diferentes Organismos Públicos facilita algunas de las zonificaciones simples que estructuran la zonificación integrada. Existen datos públicos climatológicos, geológicos, topográficos, etc., que en algunos casos es necesario agrupar en clases para posibilitar el procesamiento georreferenciado de la información. En otras ocasiones, los datos publicados no son adecuados para el detalle que un determinado estudio requiere haciéndose necesario la ejecución de trabajos que permitan la obtención de nuevos datos, aumentando notablemente el coste global del estudio.

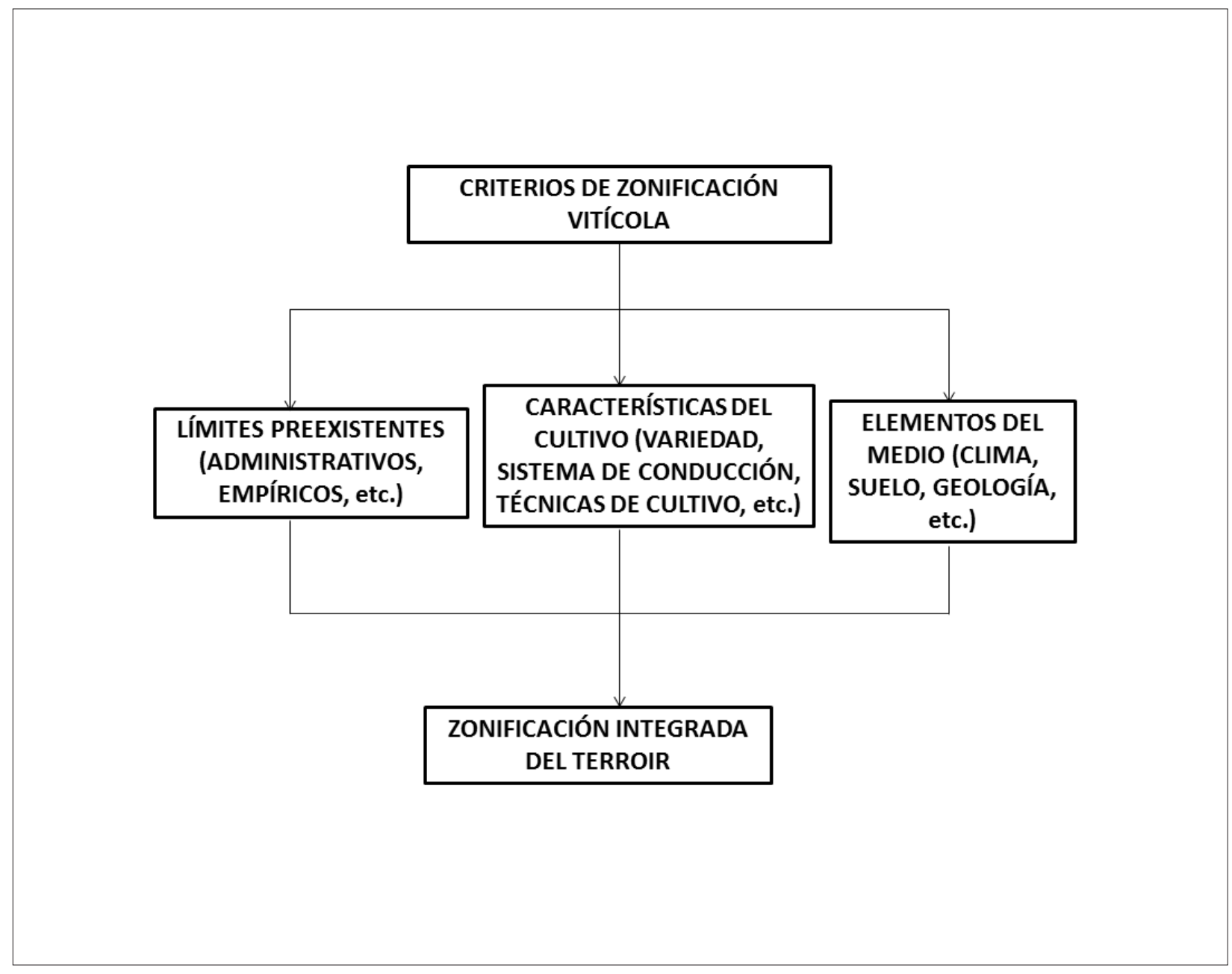

Figura 10. Criterios de zonificación incluidos en la zonificación integrada del terroir. 


\subsubsection{Límites preexistentes}

La delimitación o zonificación de regiones históricas, frente a otras recientes, se ha llevado a cabo a partir de las tradiciones seculares y características propias de la zona en cuestión, redactándose por último el reglamento de la figura a proteger (García de Lujan, 2003). En cualquier caso, es necesaria una identificación de zonas con base científica en relación con lo que la tradición ha marcado a lo largo de los años (Gil de Bernabé en Fernández, 1999).

En el caso de los vinos de Oporto se parte en 1756 de una zonificación en base a los vinos de mejor calidad que eran exportados a Inglaterra. Esta primitiva delimitación sufre sucesivas modificaciones: en 1865 se amplía, permitiendo la expansión rápida hacia el Duero Superior; en 1907 se dibujan nuevas líneas de demarcación que ahora incluyen el Duero Superior y en 1921 se incorpora una zonificación por municipios reduciendo el área de producción prácticamente al espacio actual. Hoy en día, además de la delimitación geográfica de la zona de producción de uva, se emplea un método de puntuación que clasifica los viñedos según una escala cualitativa de la A a la F, tomando como factores de la calificación parámetros edafoclimáticos y culturales determinantes en el potencial vitícola de las parcelas (Instituto dos Vinhos do Douro e do Porto, 2019).

Algunos límites preexistentes, como los políticos, pueden ser un obstáculo para la delimitación de una figura de calidad protegida. Es reseñable que en España sólo existen tres Denominaciones de Origen cuya zona de producción se extiende por más de una Comunidad Autónoma (DOCa Rioja, DOP CAVA, DOP Jumilla), cuando los límites físicos de muchas de ellas coinciden con los límites geográficos de la provincia o la Comunidad Autónoma en la que se encuentran ubicadas. Aún más difícil es encontrar Denominaciones de Origen internacionales como es el caso de la DOP Maasvallei Limburg, que comprende territorio belga y neerlandés en el valle del río Mosa a su paso por Limburgo. A pesar de que los límites administrativos o políticos no han sido definidos bajo consideraciones del medio físico que afectan al cultivo de la vid, la frontera entre España y Portugal sirve de límite geográfico para cuatro DOs españolas: DOP Rías Baixas, DOP Monterrei, DOP Arribes y DOP Ribera del Guadiana y seis portuguesas: DOC Vinho Verde, DOC Tras-Os-Montes, DOC Douro/Porto, DOC Beira Interior, DOC Alentejo y DOC Tavira.

\subsubsection{Zonificación del clima}

Desde mediados del siglo pasado se han venido realizando zonificaciones a partir de índices bioclimáticos vitícolas, la mayoría de ellos basados en la temperatura activa de la vid y partiendo de las observaciones de A.P. de Candolle a mediados del siglo XIX (Jones, 2006). El Índice de grados-día de Winkler o Índice de Winkler (IW) (Amerine \& Winkler, 1944) para un ciclo vegetativo determinado se calcula sumando las temperaturas activas desde el primero de abril hasta el 30 de octubre. El Índice heliotérmico de Branas (HX) (Branas, 1946), el Índice heliotérmico de Huglin (IH) (Huglin, 1978) y el Índice heliohidrotérmico de Constantinescu (IHC) (Constantinescu, 1967) parten del IW introduciendo en sus cálculos parámetros como la longitud del día, la latitud; la temperatura máxima diaria y la precipitación, respectivamente. Estos índices son poco discriminantes y adolecen de falta de relaciones vitícolas directas (Gómez-Miguel, 2011).

Otras zonificaciones simples propuestas son: (i) la línea de Wagner (Wagner, 1974) divide Europa en dos zonas vitícolas y queda definida por el límite septentrional de clima con influencia mediterránea, (ii) ba- 
sada en la temperatura media en el momento de maduración para un cultivar determinado (Jackson \& Lombard, 1993), proponiendo dos zonas. La zona Alfa es definida como aquella en la que la temperatura media en el momento de la vendimia para una variedad determinada se sitúa entre $9^{\circ} \mathrm{C}$ y $15^{\circ} \mathrm{C}$, mientras que en la zona Beta esta temperatura es mayor o igual a $16^{\circ} \mathrm{C}$. Según este criterio, y para estos autores, España es una zona Alfa para variedades de maduración tardía y una zona Beta para variedades de maduración temprana. Una misma variedad presentará distinta composición según la zona de cultivo, aunque en ambas zonas será posible elaborar vino de calidad.

Riou et al. (1994) realizan una zonificación dentro de la Unión Europea relacionando factores climáticos con la maduración de la uva, proponiendo una fórmula para determinar el contenido en azúcar en función de elementos como la reserva hídrica del suelo, la duración del día, la fecha de floración y la temperatura media desde el envero hasta la vendimia.

En los trabajos de los profesores Gómez Miguel y Sotés (Gómez-Miguel \& Sotés, 1990-2017) se utiliza una metodología de zonificación climática configurando un modelo que reduce las variables cuantitativas de las estaciones climáticas de la zona de estudio, con el fin de eliminar información redundante y caracterizar las áreas homogéneas desde el punto de vista climático. En la DOCa Rioja todas las variables climáticas estudiadas se reducen a la precipitación, evapotranspiración y el IHC, mientras que en la DO Ribera del Duero el modelo resultante se completó con la precipitación, el IW y el riesgo de heladas primaverales (Gómez Sánchez, 1996). En la Ribera del Miño, Blanco-Ward et al (2007) encuentran que el 90 \% de la variabilidad climática espacial se puede explicar a partir de tres elementos: la precipitación, la temperatura y el riesgo de heladas.

El sistema de clasificación climática multicriterio (MCCS) (Tonietto, 1999; Tonietto \& Carbonneau, 2004) ha sido propuesto para la caracterización macroclimática de zonas vitícolas combinando tres índices bioclimáticos: (i) el IH (Huglin, 1978); (ii) el índice de frío nocturno (Cl), que considera la temperatura media mínima nocturna en el mes previo a la vendimia, con el objeto de evaluar el potencial cualitativo de la uva en relación con la producción de metabolitos secundarios y (iii) el índice de sequía (DI), adaptación del índice de potencial hídrico del suelo de Riou (Riou et al., 1994). Jones et al. (2014) presentan un criterio específico para la zonificación climática de regiones vitícolas en Portugal a partir de estos tres mismos índices.

Se han llevado a cabo comparaciones en la distribución de zonas climáticas en el oeste de Estados Unidos (Jones et al.,2010) y en Australia (Hall \& Jones, 2010) a partir de cuatro índices bioclimáticos calculados mediante interpolación de los datos de una malla de estaciones climáticas de 400 y 80 metros respectivamente, concluyendo que no se obtienen mejores resultados con índices de fórmulas más complejas que el IW. Además, Hall y Jones (2010) apuntan que el IH es posiblemente el índice más adecuado en estudios sobre efecto del cambio climático en viticultura.

\subsubsection{Zonificación del medio}

La geología y la geomorfología permiten un enfoque sintético adaptado a la zonificación con escalas pequeñas ( $\leq$ 1:50.000), explicando el comportamiento de la vid sólo indirectamente (van Leeuwen et al., 2012). Estos autores opinan que los mapas geológicos o geomorfológicos son útiles como una primera

aproximación a la zonificación del terroir, ya que en una misma unidad de estos mapas pueden incluirse suelos muy distintos, por lo que se hace necesario la determinación de los tipos de suelos. 
En Sudáfrica, otros autores (Carey et al., 2003; Carey et al., 2008) zonifican el medio de la región de Stellenbosch a partir de diferentes variables (las unidades morfológicas del terreno, el ángulo y la orientación de la ladera, la altitud y la orientación) de forma similar a como lo hacen en Oregón Jones et al. (2004) y Jones et al. (2006), para zonificar el medio en los valles de Umpqua y Rogue utilizando la altitud, la pendiente y la orientación.

Vadour (2010) también se apoya en la FIA para el estudio de la ocupación del suelo y las estructuras parcelarias, del estado de la superficie del suelo y de la topografía y la geomorfología en la zonificación de la AOC Côtes-du-Rhône.

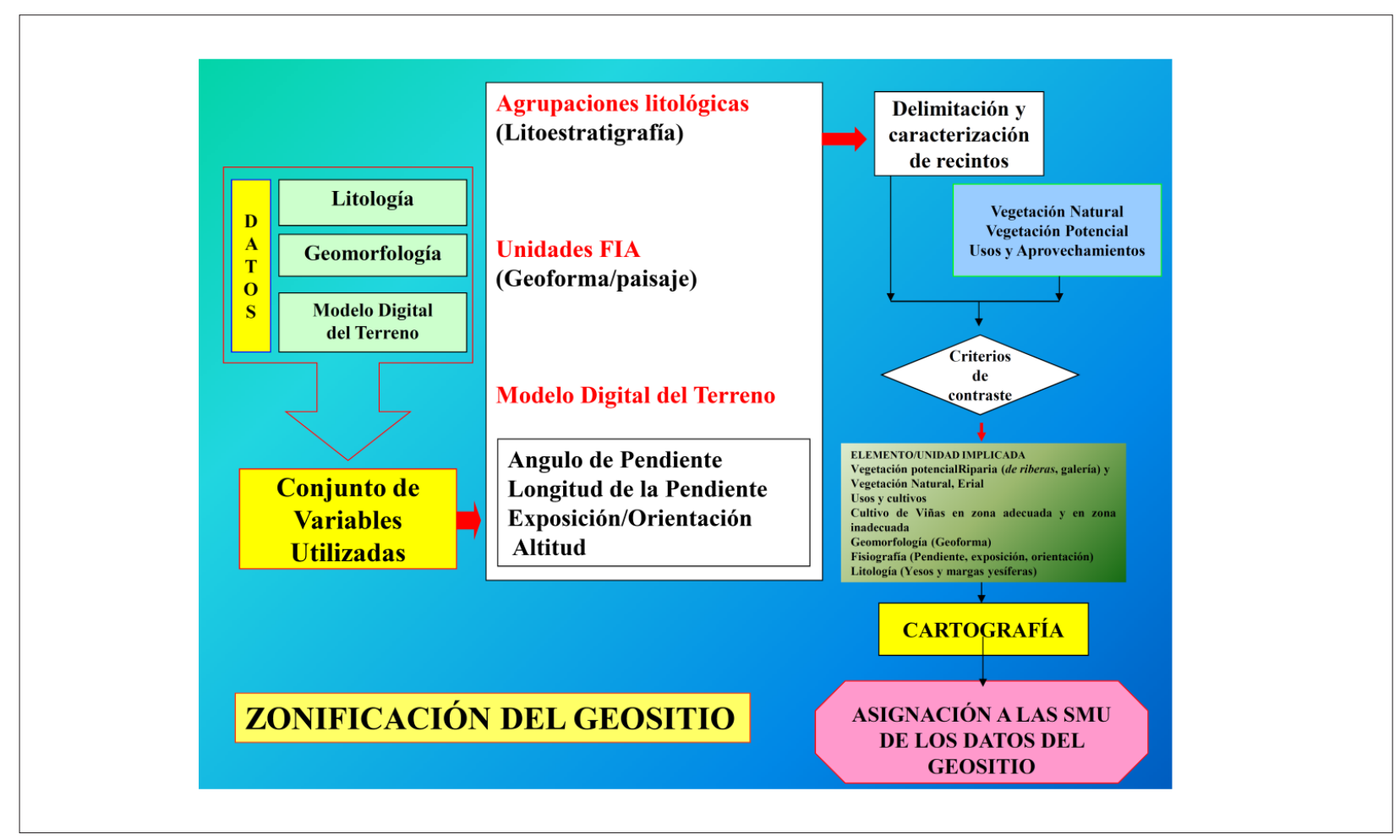

Figura 11. Esquema metodológico de la zonificación del Geositio: Geomorfología, Litología y Vegetación (Gómez-Miguel \& Sotes, 2003)

En la Figura 11 se incluye un esquema con la metodología para la zonificación del medio utilizada en la Universidad Politécnica de Madrid (UPM) según Gómez-Miguel y Sotés (1992-2017) y utilizada en este trabajo. Esta zonificación considera la geología (litología y estratigrafía) a través de la rocosidad y la naturaleza de la roca e integra el modelo digital del terreno (MDT), que aporta información sobre altitud, exposición y longitud e inclinación de la pendiente, y la distribución geográfica de las unidades de Fotointerpretación Aérea (FIA), que recoge datos relacionados con la litología, la geoforma, la pendiente, la erosión y otros.

\subsubsection{Zonificación del suelo}

De forma general, una zonificación edáfica consiste en la cartografía de la variabilidad del suelo, tanto vertical (perfil), como horizontal (geografía) dentro de un área determinada. Muchas aproximaciones a la zonificación vitícola toman prestado su enfoque de la cartografía edafológica con otras variantes, ver por ejemplo Vaudour (2010). 

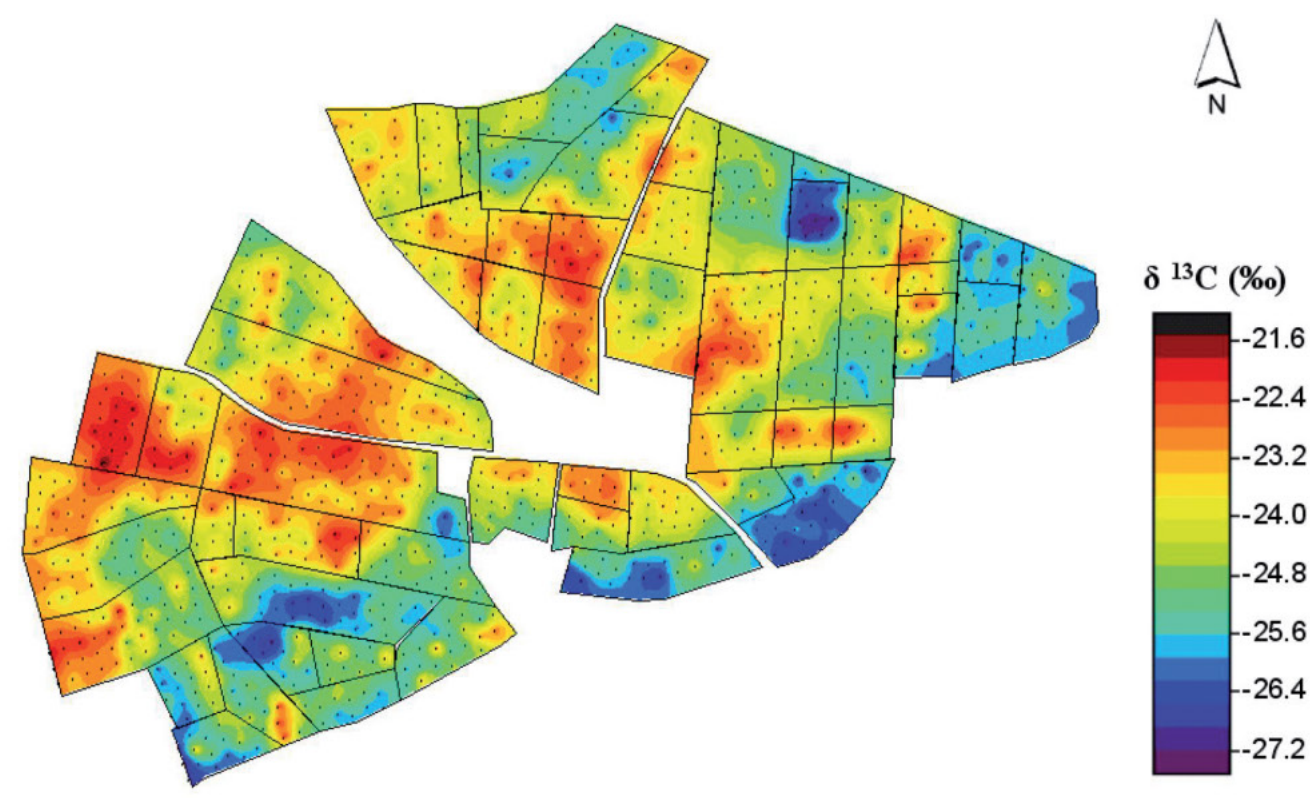

A

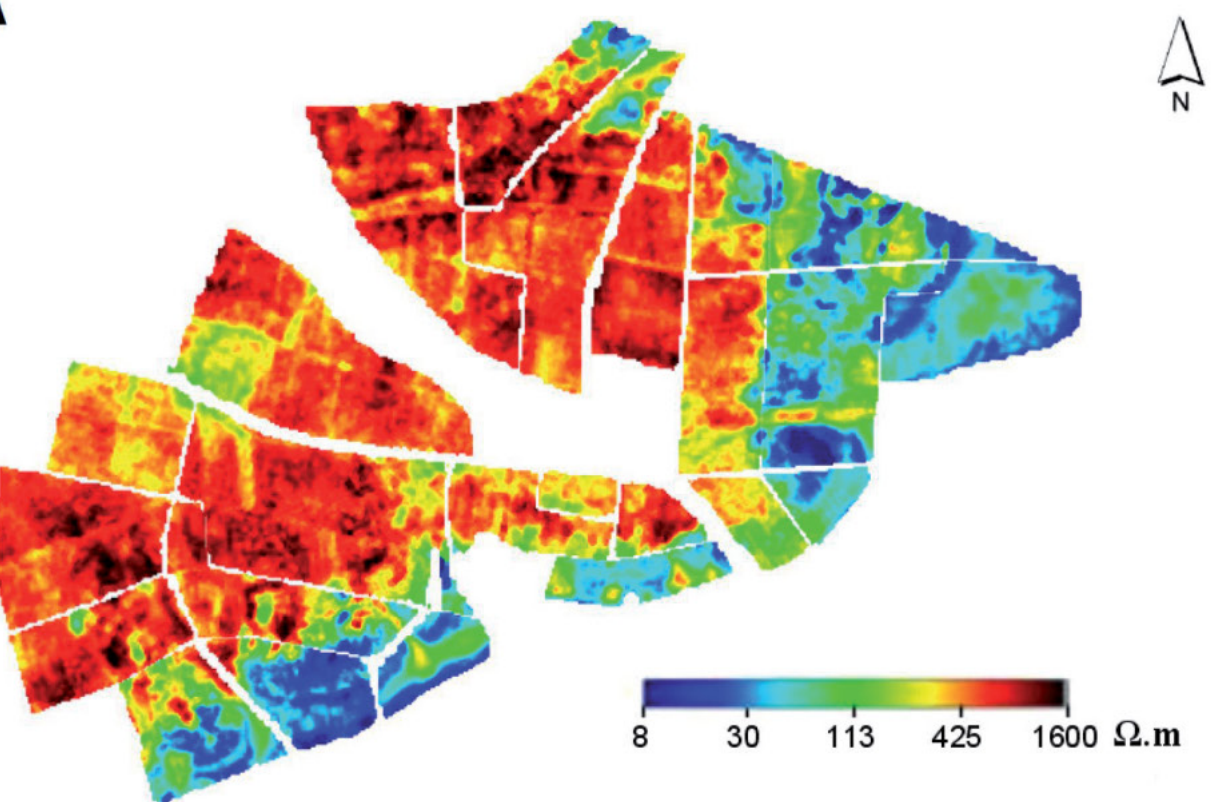

B

Figura 12. Representación de: (A) estado hídrico evaluado por la medida del C13 sobre el azúcar de la uva; (B) resistividad eléctrica del suelo (van Leeuwen et al., 2009). 
Morlat (1989) define la Unidad Base de Terroir (BTU) como un ambiente natural determinado por un componente geológico, un componente edafológico y un componente del paisaje. El principal problema que se presenta en la identificación de las BTU es la variabilidad del suelo, presentando Bodin y Morlat (2006) y Morlat y Bodin, (2006) una metodología de fácil manejo basada en la profundidad del suelo y en el contenido medio de arcilla, fundamentalmente relacionado con el grado de meteorización de la roca madre, clasificando los suelos como: roca débilmente degradada, roca moderadamente degradada y roca fuertemente degradada. En ambos estudios los autores concluyen que la zonificación propuesta permite discriminar zonas bien sea según la fenología, el régimen hídrico o el vigor; bien sea según la composición de las uvas. Esta metodología sólo utiliza el suelo de forma parcial y según van Leeuwen et al. (2012) esta metodología de zonificación no es válida en suelos aluviales, donde la profundidad del suelo es menos precisa, ya que puede haber grandes diferencias entre la profundidad edafológica y la profundidad efectiva.

En Rogue Valley, Oregon, Jones et al. (2006) proponen una zonificación de suelo a partir de cuatro de sus propiedades: drenaje, profundidad efectiva, capacidad de retención de agua y pH, considerando el drenaje como el factor más importante al verse influenciado por elementos como la textura, la profundidad, la pendiente y su orientación.

Distintos autores (Lamb et al., 2005; Andrenelli et al., 2013; Rossi et al., 2013), han reducido la zonificación edáfica a la variabilidad horizontal observada en la resistividad del suelo y van Leeuwen et al. (2009) encuentran relación entre el mapa de resistividad y el déficit hídrico estimado a partir del isótopo de Carbón (813C) medido sobre el azúcar de la uva durante la maduración (Figura 12).

La metodología del estudio de suelos empleada en este trabajo se concreta en la génesis de las unidades taxonómicas del suelo (STU) y de las unidades cartográficas del suelo (SMU) durante el proceso de reconocimiento de los mismos (USDA, 2017). El tratamiento de la información generada en las distintas capas de información por un Sistema de Información Geográfica (GIS) da como resultado la cuantificación de los contenidos y la posibilidad de su tratamiento estadístico. A partir de esta cartografía, es posible relacionar características del cultivo (distribución de variedades, por ejemplo) con las SMU.

La citada metodología fue puesta a punto por el equipo de zonificación del terroir de la UPM (Gómez-Miguel \& Sotés, 1990-2017) para la realización de mapas de gestión (orden 3 de USDA, 2017) a escalas 1:50.000 y 1:25000 (DO Ribera del Duero en 1992, DOCa Rioja en 1997, DO Rueda en 1998, DO Toro en 1999, DO Bierzo en 2001, DO Cigales en 2005, RD do Douro en 2007, DO Arribes en 2012 y DO Campo de Borja en 2017) y en mapas ejecutivos (orden 1 de USDA, 2017) de más de 400 parcelas, fincas y explotaciones a escalas comprendidas entre 1:2.500 y 1:10.000.

\subsubsection{Zonificación por teledetección}

Los mapas obtenidos por sensores remotos (teledetección) no deben confundirse con una zonificación cartografiada, porque aquellos son incapaces de discriminar sectores por las propiedades de los factores del medio (clima, litología, geomorfología, suelo) que afectan a la variabilidad geográfica del terroir (Gómez-Miguel et al., 2016) y por lo tanto, tampoco permiten explicar las causas de la variabilidad que muestran. Sin embargo, este tipo de mapas aportan información importante, son muy asequibles, facilitan la precisión de los límites y se obtienen en el momento programado y más rápidamente que 
los realizados a partir del método tradicional de zonificación detallado en los apartados anteriores (Gómez-Miguel et al., 2016).

Una de las formas de discriminar las diferencias existentes en el comportamiento entre plantas situadas dentro de un mismo viñedo o en viñedos distintos es a través de índices de vegetación (IV) calculados a partir de imágenes multiespectrales, siendo utilizados en Viticultura de Precisión (PV) desde la última década del siglo pasado y permitiendo identificar, a distintas escalas, diferentes subzonas en viñedos (Martínez \& Gómez-Miguel, 2017). Existen estudios que relacionan uno de los IV más empleados, el Índice de Vegetación de Diferencia Normalizada (NDVI), con la densidad foliar o el vigor (Hall et al., 2003; Johnson et al., 2003), con el estado hídrico de la planta (Acevedo-Opazo et al., 2008), con el índice de superficie foliar (LAl) (Johnson et al., 2003), o con el rendimiento y la composición de la uva (Hall et al., 2011), entre otros. También se han propuesto algoritmos que relacionan diferentes longitudes de onda con el contenido foliar de clorofila (Steele et al., 2008), de antocianina (Steele et al., 2009) o con la fotosíntesis neta (Zarco-Tejada et al., 2013).

Los mapas obtenidos a partir del NDVI pueden no relacionarse con las diferencias observadas en calidad, obteniendo los mejores resultados en secano (Acevedo-Opazo et al., 2008) y muestran limitaciones si no se complementa con otra información del medio. Otro inconveniente es que este tipo de sectorización sólo es posible llevarla a cabo con el viñedo ya instalado, siendo, en muchos casos, imposible modificar, por ejemplo, el portainjerto, la orientación o la densidad de plantación, si los resultados obtenidos así lo requirieran.

Lamb et al. (2004) encontraron que el NDVI es útil para predecir el rendimiento y el contenido fenólico de la uva, variando esta correlación en función del estado fenológico en el que se toma la imagen, produciéndose la máxima correlación alrededor del envero. Por su parte, Hall et al. (2011) también correlacionan el NDVI con la densidad de la vegetación y con el rendimiento, siendo esta correlación negativa al principio del ciclo y positiva al final.

Martínez y Gómez-Miguel (2018) concluyen que es posible utilizar los IV para diferenciar zonas homogéneas en el comportamiento de la vid siempre que en cada sector se mantengan uniformes los elementos del medio estudiados: la altitud, la geología y los suelos desarrollados sobre ésta, la pendiente y la orientación de la ladera.

Se han encontrado distribuciones espaciales semejantes de otros IV que se calculan a partir de operaciones con las mismas longitudes de onda que para el NDVI, rojo e infrarrojo cercano (Martínez et al., 2014).

\subsubsection{Zonificación Integrada del Terroir}

La Zonificación Integrada del Terroir (ZIT) es la generación de las Unidades Homogéneas del Medio (UHM) en relación con las características de un determinado viñedo, y se realiza mediante el tratamiento de la información obtenida en los apartados anteriores del presente capítulo. La cartografía de las clases del clima se obtiene del modelo reducido de zonificación climática; asimismo, los factores que permiten el tratamiento del modelo digital del terreno — la altitud, la exposición y la longitud y la inclinación de la pendiente - se extraen del modelo reducido de zonificación del medio natural o geosituación; las variables referentes a la litología y a la morfología del relieve se integran en el modelo a través del concepto de serie 
de suelos; y finalmente, en la evaluación de las series de suelo se utiliza un sistema paramétrico clásico en Edafología (Gómez-Miguel, 2011). Recientemente, Martínez y Gómez-Miguel (2019) proponen una ZIT que incorpora el control de este tipo de zonificación por teledetección, redefiniendo los límites cartográficos de las UHM con ayuda del NDVI. Su utilización se generaliza en este trabajo.

En general, y al igual que se ha indicado en el estudio de suelos, existen dos tipos de planteamiento: macrozonificación y microzonificación. A pequeña y media escala (inferior a 1:50.000), el medio vitícola se considera como un ecosistema definido por los elementos del medio, mientras que a mayor escala (superior a 1:25.000) es posible además relacionar estos elementos y factores con los de la caracterización del cultivo y del producto (Martínez \& Gómez-Miguel, 2019). Es necesario llevar a cabo la integración de ambos tipos de estudios, utilizando el citado en primer lugar como base de definición de unidades del medio, suficientemente homogéneas y bien caracterizadas (UHM), como para permitir el análisis pormenorizado de sus elementos definitorios y relacionarlos con los parámetros relacionados con el cultivo en estudios del segundo tipo (Gómez-Miguel, 2011).

\subsection{CONCLUSIÓN}

De todo lo anterior se pude concluir que en función de la escala de trabajo empleada en el estudio de una determinada zona, puede variar la importancia de los factores que influyen sobre el terroir.

Así, el clima es el factor de discriminación dominante en zonificaciones de grandes superficies a pequeña escala (por ejemplo un país), mientras que dentro de una región a media escala (por ejemplo una DO) la geología, la geomorfología y sus efectos mesoclimáticos son los factores principales que explican las diferencias en el desarrollo de la viña y en la composición de la uva. Por último, a escala muy grande (por ejemplo una parcela de experimentación) la variabilidad puede relacionarse con el tipo de suelo y su profundidad (van Leeuwen, 2010), por lo tanto, el suelo es el elemento de onda más corta de los que influyen en el terroir.

El efecto de la geomorfología sobre el terroir es indirecto, a través de la altitud, la pendiente y la orientación o exposición (Bramley, 2010; van Leeuwen, 2010). Esta última afecta al balance de radiación y por consiguiente a la temperatura (Bramley, 2010).

Desde una perspectiva general, las propiedades del suelo que afectan a la composición de la uva, directa o indirectamente, son las que se relacionan con la alimentación hídrica y mineral de la vid, con el desarrollo del sistema radicular, con el mesoclima del viñedo y el microclima de la planta y, en último término, con el manejo del mismo.

Los factores naturales que definen el terroir son también responsables de la variabilidad observada entre plantas de una misma parcela (variabilidad intraparcela) o de distintas fincas (variabilidad interparcela). Con el propósito de delimitar las distintas zonas con características comunes se realizan zonificaciones atendiendo a los distintos factores ambientales que afectan a la producción de uva. Es necesario realizar una zonificación climática, una zonificación de la geosituación y una zonificación edáfica para la caracterización de un viñedo o de una región vitícola dando como resultado la cartografía y caracterización de las Unidades Homogéneas del Medio (UHM) en línea con las Unidades Base del Terroir (BTU) de Morlat 
(1989). La zonificación integrada del terroir (ZIT) es, en sí misma, la validación de estas unidades mediante la caracterización de la planta y de la cosecha.

Desde finales del siglo pasado se viene empleando la Viticultura de Precisión (PV) con el objeto de realizar un manejo del viñedo lo más localizado posible. Esta herramienta se basa, fundamentalmente, en la discriminación de zonas (sectores) mediante la cartografía, caracterización y cuantificación de las variables que los diferencian.

La definición y la alta precisión de los límites entre sectores es costosa por medios convencionales, razón por la que se utilizan (Martínez \& Gómez-Miguel, 2019) imágenes multiespectrales obtenidas mediante la teledetección y los índices de vegetación relacionados para aumentar la precisión y la predictibilidad, así como para disminuir el coste general de la zonificación. Esta tecnología es complicada de aplicar en zonas extensas a escalas pequeñas.

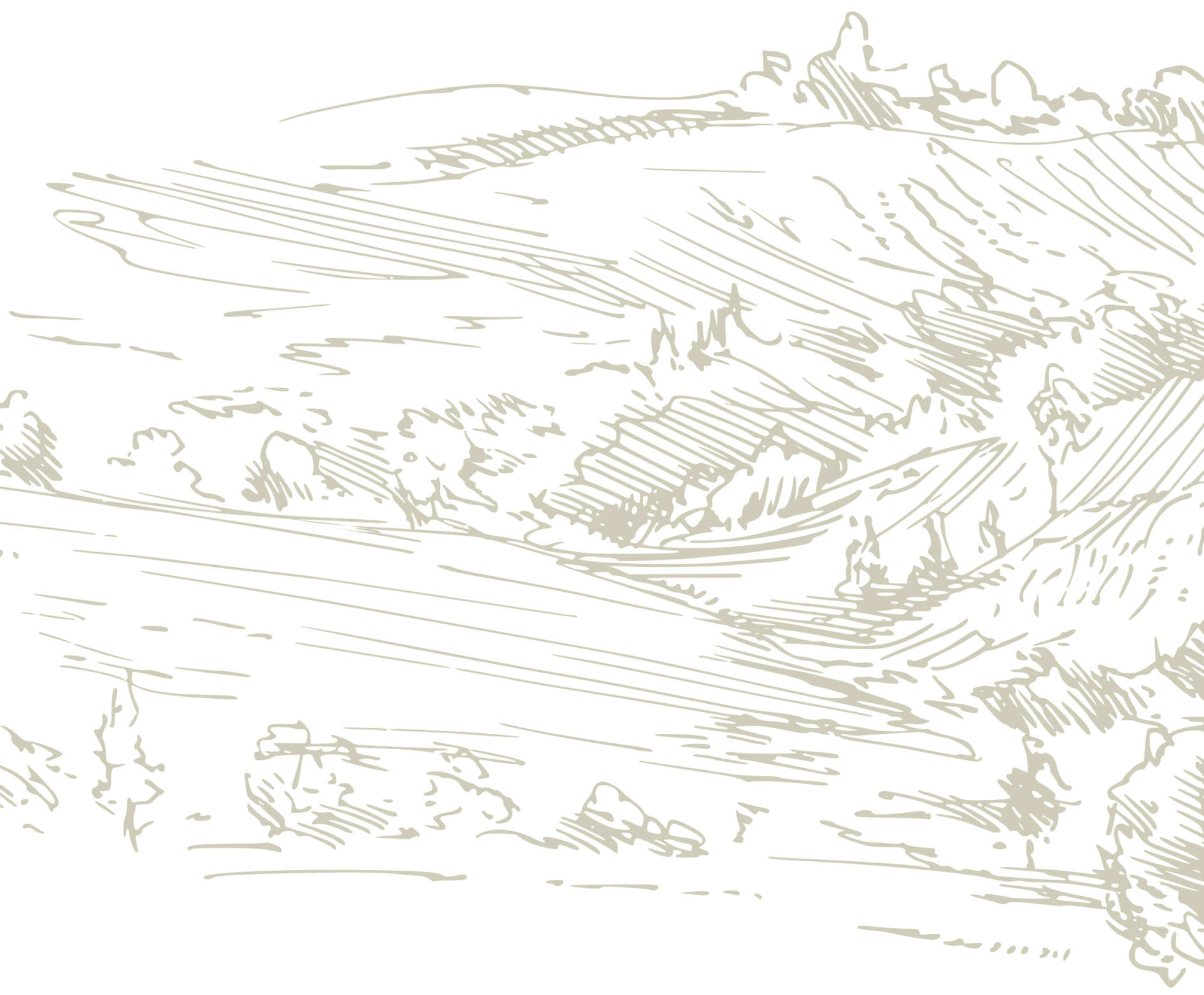



Los viñedos objeto de estudio se encuentran amparados por la DOCa Rioja, en la margen izquierda del río Ebro, en las proximidades de la población de Oyón (Figura 13), aproximadamente a tres kilómetros de Logroño. El río Ebro es el elemento vertebrador de esta Denominación de Origen, discurriendo en sentido Oeste-Este y hacia el cual se abren los espaciosos valles conformados por sus afluentes principales.

Dentro del marco de la DOCa Rioja, parte del límite oriental del municipio de Oyón sirve de divisoria entre las subzonas Rioja Alta y Rioja Oriental, situándose las parcelas experimentales (viñedos Naval, Ricio, Campillo y Majadahonda) en la Rioja Alta (Figura 13). Esta división no es abrupta y se ha de considerar como una transición entre las dos subzonas. Algunos detalles de las características y manejo de los viñedos pueden verse en el $\S 5.5$.

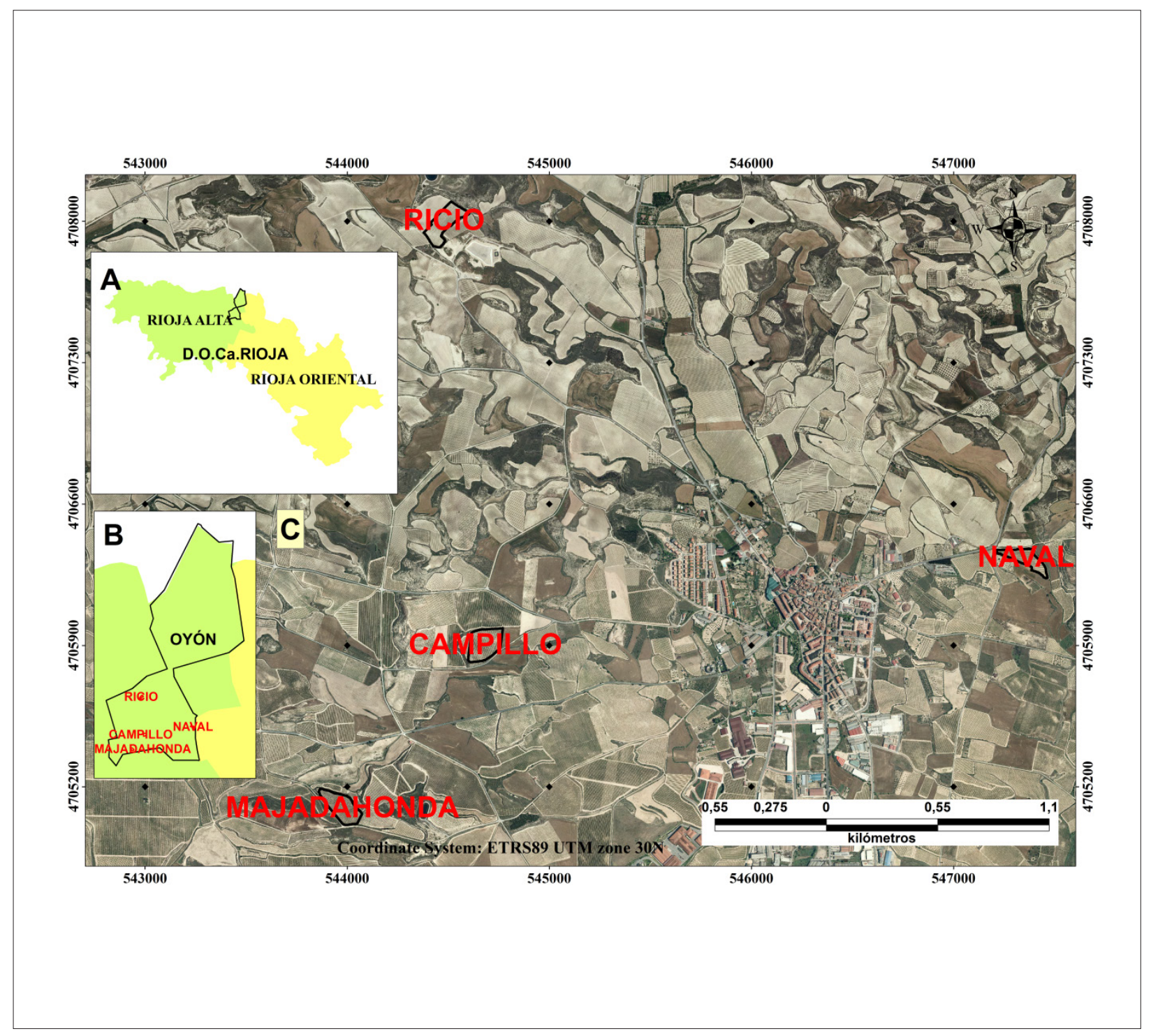

Figura 13. Situación de los viñedos (Ricio, Naval, Campillo y Majadahonda) objeto de estudio. A: en la DOCa Rioja; B: como transición entre Rioja Alta y Rioja Oriental; C: en relación con el centro urbano de Oyón.

En la descripción de la zona de estudio se utilizarán datos del estudio de zonificación de la DOCa Rioja (Gómez-Miguel \& Sotés, 1990-2017) que, como se ha dicho, también servirán para la generalización de los resultados de este trabajo. 


\subsection{CLIMA}

El clima de la DOCa Rioja es de tipo continental no muy acusado. Las masas de aire atlánticas penetran por la cuenca alta del Ebro donde su influencia es muy importante hasta una zona en las proximidades de Agoncillo, aproximadamente a 13 kilómetros hacia el Sudeste de la población de Oyón. A medida que estas masas de aire se desplazan hacia el Este su efecto se debilita y la influencia es principalmente mediterránea.

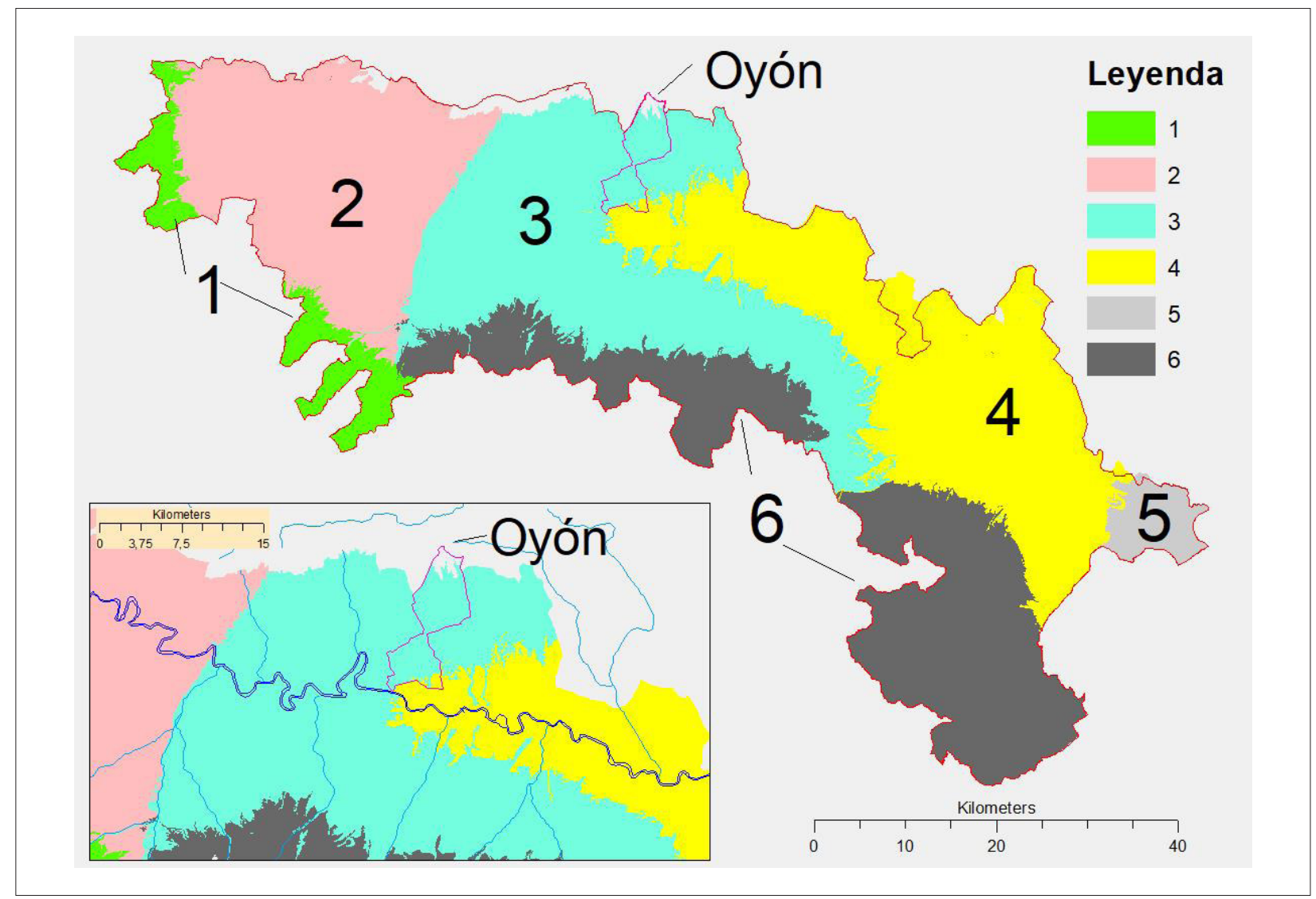

Figura 14. Zonas climáticas en la DOCa Rioja y detalle del término Municipal de Oyón ubicado principalmente en la zona 3. Elaboración propia a partir de Gómez-Miguel y Sotés (1990-2017).

En Rioja Alta, tanto la nubosidad como la pluviometría son bastante más elevadas que en Rioja Oriental donde la insolación es mayor y cuyas características climáticas son las típicas del Valle del Ebro.

Tanto la Cordillera Ibérica como los Pirineos constituyen una barrera frente a los temporales de poniente, siendo sus efectos principales una drástica disminución de la nubosidad y precipitación en el Valle del Ebro. 
El viento dominante es de poniente, si bien en primavera y otoño la mayor frecuencia corresponde a los vientos de componente Este y Noreste, consecuencia de la circulación producida por la presencia de bajas presiones que se adentran en la Península.

Una situación del tiempo que da lugar al viento típico del Noroeste (cierzo) suele asociarse a un anticiclón en el Golfo de Vizcaya y a una depresión en el Mediterráneo occidental. En verano, el viento del Noroeste es fresco provocando un notable descenso de las temperaturas, siendo su duración media de uno a tres días, mientras que en invierno suele ser mayor, de tres a siete días.

Los vientos de componente Sur (bochorno) en primavera e invierno son húmedos y templados y en verano muy secos. Una borrasca situada sobre el Golfo de Cádiz que se desplace hacia el Este puede dar lugar a vientos húmedos del Sureste que ocasionan temporales en las cuencas media y alta del Valle del Ebro.

Según la clasificación climática de Köppen-Geiger el clima de la DOCa Rioja es Csb (templado húmedo cálido, con verano seco y templado, temperatura media del mes más cálido inferior a $22^{\circ} \mathrm{C}$ ) y Strahler lo incluye dentro de los climas mediterráneos (Gómez-Miguel \& Sotés, 1990-2017; Fernández, 1999).

Desde el punto de vista agroclimático, Papadakis (1980) introduce los conceptos de clima mensual, térmico e hídrico para caracterizar el clima. La fórmula anual, según este autor, de la Estación Meteorológica de Viana será E7Vh8a, lo que representa un clima mediterráneo templado seco.

En los citados trabajos de Gómez-Miguel y Sotés (1990-2017) y Fernández (1999) la superficie de la Denominación de Origen es dividida en seis Zonas Climáticas (ZC), incluyéndose las parcelas del presente trabajo dentro de la ZC 3 (Tabla 3 y Figura 14).

En la Tabla 3 se incluyen los datos del centro de gravedad (CDG) de cada ZC y con mayor detalle los de la ZC3, además de los de la Estación Meteorológica de Viana, la más próxima a las parcelas. Como se aprecia en esta tabla sus valores están dentro del rango de variación de los de la ZC 3 y por este motivo son los registros de esta Estación los que se emplean para la caracterización climática de los viñedos objeto de estudio.

Respecto al índice de Winkler (Amerine \& Winkler, 1944), el área de estudio se encuentra en la zona III, la cual se caracteriza por producir vinos secos y dulces con cuerpo y vinos de postre menos corpulentos. Otras regiones vitícolas incluidas en esta zona son Montpellier o Milán (región de Lombardía).

Para esta misma Estación y utilizando el Sistema Multicriterio de Clasificación Climática (MCCS) (Tonietto, 1999; Tonietto \& Carbonneau, 2004) el clima se puede caracterizar como templado cálido, de noches frescas y moderadamente seco (Tabla 4). 
Tabla 3. Variables climáticas los centros de gravedad (CDG) de las seis Zonas Climáticas de la DOCa Rioja y detalle del centro de gravedad de la ZC 3 (Fernández, 1999) y de la Estación Meteorológica de Viana (Gobierno de Navarra, 2019)

\begin{tabular}{|c|c|c|c|c|c|c|c|c|}
\hline & & PRE & TM & ETPTH & ITE & $\mathrm{PH}$ & $\mathrm{IB}$ & $\mathbb{H}$ \\
\hline ZC1 & Med & 907,60 & 9,70 & 634,00 & 859,00 & 1,97 & 1,70 & 1302,80 \\
\hline ZC2 & Med & 514,03 & 11,80 & 684,53 & 1238,33 & 3,79 & 4,37 & 1764,57 \\
\hline$Z C 3$ & Med & 461,83 & 13,10 & 729,53 & 1576,33 & 4,82 & 5,50 & 2116,23 \\
\hline ZC4 & Med & 430,63 & 13,23 & 733,73 & 1606,67 & 4,88 & 7,13 & 2131,70 \\
\hline$Z C 5$ & Med & 397,13 & 13,93 & 765,60 & 1830,67 & 5,91 & 8,67 & 2364,07 \\
\hline \multirow[t]{2}{*}{ ZC6 } & Med & 486,50 & 12,40 & 700,80 & 1348,00 & 5,19 & 5,80 & 1823,70 \\
\hline & & PRE & TM & ETPTH & ITE & PH & $\mathbb{B}$ & $\mathbb{H}$ \\
\hline \multirow{4}{*}{ ZC 3} & Min & 447,70 & 12,90 & 724,20 & 1535,00 & 4,60 & 5,20 & 2067,70 \\
\hline & Med & 461,83 & 13,10 & 729,53 & 1576,33 & 4,82 & 5,50 & 2116,23 \\
\hline & Max & 483,00 & 13,40 & 739,90 & 1650,00 & 5,19 & 5,70 & 2186,50 \\
\hline & DS & 18,67 & 0,26 & 8,98 & 63,96 & 0,32 & 0,26 & 62,31 \\
\hline Viana & Med & 459,00 & 13,70 & 730,80 & 1733,00 & 5,19 & 5,00 & 2206,00 \\
\hline
\end{tabular}

Tabla 4. Aplicación de MCCS sobre datos de la serie histórica (1982-2015) de la Estación meteorológica de Viana. Elaboración propia a partir de datos de Gobierno de Navarra (2019)

\begin{tabular}{|c|c|}
\hline \multicolumn{2}{|c|}{ Estación Viana } \\
\hline Índice de Huglin (IH) & 2206 \\
\hline Clase IH & HI+1 (Templado Cálido) \\
\hline Índice de Frío Nocturno (Cl) & 13,3 \\
\hline Clase Cl & Cl+1 (Noches Frescas) \\
\hline Índice de Sequía (DI) & 46 \\
\hline Clase DI & DI+1 (Moderadamente Seco) \\
\hline
\end{tabular}

Atendiendo al MCCS, otras regiones vitícolas de características climáticas similares son Anadia, $30 \mathrm{~km}$ al sureste de Oporto y Montèlimar, en el valle del Ródano (Tonietto, 1999).

La temperatura media durante el período vegetativo (desde abril hasta octubre) es de $18,1^{\circ} \mathrm{C}$ (ver § 6.2), por lo tanto, como se vio en el capítulo anterior (Figura 7) la zona se clasifica como templada, pudiendo alcanzar la madurez la mayoría de las variedades tintas nobles: Tempranillo, Merlot, Malbec, Syrah, Garnacha y Nebbiolo entre otras (Jones, 2006). 


\subsection{GEOLOGÍA Y GEOMORFOLOGÍA}

La DOCa Rioja forma parte de la unidad morfológica de la Depresión del Ebro, la cual queda limitada al Norte por los Pirineos y los Montes Vasco-Cantábricos, al sur por la Cordillera Ibérica y al Este por la Cadena Costera Catalana. La Rioja puede ser considerada como una fosa tectónica colmatada de sedimentos terciarios y enmarcada al norte y al sur por las cadenas montañosas, Obarenes-Cantabria y Sistema Ibérico, respectivamente.

La arquitectura de la región es una consecuencia de la Orogenia Alpina cuyos efectos se han dejado sentir tanto en la Depresión como en sus bordes. Al Norte de la Denominación y en zonas relacionadas con la Cuenca Cantábrica pueden distinguirse varias unidades estructurales que tienen características paleogeográficas propias. La Sierra de la Demanda y la de Cameros conforman relieves de resistencia que han quedado sobresaliendo por encima de la Depresión, solo sus franjas de borde traducen formas de exhumación; este carácter tiene también buena parte de Obarenes-Cantabria.

Sobre el modelado del relieve, existen formas con características diferenciales que se relacionan con la litología (Figura 15):

- Modelado estructural asociado a zonas montañosas: Precámbricos, Paleozoicos, Triásicos, Jurásicos, complejo Wealdico/Purbeck, fs. Utrillas, Cretácico superior y conglomerados de Turruncum.

- Modelado residual terciario: Facies de Santurdejo, Facies de Cerezo-Altable, Facies de Haro-Transición, Facies de Alfaro-Nájera, Facies de Tudela-Lerín y conglomerados marginales calcáreos.

- Modelado cuaternario: incluye modelado fluvial (Ilanura de inundación, terrazas del Ebro y afluentes principales y fondos de valle menores), modelado de gravedad (coluviones, canchales y mangas de piedras), modelado torrencial (conos de deyección, abanicos aluviales y glacis) y otros modelados Holocenos (cubetas decalcificación, travertinos y tobas, depósitos lagunares y aluviones travertínicos).

El 85\% del viñedo existente en el municipio de Oyón, se encuentra sobre la formación Facies de Haro-Transición, bien con origen terciario (60\%), bien cuaternario (25\%). El resto de viñedos se encuentran sobre monte natural o modelado fluvial y torrencial cuaternario (Martínez \& Gómez-Miguel, 2017).

También dentro del municipio de Oyón (Martínez \& Gómez-Miguel, 2017), la mayor parte de los viñedos (82\%) se encuentran en pendientes comprendidas entre 0 y 10 , con orientación sur (42\%), este (26\%) y oeste (24\%), y entre 381 y 604 metros de altitud (88\%). 


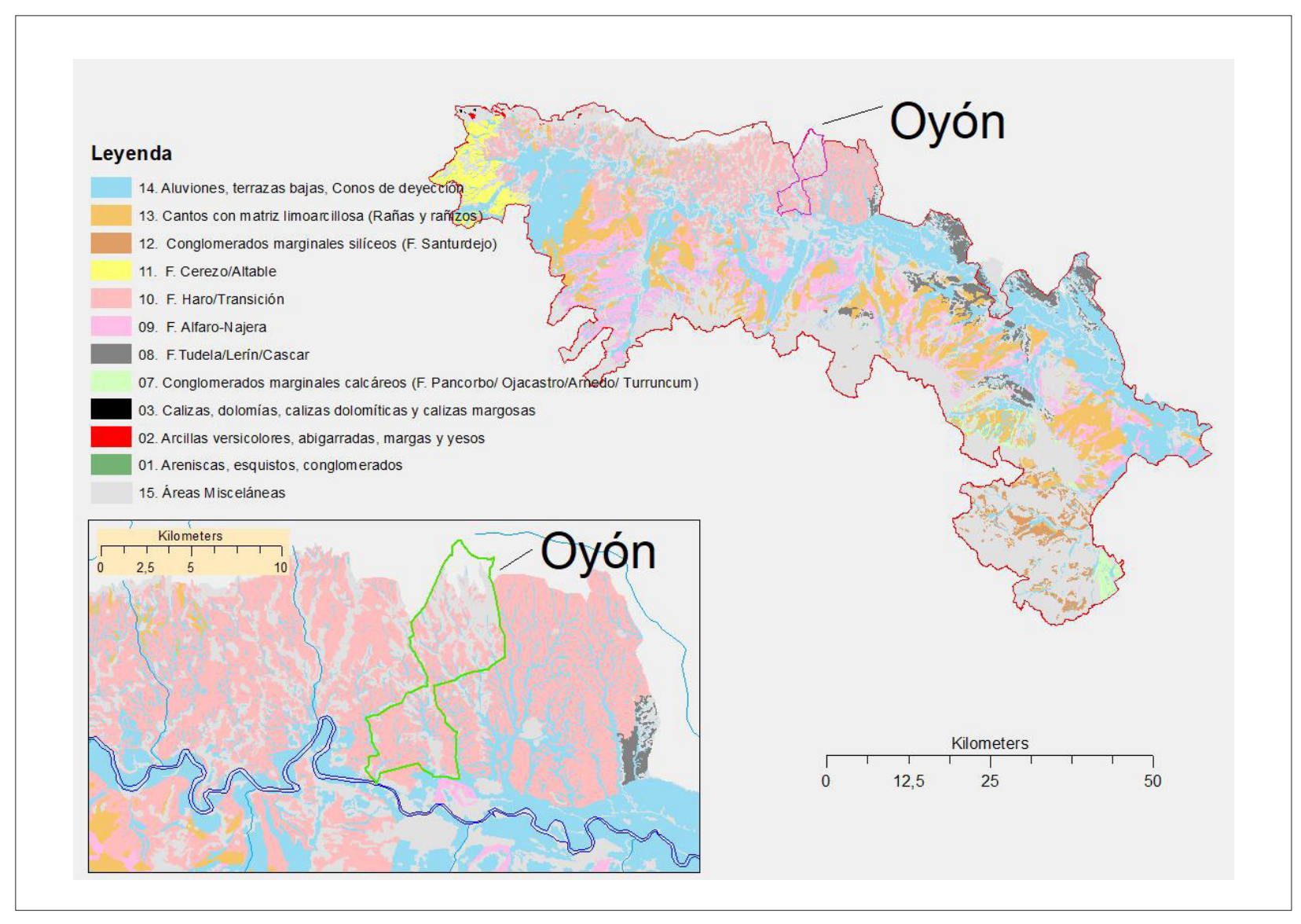

Figura 15. Zonas litológicas en la DOCa Rioja y detalle del término Municipal de Oyón ubicado principalmente en la zona 10: Formaciones Haro y Transición. Elaboración propia a partir de Gómez-Miguel y Sotés (1990-2017).

\subsection{SUELO}

En la DOCa Rioja existe una importante variedad de suelos, básicamente debido a la amplia heterogeneidad del medio. En el mapa de suelos 1:50.000 llevado a cabo por Gómez-Miguel y Sotés (1990-2017) y usado como base del presente estudio de zonificación se definen 24 series y 21 subgrupos (USDA, 1975) que definen las distintas unidades taxonómicas de suelo (STU). En el término Municipal de Oyón aparecen representadas 26 SMU de las 81 que componen el mapa de suelos de la DOCa Rioja (Figura 16) y en la Tabla 5 se incluye su contenido en términos de STU junto con su agrupación litológica, su clase (vocación vitícola) y el porcentaje (PC), el Índice de Calidad (ICA) y la clasificación (subgrupo, USDA, 1975) de las STU principal y secundaria del término Municipal de Oyón.

Como se aprecia en la Tabla 5, en Oyón, sobre la formación Facies de Haro-Transición se describen cuatro unidades politáxicas cuya serie principal es Xerochrept calcixerollico franca fina, mixta, mésica, 


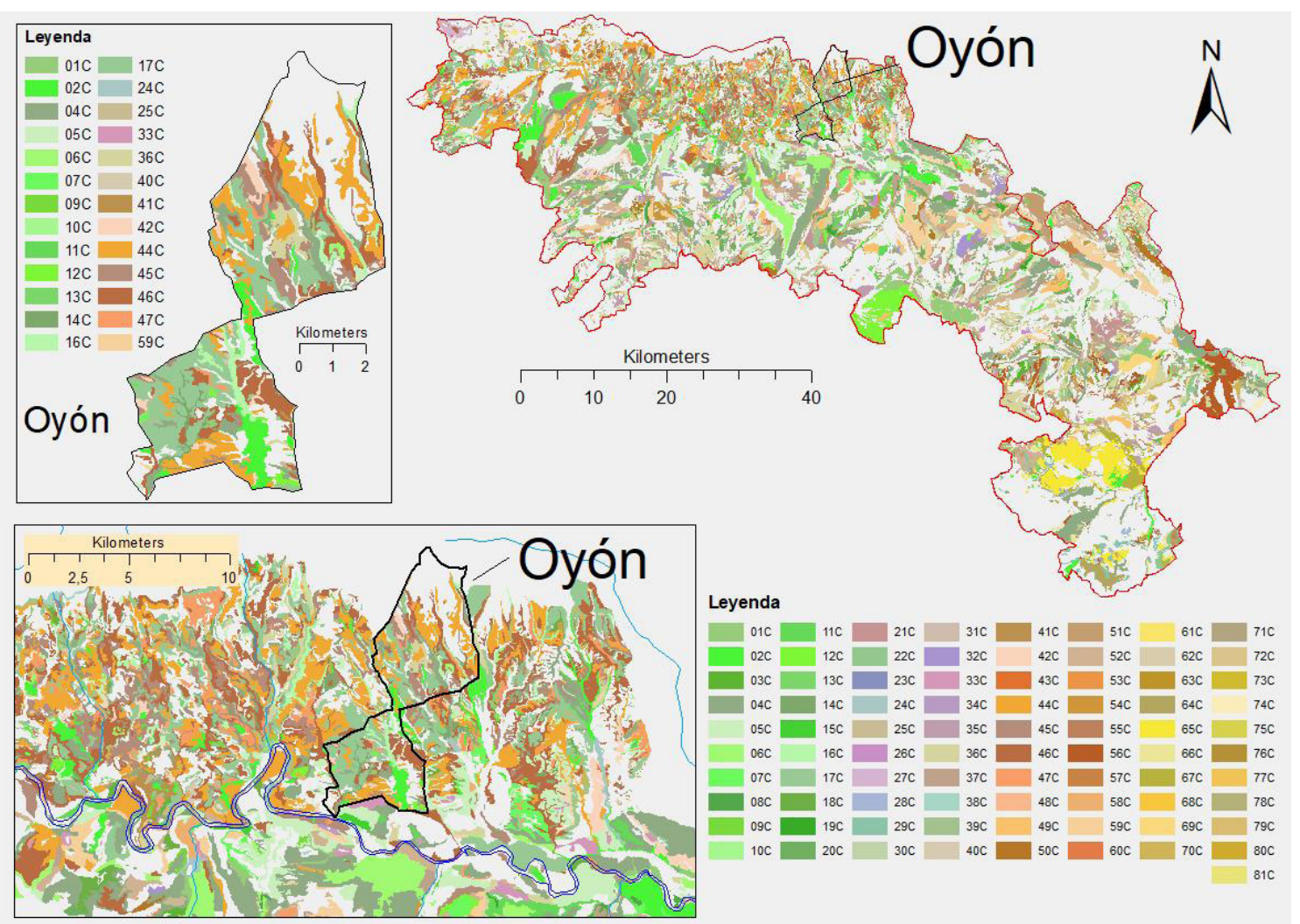

Figura 16. Mapa de suelos de la DOCa Rioja y detalle del término Municipal de Oyón. Elaboración propia a partir de Gómez-Miguel y Sotés (1990-2017).

con distintas series secundarias y/o inclusiones como por ejemplo: Haploxeralf cálcico, mésico; Xerochrept calcixerollico limosa fina, mixta, mésica y Xerorthent Lítico franca fina, mixta mésica. Estas series secundarias, así como las inclusiones que componen cada SMU permiten clasificar la vocación vitícola de cada unidad cartográfica, encontrando en Oyón y asociadas a la Facies de Haro-Transición tres unidades, que ocupan una superficie de 815,2 has clasificadas como Óptima y una (cubriendo 646,1 ha) como No Favorable.

Sobre la litología cuaternaria de la Facies de Haro (Fluvial en FHT) se describen dos SMU cuya serie principal de suelos es Xerochrept calcixerollico franca esquelética, mixta, mésica. La primera de estas SMU (16C) se clasifica como No Favorable mientras que la segunda (17C) es Adecuada. Entre ambas SMU se cubre un área de 974,5 ha. 
Tabla 5. Descripción de las SMU en términos de STU incluyendo su litología, su clase (vocación vitícola) y el porcentaje (PC), el Índice de Calidad (ICA) y la clasificación (subgrupo, USDA, 1975) de las STU principal y secundaria en el término Municipal de Oyón. Elaboración propia a partir de Gómez-Miguel y Sotés (1990-2017)

\begin{tabular}{|c|c|c|c|c|c|c|c|c|c|}
\hline \multirow{3}{*}{$\begin{array}{l}\text { SMU } \\
01 C\end{array}$} & \multirow{3}{*}{\begin{tabular}{|l} 
AREA \\
12,6
\end{tabular}} & \multirow{3}{*}{$\begin{array}{l}\text { LITOLOGÍA } \\
\text { Lanura inundación }\end{array}$} & \multirow{3}{*}{$\begin{array}{l}\text { NP } \\
17\end{array}$} & \multirow{3}{*}{\begin{tabular}{|l} 
CLASE \\
NO FAVORAB
\end{tabular}} & \multicolumn{5}{|c|}{ STU1 } \\
\hline & & & & & \multirow{2}{*}{\begin{tabular}{r|} 
SÍMBOLO \\
XnTF
\end{tabular}} & \multirow{2}{*}{\begin{tabular}{l|}
$P C$ \\
0,6
\end{tabular}} & \multirow{2}{*}{\begin{tabular}{r|}
$\mathrm{IC}$ \\
3,51
\end{tabular}} & \multicolumn{2}{|l|}{ USDA, 1975} \\
\hline & & & & & & & & XERORTHENT & TIPICO \\
\hline $02 C$ & 220,6 & Lanura inundación & 25,2 & NO FAVORAB & XpTF & 0,35 & 15,81 & XEROCHREPT & TIPICO \\
\hline O4C & 231,4 & Terrazas del Ebro & 54,3 & OPTIMA & R01 & 0,35 & 14,13 & XEROCHREPT & CALCIXEROLLICO \\
\hline $05 C$ & 23,1 & Terrazas del Ebro & 99,2 & OPTIMA & R01 & 0,4 & 14,13 & XEROCHREPT & CALCIXEROLLICO \\
\hline 06C & 12,3 & Terrazas del Ebro & 76,8 & OPTIMA & R01 & 0,4 & 14,13 & XEROCHREPT & CALCIXEROLLICO \\
\hline $07 C$ & 7,6 & Terrazas del Ebro & 81,9 & OPTIMA & R02 & 0,35 & 12,6 & XEROCHREPT & CALCIXEROLLICO \\
\hline 09 & 1,4 & Modelado torrencial & 52 & OPTIMA & R01 & 0,5 & 14,13 & XEROCHREPT & CALCIXEROLLICO \\
\hline $10 C$ & 0 & Modelado torrencial & 55 & OPTIMA & R09 & 0,35 & 25,35 & HAPLOXERALF & CALCICO \\
\hline $11 C$ & 0 & Modelado torrencial & 49,3 & OPTIMA & R01 & 0,3 & 14,13 & XEROCHREPT & CALCIXEROLLICO \\
\hline $12 C$ & 23,2 & Modelado torrencial & 66 & OPTIMA & RO3 & 0,35 & 15,7 & XEROCHREPT & CALCIXEROLLICO \\
\hline $13 C$ & 9,1 & Fuvial en FCA & 22,3 & NO FAVORAB & XpCFV & 0,4 & 6,52 & XEROCHREPT & CALCIXEROLLICO \\
\hline $14 C$ & 52,6 & Fuvial en FCA & 22,3 & NO FAVORAB & XpCFV & 0,35 & 6,52 & XEROCHREPT & CALCIXEROLLICO \\
\hline $16 C$ & 157,9 & Fluvial en FHT & 33,1 & NO FAVORAB & XpCFW & 0,4 & 15,92 & XEROCHREPT & CALCIXEROLLICO \\
\hline $17 C$ & 816,6 & Fluvial en FHT & 39,3 & ADECUADA & XpCFW & 0,4 & 15,92 & XEROCHREPT & CALCIXEROLLICO \\
\hline $24 C$ & 0,1 & Fluvial en FTL & 9,95 & NO APTA & XpCFY & 0,3 & 5 & XEROCHREPT & CALCIXEROLLICO \\
\hline $25 C$ & 13,8 & Fluvial en FTL & 9,95 & NO APTA & $X p C F Y$ & 0,3 & 5 & XEROCHREPT & CALCIXEROLLICO \\
\hline $33 C$ & 0 & F. Cerezo-Altable (FCA) & 50,2 & OPTIMA & R14 & 0,25 & 15,7 & PALEXERALF & PETROCALCICO \\
\hline $36 C$ & 97,8 & F. Cerezo-Altable (FCA) & 82,1 & OPTIMA & R03 & 0,4 & 15,7 & XEROCHREPT & CALCIXEROLLICO \\
\hline $40 C$ & 6,7 & F. Cerezo-Altable (FCA) & 9,56 & NO APTA & R21 & 0,4 & 6,52 & XEROCHREPT & CALCIXEROLLICO \\
\hline $41 C$ & 3,6 & F. Cerezo-Altable (FCA) & 8,39 & NO APTA & XnLV & 0,45 & 1,45 & XERORTHENT & LITICO \\
\hline $42 C$ & 95 & F. Cerezo-Altable (FCA) & 29,2 & NO FAVORAB & R23 & 0,35 & 8,76 & XEROCHREPT & CALCIXEROLLICO \\
\hline $44 C$ & 646,1 & $\begin{array}{l}\text { F. Haro-Transición } \\
\text { (FHT) }\end{array}$ & 25,7 & NO FAVORAB & R15 & 0,6 & 15,92 & XEROCHREPT & CALCIXEROLLICO \\
\hline $45 C$ & 261,3 & $\begin{array}{l}\text { F. Haro-Transición } \\
\text { (FHT) }\end{array}$ & 66,5 & OPTIMA & R15 & 0,6 & 15,92 & XEROCHREPT & CALCIXEROLLICO \\
\hline $46 C$ & 493,3 & $\begin{array}{l}\text { F. Haro-Transición } \\
\text { (FHT) }\end{array}$ & 62 & OPTIMA & R15 & 0,5 & 15,91 & XEROCHREPT & CALCIXEROLLICO \\
\hline $47 C$ & 60,6 & $\begin{array}{l}\text { F. Haro-Transición } \\
\text { (FHT) }\end{array}$ & 100 & OPTIMA & R15 & 0,5 & 15,92 & XEROCHREPT & CALCIXEROLLICO \\
\hline $59 C$ & 5,9 & F. Tudela Lerín (FTL) & 19,1 & NO FAVORAB & R24 & 0,45 & 9,55 & XEROCHREPT & CALCIXEROLLICO \\
\hline
\end{tabular}




\begin{tabular}{|c|c|c|c|c|c|c|c|c|}
\hline \multicolumn{5}{|c|}{ STU2 } & & & \multicolumn{2}{|c|}{ INCLUSIONES (SÍMBOLO) } \\
\hline SÍMBOLO & $P C$ & IC & & USDA, 1975 & SERIE3 & SERIE4 & SERIE5 & SERIE6 \\
\hline XpTF & 0,3 & 15,81 & XEROCHREPT & TIPICO & CF & CQ & & \\
\hline HaTF & 0,4 & 16,68 & HAPLOXERALF & TIPICO & $X_{n} T F$ & CQ & & \\
\hline R09 & 0,2 & 25,35 & HAPLOXERALF & CALICO & XpFF & XfTF & XnTF & CF \\
\hline R09 & 0,3 & 25,35 & HAPLOXERALF & CALICO & R11 & $\mathrm{Xn}_{\mathrm{nF}}$ & RO2 & $\mathrm{CF}$ \\
\hline R13 & 0,3 & 15,02 & PALEXERALF & PETROCALCICO & R11 & R07 & & \\
\hline R01 & 0,3 & 14,13 & XEROCHREPT & CALCIXEROLLICO & R11 & R11 & R05 & PaKF \\
\hline XnTF & 0,4 & 3,51 & XERORTHENT & TIPICO & HaTF & & & \\
\hline R01 & 0,3 & 14,13 & XEROCHREPT & CALCIXEROLLICO & R04 & R10 & CF & $\mathrm{CO}$ \\
\hline R03 & 0,3 & 15,7 & XEROCHREPT & CALCIXEROLLICO & R09 & R10 & XnLFT & $C F$ \\
\hline XnLFT & 0,3 & 1,45 & XERORTHENT & LITICO & R02 & R04 & R10 & R09 \\
\hline$C F$ & 0,2 & 24,5 & XEROFLUVENT & TIPICO & CQ & R01 & R09 & \\
\hline R01 & 0,2 & 14,13 & XEROCHREPT & CALCIXEROLLICO & $C F$ & R09 & CQ & XnLFV \\
\hline R15 & 0,3 & 15,92 & XEROCHREPT & CALCIXEROLLICO & XnLFW & CF & XnTFW & $\mathrm{CQ}$ \\
\hline R15 & 0,3 & 15,92 & XEROCHREPT & CALCIXEROLLICO & XpTFW & XpGFW & CF & CQ \\
\hline XpTFY & 0,3 & 15,81 & XEROCHREPT & TIPICO & CQ & XpGFY & XnTFY & XnLFY \\
\hline XpTFY & 0,3 & 15,81 & XEROCHREPT & TIPICO & CQ & XpGFY & & XnLFY \\
\hline R06 & 0,3 & 6 & XEROCHREPT & PETROCALCICO & R08 & XnTT & R10 & R04 \\
\hline R10 & 0,2 & 22,52 & HAPLOXERALF & CALCICO & R08 & R04 & R12 & $\operatorname{RaCT}$ \\
\hline XnTV & 0,3 & 1,95 & XERORTHENT & TIPICO & XnLV & & & $\mathrm{XpCV}$ \\
\hline R21 & 0,3 & 6,52 & XEROCHREPT & CALCIXEROLLICO & XnTV & R22 & & COT \\
\hline R22 & 0,3 & 6,52 & XEROCHREPT & CALCIXEROLLICO & XnTV & XnLV & CF & XpCV \\
\hline R17 & 0,2 & 2,37 & XERORTHENT & LITICO & R16 & & CQ & $C F$ \\
\hline R16 & 0,2 & 4,63 & XERORTHENT & TIPICO & R17 & XpCT & HaCT & \\
\hline R16 & 0,2 & 4,63 & XERORTHENT & TIPICO & R17 & $\mathrm{HaCW}$ & & $C F$ \\
\hline XpCW & 0,2 & 15,92 & XEROCHREPT & CALCIXEROLLICO & R16 & CQ & & CF \\
\hline$X_{n} T Y$ & 0,3 & 1,95 & XERORTHENT & TIPICO & XpTY & XpGY & & \\
\hline
\end{tabular}




\subsection{VEGETACIÓN Y CULTIVO}

Dentro del espacio que ocupa la Denominación, la agricultura es la actividad predominante y ocupa prácticamente todo el espacio del Valle, con excepción de algunos enclaves poco propicios para los cultivos (cerros erosionados, laderas con fuertes pendientes, zonas rocosas, enclaves salinos, etc.). En la Sierra, tan solo las laderas de menor pendiente o las zonas con materiales de menor resistencia son susceptibles de aprovechamiento agrícola.

En las siguientes tablas (Tabla 6, Tabla 7 y Tabla 8) se presentan datos procedentes del año 2015 de la distribución del cultivo de vid dentro de la DOCa Rioja.

Tabla 6. Distribución del viñedo en producción por subzonas y color de la variedad (CRDOCa Rioja, 2016).

\begin{tabular}{|c|c|c|c|c|c|}
\hline & \multicolumn{2}{|c|}{ RIOJA ALTA } & \multicolumn{2}{|c|}{ RIOJABAJA } & \multirow{2}{*}{ TOTAL } \\
\hline & Superficie (ha) & \% S/TOTAL & Superficie (ha) & \% S/TOTAL & \\
\hline Variedades tintas & $36.016,89$ & 58,21 & $21.849,39$ & 35,31 & $57.866,28$ \\
\hline Variedades blancas & $3.178,29$ & 5,14 & 825,79 & 1,33 & $4.004,08$ \\
\hline TOTAL & & $39.195,18$ & & $22.675,18$ & $61.870,36$ \\
\hline
\end{tabular}

En el año 2015 (CRDOCa Rioja, 2016), existían 118.926 parcelas de viñedo en el ámbito de la Denominación, cubriendo una superficie de 64.561,59 ha. De éste área, el 80\% (51.558,79 ha) se distribuye en 102.890 (87\%) parcelas con un tamaño comprendido entre 0,10 y 2 ha, evidenciando el alto nivel de atomización existente en el cultivo de la vid dentro de la DOCa Rioja. En la Figura 17 se incluye el parcelario de viñedo de 2017, apreciándose una mayor densidad de viñedos en la subzona Rioja Alta frente a Rioja Oriental. 
Tabla 7. Superficie (ha) ocupada por variedades blancas en la DOCa Rioja (CRDOCa Rioja, 2016)

\begin{tabular}{|l|r|r|r|}
\hline & TOTAL & \% S/ BLANCAS & \% S/TOTAL \\
\hline Viura & $4.018,12$ & 76,28 & 6,22 \\
\hline Verdejo & 272,80 & 5,18 & 0,42 \\
\hline Tempranillo Blanco & 442,32 & 8,40 & 0,69 \\
\hline Malvaś́a & 101,94 & 1,94 & 0,16 \\
\hline Chardonnay & 113,03 & 2,15 & 0,18 \\
\hline Sauvignon Blanc & 145,29 & 2,76 & 0,23 \\
\hline Garnacha Blanca & 101,43 & 1,93 & 0,16 \\
\hline Maturana Blanca & 21,58 & 0,41 & 0,03 \\
\hline Turruntés & 2,84 & 0,05 & 0 \\
\hline Otras & 48,25 & 0,92 & 8,16 \\
\hline TOTAL & $5.267,58$ & 100 & 0,07 \\
\hline
\end{tabular}

Tabla 8. Superficie (ha) ocupada por variedades tintas en la DOCa Rioja (CRDOCa Rioja, 2016)

\begin{tabular}{|l|r|r|r|}
\hline & TOTAL & \% S/TINTAS & \% S/TOTAL \\
\hline Tempranillo & $51.806,04$ & 87,37 & 80,24 \\
\hline Garnacha & $4.745,59$ & 8,00 & 7,35 \\
\hline Mazuel0 & $1.313,20$ & 2,21 & 2,03 \\
\hline Graciano & $1.153,72$ & 1,95 & 1,79 \\
\hline MaturanaTinta & 114,92 & 0,19 & 0,18 \\
\hline Otras & 160,54 & 0,33 & 0,25 \\
\hline TOTAL & $59,294,01$ & 100 & 91,84 \\
\hline
\end{tabular}

En el municipio de Oyón, en el año 2015 existían 990,45 ha de viñedo en producción, de las cuales 940,81 ha corresponden a variedades tintas (principalmente de la variedad Tempranillo), es decir, en este municipio el $94,99 \%$ del viñedo es de cultivares tintos.

El cultivar Tempranillo, también conocido en otras zonas de España por las sinonimias: Tinta del País, Tinto de Toro, Cencibel o UII de Llebre, es una variedad de ciclo corto, porte erguido, fértil, sensible a la sequía extrema y de maduración temprana (MAGRAMA, 2015). Para su correcta maduración es necesaria una 
Integral Térmica Eficaz mínima de $1.600^{\circ} \mathrm{C}$ y asimila muy fácilmente el potasio (potasófila), pudiendo salificar ácidos y viéndose disminuida la acidez del futuro mosto. Respecto a Chasselas, posee un desborre de 7 a 10 días posterior y madura dos semanas después.

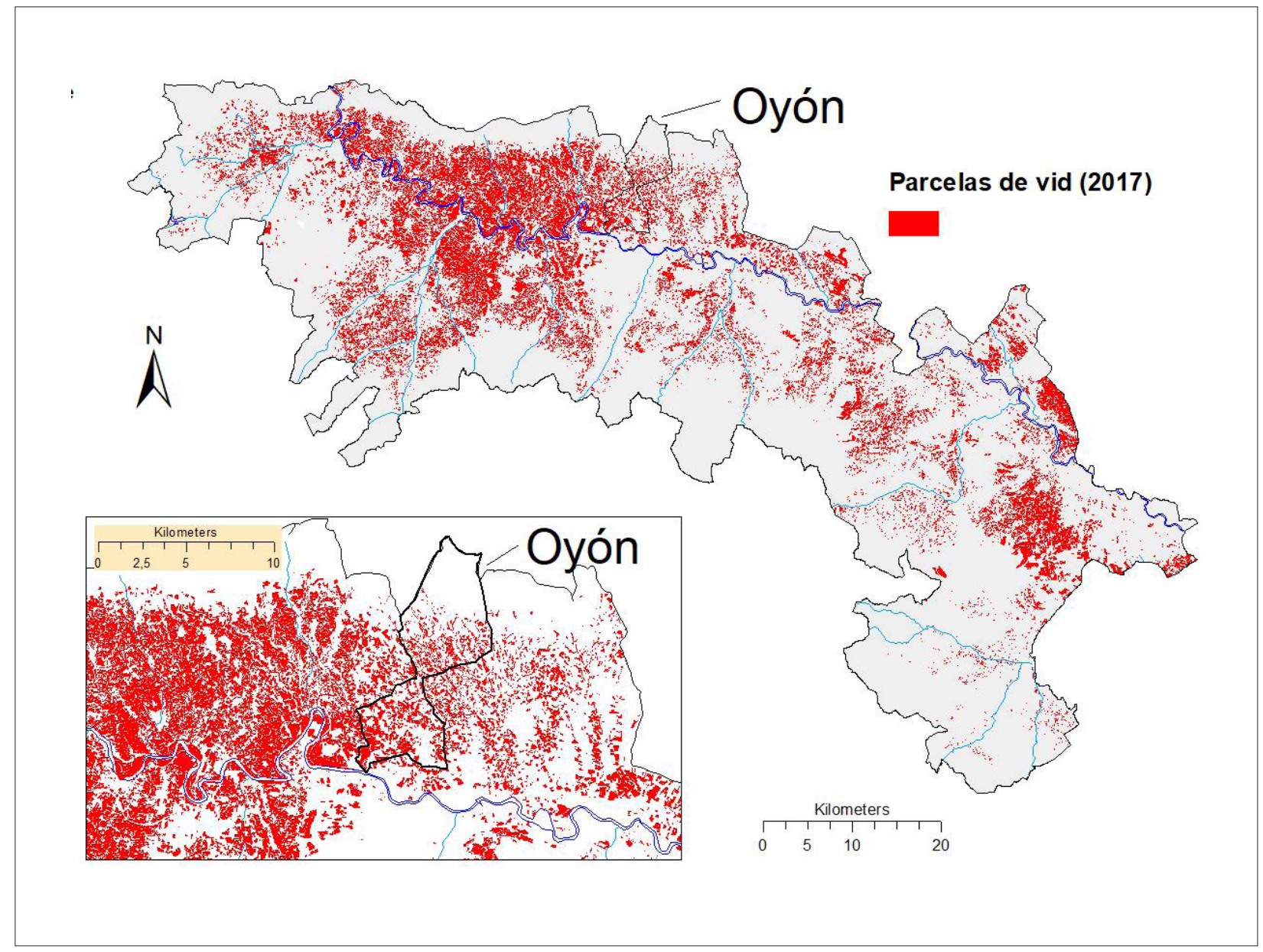

Figura 17. Distribución parcelaria del viñedo (2017) en la DOCa Rioja y detalle del término Municipal de Oyón. Elaboración propia a partir de datos del Registro Vitícola de 2017 


\subsection{RESUMEN DE LA ZONA DE ESTUDIO}

El estudio se lleva a cabo sobre cuatro parcelas situadas en el municipio de Oyón, zona que se podría considerar de transición entre las subzonas Rioja Oriental y Rioja Alta.

Atendiendo a los distintos índices bioclimáticos vitícolas, algunas características de la zona son:

- Producción de vinos secos y dulces con cuerpo y vinos de postre menos corpulentos,

- Pueden alcanzar la madurez las variedades Tempranillo, Merlot, Malbec, Syrah, Garnacha, Nebbiolo, entre otras,

- Otras regiones vitícolas similares son Montpellier, Milán, Anadia (zona de Oporto) o Montèlimar (zona del Ródano).

La mayor parte de los viñedos de la zona se sitúan sobre la formación Facies de Haro-Transición, bien con recubrimiento cuaternario, bien con origen terciario. Atendiendo a su orden edafológico, sobre la formación terciaria de la Facies de Haro se describen cuatro unidades politáxicas cuya serie principal (USDA, 1975) es Xerochrept calcixerollico franca fina, mixta, mésica, con distintas series secundarias y/o inclusiones como por ejemplo: Haploxeralf cálcico, mésico; Xerochrept calcixerollico limosa fina, mixta, mésica y Xerorthent lítico franca fina, mixta mésica. Tres de estas SMU se han clasificado, según el índice de calidad (ICA) propuesto por Gómez-Miguel y Sotés (1990-2017), como Óptimas y la otra como No Favorable.

Sobre la cobertura cuaternaria de la Facies de Haro se describen dos unidades cartográficas cuya serie de suelos principal es Xerochrept calcixerollico franca esquelética, mixta, mésica. De estas SMU, una se clasifica (también según el ICA) como Adecuada y la otra como No Favorable.

Una de las características de la DOCa Rioja es la gran atomización de las parcelas de viñedo, situándose la mayor parte de ellas entre 0,1 y 2 ha., siendo la Tempranillo la variedad de uva más cultivada. 


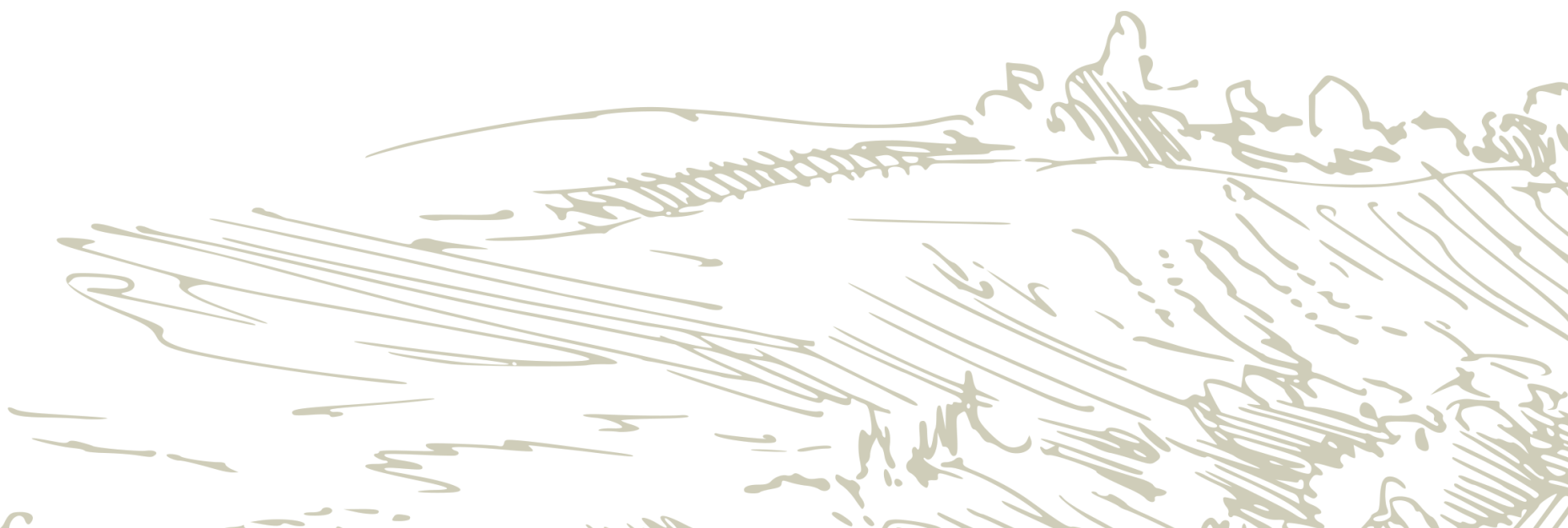

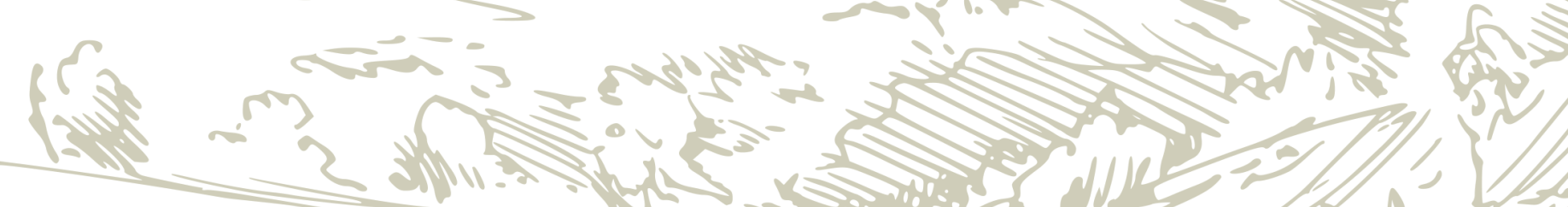




\section{CAPÍTULO 5 \\ Material \\ y métodos}

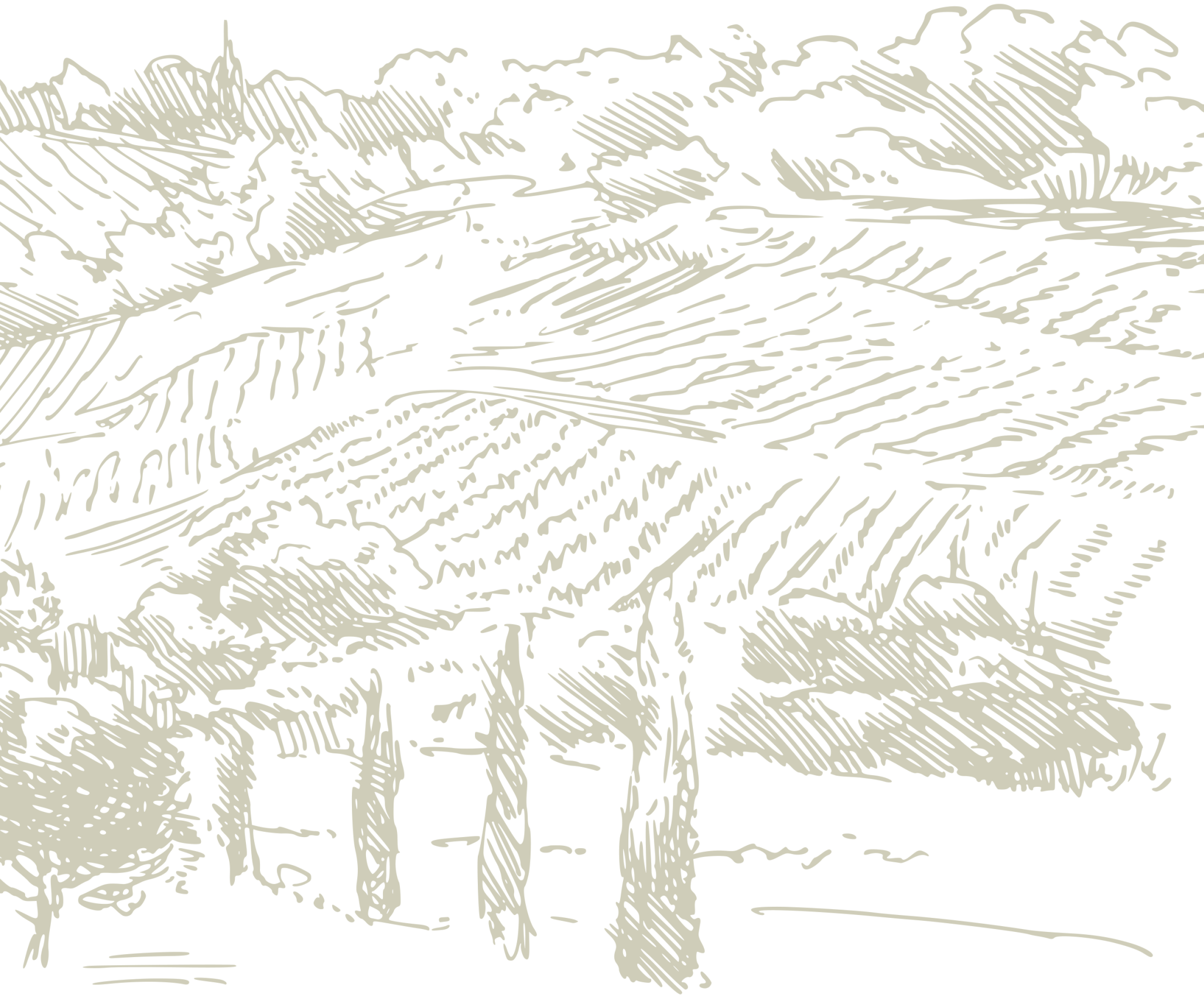





\subsection{DISEÑO EXPERIMENTAL}

El diseño experimental se describe en cada una de las diferentes fases (clima, litología, geomorfología, suelo y cultivo) que pretenden definir y completar los muestreos realizados tanto representativos de la DOCa Rioja, como homogéneos de los elementos implicados en la influencia del terroir.

El trabajo experimental se lleva a cabo durante cuatro años consecutivos (2012, 2013, 2014 y 2015) en las cuatro parcelas que fueron seleccionadas inicialmente por su representatividad atendiendo a características vitícolas: material vegetal, sistema de conducción y año de plantación.

La situación de estos viñedos y la descripción del entorno dentro de la Denominación, así como las características del medio físico de la zona han sido expuestas en el Capítulo 4 (también ver Figura 13).

\subsection{CLIMA}

La caracterización del clima permite completar la descripción de las parcelas y su definición permite la generalización a situaciones similares de la DOCa Rioja.

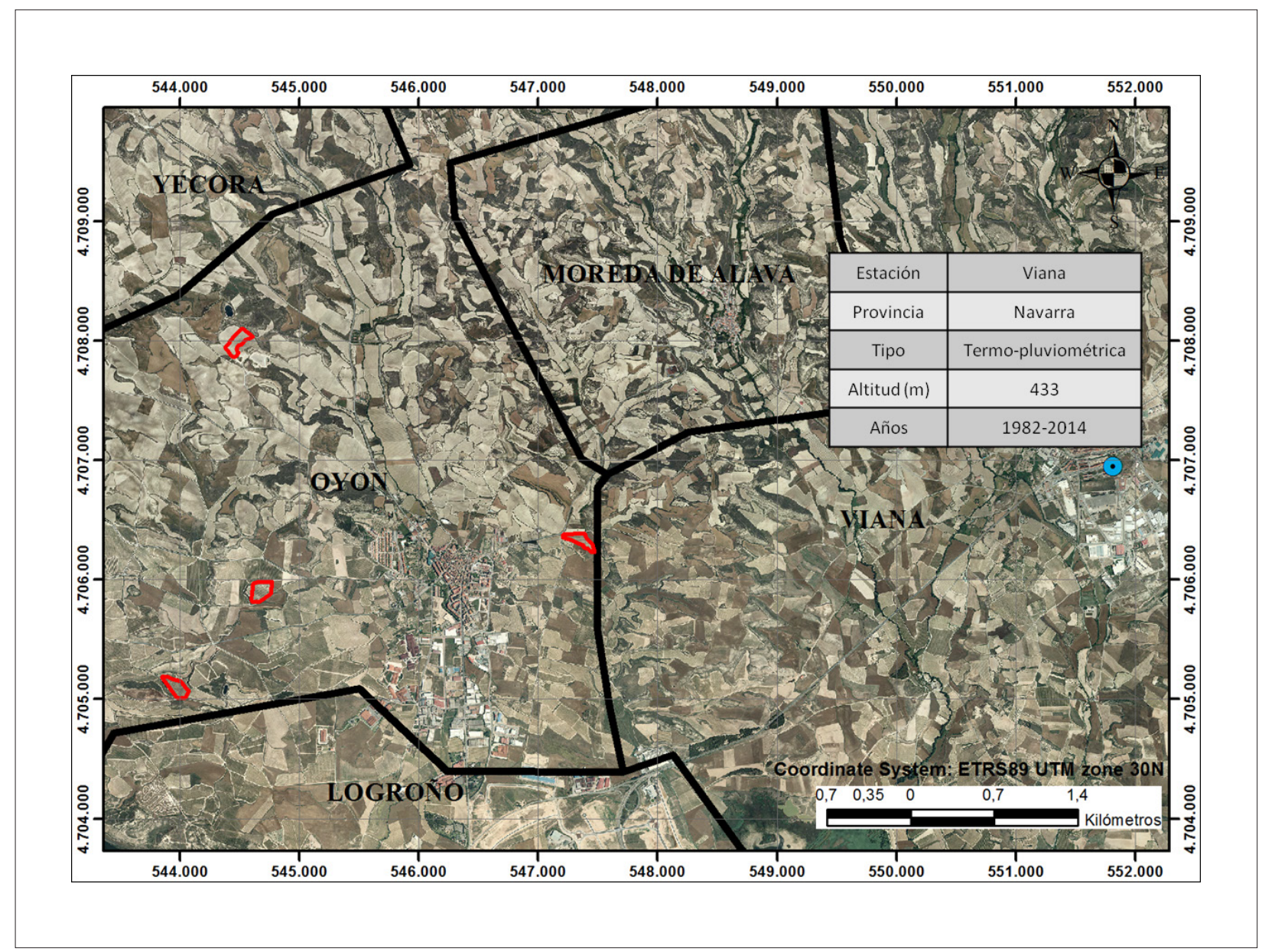

Figura 18. Características y situación de la Estación meteorológica de Viana respecto a las parcelas del ensayo. 
Para caracterizar el clima de los años en los que se lleva a cabo el estudio se utilizan los datos de la estación termo-pluviométrica de Viana (Figura 18), tal y como se expone en el Capítulo 4.

Los distintos índices bioclimáticos vitícolas permiten diferenciar las características climáticas de zonas o regiones en relación con el cultivo de la vid (Tabla 3 y Tabla 4 del § 4.1) y también se han empleado para cuantificar las diferencias climáticas de los cuatro años de estudio entre sí.

\subsection{LITOLOGÍA Y GEOMORFOLOGÍA}

La definición de la litología y de la geomorfología de la zona permite completar la de las parcelas y su caracterización la generalización a situaciones similares de la DO Ca Rioja.

La litología y las unidades geomorfológicas se obtienen a partir de la fotointerpretación aérea (FIA) convencional realizada según criterios morfológicos y patrones fotográficos de textura, tonalidad, etc., que permiten delimitar las unidades homogéneas (UHM) relacionadas con estos elementos y mejorada con la utilización del Mapa Digital del Terreno (MDT), no solo en cuanto a la comparación general con la DO (Tabla 5 del § 4.3), sino también dentro de cada parcela. Esta FIA se lleva a cabo sobre fotogramas aéreos con visión estereoscópica en combinación con ortofotos del Plan Nacional de Ortofotografía Aérea (PNOA) del Instituto Geográfico Nacional.

\subsection{SUELO}

Puesto que el objetivo general de la tesis es la utilización del mapa de gestión de la DOCa Rioja como un mapa ejecutivo, la propuesta metodológica es específica.

Como se ha dicho previamente el mapa de la DOCa Rioja de referencia es un mapa de gestión a escala 1:50.000 realizado con la metodología USDA (1993) y cuyas SMU (consociaciones, asociaciones y complejos) son la mayoría politáxicas y las STU están definidas con la versión de 1975 de Soil Taxonomy.

La forma de obtener un mapa de suelos de las parcelas a una escala ejecutiva adecuada es costosa y con los métodos de disgregación automática no se obtienen actualmente resultados completamente satisfactorios.

Por estos motivos el reconocimiento de la variabilidad horizontal (geográfica) y vertical (tipología) del suelo se realiza mediante la división de sectores definidos en la FIA y de un muestreo que reduzca la densidad de observaciones a las meramente necesarias para la identificación de las STU de cada sector. En concreto, se realizan dos observaciones de campo en cada uno de los sectores definidos en la FIA. Excepto por esta cuestión la metodología utilizada para la cartografía es la descrita en USDA (2017) y para las descripciones de campo la de (USDA, 2012), el color de cada horizonte se determina por comparación con los incluidos en la carta de color de Munsell Color Company (1990). Las determinaciones de las propiedades físicas, químicas y físicoquímicas se realizaron para las muestras de todos los horizontes del suelo de acuerdo con la metodología incluida en la Tabla 9. La clasificación se realiza en la categoría de serie en las dos versiones de Soil Taxonomy (USDA, 1975 y 2014). 
Tabla 9. Determinaciones analíticas realizadas sobre las muestras de tierra, correspondientes a las 20 calicatas abiertas

\begin{tabular}{|c|c|}
\hline DETERMINACIÓN & METODOLOGÍA \\
\hline ELEMENTOS GRUESOS (\%) & GRAVIMETRÍA \\
\hline TEXTURA (\%) & SEDIMENTACIÓN \\
\hline RETENCIÓN DE AGUA (\%) & GRAVIMETRÍA \\
\hline pH & MT-SUE-007 \\
\hline MATERIA ORGÁNICA OXIDABLE (\%) & MT-SUE-002 \\
\hline FÓSFORO OLSEN (ppm) & MT-SUE-003 \\
\hline CALIZA ACTIVA (\%) & MT-SUE-006 \\
\hline CAPACIDAD INTERCAMBIO CATIÓNICO (cmol/kg) & USDA, 2014b \\
\hline CALCIO DE CAMBIO (cmol/kg) & USDA, 2014b \\
\hline MAGNESIO DE CAMBIO (cmol/kg) & USDA, 2014b \\
\hline POTASIO DE CAMBIO (cmol/kg) & USDA, 2014b \\
\hline SODIO DE CAMBIO (cmol/kg) & USDA, 2014b \\
\hline CE SOBRE EXTRACTO 1:5 (dS/m) & CONDUCTIMETRÍA \\
\hline SODIO (ppm) & USDA, 2014b \\
\hline HIERRO (ppm) & USDA, 2014b \\
\hline COBRE (ppm) & USDA, 2014b \\
\hline MANGANESO (ppm) & USDA, 2014b \\
\hline CINC (ppm) & USDA, 2014b \\
\hline
\end{tabular}

\subsection{CULTIVO}

Los datos del registro vitícola son utilizados para la elección de las parcelas representativas y para la posterior generalización de los resultados (Figura 17 del § 4.4). La referencia y la localización de las parcelas seleccionadas se incluyen en la Figura 18 y sus características son las siguientes:

- Naval: viñedo plantado el año 1990, de la variedad tempranillo (clon RJ-43) sobre patrón 41B. El sistema de conducción es Cordón Royat bilateral formado a $60 \mathrm{~cm}$ del suelo, con un marco de plantación de 2,80 × 1,20 metros (2976 plantas/ha). La orientación de las filas es este-oeste y la altitud media de 437 m.s.n.m.

- Ricio: viñedo plantado el año 1995, de la variedad tempranillo (clon RJ-43) sobre patrón 41B. El sistema de conducción es Cordón Royat bilateral formado a $60 \mathrm{~cm}$ del suelo, con un marco de 
plantación de 2,80 x 1,20 metros (2976 plantas/ha). La orientación de las filas es 450 noreste-suroeste y la altitud media de 492 m.s.n.m.

- Campillo: viñedo plantado el año 1995, de la variedad tempranillo (clon RJ-43) sobre patrón 41B. El sistema de conducción es Cordón Royat bilateral formado a $60 \mathrm{~cm}$ del suelo, con un marco de plantación de 2,80 × 1,20 metros (2976 plantas/ha). La orientación de las filas es 70 noreste-suroeste y la altitud media de 435 m.s.n.m.

- Majadahonda: viñedo plantado el año 1990, de la variedad tempranillo (clon RJ-43) sobre patrón 41B. El sistema de conducción es Cordón Royat bilateral formado a $60 \mathrm{~cm}$ del suelo, con un marco de plantación de 2,80 x 1,20 metros (2976 plantas/ha). La orientación de las filas es 270 noreste-suroeste y la altitud media de 423 m.s.n.m.

En todas las parcelas se realiza el mismo mantenimiento del suelo, los mismos tratamientos fitosanitarios y las mismas técnicas de cultivo.

Sobre cada sector definido según $\S 5.4$ se marcan 12 cepas, repartidas en dos repeticiones (A y B) de seis cepas cada una. Estas seis cepas se distribuyen enfrentadas en dos líneas (tres cepas por línea), compartiendo por tanto la calle, y sobre las que se tomarán las medidas y las muestras de planta y uva.

Para la determinación de parámetros agronómicos y de rendimiento se muestrean cada una de las cepas dentro de cada repetición, mientras que para la determinación de la composición físicoquímica de la uva se toma una muestra representativa por cada repetición (seis cepas).

El muestreo de suelos y el muestreo del cultivo están relacionados, de forma que cada calicata se ha localizado junto a las seis cepas de cada repetición, sin dañar las raíces de ninguna de estas cepas de referencia.

\subsubsection{Mantenimiento del suelo}

En todos los viñedos se hizo una labor de subsolado previa a la plantación. Durante el ciclo vegetativo de la vid, se pasa el cultivador después de cada vendimia y dos o tres veces durante el resto del ciclo. En invierno se realiza una labor con vertedera-intercepas, de $40 \mathrm{~cm}$ de profundidad aproximadamente.

Cada 3-5 años se hace un aporte (aproximadamente de $3.000 \mathrm{~kg} / \mathrm{ha}$ ) de materia orgánica al suelo con estiércol vacuno, cuyo contenido medio en materia orgánica, N, P2O5 y K2O sobre materia fresca es de $33,40 \%, 13,44 \mathrm{~kg} / \mathrm{t}, 4,16 \mathrm{~kg} / \mathrm{t}$ y $17,67 \mathrm{~kg} / \mathrm{t}$ respectivamente, y una humedad de 53,43\%.

\subsubsection{Tratamientos fitosanitarios}

Todos los tratamientos se llevan a cabo conforme a la normativa de agricultura ecológica: Reglamento (CE) No 834/2007 del Consejo y Reglamento (CE) № 889/2008 de la Comisión, utilizándose azufre en polvo y sulfato de cobre. Se realizan entre 2 y 4 tratamientos con cada producto (30 kg/ha y 3kg/ha, respectivamente) en función de las particularidades climáticas del año. 


\subsubsection{Técnicas de cultivo y fenología}

La poda en seco se realiza dejando seis pulgares de dos yemas vistas, regulando la carga prevista mediante posterior despampanado.

La conducción de los pámpanos es vertical y ascendente recogiendo la vegetación con dos alambres regulables en altura, y el sistema de riego empleado, cuando ha sido necesario, es por aspersión.

La determinación de los estados fenológicos se realiza siguiendo la metodología propuesta por Coombe (1995), registrándose cada año la fecha de los siguientes estados mayores: brotación (4), plena floración (23), cuajado (27), envero (35) y madurez (38), coincidiendo este último estado con la fecha de vendimia.

\subsection{TELEDETECCIÓN E ÍNDICES DE VEGETACIÓN}

La teledetección es utilizada con varios objetivos. Primero, para aumentar la precisión de la delineación de los diferentes sectores; segundo, para apreciar la variabilidad temporal de tales límites; tercero, para describir la influencia de determinadas variables del medio en el cultivo y finalmente, para la optimización de la validación del resultado final.

Concretamente, para alcanzar los citados objetivos se utilizada el Índice de Vegetación de Diferencia Normalizada (NDVI) (Tabla 10) que se calcula a partir de escenas satelitales de distinta procedencia y cuyas características son:

- Imágenes multiespectrales SPOT 5, con una resolución espectral de cuatro bandas y 2,5 metros de resolución espacial. La región espectral contenida en cada una de las bandas es: B1 (500590 nm, Verde), B2 (610-680 nm, Rojo), B3 (780-890 nm, Infrarrojo cercano) and B4 (1580-1750 $\mathrm{nm})$.

- Imágenes multiespectrales Pléiades de 0,5 metros de resolución espacial y 4 bandas de resolución espectral: B1 (430-550, Azul), B2 (500-620, Verde), B3 (590-710, Rojo) y B4 (740-940, Infrarrojo cercano).

La imagen SPOT 5 se tomó el 14 de Agosto de 2013 y las imágenes Pléiades fueron tomadas el 25 de Julio de 2012, el 25 de Agosto de 2014 y el 19 de Agosto de 2015.

El cálculo del NDVI y su representación gráfica se realiza con el software ArcGIS 10.1 del Instituto de Investigación de Sistemas Medioambientales (ESRI), optando por un cálculo pixel a pixel (Figura 19). La definición de las clases (Muy baja, Baja, Media, Alta y Muy Alta) se realiza conforme a cinco cuantiles, correspondiéndose el primer cuantil con la clase Muy baja y el quinto cuantil con la clase Muy Alta. 
Tabla 10. Ecuación para el cálculo del NDVI. NIR: Absorbancia del Infrarrojo cercano y R: Absorbancia del Rojo

\begin{tabular}{|c|c|c|}
\hline Índice de Vegetación & Ecuación & Referencia \\
\hline NDVI & $\frac{N I R-R}{N I R+R}$ & (Rouse, Haas, Schell, \& Deering, 1973) \\
\hline
\end{tabular}

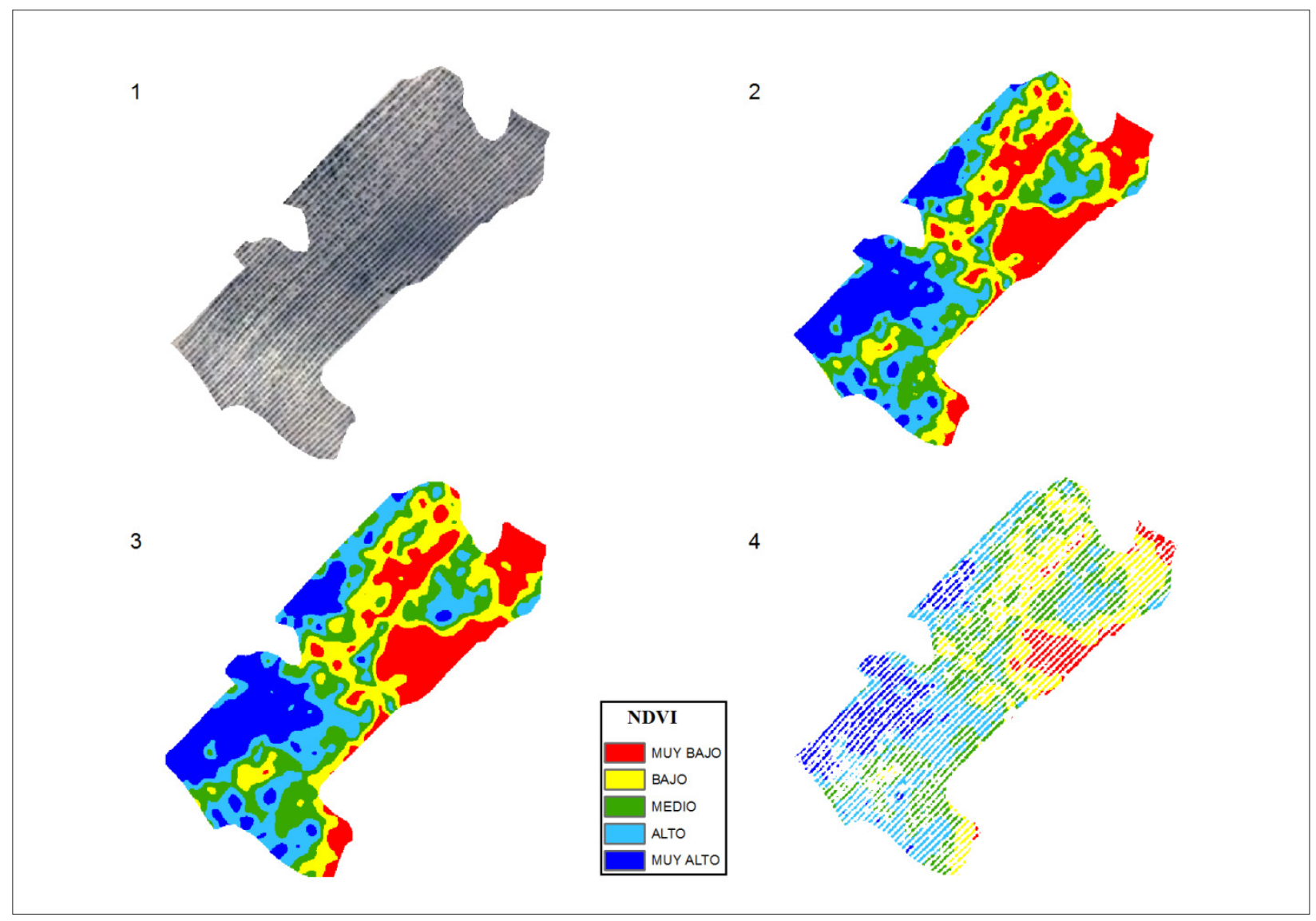

Figura 19. Parcela Ricio. Representación gráfica de: 1. Imagen satelital Pléiades; 2. NDVI calculado pixel a pixel; 3. NDVI calculando cada pixel como media de $6 \times 6$ píxeles (9m2); 4. Segementación supervisada de NDVI

\subsection{AGRONOMÍA Y PRODUCCIÓN}

En cada una de las seis cepas que componen las 20 repeticiones se realizaron medidas relacionadas con el crecimiento vegetativo y con la producción (Tabla 11).

La longitud y el calibre de los sarmientos son medidos en dos sarmientos representativos de cada planta.

El peso de los racimos por cepa se lleva a cabo el día 23 de septiembre de 2012, el 6 de octubre de 2013, el 28 de septiembre de 2014 y el 20 de septiembre de 2015, días en que se realiza la vendimia. La poda y el pesado de la madera obtenida tienen lugar el día 6 de diciembre de 2012, el 26 de noviembre de 2013, el 4 de diciembre de 2014 y el 28 de noviembre de 2015. El resto de parámetros se registran durante los días previos a la vendimia. 
Tabla 11. Medidas realizadas sobre todos los individuos de las 20 repeticiones

\begin{tabular}{|l|r|}
\hline PARÁMETRO & MÉTODO/NSTRUMENTO \\
\hline NÚMERO SARMIENTOS & CONTEO DIRECTO \\
\hline NÚMERO DE RACIMOS & CONTEO DIRECTO \\
\hline PESO DERACIMOS (g) & BÁSCULA \\
\hline LÓNGITUD SARMIENTOS (cm) & CINTAMÉTRICA \\
\hline CALLBRESARMIENTOS (cm) & PIEDEREY \\
\hline PESO DE PODA (g) & BÁSCULA \\
\hline
\end{tabular}

El índice de Ravaz relaciona la parte vegetativa y la reproductiva y es la relación entre el peso de racimos $(\mathrm{kg})$ y el peso de madera de poda $(\mathrm{kg})$. Tradicionalmente se han recomendado valores comprendidos entre 4 y 7.

\subsection{COMPOSICIÓN Y CARACTERÍSTICAS FÍSICOQUÍMICAS DE LA UVA}

Para la determinación del peso y la composición de la uva se tomaron 100 bayas obtenidas entre todos los racimos presentes en cada repetición. La toma de estas bayas tuvo lugar los días de vendimia citados en $\S 5.7$.

Tabla 12. Determinaciones analíticas realizadas sobre el procesado de 100 bayas

\begin{tabular}{|c|c|}
\hline DETERMINACIÓN & MÉTODO/INSTRUMENTO \\
\hline GRADO ALCOHÓLICO PROBABLE (\%vol.) & REFRACTÓMETRO \\
\hline ACIDEZ TOTAL (g. Ac. Tartárico/l) & OIV-MA-AS313-01 \\
\hline pH & OIV-MA-AS313-15 \\
\hline INTENSIDAD DE COLOR & OIV-MA-AS2-07B \\
\hline INDICE DE POLIFENOLES TOTALES & OIV-MA-AS2-10 \\
\hline ÁCIDO L-MÁLLCO (g/l) & AUTOANALIZADOR ENZIMÁTICO \\
\hline ANTOCIANOS (mg/l) & MÉTODO PUISSANT-LEÓN \\
\hline POTASIO (mg/l) & OIV-MA-AS322-02B \\
\hline ÁCIDOTARTÁRICO (g/l) & OIV-MA-AS313-05A \\
\hline
\end{tabular}


El peso de 100 bayas se obtiene en laboratorio con báscula de precisión digital marca On Balance, modelo KB-2000 de 0,1 g de precisión. Los parámetros relacionados con la composición de la uva son analizados por personal de la Estación Enológica de Haro en sus instalaciones, a partir de la misma muestra de 100 bayas. Para ello se hace un procesado de la muestra, pasando las cien bayas por una picadora de cocina durante 1 minuto. Sobre el mosto obtenido, se llevan a cabo las distintas determinaciones (Tabla 12).

\subsection{ZONIFICACIÓN INTEGRADA DEL TERROIR}

Como resultado de lo expuesto, la Zonificación Integrada del Terroir (ZIT) es el resultado de la integración principalmente por solapamiento de los resultados del análisis de los factores del medio (clima, litología, geomorfología, suelo, planta) mediante la creación de las UHM con resultados de los productos finales medidos en el cultivo y/o en la uva.

El uso de la teledetección (a través del NDVI) en la ZIT convencional es una aportación metodológica que permite además incluir los datos del estado del viñedo y su comportamiento interanual.

\subsection{GENERALIZACIÓN DE LOS RESULTADOS}

La generalización de los resultados se realiza mediante la identificación de las unidades de la ZIT en el mapa de gestión de la DOCa Rioja de partida. Al tratarse de SMU politáxicas, la identificación se realiza a través de las STU.

\subsection{ANÁLISIS ESTADÍSTICO}

El análisis estadístico de los diferentes datos obtenidos se efectuó mediante Análisis de Componentes Principales (ACP), Análisis Jerárquico Cluster (AJC) o Análisis de Varianza (ANOVA) univariante.

Para los análisis ANOVA se utilizó el programa SPSS, versión 15.0 (SPSS Inc. Chicago, Illinois) y la significación del análisis se determina para los niveles de probabilidad $\left.p<0.05\left(^{*}\right), p<0.01{ }^{(*}\right)$ y $\left.p<0.001{ }^{(* *}\right)$. Las medias se comparan mediante el test de Duncan para un nivel de probabilidad $p<0.05$, cuando hubo diferencias significativas en el análisis de varianza. El resto de los cálculos estadísticos se realizan con el complemento XLSTAT 2019.4.01 sobre Microsoft Excel 2010.

Respecto a los cálculos geoestadísticos, se utiliza el ya citado software ARCGIS 10.1 para el estudio de la autocorrelación espacial (a partir del método de Morans) y para el modelado y obtención de los parámetros característicos (efecto pepita, umbral y rango) de los semivariogramas.

El análisis de autocorrelación espacial de Morans determina si el patrón que sigue una distribución es disperso (Zvalue $<-2,58$ ), aleatorio $(-2,58<$ Zvalue $<2,58$ ) o agrupado (Zvalue $>2,58$ ). En este último caso, hay una probabilidad de menos del $1 \%$ de que el patrón de la distribución sea resultado de la casualidad. 
De forma análoga, el Índice de Cambardella (Ic) se utiliza para definir distintos niveles de dependencia espacial a partir de las características del semivariograma:

$$
I_{C}=\frac{C_{0}}{C_{0}+C_{1}} * 100
$$

Donde Co es el efecto pepita y C1 es la estimación de la varianza de la estructura espacial (umbral). Si el índice es menor o igual del 25\%, la variable se considera con una fuerte dependencia; si el índice está entre 25 y 75\% la variable se considera con moderada dependencia espacial; y si el índice es superior al 75\% la variable se considera con débil dependencia espacial (Cambardella et al., 1994; Cambardella \& Karlen, 1999).

\subsection{REPRESENTACIÓN Y GIS}

Los mapas y representaciones gráficas del medio natural, así como del NDVI se llevan a cabo con ayuda del software ArcGIS 10.1 (ESRI) utilizando el sistema de coordenadas ETRS 89 UTM 30. Para el cálculo y cartografiado de la altitud y otros elementos del medio físico se parte del Modelo Digital del Terrreno (MDT) con paso de malla 5 m del Instituto Geográfico Nacional (IGN, 2012). 


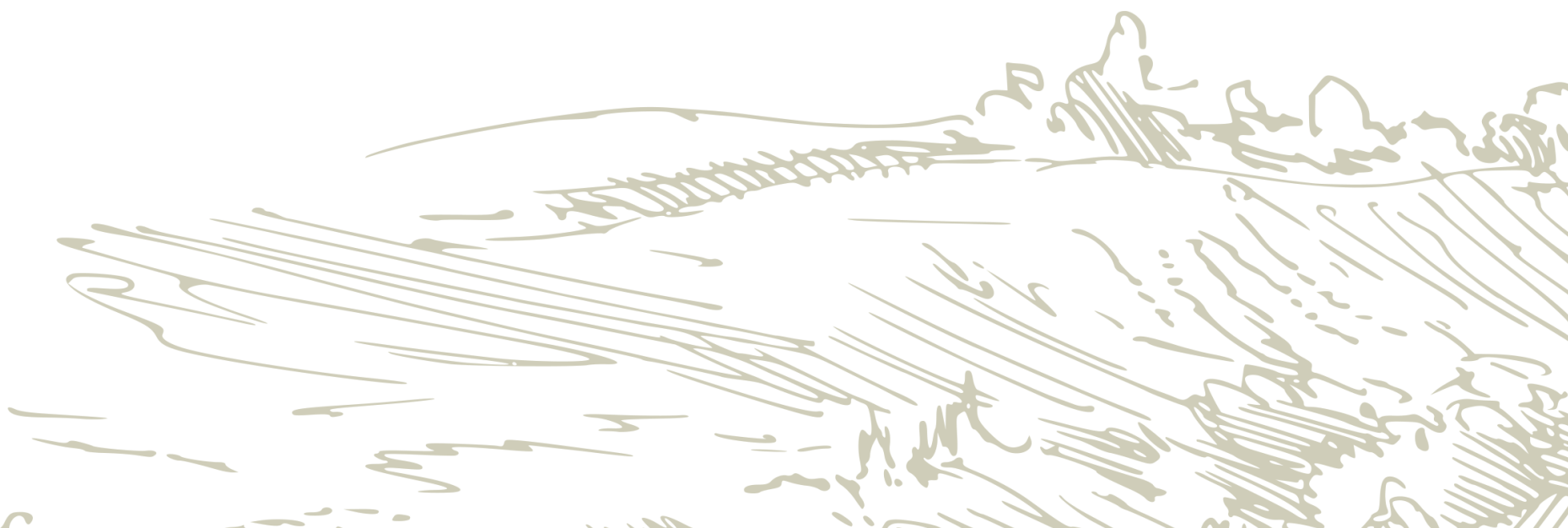

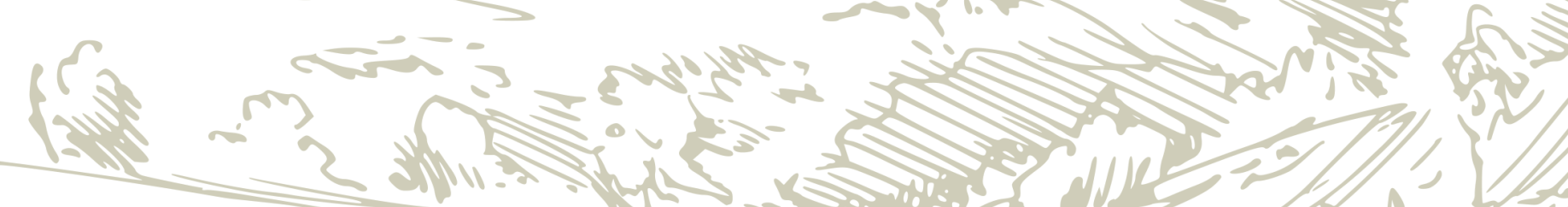




\section{CAPÍTULO 6 \\ Resultados \\ y discusión}

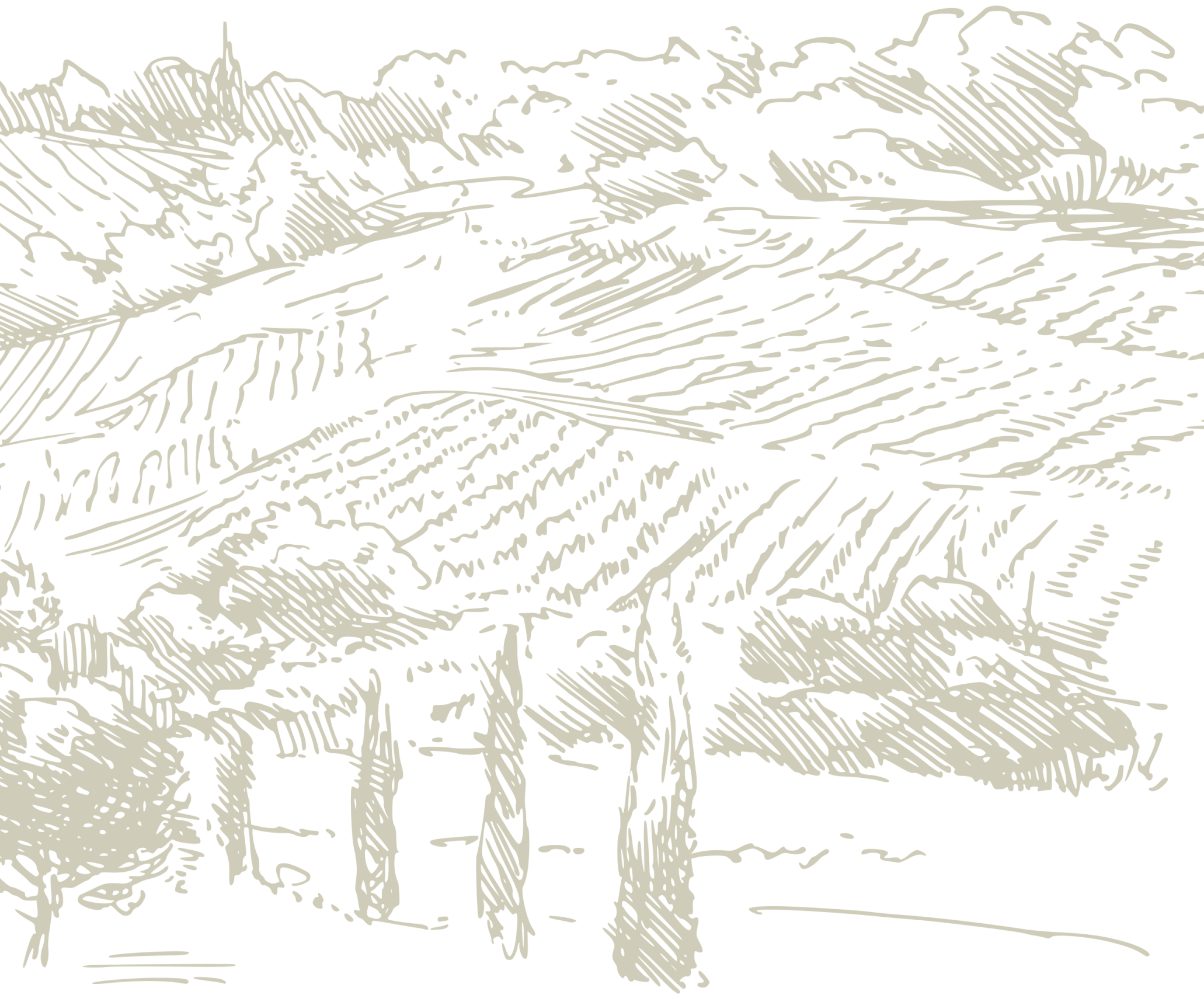





\subsection{SECTORIZACIÓN Y MUESTREO}

En la Figura 20 se puede observar el resultado de la sectorización y el muestreo realizado en las parcelas del ensayo. En concreto, se separan las unidades homogéneas que componen diez sectores (N1 y N2 en la finca Naval; R1, R2 y R3 en la finca Ricio; C1, C2 y C3 en la finca Campillo; M1 y M2 en la finca Majadahonda) y 20 perfiles de suelo y sus correspondientes puntos de muestreo de planta y uva.

El resultado de la sectorización pretende la separación de subzonas diferentes y la agrupación de subzonas iguales. En las Figuras 21 a 24 se incluye un conjunto de fotogramas y ortofotos que justifican este resultado y su análisis permite comprender el compromiso que supone realizar este tipo de fotointerpretación aérea (FIA) a escala detallada. Concretando, se han dividido las macrounidades disponibles a partir del estudio citado de la DOCa Rioja en sectores tan pequeños que las diferencias se deben no sólo al microrrelieve, al color y a los cultivos sino también a aspectos relacionados con la parcelación y el manejo histórico,es decir, a elementos con variabilidad espacial y temporal.

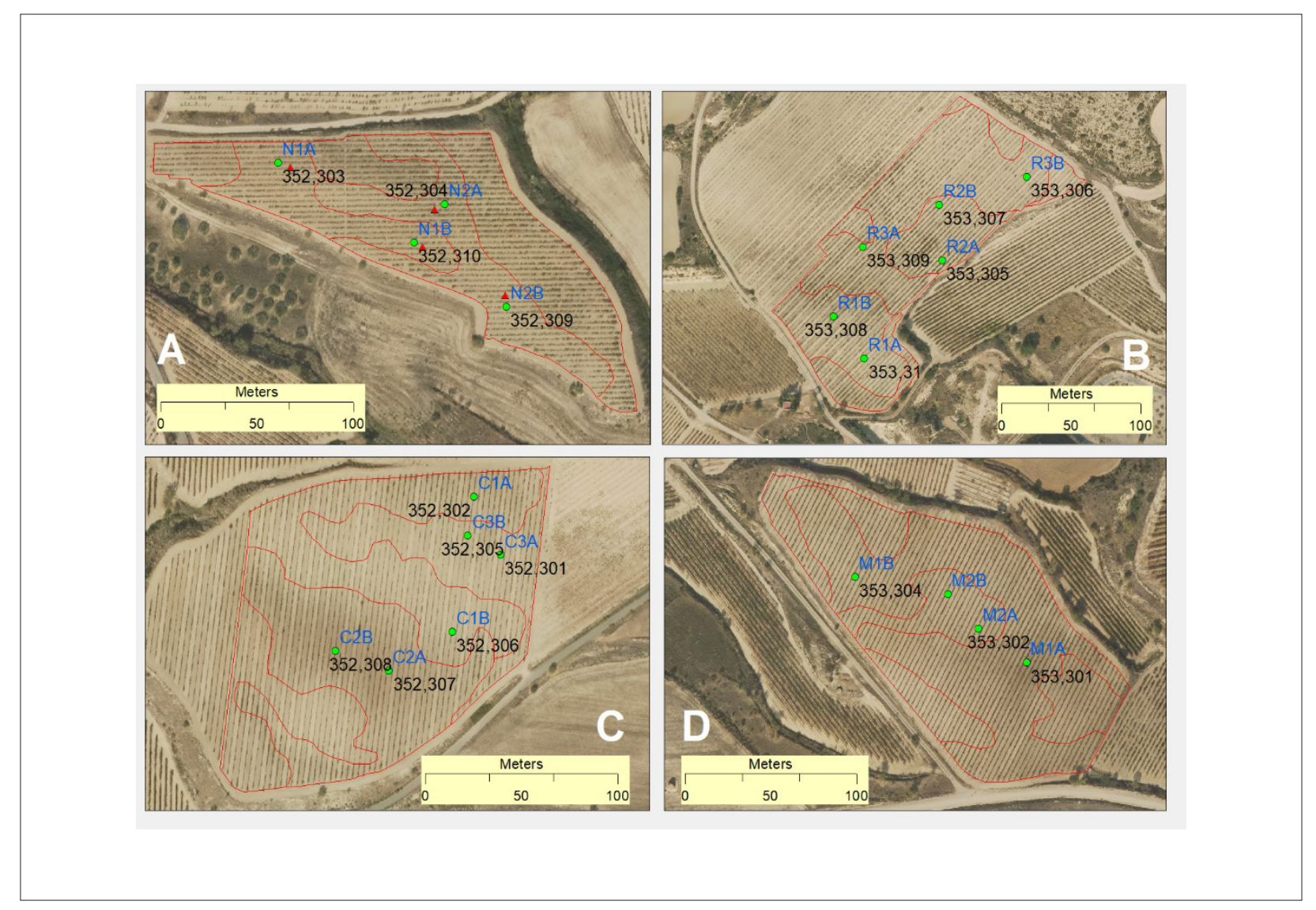

Figura 20. Resultado de la sectorización y muestreo de las parcelas A: NAVAL; B: RICIO; C: CAMPILLO y D: MAJADAHONDA con la referencia de los perfiles y la codificación utilizada en este trabajo. 

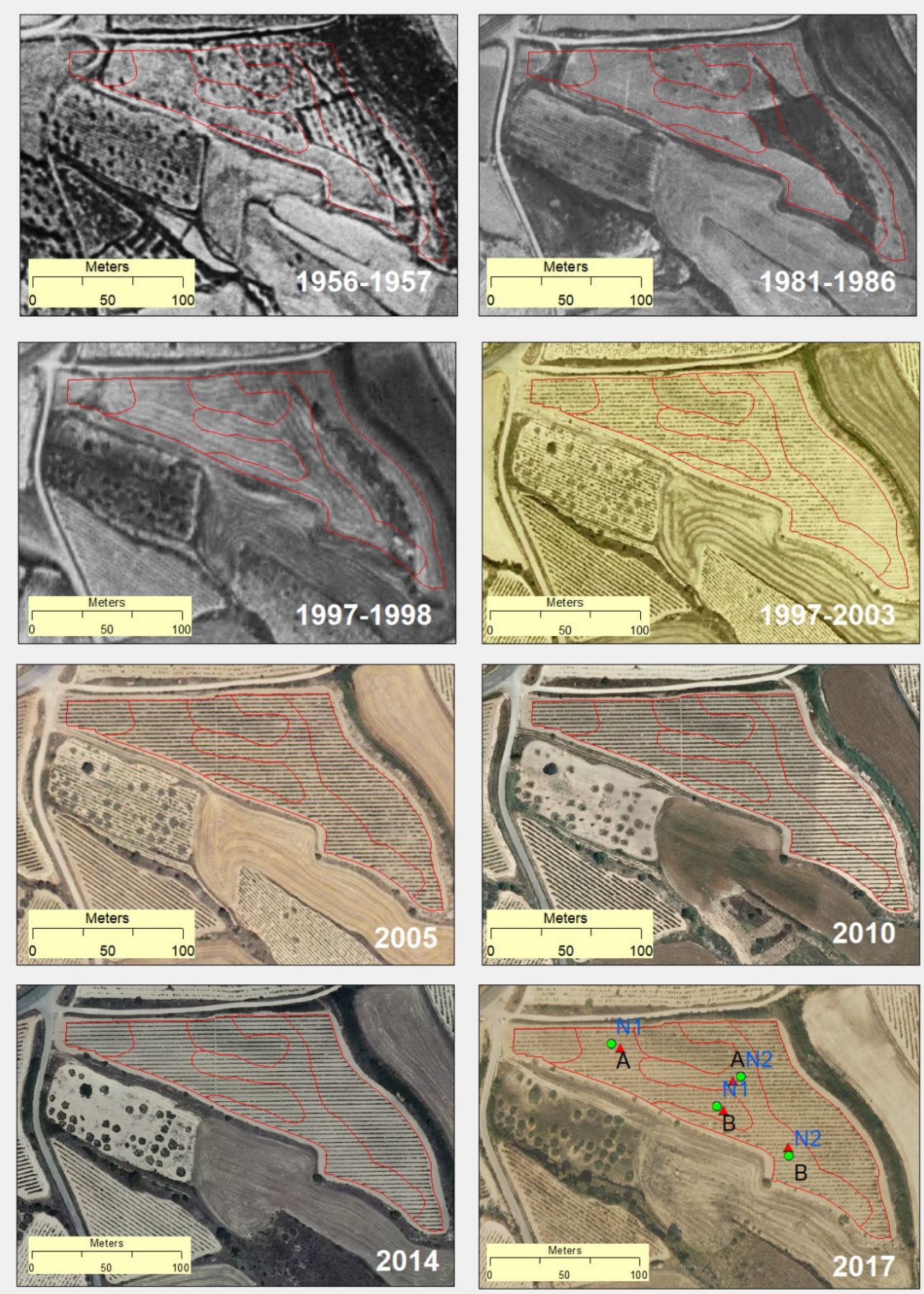

Figura 21. Sectorización y muestreo de la parcela NAVAL a partir de ortofotos procedentes de diferentes vuelos del IGN. Elaboración propia a partir de georreferenciación del IGN. 

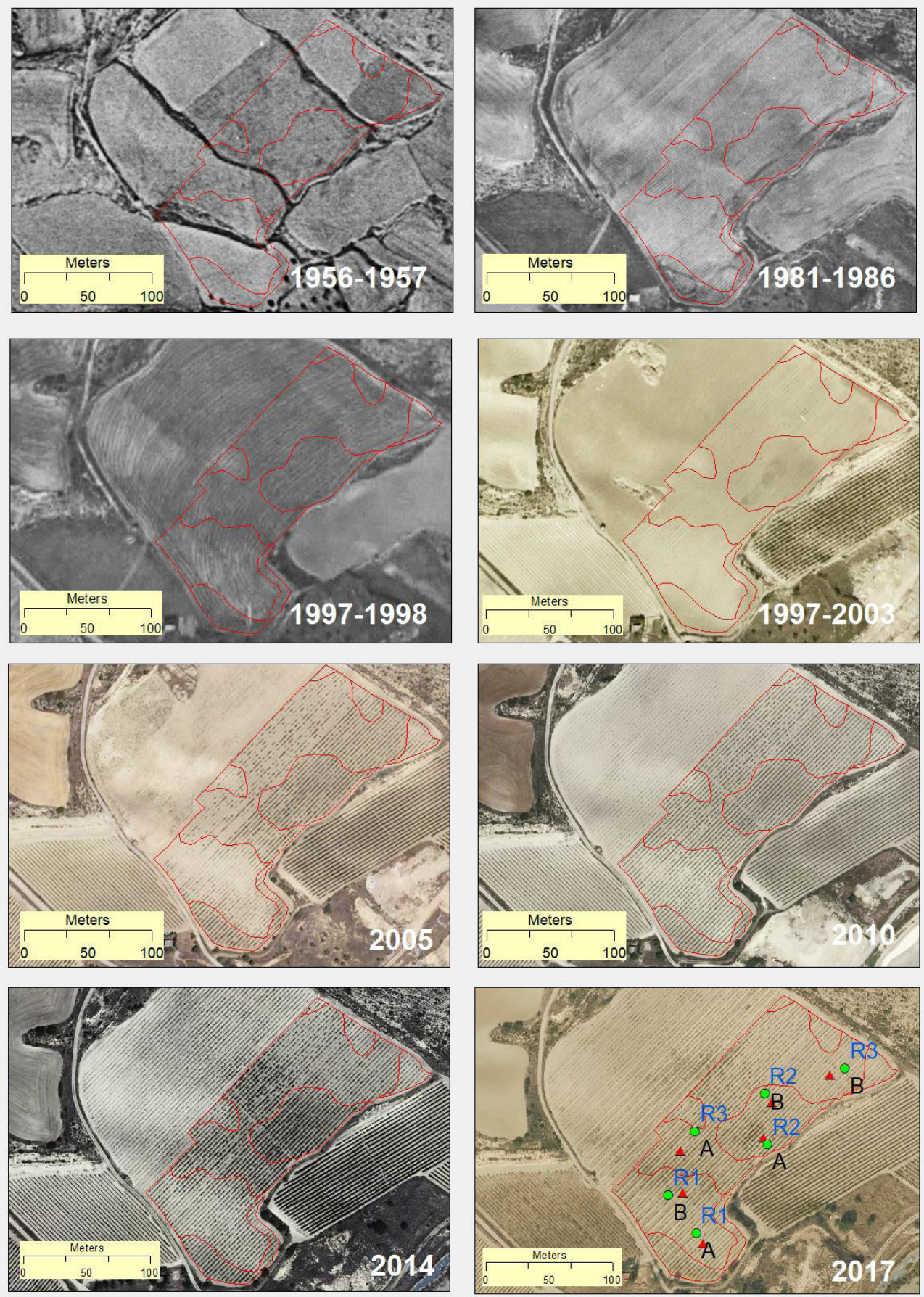

Figura 22. Sectorización y muestreo de la parcela RICIO a partir de ortofotos procedentes de diferentes vuelos del IGN. Elaboración propia a partir de georreferenciación del IGN. 

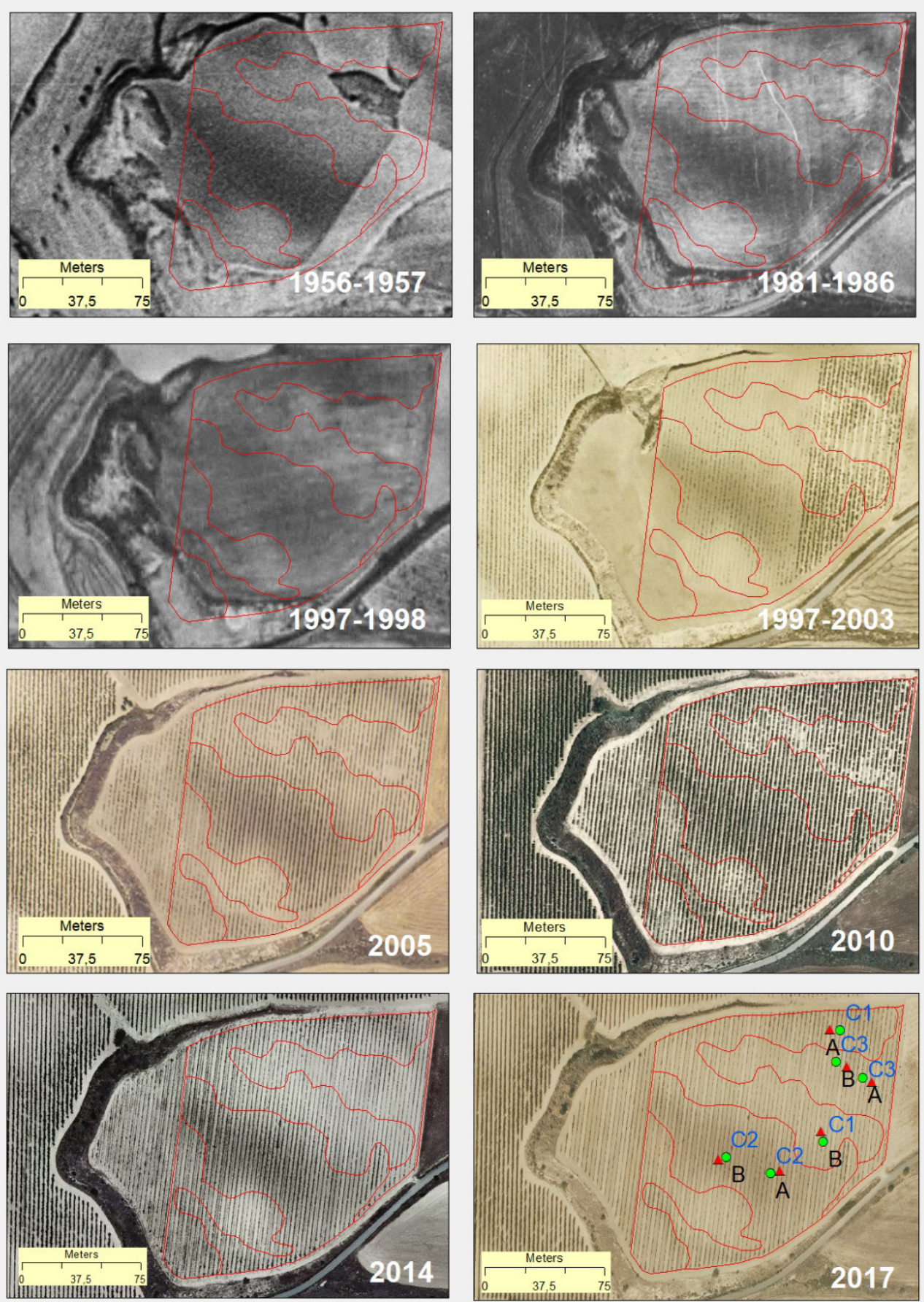

Figura 23. Sectorización y muestreo de la parcela CAMPILLO a partir de ortofotos procedentes de diferentes vuelos del IGN. Elaboración propia a partir de georreferenciación del IGN. 

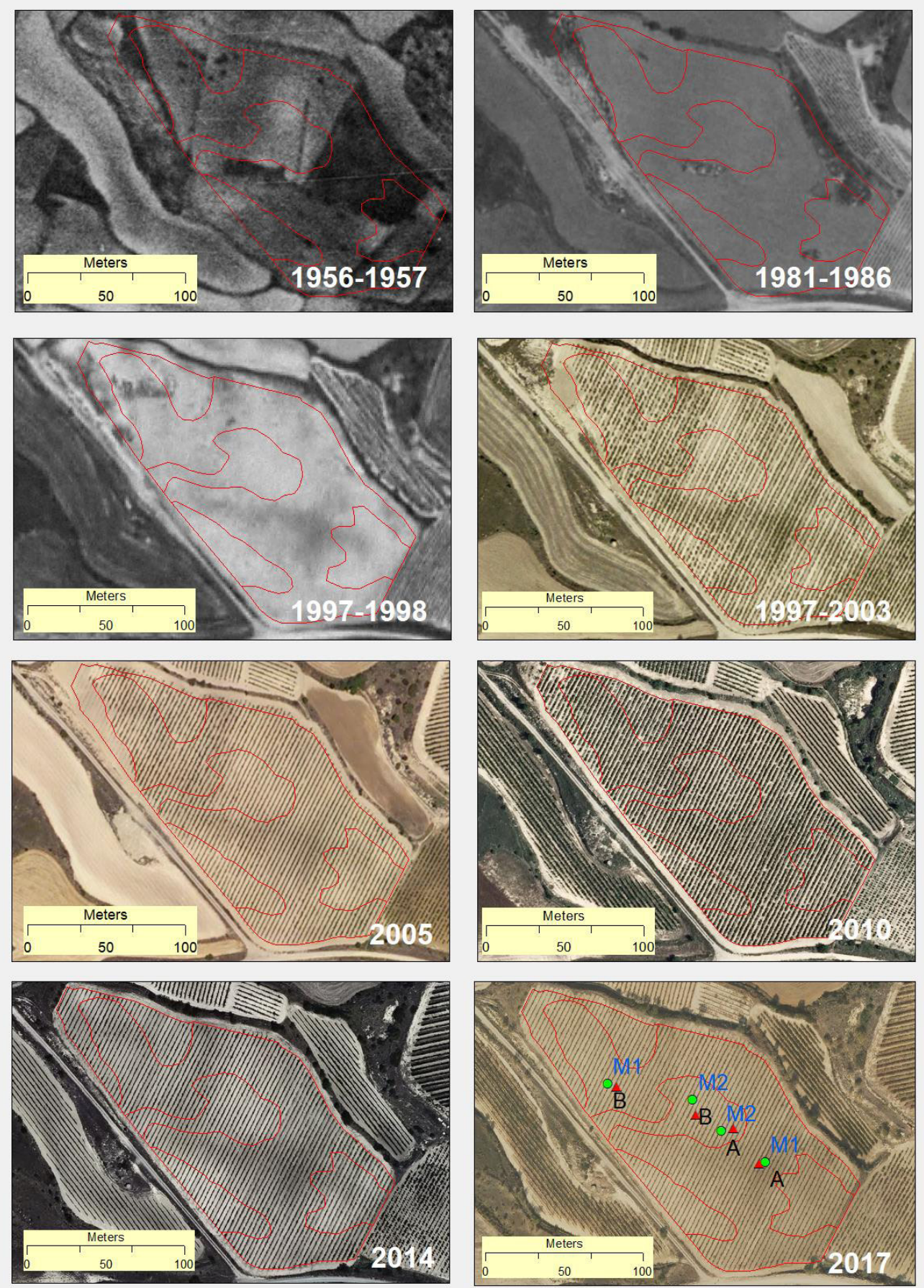

Figura 24. Sectorización y muestreo de la parcela MAJADAHONDA a partir de ortofotos procedentes de diferentes vuelos del IGN. Elaboración propia a partir de georreferenciación del IGN. 


\subsection{CLIMA}

En la Tabla 13 se presentan los datos mensuales de la temperatura media (Tm), la precipitación (P), la evapotranspiración potencial (ETP) y la evapotranspiración potencial FAO-Blaney-Criddle (ETPB-C) de los cuatro años en los que se llevó a cabo el ensayo. También se presentan los valores del Índice de Winkler y del Índice de Constantinescu, así como los mismos datos y observaciones para la serie histórica 1982-2015. En las Figuras 25 y 26 se muestran gráficamente estos resultados.

Tabla 13. Resumen de algunos elementos e índices climáticos de los años de estudio y de la serie histórica. Estación meteorológica de Viana (Gobierno de Navarra, 2019).

\begin{tabular}{|c|c|c|c|c|c|c|c|c|c|c|c|c|c|c|}
\hline & & Ene & Feb & Mar & Abr & May & Jun & Jul & Ago & Sep & Oct & Nov & Dic & ANUAL \\
\hline \multirow{4}{*}{2012} & $\operatorname{Tm}\left({ }^{\circ} \mathrm{C}\right)$ & 6,1 & 4,6 & 10,9 & 10,2 & 17 & 21,1 & 21,7 & 24,5 & 19,5 & 14,6 & 8,3 & 7 & 13,8 \\
\hline & $P(\mathrm{~mm})$ & 19 & 17,5 & 13 & 58,6 & 36,4 & 24,6 & 13 & 9,5 & 34,4 & 104 & 69,6 & 22,4 & 422 \\
\hline & $\operatorname{ETP}(\mathrm{mm})$ & 12,9 & 9 & 37,6 & 37,3 & 88,1 & 121,3 & 128,8 & 142,1 & 88,8 & 53 & 20,1 & 15,2 & 754,2 \\
\hline & ETPB-C (mm) & 27 & 21,5 & 61,8 & 61,4 & 133 & 179,7 & 190,3 & 209 & 133,9 & 83,5 & 37,2 & 30,3 & 1168,6 \\
\hline \multirow{4}{*}{2013} & $\operatorname{Tm}\left({ }^{\circ} \mathrm{C}\right)$ & 6,9 & 6 & 9 & 11,6 & 11,8 & 17,3 & 24,4 & 22,1 & 19,3 & 15,7 & 8,8 & 4,7 & 13,1 \\
\hline & $P(\mathrm{~mm})$ & 80,6 & 132,6 & 128,5 & 43,7 & 47,6 & 72,2 & 62 & 13 & 33 & 23,7 & 48,1 & 29,7 & 714,7 \\
\hline & $\operatorname{ETP}(\mathrm{mm})$ & 16,9 & 14,6 & 30,7 & 47,6 & 55 & 93,9 & 153,7 & 124,1 & 89,5 & 61,1 & 23,7 & 9,7 & 720,5 \\
\hline & ETPB-C (mm) & 32,7 & 29,4 & 52,2 & 75,9 & 86,3 & 141,1 & 225,4 & 183,7 & 134,9 & 94,9 & 42,2 & 22,4 & 1023,9 \\
\hline \multirow{4}{*}{2014} & $\operatorname{Tm}\left({ }^{\circ} \mathrm{C}\right)$ & 7,1 & 7,1 & 10 & 14,3 & 14,6 & 19,8 & 20,9 & 21,7 & 20,9 & 17,5 & 10,3 & 6,7 & 14,2 \\
\hline & $P(\mathrm{~mm})$ & 60,6 & 23,5 & 54 & 33,5 & 56 & 23,5 & 47,7 & 24,5 & 34 & 36 & 96,8 & 52,3 & 542,4 \\
\hline & $\operatorname{ETP}(\mathrm{mm})$ & 15,6 & 16,3 & 32,4 & 59,9 & 69,7 & 109,9 & 121,3 & 118,7 & 97,6 & 68,2 & 26,9 & 13,9 & 750,4 \\
\hline & ETPB-C (mm) & 30,8 & 31,8 & 54,6 & 93,3 & 107 & 163,7 & 179,8 & 176 & 146,3 & 104,9 & 46,7 & 28,4 & 1163,2 \\
\hline \multirow{4}{*}{2015} & $\operatorname{Tm}\left({ }^{\circ} \mathrm{C}\right)$ & 5,2 & 4,5 & 9,9 & 12,9 & 16,6 & 20,5 & 24,4 & 22,3 & 17,4 & 14,2 & 10,8 & 6,4 & 13,8 \\
\hline & $P(\mathrm{~mm})$ & 61 & 59,6 & 80,2 & 19,8 & 1,7 & 84 & 69,5 & 25,5 & 22,7 & 31,4 & 41,5 & 3,9 & 500,8 \\
\hline & $\operatorname{ETP}(\mathrm{mm})$ & 10,3 & 8,8 & 32,9 & 52,6 & 85,3 & 116,6 & 152,8 & 124,2 & 75,5 & 51,1 & 29,6 & 13,5 & 753,3 \\
\hline & ETPB-C (mm) & 23,4 & 21,2 & 55,2 & 83 & 129,1 & 173,1 & 224 & 183,8 & 115,2 & 80,8 & 50,6 & 27,9 & 1070,1 \\
\hline \multirow{4}{*}{$1982-2015$} & $\operatorname{Tm}\left({ }^{\circ} \mathrm{C}\right)$ & 5,7 & 7 & 9,9 & 12 & 15,9 & 19,9 & 22,6 & 22,6 & 19,2 & 14,7 & 9,3 & 6,2 & 13,8 \\
\hline & $P(m m)$ & 38 & 33,2 & 36,1 & 45,5 & 46 & 43,3 & 29,6 & 23,1 & 29,6 & 42,9 & 51,2 & 40,3 & 458,8 \\
\hline & $\operatorname{ETP}(\mathrm{mm})$ & 12 & 16,8 & 33,3 & 47,8 & 80,6 & 112 & 137 & 126,8 & 87,3 & 54 & 24,1 & 13,1 & 745 \\
\hline & ETPB-C (mm) & 25,7 & 32,6 & 55,7 & 76,2 & 122,4 & 166,7 & 201,9 & 187,5 & 131,8 & 85 & 42,9 & 27,3 & 1155,7 \\
\hline
\end{tabular}

\begin{tabular}{|l|r|r|r|r|r|}
\hline ÍNDICE & 2012 & 2013 & 2014 & 2015 & $1982-2015$ \\
\hline WINKLER & 1787 & 1592 & 1821 & 1778 & 1733 \\
\hline CONSTANTINESCU & 8,83 & 7,79 & 7,90 & 8,60 & 8,36 \\
\hline
\end{tabular}




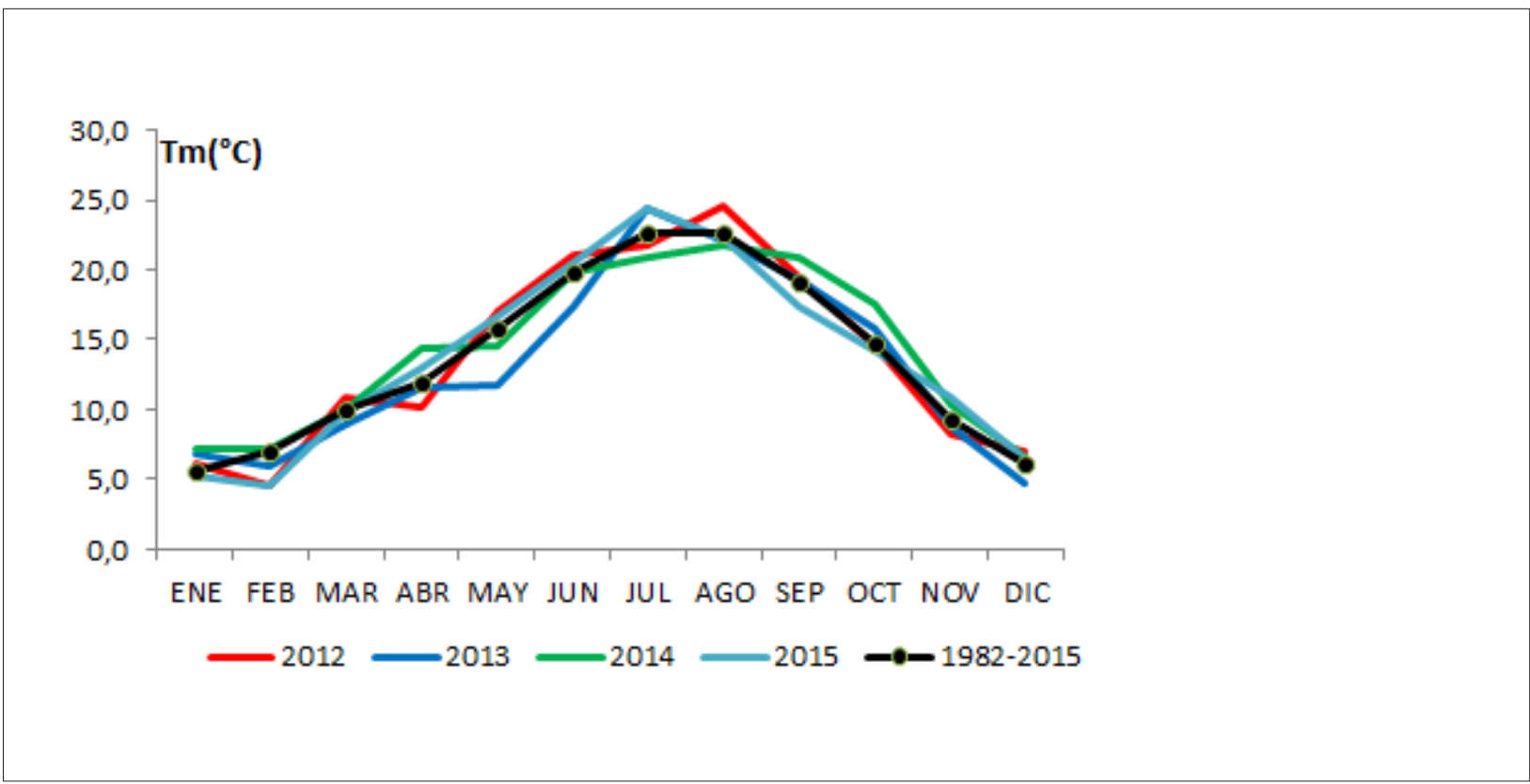

Figura 25. Temperatura media mensual de los años del ensayo y de la serie histórica. Estación meteorológica de Viana (Gobierno de Navarra, 2019).

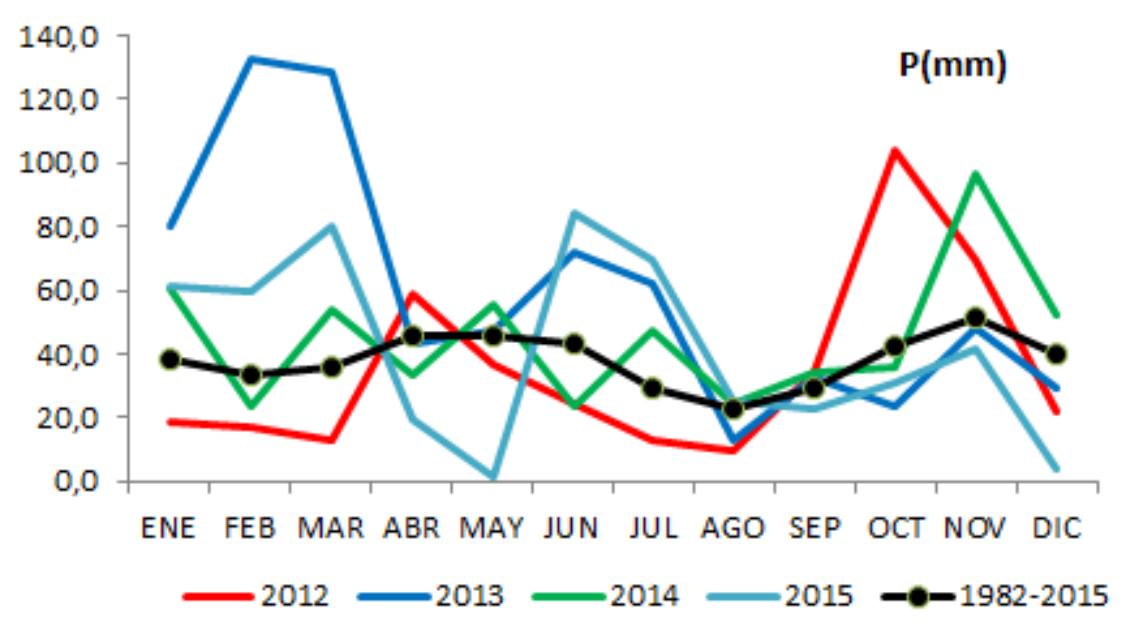

Figura 26. Precipitación mensual de los años del ensayo y de la serie histórica. Estación meteorológica de Viana (Gobierno de Navarra, 2019).

Como ya se ha señalado (\$ 4.1), el estudio climático de la DOCa Rioja divide la región en seis zonas climáticas considerando el Índice de Constantinescu (IHC) y la ETPB-C como variables explicativas de la mayor parte de la varianza, después de incluir en el análisis 16 variables e índices climático, siendo el propio análisis estadístico el que selecciona las variables. 
Tabla 14. Comparación de Índice de Constantinescu (IHC) y de evapotranspiración potencial FAO-Blaney-Criddle (ETPB-C) de los años de ensayo y de las zonas climáticas de la DOCa Rioja.

\begin{tabular}{|c|c|c|c|c|c|c|c|c|c|c|c|}
\hline & & \multicolumn{6}{|c|}{ Zonas Climáticas DO Ca Rioja (Fernández, 1999) } & \multicolumn{4}{|c|}{ AÑOS DEL ENSAYO } \\
\hline & & 1 & 2 & 3 & 4 & 5 & 6 & 2012 & 2013 & 2014 & 2015 \\
\hline & $\min$ & 4,8 & 7 & 8,6 & 10,4 & 11,7 & 7 & & & & \\
\hline \multirow[t]{4}{*}{$\mathrm{HC}$} & med & 4,8 & 8 & 8,5 & 10,9 & 12.6 & 7 & 8,83 & 7,79 & 7,9 & 8,6 \\
\hline & máx & 4,8 & 8,8 & 9 & 11,4 & 14,1 & 8,5 & & & & \\
\hline & DS & - & 0,76 & 0,4 & 0,39 & 0,97 & 0,65 & & & & \\
\hline & $\min$ & 1073 & 988 & 1065 & 1115 & 1227 & 971 & & & & \\
\hline \multirow[t]{3}{*}{ ETPB-C } & med & 1073 & 999 & 1129 & 1194 & 1254 & 1193 & 1071 & 1024 & 1066 & 1070 \\
\hline & máx & 1073 & 1010 & 1153 & 1248 & 1337 & 1206 & & & & \\
\hline & DS & - & 11,8 & 19,2 & 38,3 & 22,3 & 20,1 & & & & \\
\hline
\end{tabular}

Aunque, considerando los datos medios, el comportamiento de las parcelas de ensayo corresponde a la zona 3 (§ 4.1), la variación interanual (Tabla 14) sitúa el año 2013 más próximo a la ZC 2, algo que coincide con los resultados mostrados en las Tablas 14 y 15 y las Figuras 25 y 26, dónde se pone de manifiesto cómo este año se caracteriza por ser el de temperatura más fresca y el de mayor precipitación.

El Sistema Multicriterio de Clasificación Climática (MCCS) (Tonietto \& Carbonneau, 2004) fija tres factores (IH: Índice de Huglin; IF: Índice de Frío Nocturno; IS: Índice de Sequía) y con ellos, permite comparar los climas de diferentes zonas y subzonas del mundo así como la diferencia entre añadas.

Tabla 15. MCCS (Tonietto \& Carbonneau, 2004) aplicado a los años de ensayo y a la serie histórica. Estación meteorológica de Viana. Fuente de datos: www.meteo.navarra.es

\begin{tabular}{|l|r|r|r|r|r|}
\hline & 2012 & 2013 & 2014 & 2015 & MEDIA 82-15 \\
\hline IH & 2263 & 1987 & 2202 & 2289 & 2203 \\
\hline CLASS IH & $\mathbb{H}+1$ & $\mathbb{H}-1$ & $\mathbb{H}+1$ & $\mathbb{H}+1$ & $\mathbb{H}+1$ \\
\hline IF & 14 & 13,3 & 15 & 11,5 & 13,3 \\
\hline CLASS IF & $\mathbb{F}+1$ & $\mathbb{F}+1$ & $\mathbb{F}-1$ & $\mathbb{F}+2$ & 46 \\
\hline IS & 22 & 81 & 50 & 70 & $\mathbb{F}+1$ \\
\hline CLASS IS & IS+1 & $\mid S-1$ & $\mid S+1$ & $\mid S-1$ & \\
\hline
\end{tabular}


Siguiendo esta metodología MCCS el clima de la zona donde se enmarcan las parcelas del ensayo es templado cálido (IH+1), de noches frescas (IF+1) y moderadamente seco (IS+1). En la Tabla 15 y en la Figura 27 se ponen de relieve las desviaciones de los años de estudio con respecto a la serie histórica. Así, el año 2013 se clasifica como templado (IH-1) y subhúmedo (IS-1), el año 2014 como de noches templadas (IF-1) y el año 2015 como de noches muy frías (IF+2) y subhúmedo (IS-1). El año 2012 se clasifica igual que la serie histórica.

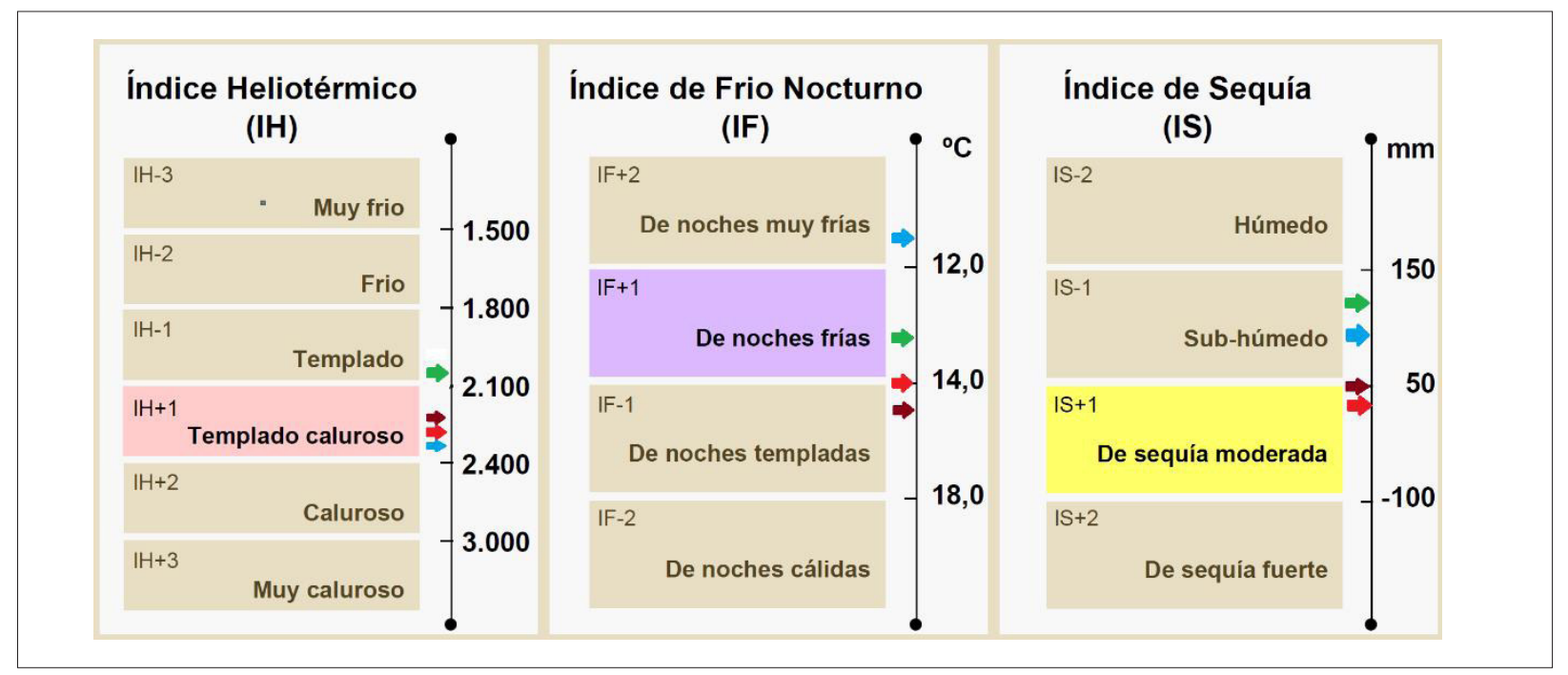

Figura 27. Comparación del año medio (rosa, morado, amarillo) con los años del ensayo [flechas: años 2012 (rojo); 2013 (verde); 2014 (marrón); 2015 (azul)] conforme a la metodología MCCS (Tonietto \& Carbonneau, 2004).

El año 2012 fue muy seco, desde enero hasta septiembre sólo se recogieron 226,0 mm de precipitación, mientras que en un año medio lo habitual en ese periodo son 324,6 mm. Por este motivo, el año 2012 se realizaron dos riegos de apoyo durante el ciclo vegetativo de la vid (Tabla 16), excepto en la parcela Ricio debido a imposibilidades técnicas.

Tabla 16. Cantidad de agua empleada por parcela durante el año 2012.

\begin{tabular}{|l|r|r|r|r|r|r|}
\hline & SUPERFICIE & \multicolumn{2}{|r|}{ RIEGO ABRIL } & \multicolumn{2}{|c|}{ RIEGO AGOSTO } & TOTAL (mm) \\
\hline CAMPILLO & $26.698 \mathrm{~m} 2$ & $1490 \mathrm{~m} 3$ & $55,81 \mathrm{~mm}$ & $2700 \mathrm{~m} 3$ & $101,13 \mathrm{~mm}$ & 156,94 \\
\hline MAJADAHONDA & $25.550 \mathrm{~m} 2$ & $2100 \mathrm{~m} 3$ & $82,19 \mathrm{~mm}$ & $2240 \mathrm{~m} 3$ & $87,67 \mathrm{~mm}$ & 169,86 \\
\hline NAVAL & $17.355 \mathrm{~m} 2$ & $1110 \mathrm{~m} 3$ & $63,96 \mathrm{~mm}$ & $1600 \mathrm{~m} 3$ & $92,19 \mathrm{~mm}$ & 156,15 \\
\hline RICI0 & $39.723 \mathrm{~m} 2$ & 0 & 0 & 0 & 0 \\
\hline
\end{tabular}

El año 2013, como ya se ha señalado, se caracteriza por ser extraordinariamente húmedo y fresco, lo que se ve reflejado en un retraso en la fecha de vendimia (Tabla 17). Tal y como se observa en la Tabla 13 y atendiendo a los índices bioclimáticos, es el único año (de los cuatro años del ensayo) que se incluiría en la zona II de Winkler (Amerine \&Winkler, 1944) mientras que el resto de los años, así como la serie histórica, se incluyen en la zona III. Respecto al índice de Huglin (Huglin \& Schneider, 1998), el año 2013 se clasificaría como IH-1 (apto para el cultivo de variedades como Cabernet Sauvignon, Merlot, Sangiovese, Chenin Blanc, Riesling y Semillon entre otras), mientras que el resto de los años, incluida la serie histórica, se clasifican como $1 \mathrm{H}+1$ (apto para el cultivo de variedades de ciclo más largo como Mazuelo, Sangiovese y Trebbiano rogmanolo entre otras). 
Tabla 17. Estados fenológicos mayores (Coombe, 1995) para las cuatro parcelas y los cuatro años de estudio.

\begin{tabular}{|c|c|c|c|c|c|c|c|c|c|c|c|}
\hline \multirow[t]{2}{*}{ Año } & \multirow[t]{2}{*}{ Parcela } & \multicolumn{2}{|c|}{ Brotación(4) } & \multicolumn{2}{|c|}{ Floración(23) } & \multicolumn{2}{|c|}{ Cuajado(27) } & \multicolumn{2}{|c|}{ Envero(35) } & \multicolumn{2}{|c|}{ Madurez(38) } \\
\hline & & FECHA & DOY & FECHA & DOY & $\mathrm{FECHA}$ & DOY & FECHA & DOY & FECHA & DOY \\
\hline \multirow{4}{*}{2012} & Campillo & \multirow{4}{*}{ 16-abr } & \multirow{4}{*}{106} & \multirow{4}{*}{ 10-jun } & \multirow{4}{*}{161} & \multirow{4}{*}{ 16-jun } & \multirow{4}{*}{167} & \multirow{4}{*}{ 08-ago } & \multirow{4}{*}{220} & \multirow{4}{*}{ 23-sep } & \multirow{4}{*}{266} \\
\hline & Majadahonda & & & & & & & & & & \\
\hline & Naval & & & & & & & & & & \\
\hline & Ricio & & & & & & & & & & \\
\hline \multirow{4}{*}{2013} & Campillo & \multirow{4}{*}{ 20-abr } & \multirow{4}{*}{110} & 22-jun & 173 & 30-jun & 181 & \multirow{4}{*}{ 26-ago } & \multirow{4}{*}{238} & \multirow{4}{*}{ 06-oct } & \multirow{4}{*}{280} \\
\hline & Majadahonda & & & 23-jun & 174 & 01-jul & 182 & & & & \\
\hline & Naval & & & 21-jun & 172 & 29-jun & 180 & & & & \\
\hline & Ricio & & & 21-jun & 172 & 29-jun & 180 & & & & \\
\hline \multirow{4}{*}{2014} & Campillo & 10-abr & 100 & 08-jun & 159 & \multirow{4}{*}{ 15-jun } & \multirow{4}{*}{166} & \multirow{4}{*}{ 14-ago } & \multirow{4}{*}{226} & \multirow{4}{*}{ 28-sep } & \multirow{4}{*}{271} \\
\hline & Majadahonda & 07-abr & 97 & 08-jun & 159 & & & & & & \\
\hline & Naval & 07-abr & 97 & 08-jun & 159 & & & & & & \\
\hline & Ricio & 12-abr & 102 & 10-jun & 161 & & & & & & \\
\hline \multirow{4}{*}{2015} & Campillo & 10-abr & 100 & 04-jun & 155 & \multirow{4}{*}{ 11-jun } & & & & & \\
\hline & Majadahonda & 10-abr & 100 & 02-jun & 153 & & & & & & \\
\hline & Naval & 12-abr & 102 & 02-jun & 153 & & & & & & \\
\hline & Ricio & $12-a b r$ & 102 & 04-jun & 155 & & & & & & \\
\hline
\end{tabular}

En el año 2014 después de floración y cuajado, a mediados de junio, se registran bajas temperaturas y Iluvias o tormentas hasta antes del envero, a mediados de agosto. El mes de septiembre fue 1,70 $\mathrm{C}$ más cálido que la media histórica.

Respecto a 2015, este año se caracterizó por una primavera ligeramente más lluviosa de lo normal y por un mayor número e intensidad de precipitaciones en el periodo floración-envero, con respecto a la serie histórica. El mes de julio fue especialmente cálido y en septiembre se registró una temperatura media mensual $1,8^{\circ} \mathrm{C}$ inferior a la serie histórica. 
Tabla 18. Días transcurridos entre algunos de los estados fenológicos mayores. DS: Desviación Estándar.

\begin{tabular}{|l|r|r|r|r|r|}
\hline & 2012 & 2103 & 2014 & 2015 & MEDIA 12-15 \\
\hline Brotación-Floración & 55 & 63 & 59 & 52 & $57(\mathrm{DS}=4,1)$ \\
\hline Brotación-Madurez & 160 & 170 & 171 & 162 & $166(\mathrm{DS}=4,6)$ \\
\hline Floración-Madurez & 105 & 107 & 111 & 109 & $108(\mathrm{DS}=2,4)$ \\
\hline Envero-Madurez & 46 & 42 & 45 & 48 & $45(\mathrm{DS}=2,2)$ \\
\hline
\end{tabular}

En la Tabla 18 se puede observar que el periodo transcurrido entre algunos de los estados fenológicos mayores se mantiene más o menos constante durante los años de estudio, a pesar de encontrarnos frente a algunos años climatológicamente muy diferentes, como es el caso del año 2013. Por ejemplo, el periodo entre la floración y la vendimia es de 108 días de media con una desviación estándar de sólo 2,4 para el periodo estudiado, lo que permitirá conocer la fecha aproximada de vendimia en el momento de la floración (mes de junio en un año normal).

\subsection{GEOLOGÍA Y GEOMORFOLOGÍA}

Las parcelas objeto de estudio se sitúan en la zona suroccidental de la hoja geológica 171 (Viana) (IGME, 1987) y en la zona noroccidental de la hoja geológica 204 (Logroño) (IGME, 1976) del Mapa Geológico de España, escala 1:50.000. El conjunto queda delimitado por la parte oriental de la Sierra de Cantabria al Norte y por la Depresión del Ebro al Sur, con una topografía suave que se adosa a los relieves norteños y cae con pendiente generalizada hacia el Sur.

Las unidades litológicas sobre las que se encuentran los viñedos del presente estudio son (IGME, 1987):

a) Facies de Haro. Areniscas ocres en paleocanales y arcillas. TERCIARIO. Mioceno medio-superior.

Está formado por una alternancia de areniscas más o menos limolíticas, areniscas de grano medio y arcillas y limos de tonos ocres y amarillentos muy característicos.

Las areniscas tienen, en líneas generales, un $25 \%$ de cuarzo, 5-10 \% de feldespato potásico, 40-45 \% de fragmentos de rocas carbonatadas y cemento calcáreo o ferruginoso. Son subangulosas a subredondedas y de grano medio a fino. Aparecen rellenando paleocanales con estratificación cruzada, base erosiva clara y extensión lateral generalmente reducida.

b) Gravas, arenas y arcillas. Aluvial y fondo de valle. CUATERNARIO. Holoceno.

Asociados a los cauces de la mayoría de los ríos y arroyos. Depósitos, generalmente poco potentes, pero que pueden alcanzar notable extensión superficial constituidos por gravas, arenas, limos y arcillas.

En estudios posteriores más detallados (Gómez-Miguel \& Sotés, 1990-2017; Fernández, 1999), se ha clasificado la región según sus formaciones geológicas, delimitando las zonas fluviales asociadas a estas formaciones. 


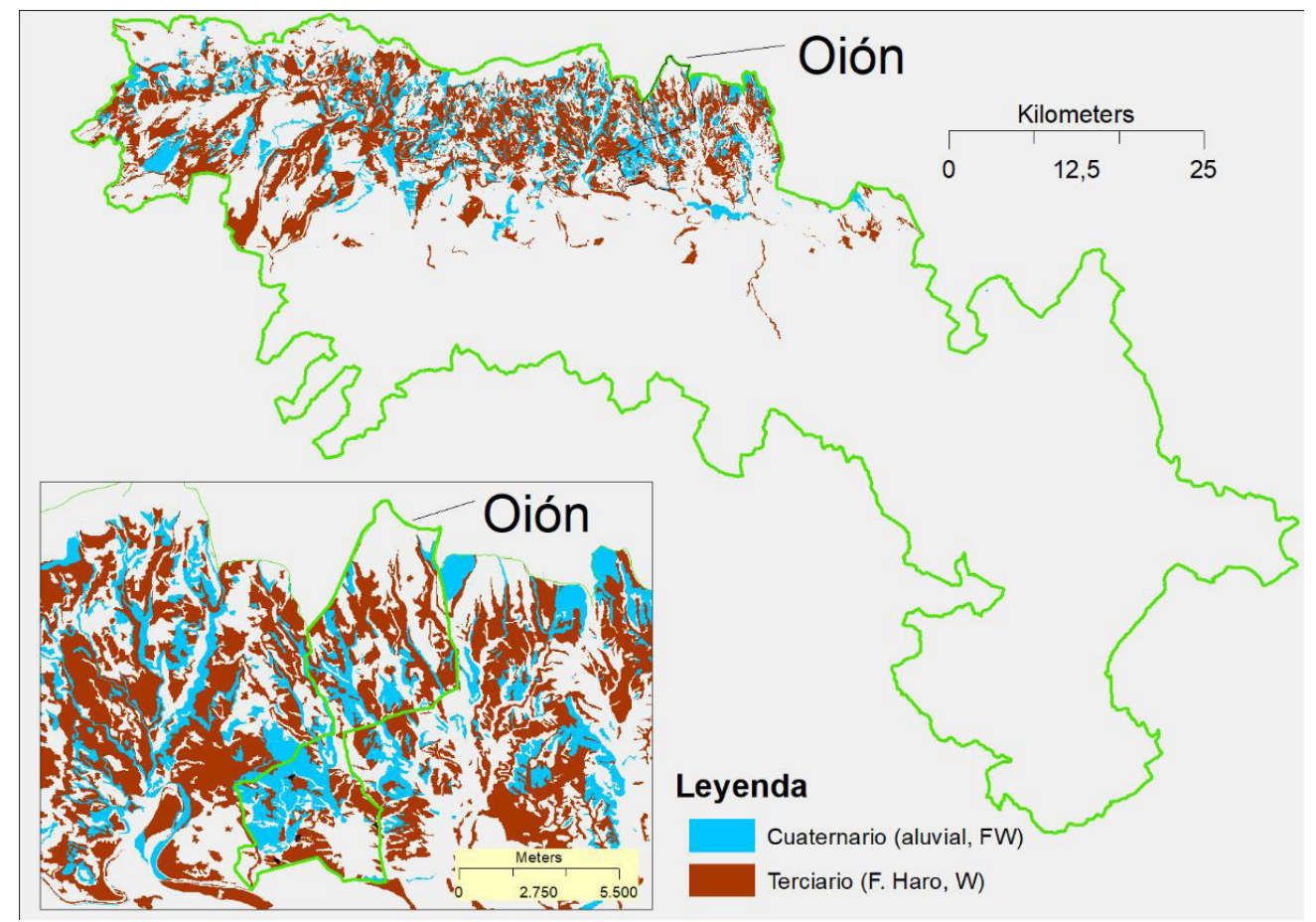

Figura 28. Distribución espacial de la formación F. de Haro (W) del Terciario y las formaciones aluviales del cuaternario asociadas a ella (FW) en la DOCa Rioja. Elaboración propia a partir de Gómez-Miguel y Sotés, 1990-2017.

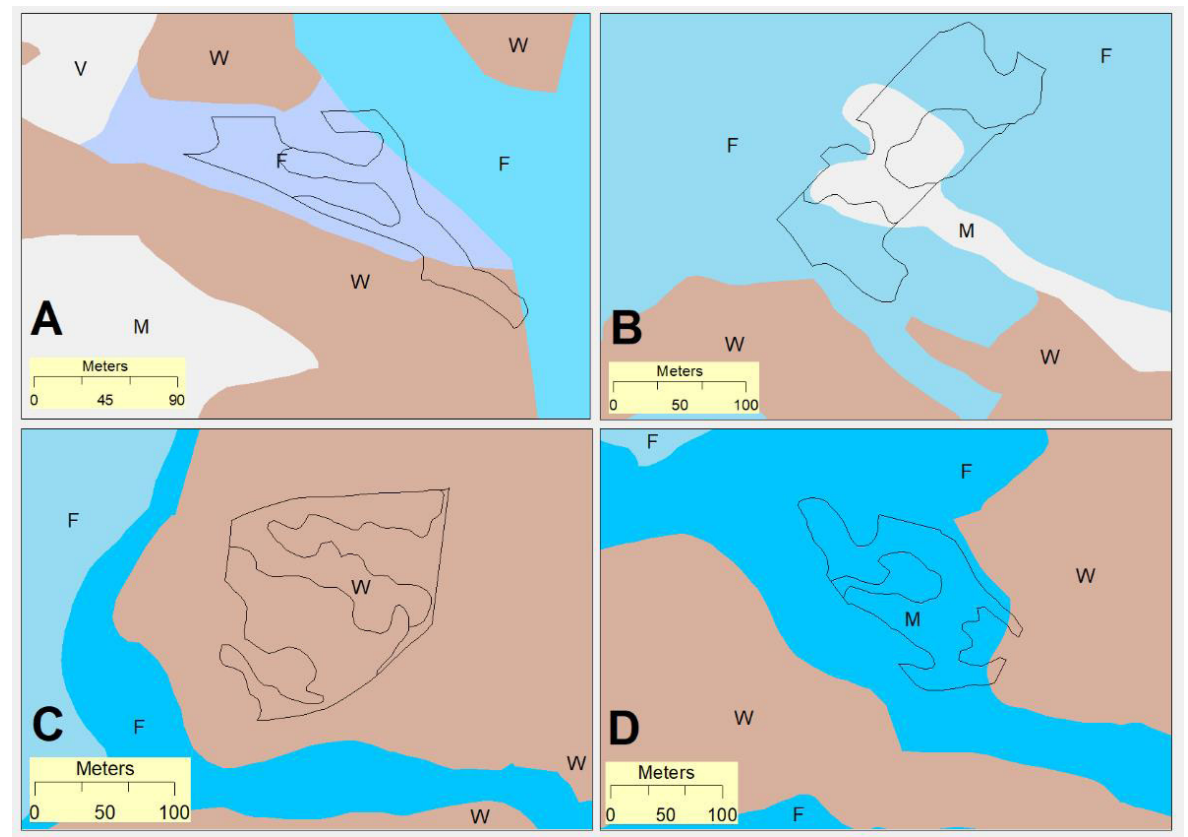

Figura 29. Detalle de la formación Facies de Haro en las parcelas del ensayo (A. NAVAL; B. RICIO; C. CAMPILLO; D. MAJADAHONDA). y su relación con los sectores realizados en el § 5.1. La falta de ajuste de los límites se debe a la gran diferencia entre las escalas de trabajo (1:2.500 versus 1:50.000). 
En la Figura 28 se aprecia la gran extensión de la F. de Haro y los materiales cuaternarios relacionados en la DOCa Rioja lo que permite prever la importancia de la generalización de los resultados. En el detalle (Figura 29) se aprecia como todas las parcelas del ensayo se sitúan sobre la formación Facies de Haro o materiales relacionados aunque de forma irregular: en el caso de las fincas Majadahonda y Campillo sobre la formación de origen terciario y Ricio y Naval sobre la formación de origen terciario y cuaternario asociado.

En la Figura 30 se ha representado gráficamente la topografía de las cuatro parcelas. Atendiendo al mesoclima, aunque no se han podido tomar medidas en cada sector, es sabido que las zonas bajas de los viñedos, como la vaguada de la parcela Ricio, registran temperaturas más bajas que las zonas altas de las parcelas (Cortiula et al., 2018). De forma análoga, respecto a la topografía y la edafología, la vaguada de Ricio se corresponde con una zona de recogida de agua y con un suelo de vega, con deposición de material, que aportará unas características particulares al viñedo, tal y como se verá en el próximo apartado.

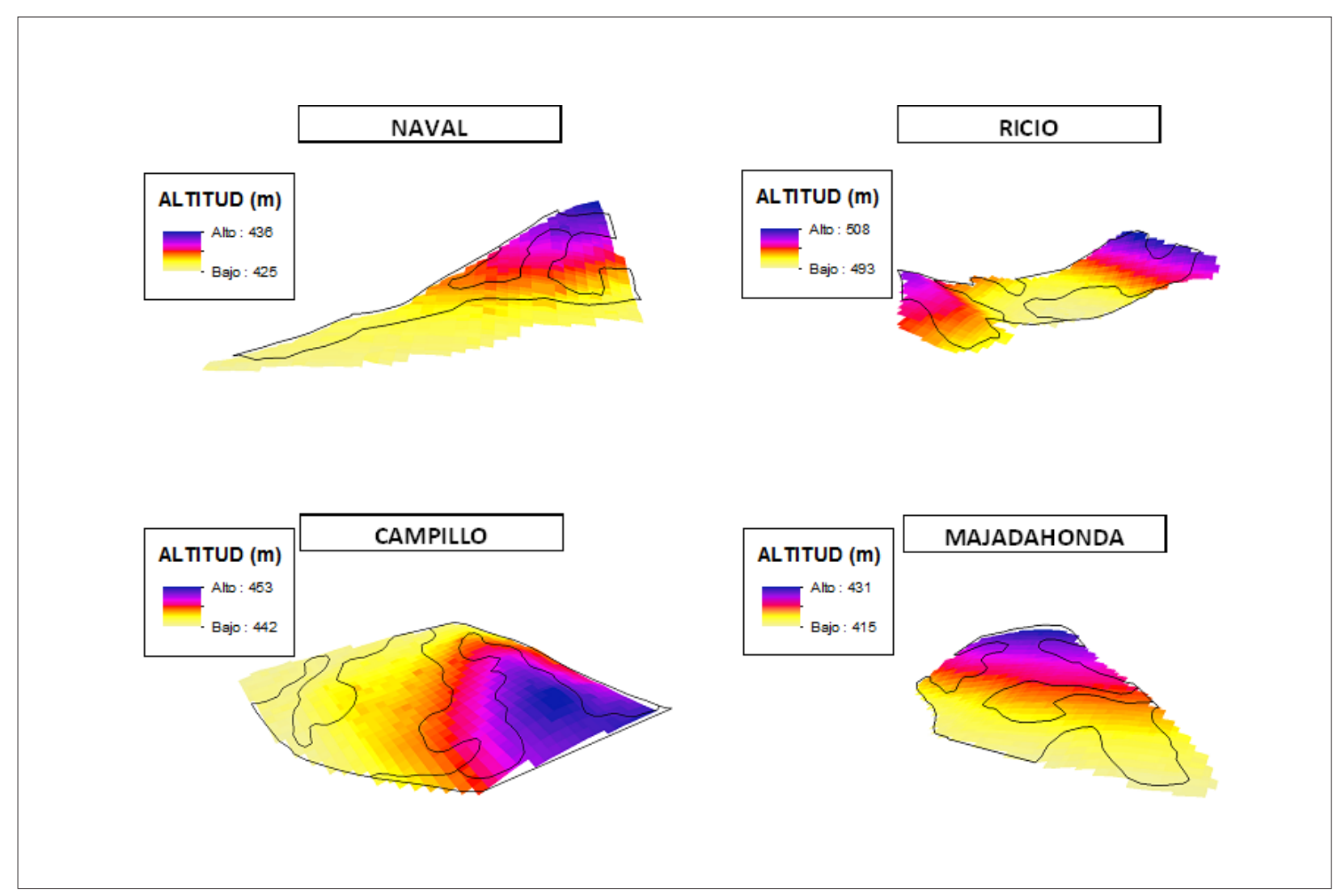

Figura 30. Representación gráfica 3D (a partir de MDT de 5m de resolución) junto con la FIA cartografiada sobre las parcelas de ensayo. 


\subsection{SUELOS}

En las regiones vitícolas españolas citadas en el § 3.3.4 y que han sido estudiadas por el equipo de la UPM se ha encontrado una diversidad de suelos relativamente importante. A nivel de Gran Grupo, en cuatro de ellos (Calcixerept, 29,3 \%; Xerorthent, 17,3 \%; Haploxerept, 14,5 \%; Haploxeralf, 12,9\%) hay tres cuartas partes del viñedo del país y, si se incluyen los seis siguientes en importancia (Haplocalcid, 6,1 \%; Torriorthent, 3,9\%; Xerofluvent, 3,4 \%; Rhodoxeralf, 2,9\%; Haploxerept, 1,34\%; Haplargid, 1,25 \%), este porcentaje llega hasta 92,89\%; los 51 grupos restantes sólo tienen el 6,57 \% (Gómez-Miguel et al., 2016).

En el § 4.3 se han incluido brevemente las características técnicas del mapa de suelos de la DOCa Rioja utilizado en su zonificación y previamente citado (Gómez-Miguel \& Sotés, 1990-2017). Utilizando la versión de Soil Taxonomy de 1975 se han definido, cartografiado y cuantificado 85 STU (41 series, 42 familias y 2 grupos cognados) en tres regímenes de humedad (arídico, xérico y áquico).

En el Término Municipal de Oyón aparecen representadas 26 SMU de las 81 que componen el mapa de suelos de la DOCa Rioja (Figura 16) y en la Tabla 5 se incluye su contenido en términos de STU junto con su agrupación litológica, su clase (vocación vitícola) y el porcentaje de ocupación (PC), el índice de calidad (ICA) y la clasificación (subgrupo, USDA, 1975) de las STU principal y secundaria en el propio Término Municipal.

Una de las características más importantes es que se trata de un mapa de gestión y en él las SMU son politáxicas como se aprecia al definir su contenido en STU en la propia Tabla 5. A este respecto y como se ha dicho (§ 2), uno de los objetivos de la tesis es la optimización del uso de este tipo de mapas de gestión con el menor coste posible.

Tabla 19. Densidad de observaciones consideradas por diferentes metodologías (obs/cm2 de mapa), el número de observaciones por ha para un mapa a escala 1:2.500 y las observaciones necesarias para las parcelas del ensayo. El porcentaje de ahorro en el ensayo es proporcional al número de observaciones.

\begin{tabular}{|c|c|c|c|c|}
\hline \multirow[b]{2}{*}{ PARCELAS DEL ENSAYO } & \multirow[b]{2}{*}{ SUPERFICIE (ha) } & \multicolumn{3}{|c|}{ Densidad de observaciones (observaciones totales a Escala 1:2.500) } \\
\hline & & $\begin{array}{r}1 \text { obs } / \mathrm{cm} 2 \text { de mapa }<> \\
16 \text { obs/ha (OlV) }\end{array}$ & $\begin{array}{r}2 \text { obs } / \mathrm{cm} 2 \text { de mapa }<> \\
32 \text { obs/ha (ORSTOM) }\end{array}$ & $\begin{array}{r}4 \text { obs/cm2 de mapa }<> \\
64 \text { obs/ha (Vink) }\end{array}$ \\
\hline NAVAL & 1,3857 & 22 & 44 & 89 \\
\hline RiClO & 1,9989 & 32 & 64 & 128 \\
\hline CAMPILLO & 2,1696 & 35 & 69 & 139 \\
\hline MAJADAHONDA & 1,9712 & 32 & 63 & 126 \\
\hline TOTALES (obs/ha) & 7,5256 & 120 & 241 & 482 \\
\hline \multicolumn{2}{|c|}{ \% sobre el ensayo (20 obs) } & 16,67 & 8,3 & 4,15 \\
\hline \multicolumn{2}{|c|}{$\%$ ahorro en el ensayo ( 20 obs) } & 83,33 & 91,7 & 95,85 \\
\hline
\end{tabular}


Existen varias formas de utilización de estos mapas (Gómez-Miguel et al., 2019). El más obvio y de mejores resultados es la ampliación de la escala hasta la situación requerida. Sin embargo, esta ampliación de escala deberá ser hecha con un muestreo suficientemente denso como para conseguir la predictibilidad adecuada al objeto del trabajo y demasiadas veces el coste de este muestreo es prohibitivo. En la Tabla 19 se incluye el resultado del cálculo para algunas densidades de observaciones sugeridas por diferentes metodologías. En el caso de menor densidad, el recomendado por la OIV (2012), supondría un coste del 83,33 $\%$ superior al del ensayo.

\subsubsection{Edafoclima}

En general, la temperatura óptima de crecimiento de las raíces de la vid es de $25^{\circ} \mathrm{C}$ mientras que tal crecimiento es débil por debajo de $10^{\circ} \mathrm{C}$ y por encima de $35^{\circ} \mathrm{C}$. El régimen de temperatura del suelo es esencialmente distinto al del medio exterior lo que justifica que la actividad del sistema radicular comience con anterioridad (lloro) y finalice con posterioridad a la parte aérea.

En la temperatura del suelo influyen diversos factores como el color, el calor específico de los materiales que lo constituyen o la topografía del relieve. Evidentemente, los constituyentes del suelo que más influyen en su temperatura (debido al calor específico) son el agua, la materia orgánica y la cobertura de vegetación superficial así como los elementos gruesos.

La humedad del suelo puede ser considerada como el resultado del balance entre aportes (lluvia, hidrología subterránea y riego) y pérdidas (escorrentía, evapotranspiración...), actuando el suelo como un agente regulador a través de sus propiedades (textura, estructura, porosidad, profundidad...) cuya importancia en el cultivo del viñedo, como se verá más adelante, es decisiva en años en los que existe escasez en la disponibilidad hídrica durante estados fenológicos determinados.

La variación de agua disponible en el suelo se debe principalmente a estos factores: la reserva de agua del suelo, la precipitación efectiva y la evapotranspiración, excluyendo los factores de manejo como el riego, la escorrentía y el lavado lateral (seepage). Esta disponibilidad se valora a partir del balance hídrico del suelo.

La reserva de agua varía considerablemente de unos perfiles a otros, desde 54,8 mm (N2B) hasta 195,5 mm (R2B). Los perfiles con mayor capacidad de retención de agua han sido los de cierto carácter fluvéntico (como C3B o R2B) así como los que tienen un suelo enterrado (por ejemplo, M1A), ver Tablas 20, 21, 22 y 23 y Figuras 31-39.

Este resultado sugiere que, al mantenerse o incluso elevarse los niveles de $\mathrm{MO}$ en profundidad se ve mejorada la capacidad de retención de agua del suelo.

En las Figuras 32-39 y en las Tablas 20-23 se incluyen las reservas mensuales y anuales de cada uno de los perfiles durante el período del ensayo. En concreto, en función de las constantes de humedad del suelo se obtiene su reserva máxima y su balance hídrico. De estos resultados se pueden extraer las siguientes conclusiones: 


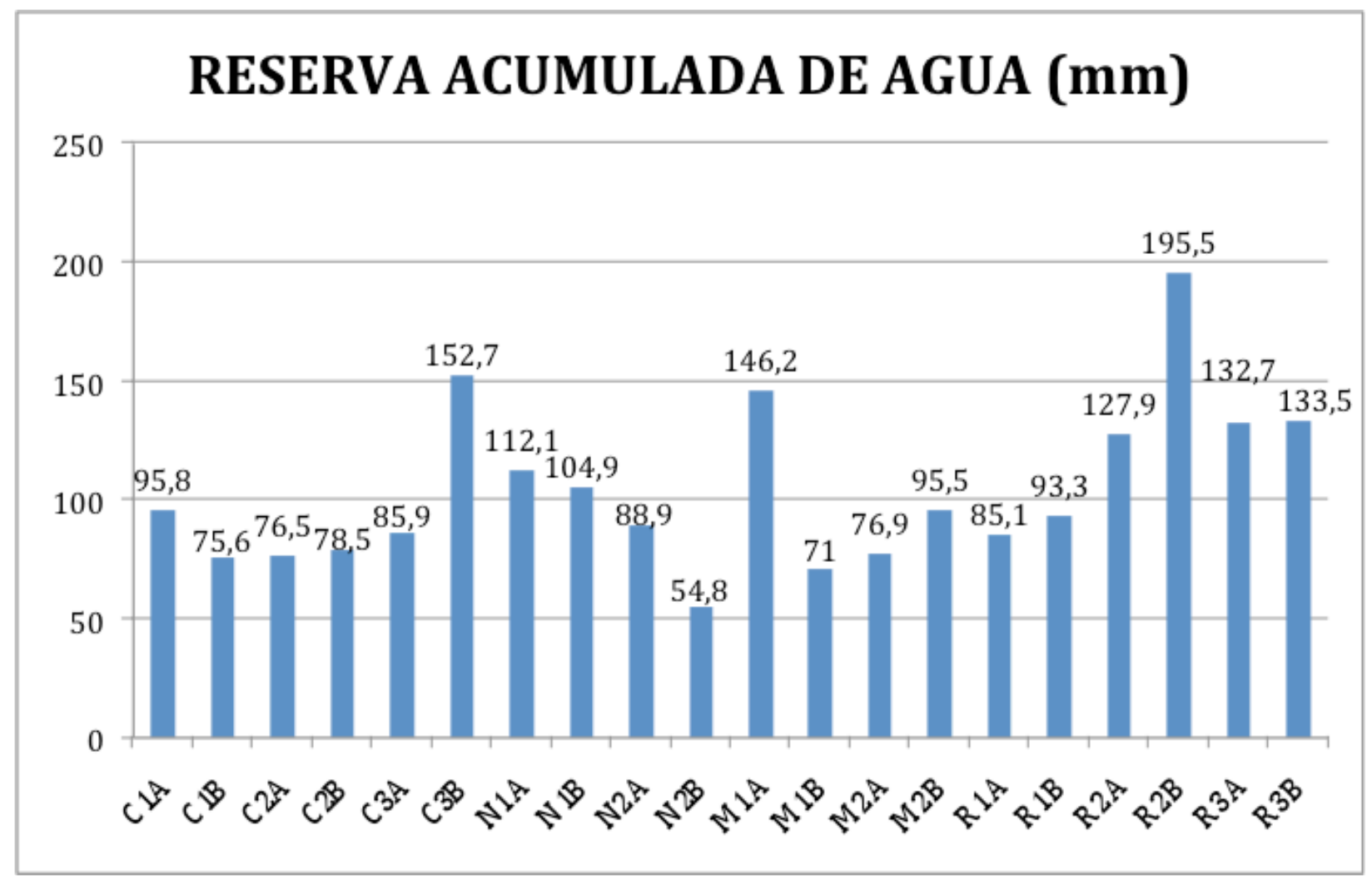

Figura 31. Reserva acumulada de agua $(\mathrm{mm})$ calculada de los 20 perfiles estudiados.

Año 2012. Este año la precipitación anual es de 422 mm y la ETP de 754,2 mm. Todo el mes de octubre empieza con una reserva acumulada relativamente elevada, alrededor de $50 \mathrm{~mm}$, redundando positivamente en la vendimia del año siguiente:

- En las unidades con reservas del suelo cercanas a $50 \mathrm{~mm}$ la reserva anual se termina en abril y la falta de agua se mantiene durante los cinco meses siguientes.

- En las unidades con reservas del suelo próximas a $75 \mathrm{~mm}$ (la más frecuente) la reserva anual se alarga hasta mediados de mayo y la falta se acorta casi medio mes.

- En las unidades con reservas del suelo superiores a $100 \mathrm{~mm}$ la humedad se mantiene mayo con una reserva importante y la falta se mantiene aproximadamente durante cuatro meses.

Año 2013. Este año la precipitación anual es de 714,7 mm y la ETP de 720,5 mm, y la reserva se comienza a acumular a partir de mediados de noviembre. El hecho de que la reserva venga elevada del año 2012 y que gran parte de la precipitación tenga lugar en el primer trimestre del año provocan unas reservas elevadas y una disponibilidad abundante durante el ciclo vegetativo:

- En las unidades con reservas del suelo cercanas a $50 \mathrm{~mm}$ la reserva anual distribuye con máximos entre diciembre y abril-mayo y la falta de agua permanece, al menos, desde primeros de junio hasta mediados de noviembre. 
- En las unidades con reservas del suelo próximas a 75 mm (la más frecuente) la reserva es superior y llega hasta finales de junio.

- En las unidades con reservas del suelo superiores a $100 \mathrm{~mm}$ la reserva llega hasta mediados de julio.

- Año 2014. Este año la precipitación anual es de 542,4 mm y la ETP de 798,2 mm. Todo el mes de noviembre empieza con una reserva acumulada relativamente elevada, alrededor de $70 \mathrm{~mm}$, lo que influirá en la cosecha del año siguiente:

- En las unidades con reservas del suelo cercanas a $50 \mathrm{~mm}$ la reserva anual se termina prácticamente a mediados de abril y la falta de agua se mantiene durante los seis meses siguientes.

- En las unidades con reservas del suelo próximas a $75 \mathrm{~mm}$ (la más frecuente) la reserva anual se alarga hasta mediados de mayo y la falta se acorta casi medio mes.

- En las unidades con reservas del suelo superiores a $100 \mathrm{~mm}$ la humedad hasta mediados de junio y la falta solo dura aproximadamente cuatro meses. 
Figura 32. Representación gráfica de la reserva de agua del suelo $(\mathrm{mm})$ durante el año 2012 en los diferentes perfiles del ensayo.

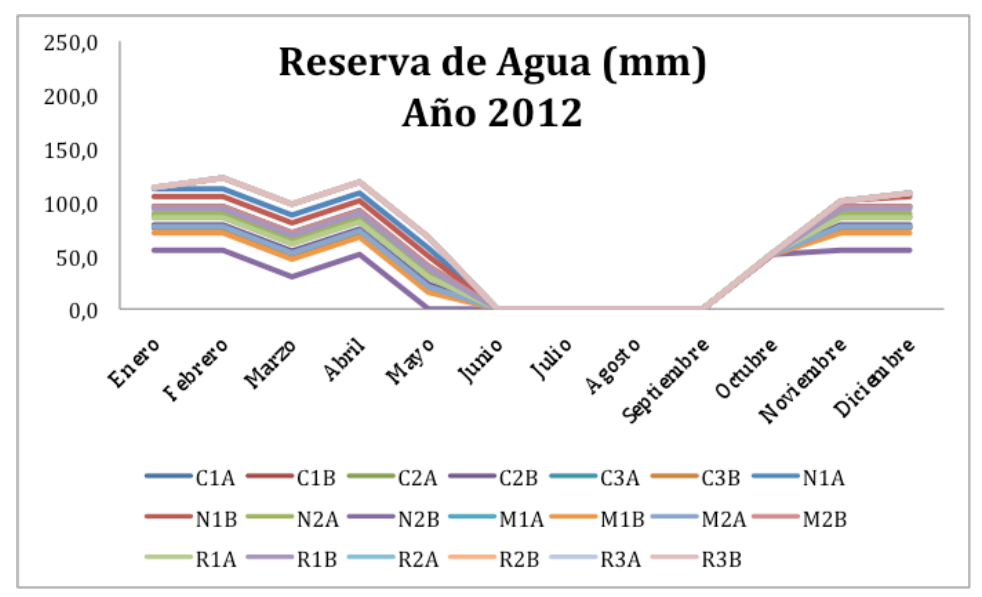

Tabla 20. Reserva de agua (mm) mensual y anual del suelo durante el año 2012 en los diferentes perfiles del ensayo.

\begin{tabular}{|c|c|c|c|c|c|c|c|c|c|c|c|c|c|}
\hline 2012 & Ene & Feb & Mar & $\mathrm{Abr}$ & May & Jun & Jul & Ago & Sep & Oct & Nov & Dic & AÑO \\
\hline$R=95,8(C 1 A)$ & 95,8 & 95,8 & 71,2 & 92,5 & 40,8 & 0 & 0 & 0 & 0 & 51 & 95,8 & 95,8 & 638,7 \\
\hline $\mathrm{R}=76,6(\mathrm{C} 1 \mathrm{~B})$ & 76,6 & 76,6 & 52 & 73,3 & 21,6 & 0 & 0 & 0 & 0 & 51 & 76,6 & 76,6 & 504,3 \\
\hline$R=76,5(C 2 A)$ & 76,5 & 76,5 & 51,9 & 73,2 & 21,5 & 0 & 0 & 0 & 0 & 51 & 76,5 & 76,5 & 503,6 \\
\hline$R=78,5(C 2 B)$ & 78,5 & 78,5 & 53,9 & 75,2 & 23,5 & 0 & 0 & 0 & 0 & 51 & 78,5 & 78,5 & 517,6 \\
\hline$R=85,9(C 3 A)$ & 85,9 & 85,9 & 61,3 & 82,6 & 30,9 & 0 & 0 & 0 & 0 & 51 & 85,9 & 85,9 & 569,4 \\
\hline$R=152,7(C 3 B)$ & 114 & 122 & 97,7 & 119 & 67,3 & 0 & 0 & 0 & 0 & 51 & 100,5 & 107,7 & 779,3 \\
\hline $\mathrm{R}=112,1$ (N1A) & 112 & 112 & 87,5 & 109 & 57,1 & 0 & 0 & 0 & 0 & 51 & 100,5 & 107,7 & 736,8 \\
\hline $\mathrm{R}=104,9$ (N1B) & 105 & 105 & 80,3 & 102 & 49,9 & 0 & 0 & 0 & 0 & 51 & 100,5 & 104,9 & 698 \\
\hline$R=88,9(N 2 A)$ & 88,9 & 88,9 & 64,3 & 85,6 & 33,9 & 0 & 0 & 0 & 0 & 51 & 88,9 & 88,9 & 590,4 \\
\hline $\mathrm{R}=54,8$ (N2B) & 54,8 & 54,8 & 30,2 & 51,5 & 0 & 0 & 0 & 0 & 0 & 51 & 54,8 & 54,8 & 351,9 \\
\hline$R=146,2(M 1 A)$ & 114 & 122 & 97,7 & 119 & 67,3 & 0 & 0 & 0 & 0 & 51 & 100,5 & 107,7 & 779,3 \\
\hline $\mathrm{R}=71,0$ (M1B) & 71 & 71 & 46,4 & 67,7 & 16 & 0 & 0 & 0 & 0 & 51 & 71 & 71 & 465,1 \\
\hline$R=76,9(M 2 A)$ & 76,9 & 76,9 & 52,3 & 73,6 & 21,9 & 0 & 0 & 0 & 0 & 51 & 76,9 & 76,9 & 506,4 \\
\hline$R=95,5$ (M2B) & 95,5 & 95,5 & 70,9 & 92,2 & 40,5 & 0 & 0 & 0 & 0 & 51 & 95,5 & 95,5 & 636,6 \\
\hline$R=85,1(R 1 A)$ & 85,1 & 85,1 & 60,5 & 81,8 & 30,1 & 0 & 0 & 0 & 0 & 51 & 85,1 & 85,1 & 563,8 \\
\hline $\mathrm{R}=93,3$ (R1B) & 93,3 & 93,3 & 68,7 & 90 & 38,3 & 0 & 0 & 0 & 0 & 51 & 93,3 & 93,3 & 621,2 \\
\hline$R=127,9(R 2 A)$ & 114 & 122 & 97,7 & 119 & 67,3 & 0 & 0 & 0 & 0 & 51 & 100,5 & 107,7 & 779,3 \\
\hline$R=195,5(R 2 B)$ & 114 & 122 & 97,7 & 119 & 67,3 & 0 & 0 & 0 & 0 & 51 & 100,5 & 107,7 & 779,3 \\
\hline$R=132,7(R 3 A)$ & 114 & 122 & 97,7 & 119 & 67,3 & 0 & 0 & 0 & 0 & 51 & 100,5 & 107,7 & 779,3 \\
\hline$R=133,5$ (R3B) & 114 & 122 & 97,7 & 119 & 67,3 & 0 & 0 & 0 & 0 & 51 & 100,5 & 107,7 & 779,3 \\
\hline$\sum(\mathrm{P}-\mathrm{ETP})$ & 6,1 & 14,6 & -10 & 11,3 & -40 & -137 & -253 & -386 & -440 & -389 & -339 & -332 & $-2294,3$ \\
\hline
\end{tabular}


Figura 33. Representación gráfica de la reserva de agua del suelo (mm) durante el año 2013 en los diferentes perfiles del ensayo.

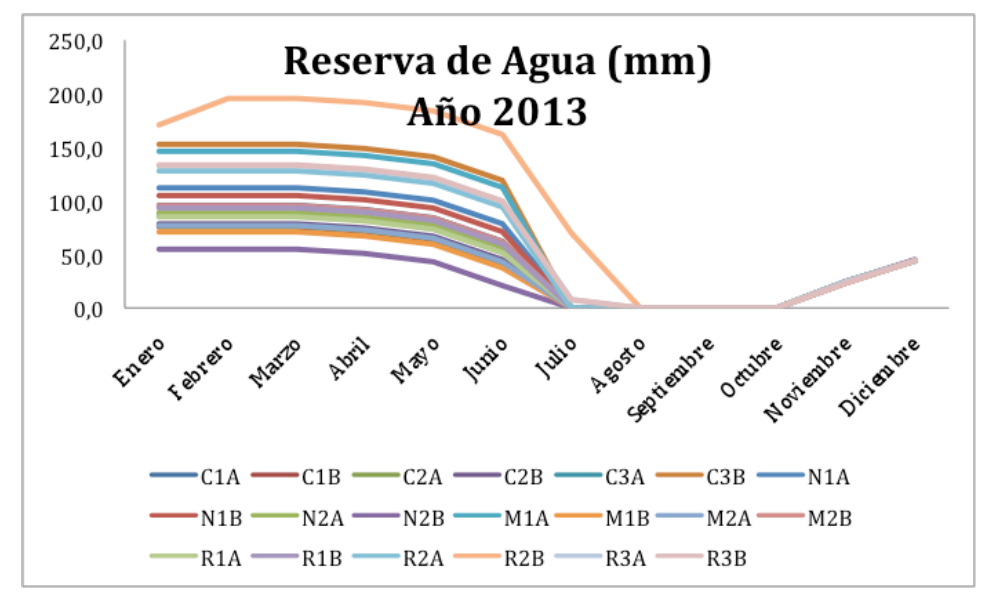

Tabla 21. Reserva de agua (mm) mensual y anual del suelo durante el año 2013 en los diferentes perfiles del ensayo.

\begin{tabular}{|c|c|c|c|c|c|c|c|c|c|c|c|c|c|}
\hline 2013 & Ene & Feb & Mar & Abr & May & Jun & Jul & Ago & Sep & Oct & Nov & Dic & AÑO \\
\hline$R=95,8(C 1 A)$ & 95,8 & 95,8 & 96 & 91,9 & 85 & 62,8 & 0 & 0 & 0 & 0 & 24,4 & 44,4 & 595,4 \\
\hline$R=76,6(C 1 B)$ & 76,6 & 76,6 & 77 & 72,7 & 65 & 43,6 & 0 & 0 & 0 & 0 & 24,4 & 44,4 & 480,2 \\
\hline$R=76,5(C 2 A)$ & 76,5 & 76,5 & 77 & 72,6 & 65 & 43,5 & 0 & 0 & 0 & 0 & 24,4 & 44,4 & 479,6 \\
\hline$R=78,5$ (C2B) & 78,5 & 78,5 & 79 & 74,6 & 67 & 45,5 & 0 & 0 & 0 & 0 & 24,4 & 44,4 & 491,6 \\
\hline$R=85,9(C 3 A)$ & 85,9 & 85,9 & 86 & 82 & 75 & 52,9 & 0 & 0 & 0 & 0 & 24,4 & 44,4 & 536 \\
\hline$R=152,7(C 3 B)$ & 108 & 153 & 153 & 149 & 141 & 120 & 28 & 0 & 0 & 0 & 24,4 & 44,4 & 920,2 \\
\hline $\mathrm{R}=112,1(\mathrm{~N} 1 \mathrm{~A})$ & 108 & 112 & 112 & 108 & 101 & 79,1 & 0 & 0 & 0 & 0 & 24,4 & 44,4 & 689,2 \\
\hline $\mathrm{R}=104,9$ (N1B) & 105 & 105 & 105 & 101 & 94 & 71,9 & 0 & 0 & 0 & 0 & 24,4 & 44,4 & 650 \\
\hline $\mathrm{R}=88,9$ (N2A) & 88,9 & 88,9 & 89 & 85 & 78 & 55,9 & 0 & 0 & 0 & 0 & 24,4 & 44,4 & 554 \\
\hline $\mathrm{R}=54,8$ (N2B) & 54,8 & 54,8 & 55 & 50,9 & 44 & 21,8 & 0 & 0 & 0 & 0 & 24,4 & 44,4 & 349,4 \\
\hline$R=146,2(M 1 A)$ & 108 & 146 & 146 & 142 & 135 & 113 & 21,5 & 0 & 0 & 0 & 24,4 & 44,4 & 881,2 \\
\hline $\mathrm{R}=71,0$ (M1B) & 71 & 71 & 71 & 67,1 & 60 & 38 & 0 & 0 & 0 & 0 & 24,4 & 44,4 & 446,6 \\
\hline$R=76,9(\mathrm{M} 2 \mathrm{~A})$ & 76,9 & 76,9 & 77 & 73 & 66 & 43,9 & 0 & 0 & 0 & 0 & 24,4 & 44,4 & 482 \\
\hline $\mathrm{R}=95,5$ (M2B) & 95,5 & 95,5 & 96 & 91,6 & 84 & 62,5 & 0 & 0 & 0 & 0 & 24,4 & 44,4 & 593,6 \\
\hline$R=85,1(R 1 A)$ & 85,1 & 85,1 & 85 & 81,2 & 74 & 52,1 & 0 & 0 & 0 & 0 & 24,4 & 44,4 & 531,2 \\
\hline$R=93,3$ (R1B) & 93,3 & 93,3 & 93 & 89,4 & 82 & 60,3 & 0 & 0 & 0 & 0 & 24,4 & 44,4 & 580,4 \\
\hline$R=127,9$ (R2A) & 108 & 128 & 128 & 124 & 117 & 94,9 & 3,2 & 0 & 0 & 0 & 24,4 & 44,4 & 771,4 \\
\hline$R=195,5(R 2 B)$ & 108 & 196 & 196 & 192 & 184 & 163 & 70,8 & 0 & 0 & 0 & 24,4 & 44,4 & 1177 \\
\hline$R=132,7(\mathrm{R} 3 \mathrm{~A})$ & 108 & 133 & 133 & 129 & 121 & 99,7 & 8 & 0 & 0 & 0 & 24,4 & 44,4 & 800,2 \\
\hline$R=133,5$ (R3B) & 108 & 134 & 134 & 130 & 122 & 101 & 8,8 & 0 & 0 & 0 & 24,4 & 44,4 & 805 \\
\hline$\sum(\mathrm{P}-\mathrm{ETP})$ & 63,7 & 182 & 280 & 276 & 268 & 247 & 155 & 44 & $-12,8$ & -50 & $-25,8$ & $-5,8$ & 1419,1 \\
\hline
\end{tabular}


Figura 34. Representación gráfica de la reserva de agua del suelo $(\mathrm{mm})$ durante el año 2014 en los diferentes perfiles del ensayo.

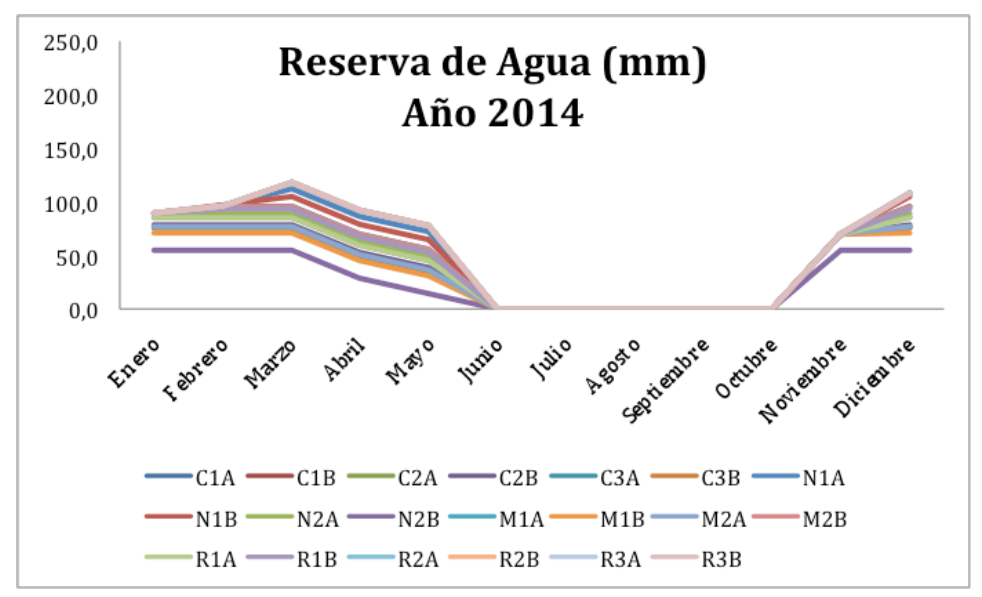

Tabla 22. Reserva de agua (mm) mensual y anual del suelo durante el año 2014 en los diferentes perfiles del ensayo.

\begin{tabular}{|c|c|c|c|c|c|c|c|c|c|c|c|c|c|}
\hline 2014 & Ene & Feb & Mar & $A b r$ & May & Jun & Jul & Ago & Sep & Oct & Nov & Dic & AÑO \\
\hline$R=95,8(C 1 A)$ & 95,8 & 95,8 & 96 & 69,4 & 56 & 0 & 0 & 0 & 0 & 0 & 69,9 & 95,8 & 578,2 \\
\hline$R=76,6(C 1 B)$ & 76,6 & 76,6 & 77 & 50,2 & 37 & 0 & 0 & 0 & 0 & 0 & 69,9 & 76,6 & 463 \\
\hline$R=76,5(C 2 A)$ & 76,5 & 76,5 & 77 & 50,1 & 36 & 0 & 0 & 0 & 0 & 0 & 69,9 & 76,5 & 462,4 \\
\hline$R=78,5(C 2 B)$ & 78,5 & 78,5 & 79 & 52,1 & 38 & 0 & 0 & 0 & 0 & 0 & 69,9 & 78,5 & 474,4 \\
\hline$R=85,9(C 3 A)$ & 85,9 & 85,9 & 86 & 59,5 & 46 & 0 & 0 & 0 & 0 & 0 & 69,9 & 85,9 & 518,8 \\
\hline$R=152,7(C 3 B)$ & 153 & 153 & 153 & 126 & 113 & 26,2 & 0 & 0 & 0 & 0 & 69,9 & 108 & 901,4 \\
\hline$R=112,1(N 1 A)$ & 112 & 112 & 112 & 85,7 & 72 & 0 & 0 & 0 & 0 & 0 & 69,9 & 108 & 672,2 \\
\hline $\mathrm{R}=104,9$ (N1B) & 105 & 105 & 105 & 78,5 & 65 & 0 & 0 & 0 & 0 & 0 & 69,9 & 105 & 632,8 \\
\hline$R=88,9(N 2 A)$ & 88,9 & 88,9 & 89 & 62,5 & 49 & 0 & 0 & 0 & 0 & 0 & 69,9 & 88,9 & 536,8 \\
\hline $\mathrm{R}=54,8$ (N2B) & 54,8 & 54,8 & 55 & 28,4 & 15 & 0 & 0 & 0 & 0 & 0 & 54,8 & 54,8 & 317,1 \\
\hline$R=146,2(M 1 A)$ & 146 & 146 & 146 & 120 & 106 & 19,7 & 0 & 0 & 0 & 0 & 69,9 & 108 & 862,4 \\
\hline $\mathrm{R}=71,0$ (M1B) & 71 & 71 & 71 & 44,6 & 31 & 0 & 0 & 0 & 0 & 0 & 69,9 & 71 & 429,4 \\
\hline$R=76,9(M 2 A)$ & 76,9 & 76,9 & 77 & 50,5 & 37 & 0 & 0 & 0 & 0 & 0 & 69,9 & 76,9 & 464,8 \\
\hline $\mathrm{R}=95,5$ (M2B) & 95,5 & 95,5 & 96 & 69,1 & 55 & 0 & 0 & 0 & 0 & 0 & 69,9 & 95,5 & 576,4 \\
\hline$R=85,1(R 1 A)$ & 85,1 & 85,1 & 85 & 58,7 & 45 & 0 & 0 & 0 & 0 & 0 & 69,9 & 85,1 & 514 \\
\hline$R=93,3$ (R1B) & 93,3 & 93,3 & 93 & 66,9 & 53 & 0 & 0 & 0 & 0 & 0 & 69,9 & 93,3 & 563,2 \\
\hline$R=127,9(R 2 A)$ & 128 & 128 & 128 & 102 & 88 & 1,4 & 0 & 0 & 0 & 0 & 69,9 & 108 & 752,6 \\
\hline$R=195,5(R 2 B)$ & 153 & 161 & 182 & 156 & 142 & 55,6 & 0 & 0 & 0 & 0 & 69,9 & 108 & 1027,4 \\
\hline$R=132,7(R 3 A)$ & 133 & 133 & 133 & 106 & 93 & 6,2 & 0 & 0 & 0 & 0 & 69,9 & 108 & 781,4 \\
\hline$R=133,5$ (R3B) & 134 & 134 & 134 & 107 & 93 & 7 & 0 & 0 & 0 & 0 & 69,9 & 108 & 786,2 \\
\hline$\sum(\mathrm{P}-\mathrm{ETP})$ & 45 & 52,2 & 74 & 47,4 & 34 & $-52,7$ & -126 & -221 & -284 & -316 & -246 & -208 & $-1202,2$ \\
\hline
\end{tabular}


Figura 35. Representación gráfica de la reserva de agua del suelo (mm) durante el año 2015 en los diferentes perfiles del ensayo.

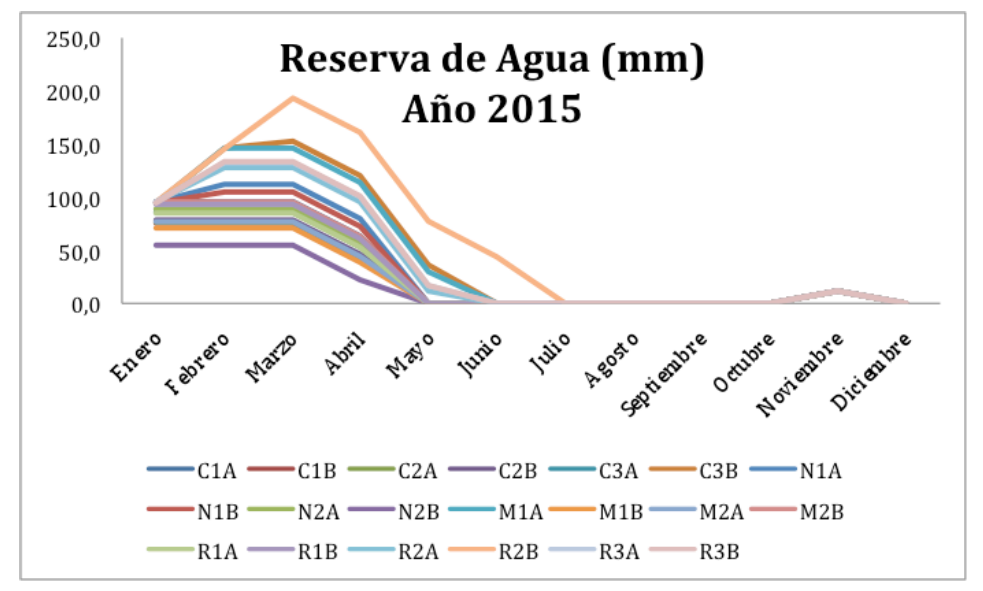

Tabla 23. Reserva de agua (mm) mensual y anual del suelo durante el año 2015 en los diferentes perfiles del ensayo.

\begin{tabular}{|c|c|c|c|c|c|c|c|c|c|c|c|c|c|}
\hline 2015 & Ene & Feb & Mar & $\mathrm{Abr}$ & May & Jun & Jul & Ago & Sep & Oct & Nov & Dic & AÑO \\
\hline$R=95,8(C 1 A)$ & 51 & 95,8 & 96 & 63 & 0 & 0 & 0 & 0 & 0 & 0 & 11,9 & 0,3 & 317,8 \\
\hline$R=76,6(C 1 B)$ & 51 & 76,6 & 77 & 43,8 & 0 & 0 & 0 & 0 & 0 & 0 & 11,9 & 0,3 & 260,2 \\
\hline$R=76,5(C 2 A)$ & 51 & 76,5 & 77 & 43,7 & 0 & 0 & 0 & 0 & 0 & 0 & 11,9 & 0,3 & 259,9 \\
\hline$R=78,5$ (C2B) & 51 & 78,5 & 79 & 45,7 & 0 & 0 & 0 & 0 & 0 & 0 & 11,9 & 0,3 & 265,9 \\
\hline$R=85,9(C 3 A)$ & 51 & 85,9 & 86 & 53,1 & 0 & 0 & 0 & 0 & 0 & 0 & 11,9 & 0,3 & 288,1 \\
\hline $\mathrm{R}=152,7$ (C3B) & 51 & 102 & 149 & 116 & 33 & 0,1 & 0 & 0 & 0 & 0 & 11,9 & 0,3 & 463,2 \\
\hline$R=112,1$ (N1A) & 51 & 102 & 112 & 79,3 & 0 & 0 & 0 & 0 & 0 & 0 & 11,9 & 0,3 & 356,4 \\
\hline $\mathrm{R}=104,9$ (N1B) & 51 & 102 & 105 & 72,1 & 0 & 0 & 0 & 0 & 0 & 0 & 11,9 & 0,3 & 342 \\
\hline$R=88,9(N 2 A)$ & 51 & 88,9 & 89 & 56,1 & 0 & 0 & 0 & 0 & 0 & 0 & 11,9 & 0,3 & 297,1 \\
\hline $\mathrm{R}=54,8$ (N2B) & 51 & 54,8 & 55 & 22 & 0 & 0 & 0 & 0 & 0 & 0 & 11,9 & 0,3 & 194,8 \\
\hline$R=146,2(M 1 A)$ & 51 & 102 & 146 & 113 & 30 & 0 & 0 & 0 & 0 & 0 & 11,9 & 0,3 & 454,4 \\
\hline $\mathrm{R}=71,0$ (M1B) & 51 & 71 & 71 & 38,2 & 0 & 0 & 0 & 0 & 0 & 0 & 11,9 & 0,3 & 243,4 \\
\hline$R=76,9(M 2 A)$ & 51 & 76,9 & 77 & 44,1 & 0 & 0 & 0 & 0 & 0 & 0 & 11,9 & 0,3 & 261,1 \\
\hline $\mathrm{R}=95,5$ (M2B) & 51 & 95,5 & 96 & 62,7 & 0 & 0 & 0 & 0 & 0 & 0 & 11,9 & 0,3 & 316,9 \\
\hline$R=85,1(R 1 A)$ & 51 & 85,1 & 85 & 52,3 & 0 & 0 & 0 & 0 & 0 & 0 & 11,9 & 0,3 & 285,7 \\
\hline$R=93,3$ (R1B) & 51 & 93,3 & 93 & 60,5 & 0 & 0 & 0 & 0 & 0 & 0 & 11,9 & 0,3 & 310,3 \\
\hline$R=127,9$ (R2A) & 51 & 102 & 128 & 95,1 & 12 & 0 & 0 & 0 & 0 & 0 & 11,9 & 0,3 & 399,5 \\
\hline$R=195,5(R 2 B)$ & 51 & 102 & 149 & 116 & 33 & 0,1 & 0 & 0 & 0 & 0 & 11,9 & 0,3 & 463,2 \\
\hline$R=132,7$ (R3A) & 51 & 102 & 133 & 99,9 & 16 & 0 & 0 & 0 & 0 & 0 & 11,9 & 0,3 & 413,9 \\
\hline$R=133,5$ (R3B) & 51 & 102 & 134 & 101 & 17 & 0 & 0 & 0 & 0 & 0 & 11,9 & 0,3 & 416,3 \\
\hline$\sum(\mathrm{P}-\mathrm{ETP})$ & 50,7 & 102 & 149 & 116 & 32 & $-0,2$ & $-83,5$ & -182 & -235 & -255 & -243 & -254 & $-803,4$ \\
\hline
\end{tabular}


Año 2015. Este año la ETP es de 755,2 mm y la precipitación anual es de 508 mm y de una distribución anómala. Los meses de octubre, noviembre y diciembre el suelo está prácticamente seco lo que probablemente tenga una incidencia negativa sobre la brotación del año 2016. La reserva empieza a acumularse con valores de cierta importancia (aproximadamente $50 \mathrm{~mm}$ ) a partir de enero:

- En las unidades con reservas del suelo cercanas a $50 \mathrm{~mm}$ la reserva anual se termina a primeros de abril y la falta de agua se mantiene durante los ocho meses siguientes.

- En las unidades con reservas del suelo próximas a $75 \mathrm{~mm}$ (la más frecuente) la reserva anual se alarga hasta finales de abril y la falta se acorta casi medio mes.

- En las unidades con reservas del suelo superiores a $100 \mathrm{~mm}$ la humedad se mantiene hasta mayo con una reserva importante y la falta se alarga durante siete meses.

Como ya se ha señalado, estas consideraciones se realizan en situaciones sin riego y, por lo tanto, la reserva máxima está definida por el régimen de precipitación, sin embargo, en caso de incluir el riego en el balance se han de considerar las reservas máximas de las diferentes unidades realizadas a partir de las constantes de humedad. Estas reservas son bastante grandes cuando se trata de suelos profundos y arcillosos y muy variables en cada finca y desde luego han de ser utilizadas a la hora de determinar las dosis de riego y la profundidad del bulbo (en caso de riego por goteo).

Desde el punto de vista taxonómico, los suelos de las parcelas del ensayo se sitúan en el régimen de temperatura mésico, lo que en general significa que la temperatura media anual del suelo a $50 \mathrm{~cm}$ es superior a $8^{\circ} \mathrm{C}$ pero inferior a $15^{\circ} \mathrm{C}$ y la diferencia entre las medias de verano e invierno supera los $5^{\circ} \mathrm{C}$. Del mismo modo, el régimen de humedad de los suelos de las parcelas es xérico, lo que supone que el suelo está seco al menos la mitad de los días en los que la temperatura del suelo es superior a 5C, está seco más de 45 días consecutivos durante los cuatro meses siguientes al solsticio de verano y está húmedo más de 45 días consecutivos durante los cuatro meses siguientes al solsticio de invierno. 

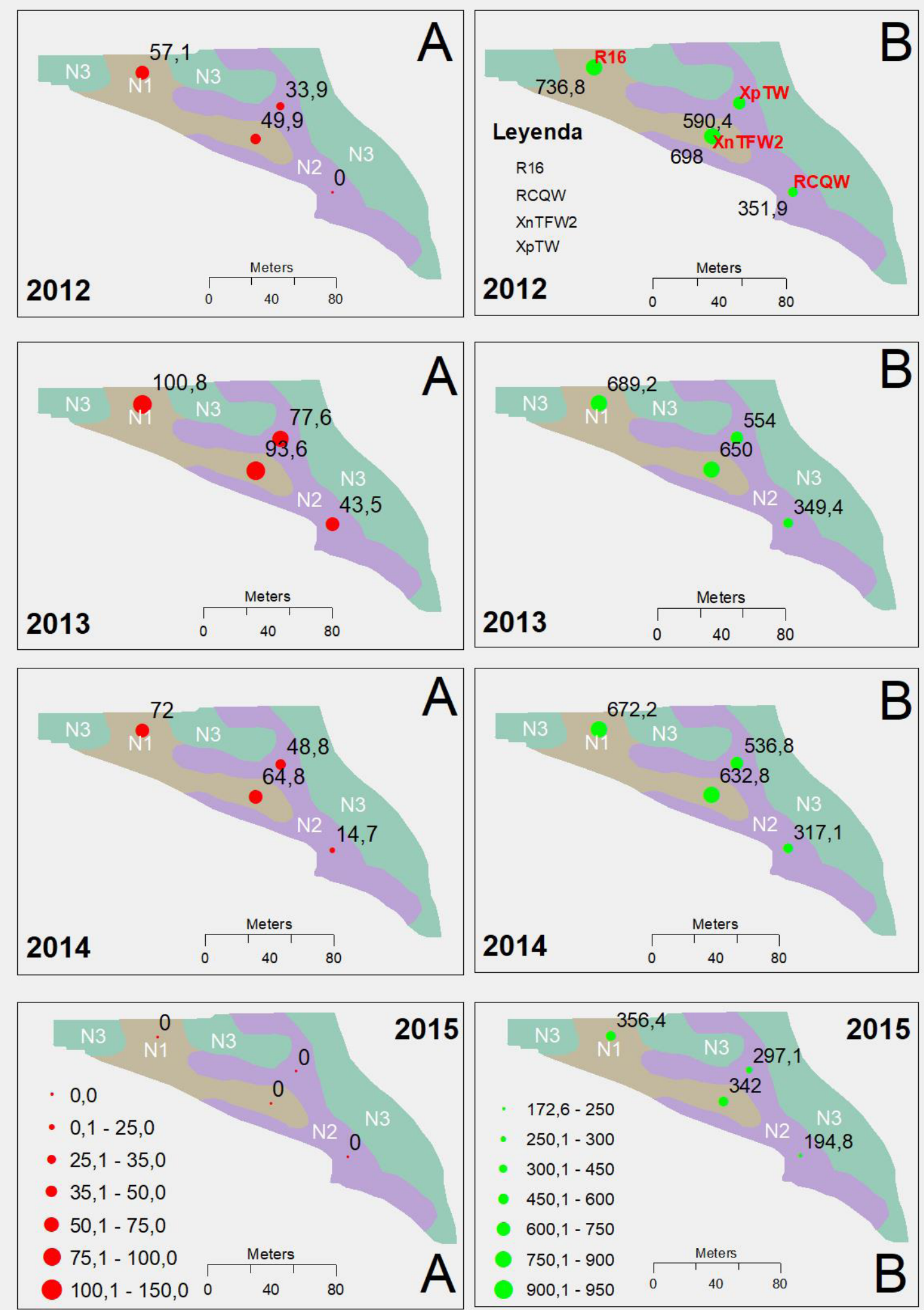

Figura 36. Representación de la reserva de agua $(\mathrm{mm})$ de los diferentes perfiles en la parcela NAVAL para cada uno de los años de ensayo. En la columna A se representa la reserva de agua del suelo del mes de mayo y en la columna B se recoge la reserva anual como suma de las reservas mensuales, aunque no es un valor físicamente justificable, si es un buen indicativo del agua disponible para el cultivo. En la figura 2012B también se incluye el símbolo de la STU del mapa de la DOCa Rioja (ver Tabla 25). 

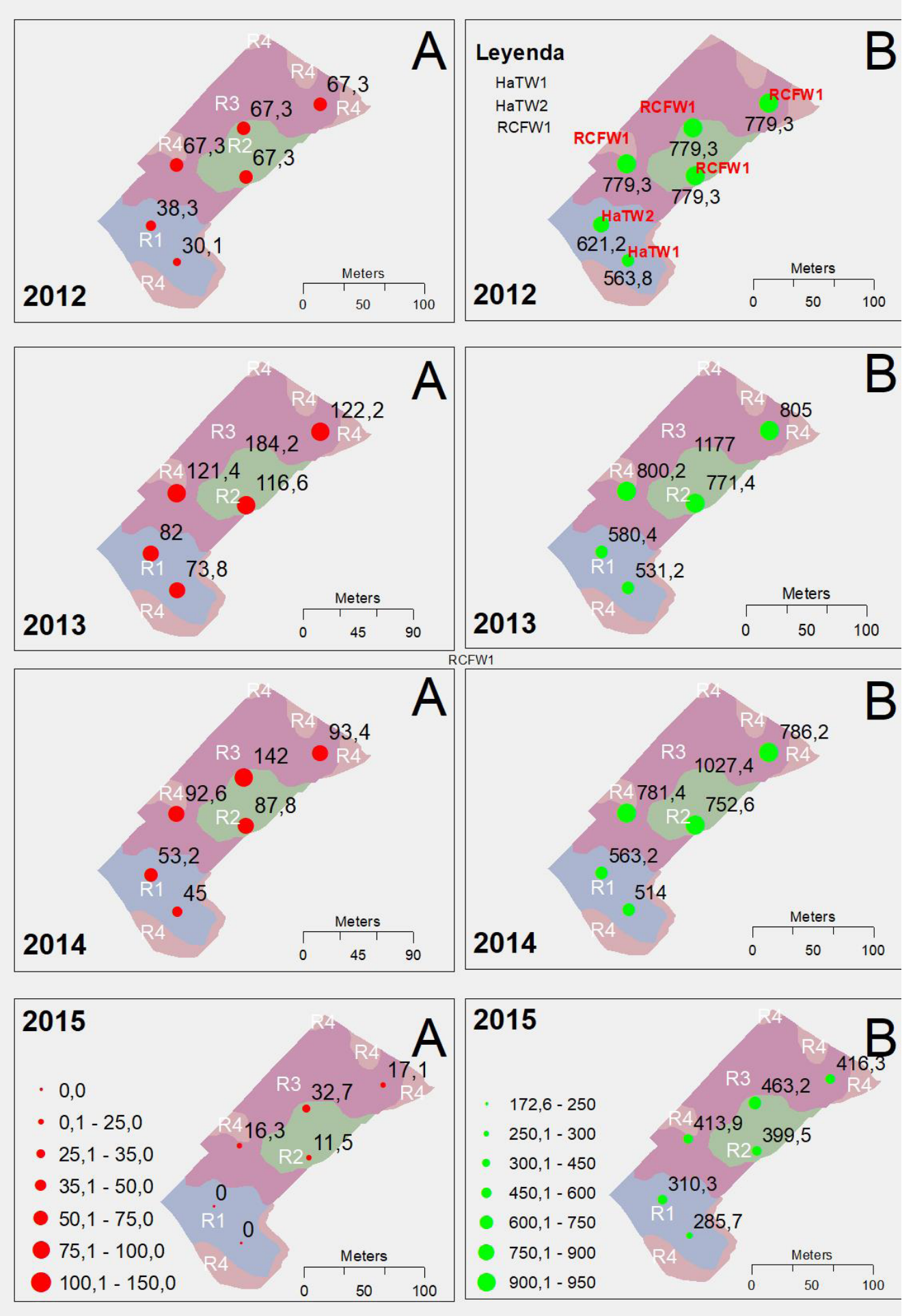

Figura 37. Representación de la reserva de agua $(\mathrm{mm})$ de los diferentes perfiles en la parcela RICIO para cada uno de los años de ensayo. En la columna A se representa la reserva de agua del suelo del mes de mayo y en la columna B se recoge la reserva anual como suma de las reservas mensuales, aunque no es un valor físicamente justificable, si es un buen indicativo del agua disponible para el cultivo. En la figura 2012B también se incluye el símbolo de la STU del mapa de la DOCa Rioja (ver Tabla 25). 

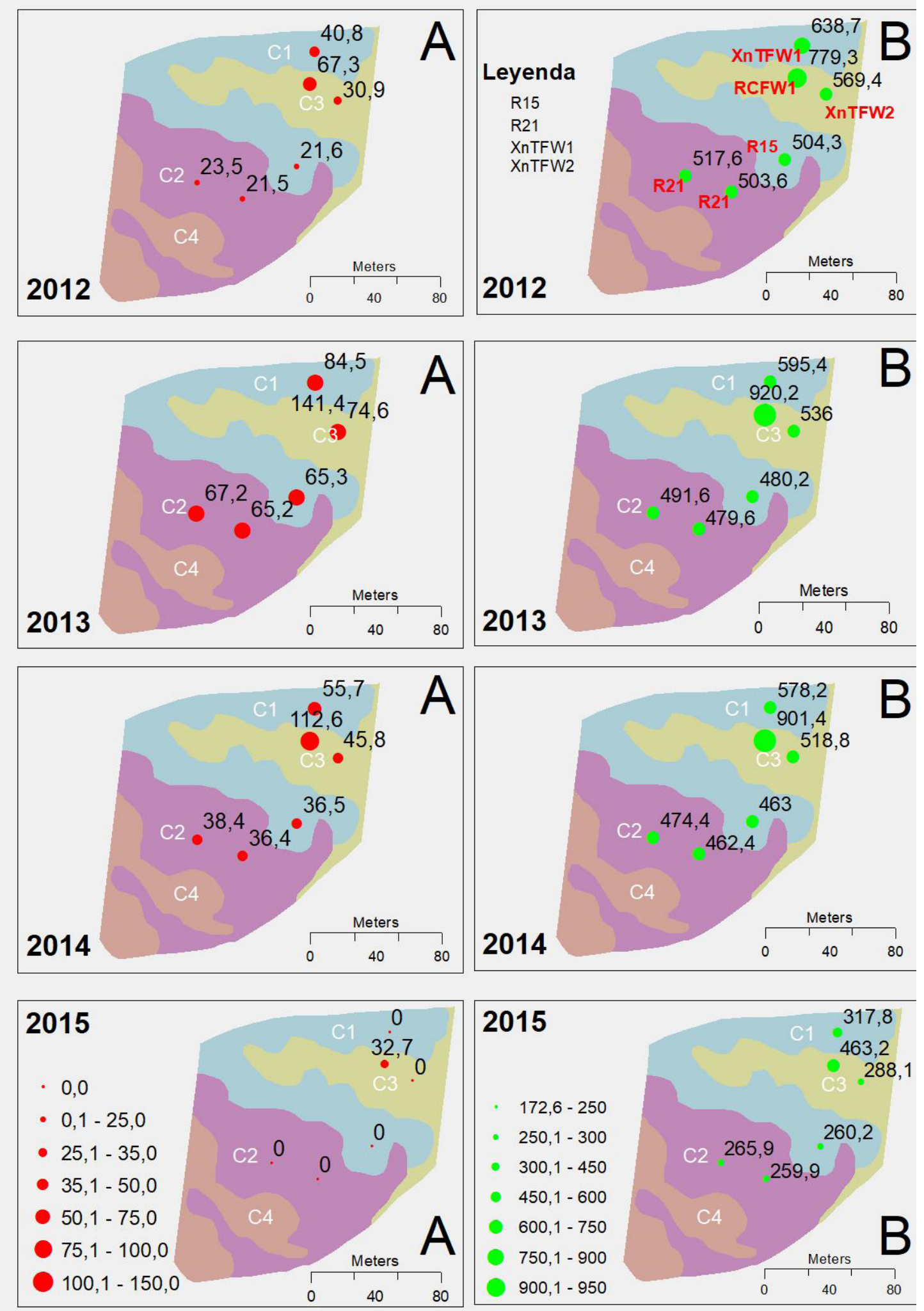

Figura 38. Representación de la reserva de agua $(\mathrm{mm})$ de los diferentes perfiles en la parcela CAMPILLO para cada uno de los años de ensayo. En la columna A se representa la reserva de agua del suelo del mes de mayo y en la columna B se recoge la reserva anual como suma de las reservas mensuales, aunque no es un valor físicamente justificable, si es un buen indicativo del agua disponible para el cultivo. En la figura 2012B también se incluye el símbolo de la STU del mapa de la DOCa Rioja (ver Tabla 25). 

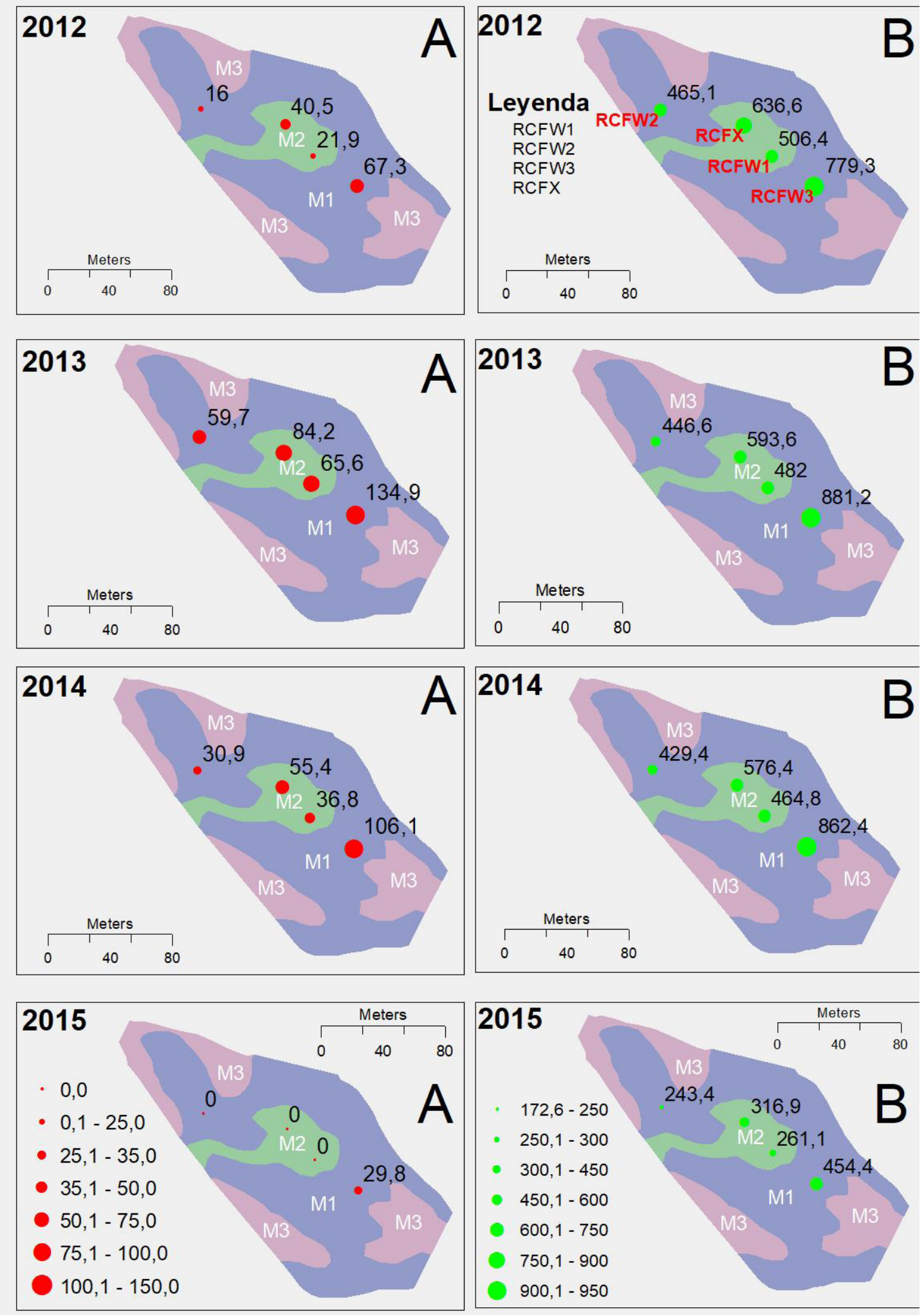

Figura 39. Representación de la reserva de agua $(\mathrm{mm})$ de los diferentes perfiles en la parcela MAJADAHONDA para cada uno de los años de ensayo. En la columna A se representa la reserva de agua del suelo del mes de mayo y en la columna B se recoge la reserva anual como suma de las reservas mensuales, aunque no es un valor físicamente justificable, si es un buen indicativo del agua disponible para el cultivo. En la figura 2012B también se incluye el símbolo de la STU del mapa de la DOCa Rioja (ver Tabla 25). 


\subsubsection{Clasificación y correlación}

Tal y cómo ya se ha señalado, se describió un perfil de suelo en cada una de las repeticiones de plantas dónde se tomaron muestras vegeto-productivas y de composición de la uva.

En relación con las propiedades de los suelos, aunque no es el objetivo de este trabajo realizar un análisis exhaustivo de los resultados parece pertinente realizar una breve discusión, incluyéndose una breve descripción comparativa en la Tabla 24.

Tabla 24. Algunas peculiaridades comparativas de los perfiles descritos

\begin{tabular}{|c|c|}
\hline Perfil & OBSERVACIONES \\
\hline $\mathrm{C} 1 \mathrm{~A}$ & Mantiene un 2,3\% arena por debajo de $60 \mathrm{~cm}$ \\
\hline $\mathrm{C} 1 \mathrm{~B}$ & El horizonte Bk tiene abundantes raíces \\
\hline $\mathrm{C} 2 \mathrm{~A}$ & El Ky la M0 muy elevados en el epipedón y M0 elevada hasta $45 \mathrm{~cm}$. Contacto lítico a $80 \mathrm{~cm}$ \\
\hline $\mathrm{C} 2 \mathrm{~B}$ & Semejante a C2A, pero sin Kalto \\
\hline $\mathrm{C} 3 \mathrm{~A}$ & Suelo original de 75 a $130 \mathrm{~cm}$, sin actividad de raíces y con niveles más elevados de CE \\
\hline $\mathrm{C} 3 \mathrm{~B}$ & Ab de 12 a $45 \mathrm{~cm}$, contacto lítico a $85 \mathrm{~cm}$. Alta capacidad de retención de agua \\
\hline N1A & Suelo modificado de 0 a $60 \mathrm{~cm}$, raíces abundantes en todo el perfil \\
\hline N1B & Niveles de MO homogéneos en todos los horizontes, raíces abundantes en todo el perfil \\
\hline N2A & $160 \mathrm{~cm}$ de profundidad con raíces en todo el perfil \\
\hline $\mathrm{N} 2 \mathrm{~B}$ & Semejante a N2A, pero con nivel freático a $115 \mathrm{~cm}$ \\
\hline M1A & Suelo modificado, niveles altos de K en superficie. Alta capacidad de retención de agua \\
\hline M1B & Contacto lítico a $75 \mathrm{~cm}$. Niveles elevados de MO hasta $60 \mathrm{~cm}$ \\
\hline $\mathrm{M} 2 \mathrm{~A}$ & Raíces por todo el perfil. Contacto lítico a $75 \mathrm{~cm}$. \\
\hline M2B & Semejante a M2B pero más profundo. Contacto lítico a $93 \mathrm{~cm}$ \\
\hline R1A & Raíces en todo el perfil. Aumenta CIC en profundidad \\
\hline R1B & Semejante a R1A pero de menor profundidad. Contacto lítico a $80 \mathrm{~cm}$ \\
\hline R2A & Altos niveles de M0 (por encima de 3 a partir de $1 \mathrm{~m}$ ), raíces en todo el perfil \\
\hline R2B & Semejante a R2A. Contenido en M0 de 3,6\% entre 50 y $80 \mathrm{~cm}$ \\
\hline R3A & Raíces en todo el perfil (152 cm). Carácter fluvéntico pero contenidos de M0 más bajos que R2A y R2B \\
\hline R3B & Semejante a R3A \\
\hline
\end{tabular}


En general, los horizontes de los suelos del ensayo tienen pH alcalino (entre 8,1 y 8,9), están saturados en bases ( $V=100 \%$, principalmente por calcio), sin problemas de salinidad (CE entre 0,2 y 0,8 dS/m), ni alcalinidad (PSI<10\%) y niveles altos de caliza activa (por encima del $10 \%$ y hasta $17,6 \%$ ) que no deberían suponer un problema empleando el 41B como portainjerto. En todos los horizontes analizados se encontraron niveles bajos de arena (por debajo del 25\%), y niveles variables de limo (entre 35 y 70\%) y arcilla (entre 20 y 60) con clases texturales (USDA, 2014) variadas: arcilloso, arcillo limoso, franco arcilloso, franco arcillo limoso, franco y franco limoso.

De acuerdo con la calibración propuesta por la Diputación de Álava (Tabla 1 del § 3.1.3) en los epipedones encontrados aparecen: niveles normales o altos de materia orgánica, encontrando en algunos casos niveles muy altos (por encima de 2,5\%); niveles altos y muy altos de P; niveles muy bajos de K y niveles bajos o muy bajos de Mg. Los niveles altos de MO y de P se deben a los aportes de estiércol vacuno que se realizan regularmente.

Asimismo, en la Figura 39 se presenta el dendrograma resultante de realizar el análisis jerárquico cluster (AJC) para las variables del suelo estudiadas, lo que permite valorar su influencia sobre la discriminación de los sectores. Estas variables se pueden agrupar en tres conjuntos que para su descripción se han representado por G1, G2 y G3, que más adelante se emplearán en los análisis estadísticos junto con los parámetros relacionados con el cultivo.

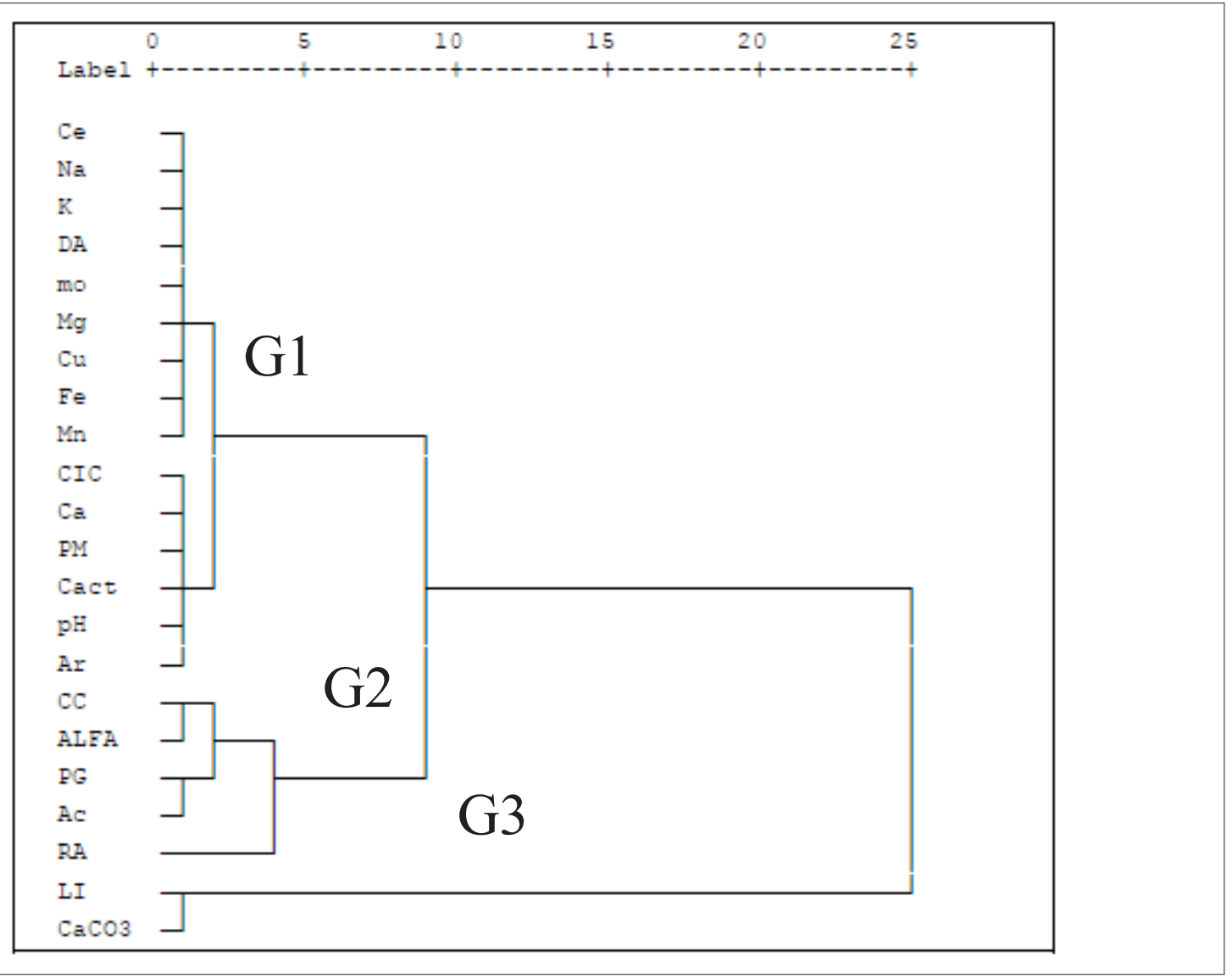

Figura 40. Dendrograma del análisis jerárquico cluster (AJC) de las variables del suelo analizadas. 
El primer grupo, representado por G1, incluye las variables relacionadas con el complejo de cambio (MO, ClC, Ca, Mg, Na, K) y algunas propiedades físicas (DA, Ar, PM) y químicas y oligoelementos (CE1:5, pH, $\mathrm{Cact}, \mathrm{Cu}, \mathrm{Fe}, \mathrm{Mn})$.

El segundo grupo, G2, está formado por otras variables como CC, ALFA, PG, Ac y RA. Generalizando, se podría hablar de un grupo descriptor del contenido en arcilla y su mineralogía así como de la capacidad de retención de agua del suelo, característica de alto interés vitícola (van Leeuwen et al., 2009).

Se define un último grupo, G3, formado por dos variables: el contenido en limo (LI) y el contenido en caliza total (CaCo3), este hecho viene a confirmar los problemas que plantea la correlación relacionada con las familias texturales, ya que una gran parte del carbonato cálcico aparece en la fracción del limo.

Respecto a la fertilidad potencial, cuantificada como ClC, son suelos con niveles bajos o medios (Garrido Valero, 1993) y semejantes a los epipedones de DOCa Rioja citados en la bibliografía por Gómez-Miguel en 2002 (n 592: media 1,4%, DS 0,58) y por Peregrina et al. en 2010 (n 120). Es interesante observar cómo la $\mathrm{MO}$ aporta una gran parte de CIC posiblemente por la naturaleza de las arcillas (bajos valores de ALFA) lo que es la causa de la alta correlación entre esta CIC y la MO (Figura 41).

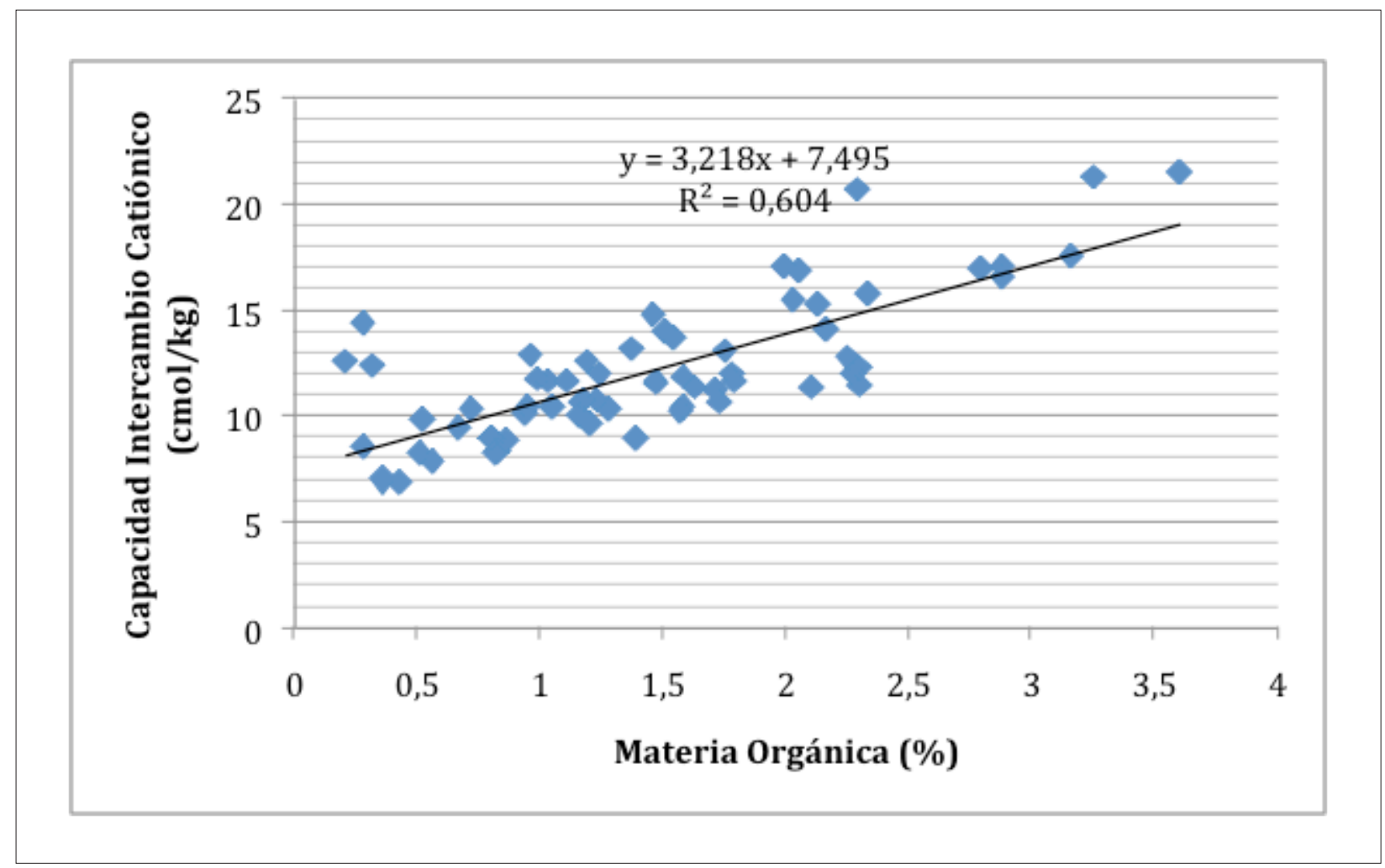

Figura 41. Regresión lineal entre la materia orgánica (mo) y la capacidad de intercambio catiónico (CIC).

La clasificación de los suelos del ensayo se ha realizado de acuerdo con las dos versiones de Soil Taxonomy empleadas en la tesis, la utilizada en el mapa de suelos de la DOCa Rioja (USDA, 1994) y las más reciente (USDA, 2014). Los resultados de ambas se incluyen en la Tabla 25. 
Tabla 25. Relación entre las STU en la DOCa Rioja de las formaciones del Cuaternario (FW) y del Terciario de F. Haro-Transición (W) y los perfiles del ensayo.

\begin{tabular}{|c|c|c|c|c|}
\hline \multicolumn{4}{|c|}{ PERFILES DEL ENSAYO } & \multirow{2}{*}{$\begin{array}{l}\text { STU de la } \\
\text { DO Ca Rioja } \\
\text { SímBOLO }\end{array}$} \\
\hline CÓDIGO & PERFIL & CLASIFICACIÓN (USDA, 2014) & CLASIFICACIÓN (USDA, 1994) & \\
\hline C1A & 352302 & Xerorthent típico, arcillosa pesada, mésica, carbonatada & Xerorthent típico, arcillosa pesada, mésica, carbonatada & XnTFW1 \\
\hline $\mathrm{C} 1 \mathrm{~B}$ & 352306 & Calcixerept típico, arcillosa pesada, mésica, mixta & Xerochrept calcixeróllico, arcillosa pesada, mésica, mixta & R15 \\
\hline C2A & 352307 & Calcixerept típico, arcillosa pesada, mésica, mixta & Xerochrept calcixeróllico, arcillosa pesada, mésica, mixta & R21 \\
\hline$C 2 B$ & 352308 & Calcixerept típico, arcillosa pesada, mésica, mixta & Xerochrept calcixeróllico, arcillosa pesada, mésica, mixta & R21 \\
\hline $\mathrm{C} 3 \mathrm{~A}$ & 352301 & $\begin{array}{l}\text { Xerorthent thaptoalfico, francofina pesada, mésica, carbo- } \\
\text { natada }\end{array}$ & Xerorthent típico, fracofina pesada, mésica, carbonatada & XnTFW2 \\
\hline C $3 B$ & 352305 & $\begin{array}{l}\text { Haploxerept fluvéntico, francofina pesada, mésica, carbo- } \\
\text { natada }\end{array}$ & $\begin{array}{l}\text { Xerochrept fluvéntico, francofina pesada, mésica, carbona- } \\
\text { tada }\end{array}$ & RCFW1 \\
\hline N1A & 352303 & $\begin{array}{l}\text { Xerorthent thaptoincéptico, esquelética francofina pesada, } \\
\text { mésica, carbonatada }\end{array}$ & $\begin{array}{l}\text { Xerorthent típico, esquelética francofina pesada, mésica, } \\
\text { carbonatada }\end{array}$ & R16 \\
\hline N1B & 352310 & Xerorthent típico, francofina pesada, mésica, carbonatada & Xerorthent típico, fracofina pesada, mésica, carbonatada & XnTFW2 \\
\hline N2A & 352304 & $\begin{array}{l}\text { Haploxerept típico, esquelética francofina pesada, mésica, } \\
\text { carbonatada }\end{array}$ & $\begin{array}{l}\text { Xerochrept típico, esquelética francofina pesada, mésica, } \\
\text { carbonatada }\end{array}$ & XpTW \\
\hline N2B & 352309 & Haploxerept aquico, francofina pesada, mésica, carbonatada & Xerochrept aquico, francofina pesada, mésica, carbonatada & RCQW \\
\hline M1A & 353301 & $\begin{array}{l}\text { Xerorthent thaptoincéptico, francofina pesada, mésica, } \\
\text { carbonatada }\end{array}$ & $\begin{array}{l}\text { Xerorthent thaptoincéptico, francofina pesada, mésica, } \\
\text { carbonatada }\end{array}$ & RCFW3 \\
\hline M1B & 353304 & $\begin{array}{l}\text { Xerofluvent típico, esquelético francofina pesada, mésica, } \\
\text { carbonatada }\end{array}$ & $\begin{array}{l}\text { Xerofluvent típico, esquelético francofina pesada, mésica, } \\
\text { carbonatada }\end{array}$ & RCFW2 \\
\hline M2A & 353302 & Xerofluvent típico, francofina pesada, mésica, carbonatada & Xerofluvent típico, francofina pesada, mésica, carbonatada & RCFW1 \\
\hline M2B & 353303 & $\begin{array}{l}\text { Haploxerept fluvéntico, esquelético francofina pesada, } \\
\text { mésica, carbonatada }\end{array}$ & $\begin{array}{l}\text { Xerochrept fluvéntico, esquelético francofina pesada, mésica, } \\
\text { carbonatada }\end{array}$ & RCFX \\
\hline R1A & 353310 & Haploxeralf típico, francafina pesada, mésica, carbonatada & Haploxeralf típico, francafina pesada, mésica, carbonatada & HaTW1 \\
\hline R1B & 353308 & Haploxeralf típico, arcillosa pesada, mésica, carbonatada & Haploxeralf típico, arcillosa pesada, mésica, carbonatada & HaTW2 \\
\hline R2A & 353305 & $\begin{array}{l}\text { Xerofluvent típico, esquelético francofina pesada, mésica, } \\
\text { carbonatada }\end{array}$ & $\begin{array}{l}\text { Xerofluvent típico, esquelético francofina pesada, mésica, } \\
\text { carbonatada }\end{array}$ & RCFW1 \\
\hline R2B & 353307 & Xerofluvent típico, francofina pesada, mésica, carbonatada & Xerofluvent típico, francofina pesada, mésica, carbonatada & RCFW1 \\
\hline R3A & 353309 & Xerofluvent típico, francofina pesada, mésica, carbonatada & Xerofluvent típico, francofina pesada, mésica, carbonatada & RCFW1 \\
\hline R3B & 353306 & Xerofluvent típico, francofina pesada, mésica, carbonatada & Xerofluvent típico, francofina pesada, mésica, carbonatada & RCFW1 \\
\hline
\end{tabular}


En la misma Tabla 25 también está incluida la identificación de las diferentes STU de las unidades del ensayo y las del mapa de suelos de la DOCa Rioja (Gómez-Miguel \& Sotés, 1997). La correlación de unas y otras se ha visto dificultada en el nivel categórico de familia por la identificación en esta zona del original en relación con la determinación de la textura. Como ya se aludió más arriba en los suelos calizos el contenido en carbonatos totales altera la fracción limo y por lo tanto los valores relativos de arena y arcilla. En estos casos se ha optado por añadir un número al final del símbolo y considerarlo como variante de la posible STU.

De las cuatro parcelas estudiadas, tres (Campillo, Naval y Majadahonda) se encuentran, según el mapa de gestión de referencia, en la SMU 44C y sobre una geomorfología W122 (superficies estructurales, poco extensas y escalonadas de relieve ondulado de la F. de Haro-Transición). La citada unidad está compuesta por las STU Calcixerept típico, francafina, mésica (60\%); Xerorthent lítico, francafina, mésica (20\%); Xerorthent típico, fina, mésica (10\%) y grupos cognados (10\%).

Siguiendo la nomenclatura de los citados trabajos, en la parcela Ricio se encuentran dos SMU, 17C y 46C, sobre las litogeomorfas FW22 (terraza baja de afluente principal del Ebro asociado a la F. de Haro-Transición) y W221 (ladera de pendiente moderada con afloramientos comunes de la F. de Haro-Transición), respectivamente. La primera SMU está constituida por las STUs Calcixerept típico, mésica (40\%); Calcixerept típico, francafina, mésica (30\%); Xerorthent típico, mésica (10\%); Xerorthent gypsico, mésico (10\%) y grupos cognados (10\%) y la segunda SMU por Calcixerept típico, francafina, mésica (50\%); Xerorthent típico, fina, mésica (20\%); Xerorthent lítico, francafina, mésica (10\%); Haploxeralf cálcico, mésica (15\%) y grupos cognados fluvéntico y áquico (5\%).

De las 342.526,74 ha de terreno de la DOCa Rioja, la litología W ocupa 39.377,78 ha y la SMU 44C ocupa una superficie de 10.069 ha, de las cuales 5.995 ha se sitúan sobre la litogeoforma W122. Por su parte, las SMUs 17C y 46C representan una superficie de 6.080 ha (1.886 ha sobre la litogeoforma FW22) y 16.046 ha (8.863 ha sobre la litogeoforma W221), respectivamente.

En relación con la superficie de viñedo existente en la denominación, la SMU 44C representa un 7,8\% (5,8\% sobre W122), la SMU 17 C un 4,1\% (1,9\% sobre FW22) y la SMU $46 C$ un 10,7\% (5,7\% sobre W221). Es decir, el 13,4 \% del viñedo amparado por la DOCa Rioja se encuentra sobre las mismas SMU y litogeoformas (Gómez-Miguel \& Sotés, 1997) que las de los viñedos objeto de este estudio.

Esta forma de correlación por solapamiento tiene problemas por llevarse a cabo en mapas con dos escalas muy diferentes, pero existe otro modo de correlacionar ambas situaciones utilizando las STU de ambos mapas. Esto es lo que se ha hecho para obtener el resultado de la Tabla 25. Además de los problemas con las familias texturales, se han encontrado problemas adicionales principalmente debidos al manejo histórico (concentración parcelaria, nivelaciones...) como se aprecia en las fotografías de las Figuras 21-24.

A la vista de la Tabla 5 del Capítulo 4, solamente el perfil del sector N1A (Xerorthent thaptoincéptico, esquelética, francofina, pesada, mésica, carbonatada o su equivalente Xerorthent típico, arcillosa pesada, mésica, carbonatada) aparece como STU (en forma de serie secundaria o como inclusión) de alguna de las SMU clasificadas como óptimas sobre la Facies de Haro-Transición en Oyón.

En las parcelas Majadahonda y Ricio se han encontrado suelos del subgrupo Xerofluvent típico, característicos por el decrecimiento irregular de materia orgánica en profundidad y relacionados con zonas de 
deposición de material. También en la parcela Ricio, y en Campillo, se han descrito suelos como Calcixerept típico o Haploxeralf típico, habituales en los viñedos de la DOCa Rioja y de otras Denominaciones de España (Gómez-Miguel \& Sotés, 1990-2017).

\subsection{ZONIFICACIÓN INTEGRADA DEL TERROIR (ZIT)}

Como se ha dicho en los apartados 3.3.6 y 5.9, la ZIT es el proceso de integración de la planta y el producto en las Unidades Homogéneas del Medio (UHM). El método seguido se describe en trabajos anteriores a distintas escalas (Gómez-Miguel \& Sotés, 1990-2017; Martínez \& Gómez-Miguel, 2019).

En el presente trabajo, la selección de las parcelas del ensayo se ha realizado buscando la homogeneidad de clima, litología, geomorfología y de aspectos vitícolas, con la única dificultad que conlleva la pequeña escala de los estudios de partida. Este problema se ha intentado solventar mediante la realización de una sectorización que se basa simplemente en la fotointerpretación aérea (FIA), utilizando el mayor número de vuelos históricos disponible.

Aunque el resultado se ha demostrado satisfactorio se han detectado deficiencias en relación con la información de mayor detalle obtenida mediante el muestreo de suelos, por lo tanto, es necesario realizar los ajustes que permitan mejorar esta sectorización previa.

El dibujo de los nuevos sectores será la base que permita la ZIT, el análisis de los componentes vegeto-productivos y de composición de la uva, que completarán el estudio.

\subsubsection{Teledetección: ajuste y precisión de los límites}

En relación con las imágenes utilizadas hay que destacar que la del año 2013 es de una resolución espacial de 2,5 m/pixel mientras que la resolución del resto de imágenes es de 0,5 m/pixel, esto no debería afectar a los resultados ya que se considera habitualmente que el empleo de imágenes con una resolución espacial de 2,5 m/pixel es suficiente para estos usos y su aplicación en VP.

Al estudiar la relación espacial de los valores que definen el NDVI (Tabla 26) se aprecia que en todos los casos el patrón que siguen las distribuciones es agrupado (Z-value $>2,58$ ) y con fuerte dependencia espacial (IC $\leq 25)$. Para el año 2013, donde se empleó una imagen de 2,5 m de resolución espacial, los valores de z-value son los más bajos de los estudiados y respecto al Ic también se aprecia una tendencia hacia valores bajos, por debajo de uno, para tres de los cuatro años de estudio. En cualquier caso, las distribuciones NDVI calculadas a partir de imágenes de resolución espacial 0,5 o 2,5 metros han mostrado altas correlaciones espaciales. 
Tabla 26. Valores geoestadísticos de las distribuciones NDVI. NMI: Índice de Morans, Z-Value, valores del semivariograma (CO y C1) e Ic: Índice de Cambardella.

\begin{tabular}{|c|c|c|c|c|c|c|}
\hline & & & \multirow[b]{2}{*}{ Co(Nugget) } & \multirow[b]{2}{*}{ C1(Sill) } & \multirow[b]{2}{*}{ k } \\
\hline & & $\mathrm{NMI}$ & Z-VALUE & & & \\
\hline \multirow{4}{*}{ CAMPILLO } & NDVI2015 & 0,998 & 414,94 & 0,12 & 0,89 & 11,88 \\
\hline & NDVI2014 & 0,998 & 414,75 & 0,13 & 0,85 & 13,27 \\
\hline & NDVI2013 & 0,975 & 107,15 & 0,01 & 1,11 & 0,89 \\
\hline & NDVI2012 & 0,995 & 413,79 & 0,01 & 1 & 0,99 \\
\hline \multirow{4}{*}{$\mathrm{RIClO}$} & NDVI2015 & 0,998 & 397,42 & 0,22 & 0,77 & 22,22 \\
\hline & NDVI2014 & 0,998 & 397,68 & 0,15 & 0,92 & 14,02 \\
\hline & NDVI2013 & 0,989 & 77,56 & 0,01 & 1,05 & 0,94 \\
\hline & NDVI2012 & 0,997 & 396,98 & 0,17 & 0,83 & 17,00 \\
\hline \multirow{4}{*}{ MAJADAHONDA } & NDVI2015 & 0,996 & 394,32 & 0,1 & 0,9 & 10,00 \\
\hline & NDVI2014 & 0,997 & 394,37 & 0,01 & 1,18 & 0,84 \\
\hline & NDVI2013 & 0,958 & 74,83 & 0,01 & 1,48 & 0,67 \\
\hline & NDVI2012 & 0,997 & 394,6 & 0,19 & 0,82 & 18,81 \\
\hline \multirow{4}{*}{ NAVAL } & NDVI2015 & 0,996 & 329,96 & 0,02 & 0,98 & 2,00 \\
\hline & NDVI2014 & & & & & \\
\hline & NDVI2013 & 0,971 & 63,17 & 0,15 & 0,82 & 15,46 \\
\hline & NDVI2012 & & & & & \\
\hline
\end{tabular}

La representación automática del NDVI para las diferentes parcelas del ensayo y para los diferentes años con distintos métodos permite hacer algunas consideraciones de importancia (Figuras 42-46).

Utilizando, para cada año, una imagen para cada parcela (columna A de las Figuras 42-45) se consigue relacionar todos los valores del NDVI de las parcelas y apreciar el valor relativo de cada una de ellas. Si, por el contrario, utilizamos una única imagen para todas las parcela (columna B de las Figuras 42-45) los valores del NDVI no son comparables dentro de cada parcela. Sin embargo, en este último caso los colores son más discriminantes de la variabilidad interparcela.

En NAVAL (Figura 42), las subzonas obtenidas con las imágenes de A y B del año 2013 son similares ya que los valores del NDVI también los son. Sin embargo, el año 2015 es diferente fundiéndose en A dos de las subzonas diferenciadas en B. Habrían sido muy convenientes las imágenes de los años que faltan, aunque los ajustes parcelarios de los años 1956 y 1957 y posteriores sean la causa de estos problemas. 

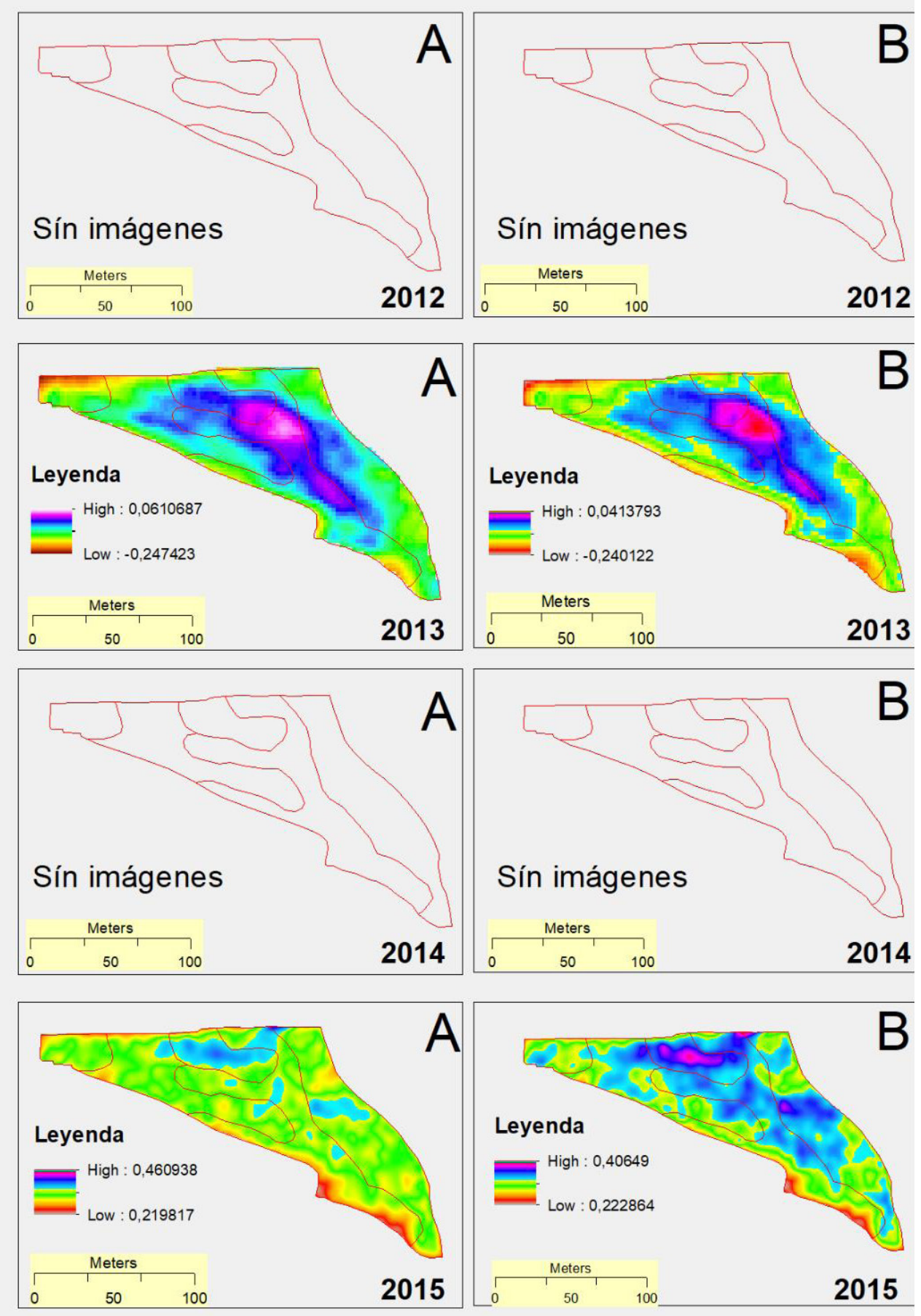

Figura 42. Representación de los sectores obtenidos por la FIA sobre el NDVI para la parcela NAVAL y para los diferentes años con dos métodos distintos: en la columna A se ha utilizado como universo todas las parcelas en su conjunto y en la B únicamente cada parcela. 

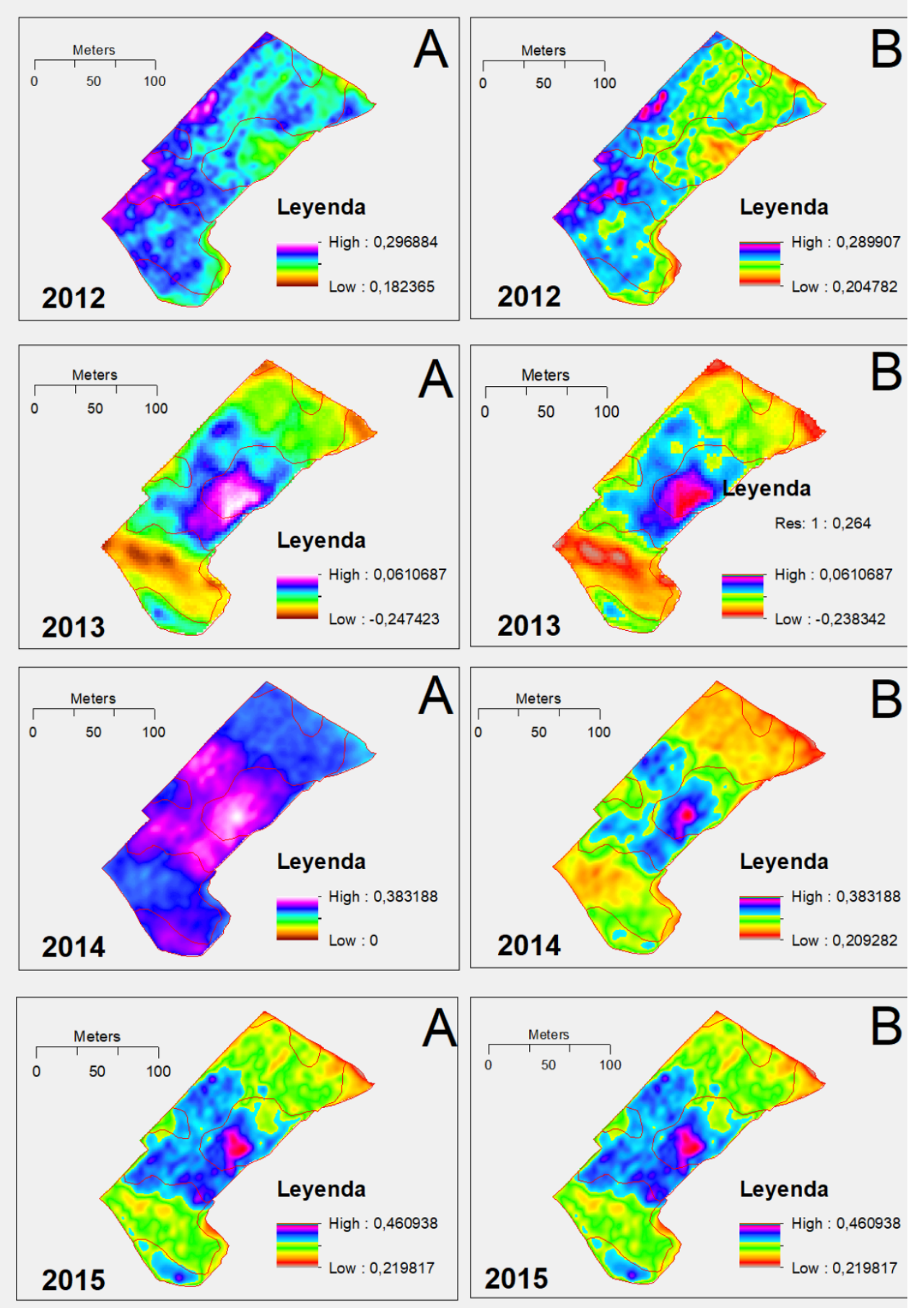

Figura 43. Representación de los sectores obtenidos por la FIA sobre el NDVI para la parcela RICIO y para los diferentes años con dos métodos distintos: en la columna A se ha utilizado como universo todas las parcelas en su conjunto y en la B únicamente cada parcela. 

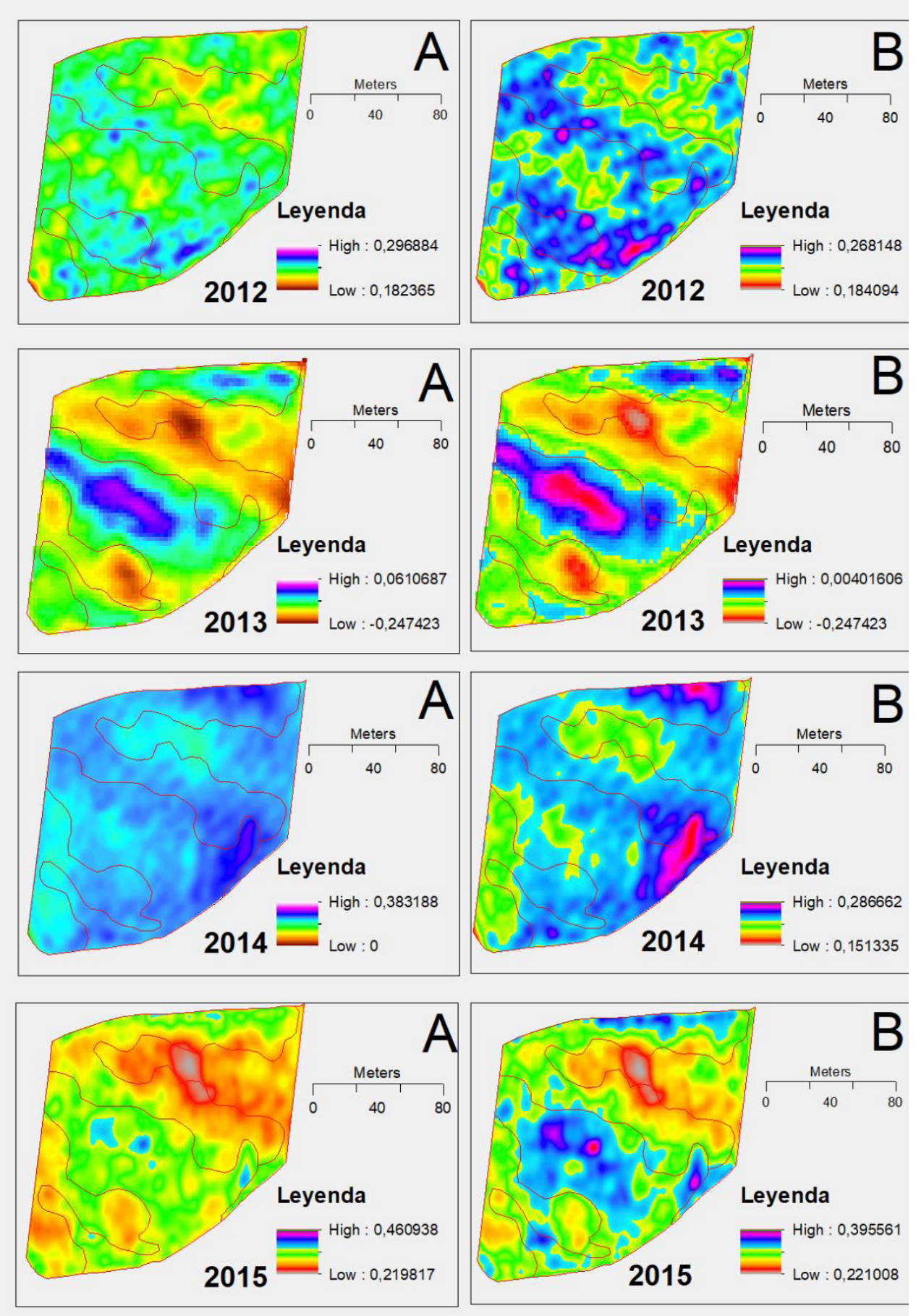

Figura 44. Representación de los sectores obtenidos por la FIA sobre el NDVI para la parcela CAMPILLO y para los diferentes años con dos métodos distintos: en la columna A se ha utilizado como universo todas las parcelas en su conjunto y en la B únicamente cada parcela. 

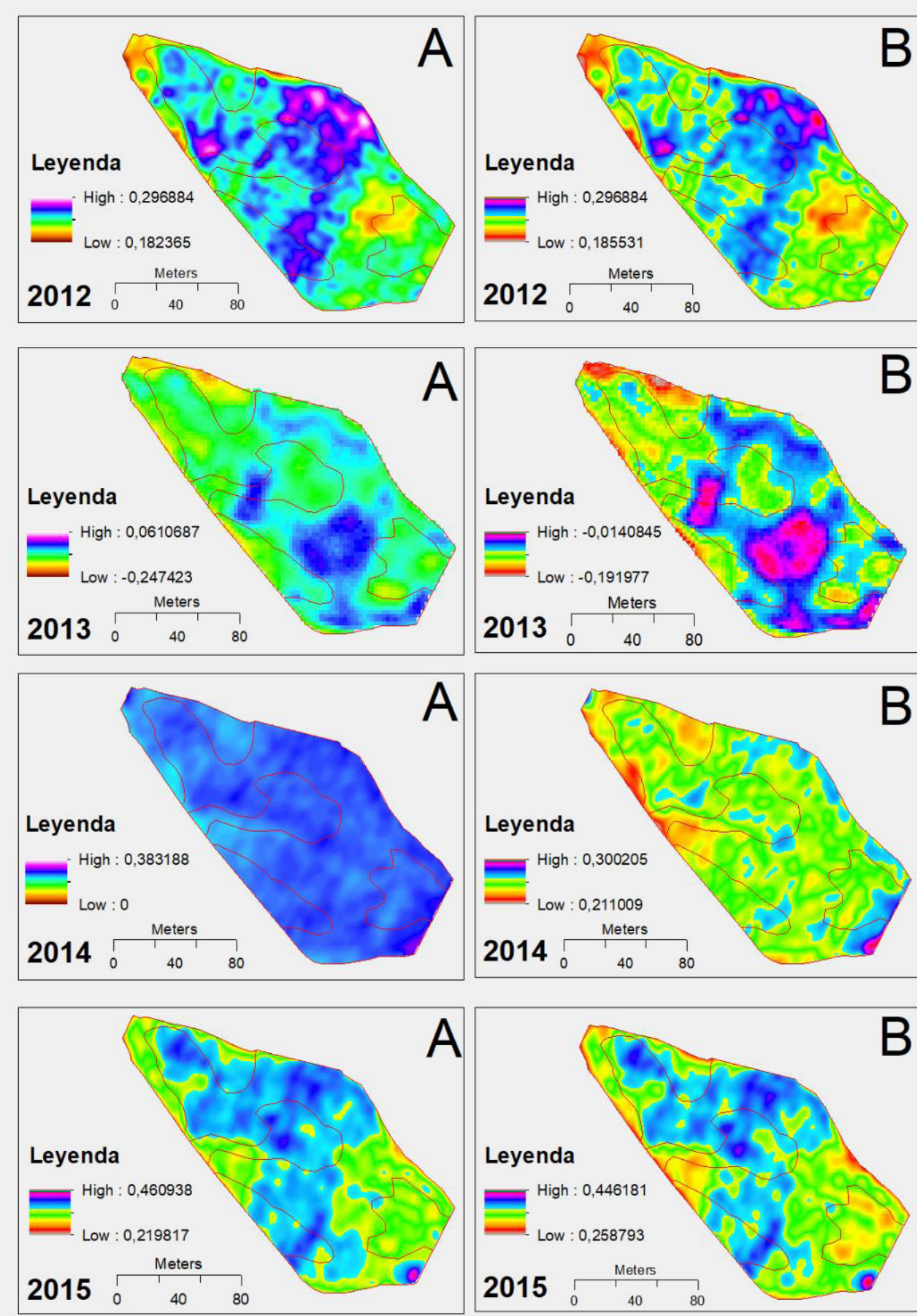

Figura 45. Representación de los sectores obtenidos por la FIA sobre el NDVI para la parcela MAJADAHONDA y para los diferentes años con dos métodos distintos: en la columna A se ha utilizado como universo todas las parcelas en su conjunto y en la B únicamente cada parcela. 
En RIClO (Figura 43), las subzonas obtenidas con las imágenes de A y B son compatibles en los años 2013, 2014 y 2015 y en ellos los sectores se adecúan bien con las subzonas y solamente es mejorable la precisión de los límites. En relación con el año 2012 se aprecian las disrupciones ocasionadas por la destrucción de bancales y lindes posteriores a 1957 y siguientes (Figura 22), también las condiciones meterorológicas particulares pueden provocar estas singularidades.

En CAMPILLO (Figura 44), las subzonas obtenidas con las imágenes de A y B son compatibles en los años 2013 y 2015 y en ellos los sectores se adecúan bien con las subzonas y solamente es mejorable la precisión de los límites. En relación con los años 2012 y 2015, posiblemente las condiciones climáticas específicas hacen que afloren los problemas planteados por el manejo en los años 1981-1986 (Figura 23).

En MAJADAHONDA (Figura 45) las subzonas obtenidas con las imágenes de A y B son compatibles salvo por las del año 2014. Los sectores se adecúan bien con las subzonas y solamente es mejorable la precisión de los límites.

La Figura 45 muestra otra representación de los sectores obtenidos por la FIA sobre las subzonas deducidas del NDVI para los cuatro años de estudio y para las cuatro parcelas. Como se aprecia, hay similitudes entre las distribuciones del NDVI y de la FIA, especialmente en las parcelas Ricio y Campillo. En el caso de Naval y Majadahonda las diferencias observadas entre NDVI y FIA (durante todos los años de estudio) pueden deberse, como se ha dicho, a la modificación del terreno realizada previamente a la plantación del viñedo. También es reseñable, a la vista de las parcelas Ricio y Campillo, la estabilidad temporal encontrada en la distribución gráfica del NDVI, independientemente de la resolución espacial de la imagen. En este sentido, Tisseyre et al. (2007) citan varios trabajos en los que la distribución espacial de diferentes factores (como el estado hídrico de la planta) o de cualidades del cultivo (rendimiento y vigor) permanecen constantes en el tiempo (Ojeda et al., 2005).

A la vista de la representación gráfica del NDVI del año 2012 (Figura 46) parece que la fuerte sequía sufrida este año afecta a la distribución espacial de los índices de vegetación. Atendiendo exclusivamente a la parcela Ricio se aprecia cómo se invierte la categoría en la se encuentran los distintos sectores, es decir, el sector R2 aparece como el de mayor NDVI durante los años $2013(0,18), 2014(0,24)$ y $2015(0,38)$ mientras que en el año $2012(0,24)$ es el sector con menores valores de NDVI. Sucede lo opuesto con el sector R1. Esta singularidad del año 2012 se comentará más adelante, siendo el sector R2 el de menor crecimiento vegetativo, poniéndose de manifiesto la relación entre el crecimiento vegetativo y el NDVI. Sin embargo, la producción de R2 en 2012 siguió siendo la más elevada de los tres sectores estudiados en la parcela Ricio, por lo que el NDVI no discriminó sectores según el rendimiento. Por lo tanto, en condiciones de extrema sequía, no parece que el NDVI sea un buen método de diagnóstico del rendimiento ni de la composición de la cosecha, aunque siempre lo ha sido del crecimiento vegetativo. 

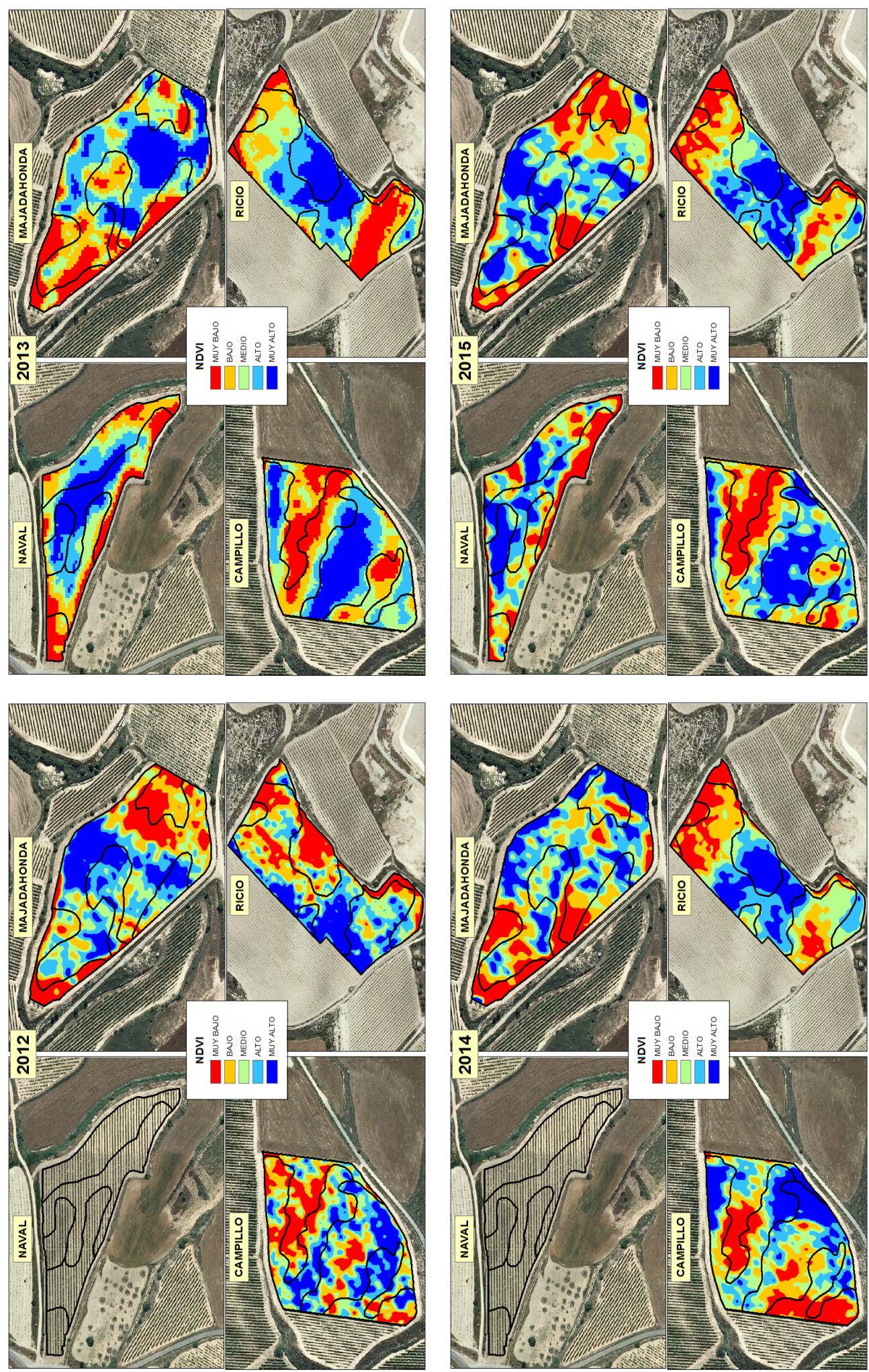

Figura 46. FIA y clasificación del NDVI, calculado pixel a pixel, para las cuatro parcelas experimentales y los cuatro años de estudio 
En la Figura 47 se incluye la representación gráfica de la sectorización definitiva de las parcelas del ensayo que se van a utilizar para la ZIT. En la misma figura se muestra la generalización de los perfiles del ensayo (columna A) a todos los sectores de las parcelas, incluidos aquellos que no se han muestreado, y la equivalencia con la simbología de la STU del estudio de la DOCa Rioja que se viene utilizando (columna B, ver tabla 25).

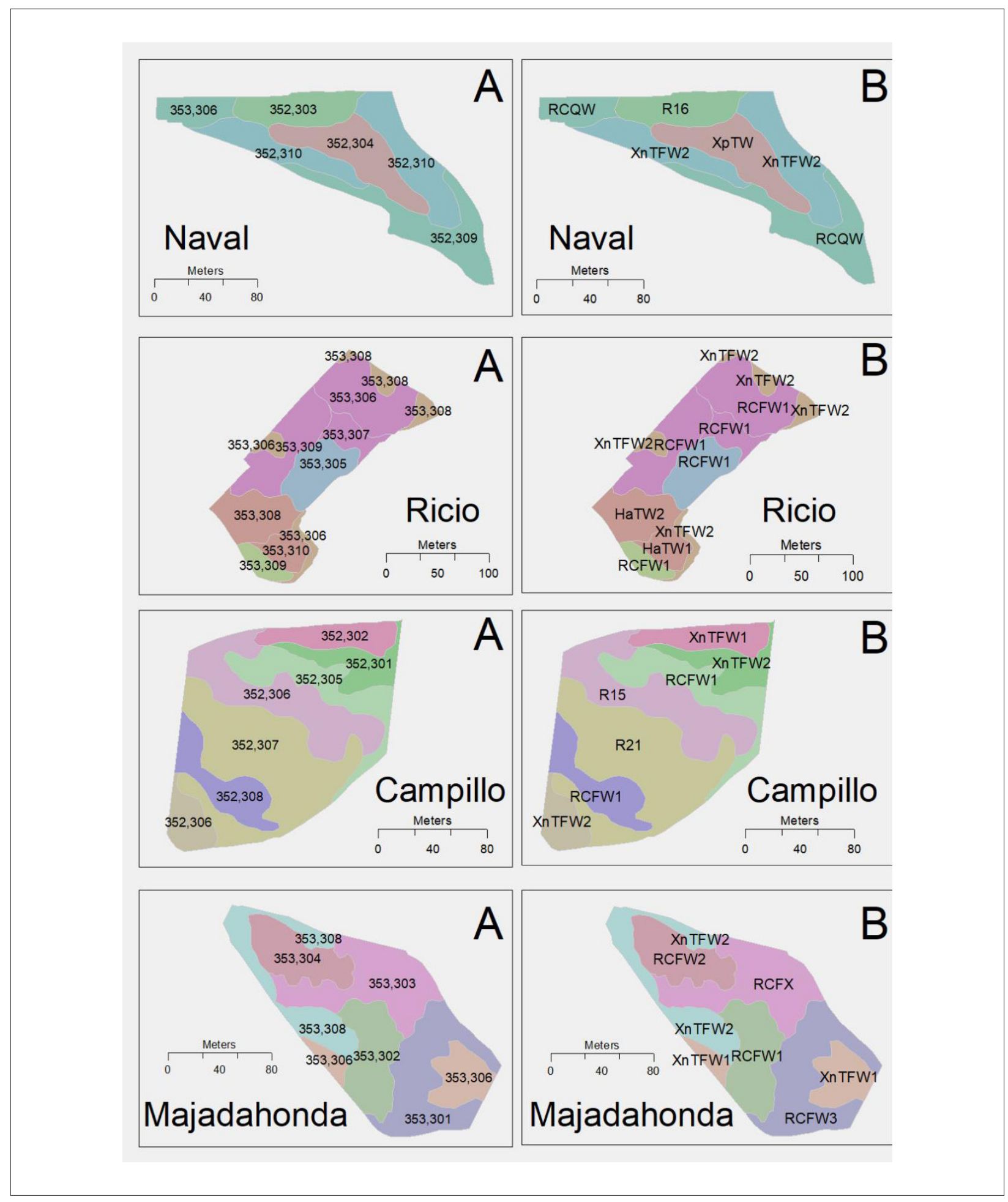

Figura 47. Sectorización definitiva de las parcelas del ensayo, incluyendo: Columna A, generalización de los perfiles del ensayo; Columna B, equivalencia con STU de Gómez-Miguel y Sotés (1997). 
Para la realización de esta sectorización se han utilizado todas las herramientas descritas en los apartados previos y el resultado constituye el mapa de las UHM definitivo que permite la asignación de variables del medio a cada sector de forma que se pueda proceder a la realización de la ZIT definitiva.

En concreto, primero se ha procedido a dividir los sectores de la FIA (Figura 20) que suponían una variabilidad importante en cada una de las propiedades de los suelos, como por ejemplo las derivadas del balance hídrico (Figuras 36 a 39) y las de los perfiles, y posteriormente se ha complementado el resultado incrementando la precisión de los límites mediante la utilización de los elementos procedentes de los distintos tratamientos del NDVI (Figuras 42 a 46), dando especial importancia al análisis de estabilidad de los sectores.

\subsubsection{Componentes vegeto-productivos}

En este apartado se incluye el análisis de los resultados de los componentes vegeto-productivos de las parcelas del ensayo según la sectorización propuesta en § 6.1.

Desde un punto de vista interparcela, la finca Naval y los sectores R2 y R3 de Ricio se caracterizan por su carácter vigoroso, así como por rendimientos elevados. En el caso de Ricio, se han encontrado un mayor número de racimos mientras que en Naval es el peso de los mismos el componente del rendimiento responsable de las altas producciones. En el extremo opuesto, los sectores C1 y C3 de la finca Campillo y la finca Majadahonda presentan menores rendimientos y un crecimiento vegetativo más limitado.

Respecto al clima, no es posible encontrar diferencias entre los sectores debido a que no existen datos climáticos individualizados para cada sector, ni para cada parcela. Sin embargo, si se pueden establecer algunas asociaciones entre el clima anual y la respuesta de la vid. Se ha comentado en $\S 6.2$ que los años 2013 y 2015 se clasifican como de régimen subhúmedo (IS-1) mientras que 2012, 2014 y la serie histórica se incluyen en régimen moderadamente seco (IS+1). Esta mayor disponibilidad hídrica durante las campañas 2013 y 2015 provocó un mayor vigor y crecimiento vegetativo, aunque no ha tenido este efecto sobre el rendimiento, cosechando los racimos más pesados los años 2012 y 2014 y las producciones más altas los años 2012, 2013 y 2014.

Analizando los resultados a escala intraparcela en el viñedo Ricio, se observa un comportamiento anómalo el año 2012 en el sector R2, que el resto de los años se mostró productivo y vigoroso y en este año el crecimiento vegetativo se vio limitado respecto a R1 y R3. Tal y como se ha señalado en § 6.2, el año 2012 fue extremadamente seco, pudiendo alterar el excesivo déficit hídrico las diferencias encontradas entre sectores, aunque se mantiene la estabilidad temporal de la zonificación. Además, el NDVI (Figura 46) también ha recogido esta anomalía, que también puede deberse a la destrucción de bancales y lindes como se ha comentado en $\S 6.5 .1$.

En la Tabla 27 se presentan los estadísticos relacionados con el análisis de varianza (ANOVA) para las características vegeto-productivas estudiadas. 
Tabla 27. Análisis de varianza (ANOVA) por sectores, años y la interacción Año*Sector para Número de racimos, Peso del racimo, Producción, Número de sarmientos, Calibre del sarmiento, Peso de poda y Longitud del sarmiento; gl: grados de libertad, SS: Suma de cuadrados; MC: Media cuadrática, Sig: grado de significación para un nivel de probabilidad $p<0,05\left({ }^{*}\right), p<0,01\left({ }^{* *}\right), p<0,001(* * *)$ y no significativo (ns).

\begin{tabular}{|c|c|c|c|c|c|c|c|c|c|c|c|c|}
\hline & \multicolumn{4}{|c|}{ Número de Racimos } & \multicolumn{4}{|c|}{ Peso de Racimo } & \multicolumn{4}{|c|}{ Producción } \\
\hline & gl & SS & MC & Sig. & $\mathrm{gl}$ & SS & $M C$ & Sig. & gl & SS & MC & Sig. \\
\hline Sector & 9 & 2013,77 & 223,75 & *** & 9 & 734465,38 & 81607,26 & $* * *$ & 9 & 168124474 & 18680497 & $* * *$ \\
\hline Año & 3 & 436,46 & 145,49 & $* * *$ & 3 & 72520,01 & 24173,34 & $* * *$ & 3 & 17506953.7 & 5835651.2 & $* * *$ \\
\hline Año*Sector & 27 & 2113,22 & 78,27 & $* * *$ & 27 & 409461,97 & 15165,26 & $* * *$ & 27 & 67128231.7 & 2486230.8 & *** \\
\hline \multirow[t]{3}{*}{ Error } & 430 & 6018,6 & 14.00 & & 430 & 655028,63 & 1523,32 & & 430 & 199454164 & 463846.89 & \\
\hline & \multicolumn{4}{|c|}{ Número de Sarmientos } & \multicolumn{4}{|c|}{ Calibre de Sarmiento } & \multicolumn{4}{|c|}{ Peso de Poda } \\
\hline & gl & SS & $M C$ & Sig. & $\mathrm{gl}$ & SS & $M C$ & Sig. & gl & SS & $M C$ & Sig. \\
\hline Sector & 9 & 419,9 & 46,65 & *** & 9 & 1,91 & 0,21 & *** & 9 & 10224705,3 & 1136078,4 & $* * *$ \\
\hline Año & 3 & 718,53 & 239,51 & $* * *$ & 3 & 5,13 & 1,71 & $* * *$ & 3 & 13865645 & 4621881,7 & $* * *$ \\
\hline Año* Sector & 27 & 761,19 & 28,19 & $* * *$ & 27 & 1,5 & 0,6 & $* * *$ & 27 & 5623183,5 & 208266,06 & $* * *$ \\
\hline \multirow[t]{3}{*}{ Error } & 430 & 1580,42 & 3.67 & & 430 & 4,1 & 0,01 & & 430 & 11141985,7 & 25911,59 & \\
\hline & \multicolumn{4}{|c|}{ Longitud de Sarmiento } & & & & & & & & \\
\hline & gl & SS & MC & Sig. & & & & & & & & \\
\hline Sector & 9 & 140927,3 & 15658,59 & $* * *$ & & & & & & & & \\
\hline Año & 3 & 252124,18 & 84041,39 & $* * *$ & & & & & & & & \\
\hline Año* Sector & 27 & 80721,89 & 2989,7 & *** & & & & & & & & \\
\hline Error & 430 & 120040,41 & 279,16 & & & & & & & & & \\
\hline
\end{tabular}

En la Tabla 28 se presentan los resultados de los parámetros vegeto-productivos agrupados según el test de Duncan (cuando hubo diferencias significativas) de cada uno de los años de estudio: 2012, 2013, 2014 y 2015. En todas las campañas (excepto para el número de racimos en el año 2013) se han encontrado diferencias significativas entre los distintos sectores. En este capítulo se analizará la relación entre los parámetros estudiados y los sectores definidos en cada parcela del ensayo.

Por otro lado, en la Tabla 29 se pueden observar los resultados del análisis ANOVA a partir del valor medio de los parámetros vegeto-productivos obtenidos durante los cuatro años. Aparecen diferencias significativas en todos los parámetros, agrupándose los sectores según el test de Duncan. Una representación gráfica de estos resultados puede observarse en la Figura 48.

Por último, en la Tabla 30 se presentan los valores vegeto-productivos de cada añada sin discriminar por sectores. De nuevo, encontramos diferencias significativas para todos los parámetros, agrupando los años según el test de Duncan. En la Figura 49 puede observarse una representación gráfica de estos resultados. 
Tabla 28. Valores separados por sectores de comparación de medias y sus agrupaciones mediante el test de Duncan, así como su significación (sg) para un nivel de probabilidad $p<0,001\left(^{* *}\right) ; p<0,01\left(^{* *}\right) ; p<0,05\left(^{*}\right)$ y ns (no significativo) para: NRAC (No de Racimos), PROD (Racimos*PRacimo), PRAC (Peso del racimo, gr), LONG (Longitud del sarmiento, cm), CAL (Calibre del sarmiento, cm), PESOMAD (Peso de madera de poda, gr) y RAVAZ (Índice de Ravaz: Pesomad/Producción). Resultados para cada uno de los años de estudio.

\begin{tabular}{|c|c|c|c|c|c|c|c|c|c|}
\hline AÑO & PARCELA & SECTOR & NRAC & PROD & PRAC & LONG & CAL & PESOMAD & RAVAZ \\
\hline \multirow{11}{*}{2012} & \multirow{3}{*}{ CAMPILLO } & C1 & $10,75 a b c$ & $1372,83 \mathrm{abc}$ & $123,56 b$ & 58,17 a & 0,8998 bc & $154,00 \mathrm{a}$ & $8,9 \mathrm{~cd}$ \\
\hline & & 02 & $9,75 a b$ & $1793,25 \mathrm{~cd}$ & $187,87 \mathrm{c}$ & $73,75 b$ & 0,987 cde & $374,25 \mathrm{c}$ & $4,9 a b$ \\
\hline & & C3 & $12,08 \mathrm{bc}$ & $1098,92 \mathrm{ab}$ & $90,29 a b$ & $50,92 a$ & $0,8114 a$ & $139,42 \mathrm{a}$ & $7,8 \mathrm{bcd}$ \\
\hline & \multirow{2}{*}{$\begin{array}{l}\text { MAJADA } \\
\text { HONDA }\end{array}$} & M1 & $9,33 \mathrm{ab}$ & $1595,67 \mathrm{bcd}$ & $180,01 \mathrm{c}$ & $111,75 c$ & 1,0422 e & $425,75 \mathrm{~cd}$ & $3,6 a$ \\
\hline & & M2 & $8,25 \mathrm{a}$ & $1416,5 \mathrm{abcd}$ & $172,02 \mathrm{C}$ & $83,08 \mathrm{~b}$ & 0,9852 cde & $258,00 \mathrm{~b}$ & $5,4 a b$ \\
\hline & \multirow{2}{*}{ NAVAL } & N1 & $11,42 a b c$ & $1982,5 d$ & $171,92 \mathrm{c}$ & $115,75 c$ & 1,0120 de & $453,67 d$ & $4,5 \mathrm{a}$ \\
\hline & & N2 & $10,25 a b c$ & $1872,75 \mathrm{~cd}$ & $180,93 c$ & $115,50 \mathrm{c}$ & 1,0323 e & $492,75 d$ & $3,9 a$ \\
\hline & \multirow{4}{*}{$\mathrm{RICIO}$} & R1 & $9,83 a b$ & $832,33 \mathrm{a}$ & $80,32 a$ & $47,08 \mathrm{a}$ & $0,8613 a b$ & $96,75 a$ & $10,2 d$ \\
\hline & & R2 & $13,58 \mathrm{c}$ & $1387,17 \mathrm{abcd}$ & $99,63 \mathrm{ab}$ & $53,33 a$ & $0,9378 \mathrm{bcd}$ & $152,92 \mathrm{a}$ & $9,4 d$ \\
\hline & & R3 & $11,33 a b c$ & $1050,33 \mathrm{ab}$ & 85,91 a & $53,92 a$ & 0,9534 cde & 156,83 a & $6,35 a b c$ \\
\hline & & $\mathrm{sg}$ & $*$ & $* * *$ & $* * *$ & $* * *$ & $* * *$ & $* * *$ & *** \\
\hline \multirow{11}{*}{2013} & \multirow{3}{*}{ CAMPILLO } & C1 & 12,67 & $794,83 \mathrm{ab}$ & 63,57 a & 96,67 a & $1,0725 b c$ & 380,83 a & 2,19abc \\
\hline & & 02 & 12,42 & $884,75 a b c$ & $75,14 a b$ & $131,67 \mathrm{~cd}$ & $1,2025 d$ & $690,42 \mathrm{~cd}$ & $1,40 \mathrm{a}$ \\
\hline & & C3 & 12,42 & $588,42 \mathrm{a}$ & $46,49 a$ & 95,83 a & $0,9750 \mathrm{a}$ & 369,17 a & $1,82 a b c$ \\
\hline & \multirow{2}{*}{$\begin{array}{l}\text { MAJADA } \\
\text { HONDA }\end{array}$} & M1 & 12,58 & 1233,92 bcd & 97,98 bc & $137,92 \mathrm{~d}$ & 1,2500 de & 625,25 bc & $2,15 a b c$ \\
\hline & & M2 & 13,33 & $873,00 a b c$ & $63,08 \mathrm{a}$ & $118,33 b c$ & $1,0700 b c$ & $466,25 a b$ & 1,89abc \\
\hline & \multirow{2}{*}{ NAVAL } & N1 & 12,67 & $2887,00 \mathrm{f}$ & 229,05 e & 164,17 e & 1,2625 de & 917,17 ef & $3,42 d$ \\
\hline & & N2 & 10,33 & 2402,67 e & 230,32 e & 164,17 e & $1,24 \mathrm{de}$ & 937,50 ef & $2,62 \mathrm{~cd}$ \\
\hline & \multirow{3}{*}{ RICIO } & R1 & 11,00 & $1280,67 \mathrm{bcd}$ & $117,74 \mathrm{~cd}$ & $107,92 a b$ & $1,1125 c$ & $531,42 a b c$ & $2,44 b c$ \\
\hline & & R2 & 11,67 & $1526,83 d$ & $132,56 d$ & 158,33 e & 1,2725 e & $1101,00 \mathrm{f}$ & $1,60 \mathrm{ab}$ \\
\hline & & R3 & 11,33 & $1375,00 \mathrm{~cd}$ & $125,78 \mathrm{~cd}$ & $140,83 d$ & $1,0450 \mathrm{~b}$ & 819,08 de & $1,74 a b c$ \\
\hline & & sg & ns & $* * *$ & $* * *$ & $* * *$ & $* * *$ & $* * *$ & $* * *$ \\
\hline \multirow{11}{*}{2014} & \multirow{3}{*}{ CAMPILLO } & C1 & $7,58 \mathrm{ab}$ & $758,58 \mathrm{ab}$ & $99,08 \mathrm{ab}$ & $58,75 a$ & $0,807 b$ & $156,5 a b$ & $5,4 b c$ \\
\hline & & 02 & $10,83 \mathrm{C}$ & $1169,50 \mathrm{bc}$ & $106,67 a b$ & $80,42 b$ & $0,882 c$ & $286,42 \mathrm{~cd}$ & $4,0 a b$ \\
\hline & & C3 & $6,92 \mathrm{a}$ & $560,33 \mathrm{ab}$ & $77,01 a b$ & $52,92 \mathrm{a}$ & $0,784 a b$ & $128,5 \mathrm{a}$ & $4,4 a b$ \\
\hline & \multirow{2}{*}{$\begin{array}{l}\text { MAJADA } \\
\text { HONDA }\end{array}$} & M1 & 7,55 ab & $709,63 \mathrm{ab}$ & $93,55 a b$ & $60,91 \mathrm{a}$ & $0,793 a b$ & $129,91 \mathrm{a}$ & $5,1 a b c$ \\
\hline & & M2 & $5,33 a$ & $386,25 \mathrm{a}$ & $71,14 \mathrm{a}$ & 46,67 a & 0,727 a & $86,58 \mathrm{a}$ & $4,7 a b$ \\
\hline & \multirow{2}{*}{ NAVAL } & N1 & $12,17 \mathrm{~cd}$ & $2508,08 \mathrm{e}$ & $202,83 d$ & $88,75 b$ & $0,992 d$ & $293,42 \mathrm{~cd}$ & $8,5 \mathrm{de}$ \\
\hline & & N2 & $13,25 \mathrm{~cd}$ & $3577,78 \mathrm{f}$ & 268,60 e & $90,83 \mathrm{~b}$ & $0,926 \mathrm{~cd}$ & $371,17 d$ & $9,6 \mathrm{e}$ \\
\hline & \multirow{3}{*}{$\mathrm{RIClO}$} & R1 & $10,33 b c$ & $1686 \mathrm{~cd}$ & $153,32 \mathrm{c}$ & $88,75 b$ & $0,913 c$ & $235,83 b c$ & $7,0 \mathrm{~cd}$ \\
\hline & & R2 & 17,00 e & 1938,67 de & $112,95 b$ & $88,33 b$ & $0,912 c$ & 658,83 e & $3,0 \mathrm{a}$ \\
\hline & & R3 & 14,83 de & 2260,92 de & $149,87 \mathrm{c}$ & $90,00 \mathrm{~b}$ & $0,953 \mathrm{~cd}$ & $326,92 \mathrm{~cd}$ & $7,5 \mathrm{~d}$ \\
\hline & & $\mathrm{sg}$ & $* * *$ & $* * *$ & $* * *$ & $* * *$ & $* * *$ & $* * *$ & $* * *$ \\
\hline \multirow{11}{*}{2015} & \multirow{3}{*}{ CAMPILLO } & C1 & $4 a$ & $330,5 a$ & $86,25 a b c$ & $75,5 \mathrm{ab}$ & $0,862 a$ & $228,7 \mathrm{a}$ & $1,64 a b$ \\
\hline & & 02 & $6,42 a b$ & $481,17 \mathrm{a}$ & $78,63 a b c$ & $101,25 c$ & $1,048 \mathrm{~cd}$ & $276,67 a b$ & $1,89 a b$ \\
\hline & & C3 & $6 a$ & $552,00 \mathrm{a}$ & $98,10 b c$ & $77,5 a b$ & $0,916 a b$ & $297,5 a b$ & $1,83 a b$ \\
\hline & \multirow{2}{*}{$\begin{array}{l}\text { MAJADA } \\
\text { HONDA }\end{array}$} & M1 & $5,78 \mathrm{a}$ & $356,78 a$ & $68,17 a b$ & $82,33 a b$ & $0,867 a$ & $348,44 a b$ & $0,91 \mathrm{a}$ \\
\hline & & M2 & $5,6 a$ & $316,2 a$ & $56,15 a$ & $84 a b$ & $0,851 a$ & $442,8 b c$ & $0,76 a$ \\
\hline & \multirow{2}{*}{ NAVAL } & N1 & $9,75 b c$ & $1991,5 d$ & $198,25 d$ & $122,08 \mathrm{~d}$ & $1,041 \mathrm{~cd}$ & $570,33 c$ & $3,5 c$ \\
\hline & & N2 & $10,25 \mathrm{c}$ & $1901,33 \mathrm{~cd}$ & $186,23 d$ & $107,5 \mathrm{c}$ & $0,993 \mathrm{bcd}$ & $534,67 \mathrm{c}$ & $3,6 c$ \\
\hline & \multirow{4}{*}{ RICIO } & R1 & $11,92 \mathrm{~cd}$ & $1300,75 b$ & $105,08 \mathrm{c}$ & $71,25 a$ & $1,087 d$ & $362,67 a b$ & $3,57 c$ \\
\hline & & R2 & $18,5 \mathrm{e}$ & $1708,25 \mathrm{bcd}$ & $89,11 b c$ & $107,08 \mathrm{c}$ & $0,967 a b c$ & $845,5 d$ & $2,49 b c$ \\
\hline & & R3 & $14,67 d$ & $1339,33 b c$ & $91,27 b c$ & $88,33 b$ & $0,867 a$ & $540,17 c$ & $2,7 \mathrm{bc}$ \\
\hline & & $\mathrm{sg}$ & $* * *$ & $* * *$ & $* * *$ & $* * *$ & $* * *$ & $* * *$ & $* * *$ \\
\hline
\end{tabular}


Tabla 29. Valores separados por sectores de comparación de medias y sus agrupaciones mediante el test de Duncan, así como su significación (sg) para un nivel de probabilidad $p<0,001\left(^{* *}\right) ; p<0,01\left(^{* *}\right) ; p<0,05(*)$ y ns (no significativo) para: NRAC (No de Racimos), PROD (Racimos*PRacimo), PRAC (Peso del racimo, gr), NPAMP (№ de Pámpanos), LONG (Longitud del sarmiento, cm), CAL (Calibre del sarmiento, cm), PESOMAD (Peso de madera de poda, gr) y RAVAZ (Índice de Ravaz: Pesomad/Producción). Resultados para la media de los cuatro años de ensayo.

\begin{tabular}{|c|c|c|c|c|c|c|c|c|c|c|}
\hline AÑO & PARCELA & SECTOR & NRAC & PROD & PRAC & NPAMP & LONG & CAL & PESOMAD & RAVAZ \\
\hline \multirow{11}{*}{$\begin{array}{l}\text { MEDIA 2012- } \\
2015\end{array}$} & \multirow{3}{*}{ CAMPILLO } & C1 & $8,96 a$ & $835,22 a b c$ & $93,41 a b$ & $10,41 a b$ & $72,13 a b$ & $0,91 b$ & $230,06 a$ & $4,64 c$ \\
\hline & & C2 & $9,85 a b c$ & $1082,17 \mathrm{~cd}$ & $112,08 \mathrm{c}$ & $11,17 b c$ & 96,77 de & 1,03 de & $406,94 \mathrm{~cd}$ & $3,05 a$ \\
\hline & & C 3 & $9,5 a b$ & $706,35 \mathrm{a}$ & $77,1 \mathrm{a}$ & $10,02 a$ & $68,93 \mathrm{a}$ & $0,87 a$ & $230,87 a$ & $4,06 \mathrm{bc}$ \\
\hline & \multirow{2}{*}{$\begin{array}{l}\text { MAJADA } \\
\text { HONDA }\end{array}$} & M1 & $9,04 \mathrm{a}$ & $1022,09 \mathrm{bcd}$ & $113,15 \mathrm{c}$ & $11,98 \mathrm{~cd}$ & 100,16 de & $1 d$ & $390,39 c$ & $3,02 \mathrm{a}$ \\
\hline & & M2 & $8,24 \mathrm{a}$ & 766,76 ab & $92,09 a b$ & $11,74 \mathrm{~cd}$ & $82,98 \mathrm{c}$ & $0,91 \mathrm{~b}$ & $307,78 \mathrm{~b}$ & $3,3 a b$ \\
\hline & \multirow{2}{*}{ NAVAL } & N1 & $11,5 c$ & $2342,27 \mathrm{~g}$ & $200,51 d$ & $10,33 a b$ & $122,69 f$ & $1,08 \mathrm{f}$ & 558,65 e & $4,97 \mathrm{~cd}$ \\
\hline & & N2 & $11,02 b c$ & $2438,62 \mathrm{~g}$ & 216,52 e & $10,58 a b$ & $119,5 f$ & 1,05 ef & 584,02 e & $4,94 \mathrm{~cd}$ \\
\hline & \multirow{4}{*}{ RICIO } & R1 & $10,77 b c$ & 1274,94 de & $114,11 \mathrm{c}$ & $12,19 d$ & $78,75 b c$ & $0,99 \mathrm{~cd}$ & $306,67 \mathrm{~b}$ & $5,8 d$ \\
\hline & & R2 & $15,19 \mathrm{e}$ & $1640,23 \mathrm{f}$ & $108,56 b c$ & $13,00 \mathrm{e}$ & 101,77 e & $1,02 \mathrm{de}$ & $689,56 \mathrm{f}$ & $4,13 b c$ \\
\hline & & R3 & $13,04 \mathrm{~d}$ & 1506,40 ef & $113,21 \mathrm{c}$ & $11,67 \mathrm{~cd}$ & $93,27 d$ & $0,95 \mathrm{c}$ & $460,75 d$ & $4,56 \mathrm{C}$ \\
\hline & & $s g$ & $* * *$ & $* * *$ & *** & *** & $* * *$ & *** & $* * *$ & $* * *$ \\
\hline
\end{tabular}

Tabla 30. Valores separados por años de comparación de medias y sus agrupaciones mediante el test de Duncan, así como su significación (sg) para un nivel de probabilidad $p<0,001\left(^{* *}\right) ; p<0,01\left(^{(*)}\right) ; p<0,05\left({ }^{*}\right)$ y ns (no significativo) para: NRAC (No de Racimos), PROD (Racimos*PRacimo), PRAC (Peso del racimo, gr), NPAMP (№ de Pámpanos), LONG (Longitud del sarmiento, cm), CAL (Calibre del sarmiento, cm), PESOMAD (Peso de madera de poda, gr) y RAVAZ (Índice de Ravaz: Pesomad/Producción).

\begin{tabular}{|l|r|r|r|r|r|r|r|r|}
\hline AÑO & NRAC & PROD & PRAC & NPAMP & LONG & CAL & PESOMAD & RAVAZ \\
\hline 2012 & $10,66 \mathrm{~b}$ & $1440,22 \mathrm{~b}$ & $137,25 \mathrm{c}$ & $10,87 \mathrm{~b}$ & $76,32 \mathrm{a}$ & $0,95 \mathrm{~b}$ & $270,43 \mathrm{a}$ & $6,5 \mathrm{c}$ \\
\hline 2013 & $12,04 \mathrm{c}$ & $1384,71 \mathrm{~b}$ & $118,17 \mathrm{~b}$ & $11,24 \mathrm{~b}$ & $131,58 \mathrm{c}$ & $1,15 \mathrm{c}$ & $683,8 \mathrm{c}$ & $2,13 \mathrm{a}$ \\
\hline 2014 & $10,6 \mathrm{~b}$ & $1562,68 \mathrm{~b}$ & $133,84 \mathrm{c}$ & $9,93 \mathrm{a}$ & $74,75 \mathrm{a}$ & $0,87 \mathrm{a}$ & $268,56 \mathrm{a}$ & $5,92 \mathrm{~b}$ \\
\hline 2015 & $9,60 \mathrm{a}$ & $1079,89 \mathrm{a}$ & $108,12 \mathrm{a}$ & $13,34 \mathrm{c}$ & $92,62 \mathrm{~b}$ & $0,95 \mathrm{~b}$ & $45393 \mathrm{~b}$ & $2,37 \mathrm{a}$ \\
\hline & $* *$ & $* * *$ & $* * *$ & $* * *$ & $* * *$ & $* * *$ & $* * *$ & $* * *$ \\
\hline
\end{tabular}

\subsubsection{Número de racimos}

Respecto al número de racimos por planta, en el año 2013 no se encontraron diferencias significativas entre los distintos sectores, mientras que en el año 2012 las diferencias fueron moderadamente significativas y altamente significativas para los años 2014 y 2015. En el sector R2 se han encontrado el mayor número de racimos durante los años 2012, 2014 y 2015. El sector R3 también muestra tendencia hacia una alta producción de racimos.

La parcela Majadahonda es la que menor número de racimos por planta produce, particularmente el sector M2. También la parcela Campillo muestra una tendencia hacia la baja producción de racimos, especialmente los sectores C1 y C3.

Atendiendo a las distintas añadas se han encontrado diferencias significativas, Tabla 30, siendo el año 2013 el de mayor producción de racimos, todo lo contrario a lo sucedido en el año 2015 (Figura 49). 

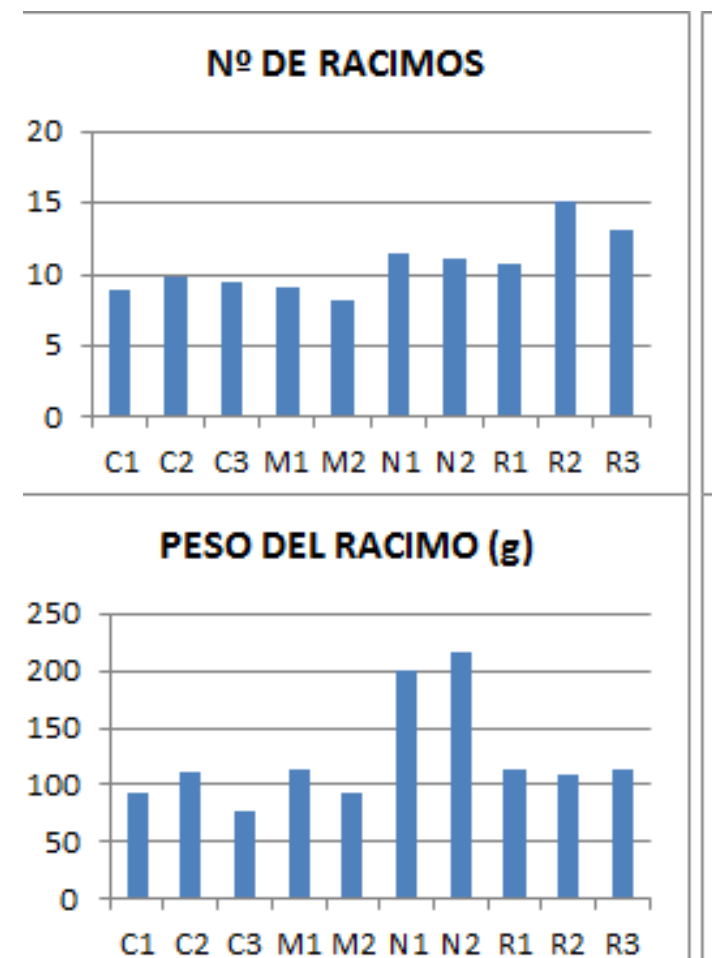

LONGITUD DE SARMIENTOS

(cm)

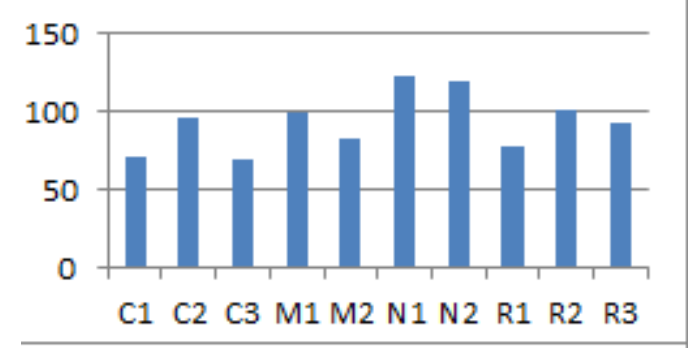

PESO MADERA DE PODA (g)

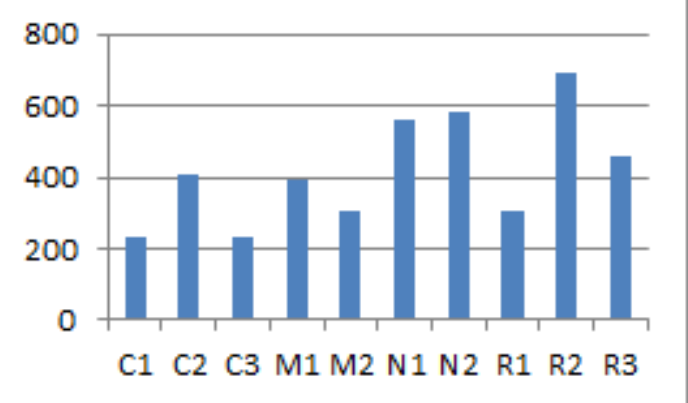

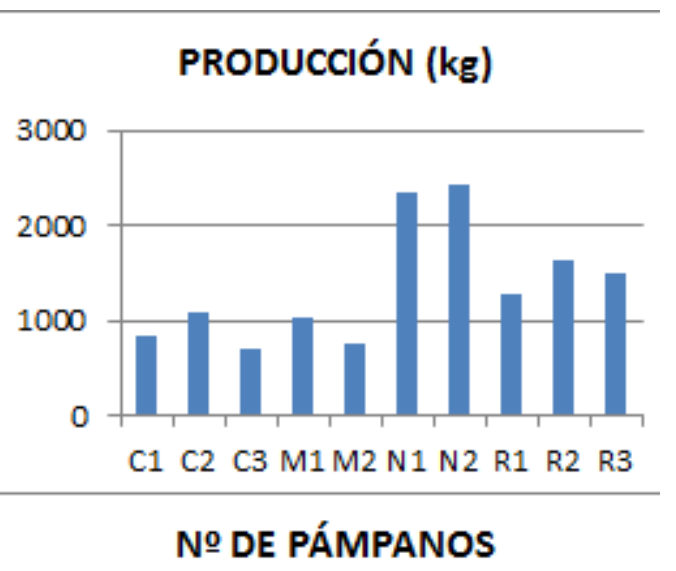
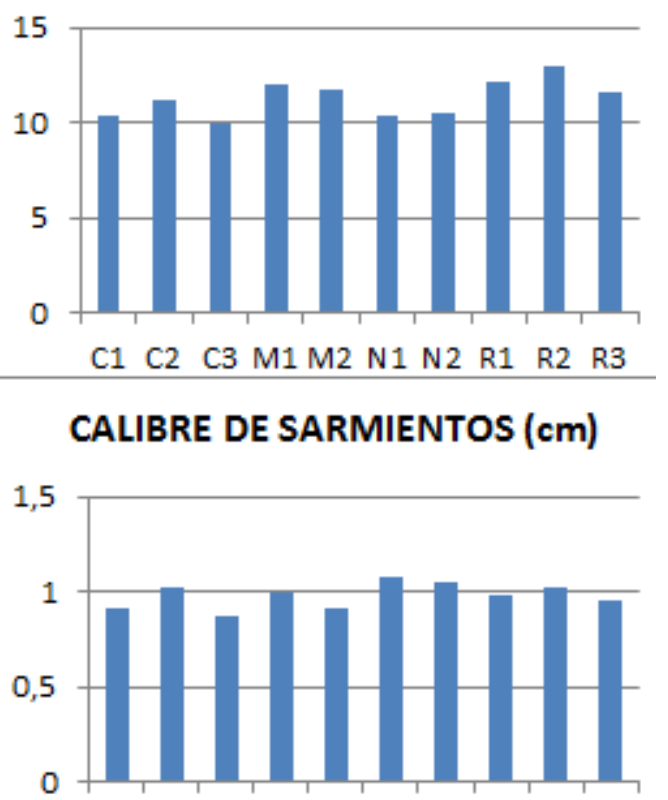

C1 C2 C3 M1 M2 N1 N2 R1 R2 R3

ÍNDICE DE RAVAZ

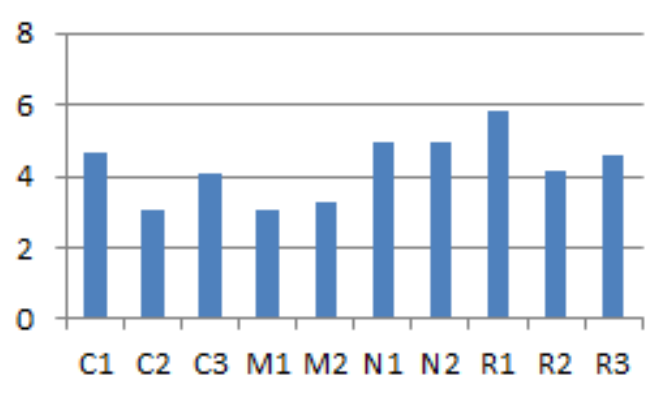

Figura 48. Representación de las variables vegeto-productivas estudiadas por sectores: C1, C2 y C3: CAMPILLO; M1 Y M2: MAJADAHONDA; N1 Y N2: NAVAL; R1, R2 Y R3: RICIO. 


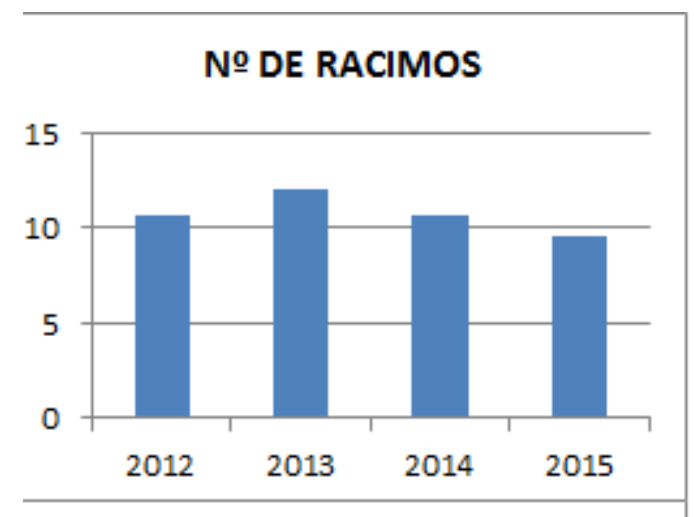

PESO DEL RACIMO (g)

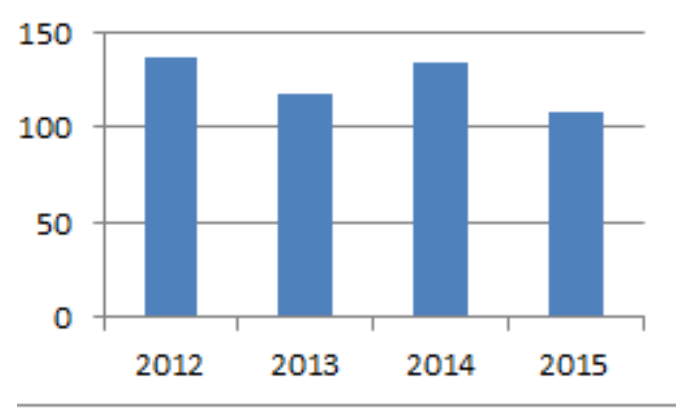

LONGITUD DE SARMIENTOS

(cm)

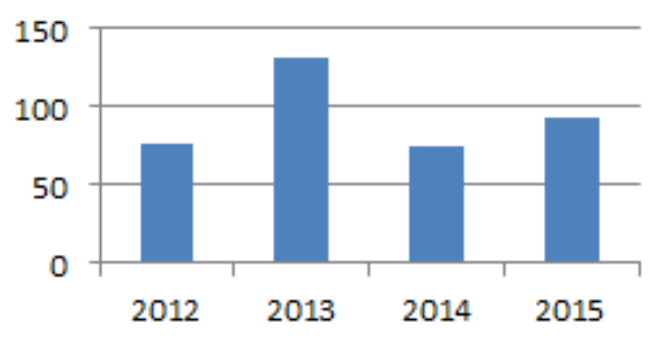

PESO MADERA DE PODA (g)

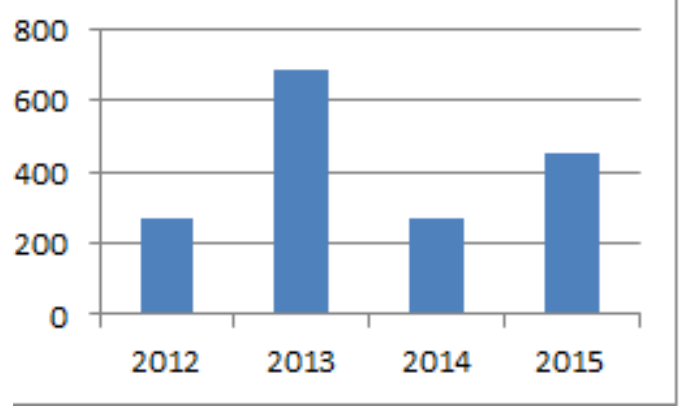

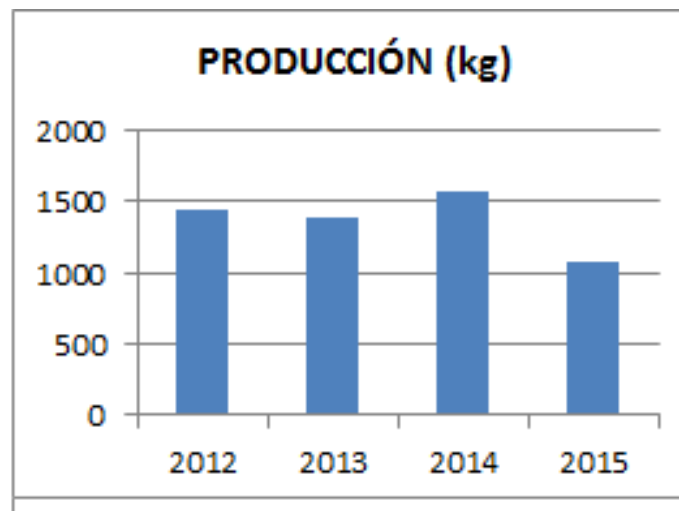

№ DE PÁMPANOS

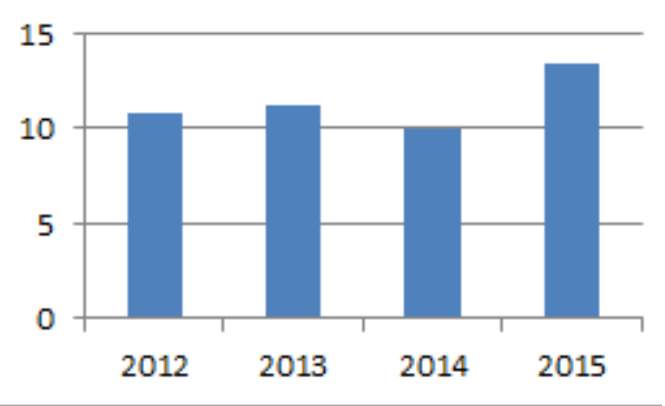

CALIBRE DE SARMIENTOS (cm)

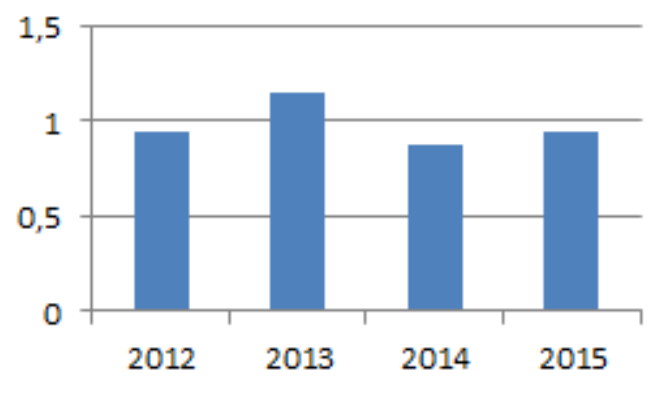

ÍNDICE DE RAVAZ

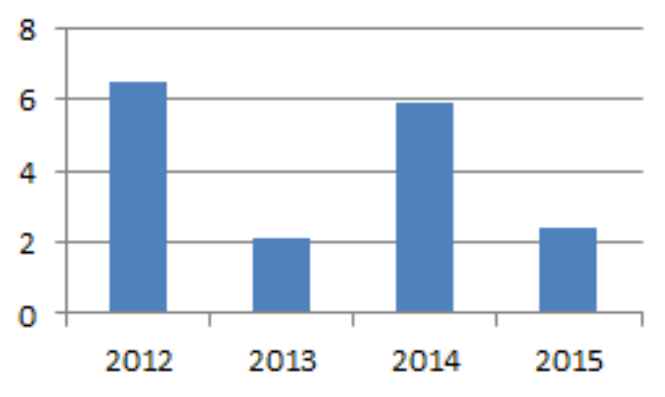

Figura 49. Representación de las variables vegeto-productivas estudiadas durante los cuatro años de ensayo.. 


\subsubsection{Peso del racimo y producción}

La finca Naval, sectores N1 y N2, ha mostrado un mayor peso de los racimos y una mayor producción durante los cuatro años de estudio.

El sector R2 de la finca Ricio, y en menor medida el sector R3, se han caracterizado por una alta producción de racimos de peso moderado, lo que se traduce en unos niveles de producción elevados sin llegar a los valores de la finca Naval, con menor número de racimos, pero de mayor peso (Figura 48).

En general, la parcela Majadahonda produce racimos de bajo peso, lo que unido al poco número de racimos hace que sus producciones sean más limitadas. Un comportamiento similar muestran los sectores C1 y C3, de la finca Campillo (Figura 48).

El año 2015 se caracterizó por tener un menor peso de racimos, lo que unido al menor número de racimos producidos por planta durante esa campaña provoca una disminución altamente significativa de la producción de cosecha.

\subsubsection{Longitud y calibre del sarmiento}

La parcela Naval (N1 y N2) ha desarrollado unos sarmientos de gran longitud y calibre durante los cuatro años. También los sectores R2 y C2 han mostrado tendencia hacia la producción de sarmientos más largos y gruesos. Por el contrario, los sectores C1 y C3 de la parcela Campillo, tienden a producir sarmientos de menor longitud y calibre.

Respecto a la diferencia entre añadas, en las campañas 2012 y 2014 la longitud y el calibre de los sarmientos fueron inferiores a los otros años, encontrando diferencias altamente significativas (Figura 49).

\subsubsection{Peso de madera de poda}

El sector R2 de la parcela Ricio y los dos sectores de la parcela Naval han mostrado un mayor peso de la madera de poda frente al resto de sectores. También el sector C2 de la parcela Campillo muestra una tendencia hacia la alta producción de madera, mientras que los sectores C1 y C3 de esta parcela producen menor peso de madera de poda, atendiendo a los resultados obtenidos durante los cuatro años.

Al igual que sucedía con la longitud y el calibre de los sarmientos, el peso de la madera de poda de los años 2012 y 2014 fue inferior a la de los años 2013 y 2015, siendo también las diferencias altamente significativas (Figura 49).

\subsubsection{5. Índice de Ravaz. Equilibrio vegeto-productivo}

La tendencia del Índice de Ravaz es a tomar los valores más elevados en la parcela Naval y en el sector R1 de la parcela Ricio, mientras que la parcela Majadahonda junto con el sector C2 de Campillo tienden a mostrar los valores más bajos (Figura 48). 
Durante los años 2013 y 2015 se ha visto favorecido el crecimiento vegetativo frente a la producción de uva, tomando el índice de Ravaz valores más bajos, mientras que en el año 2012 este equilibrio se desplazó de manera altamente significativa hacia la producción de cosecha (Figura 49).

\subsubsection{Composición de la uva}

En la Tabla 31 se presentan los estadísticos relacionados con el análisis de varianza (ANOVA) para las propiedades de la uva estudiadas.

Tabla 31. Análisis de varianza (ANOVA) por sectores, años y la interacción Año*Sector para Grado de Alcohol Probable, Acidez Total, pH, Ácido Málico, Índice de Color, Índice de Polifenoles Totales, Antocianos, Peso de 100 bayas, Potasio y Ácido Tartárico; gl: grados de libertad, SS: Suma de cuadrados; MC: Media cuadrática, Sig: grado de significación para un nivel de probabilidad $p<0,05\left(^{*}\right)$, $p<0,01\left(^{* *}\right), p<0,001\left(^{* *}\right)$ y no significativo (ns).

\begin{tabular}{|c|c|c|c|c|c|c|c|c|c|c|c|c|}
\hline & \multicolumn{4}{|c|}{ Grado de Alcohol Probable } & \multicolumn{4}{|c|}{ Acidez } & \multicolumn{4}{|c|}{ pH } \\
\hline & gl & SS & $M C$ & Sig. & $\mathrm{gl}$ & SS & $M C$ & Sig. & $\mathrm{gl}$ & SS & $M C$ & Sig. \\
\hline Sector & 9 & 16,80 & 1,87 & *** & 9 & 11,35 & 1,26 & $* * *$ & 9 & 0,54 & 0,06 & *** \\
\hline Año & 3 & 119,5 & 39,83 & $* * *$ & 3 & 120,76 & 40,25 & $* * *$ & 3 & 3,2 & 1,07 & $* * *$ \\
\hline Año*Sector & 27 & 26,53 & 0,98 & ** & 27 & 13,56 & 0,5 & * & 27 & 0,35 & 0,01 & $* *$ \\
\hline \multirow[t]{3}{*}{ Error } & 40 & 15,04 & 0,38 & & 40 & 9,97 & 0,25 & & 40 & 0,21 & 0,00 & \\
\hline & \multicolumn{4}{|c|}{ Ácido Málico } & \multicolumn{4}{|c|}{ Índice de Color } & \multicolumn{4}{|c|}{ Índice de Polifenoles Totales } \\
\hline & $\mathrm{gl}$ & SS & $M C$ & Sig. & $g l$ & SS & $M C$ & Sig. & $g l$ & SS & $M C$ & Sig. \\
\hline Sector & 9 & 11,96 & 1,33 & ** & 9 & 345,71 & 38,41 & $* *$ & 9 & 2431,56 & 270,17 & *** \\
\hline Año & 3 & 33,49 & 11,16 & $* * *$ & 3 & 505,94 & 168,65 & $* * *$ & 3 & 2047,84 & 682,61 & *** \\
\hline Año*Sector & 27 & 16,34 & 0,60 & * & 27 & 168,12 & 6,23 & ns & 27 & 1855,39 & 68,72 & ** \\
\hline \multirow[t]{3}{*}{ Error } & 40 & 14,93 & 0,37 & & 40 & 355,69 & 8,89 & & 40 & 946,35 & 23,66 & \\
\hline & \multicolumn{4}{|c|}{ Antocianos } & \multicolumn{4}{|c|}{ Peso de 100 Bayas } & \multicolumn{4}{|c|}{ Potasio } \\
\hline & $\mathrm{gl}$ & SS & $M C$ & Sig. & gl & SS & $M C$ & Sig. & gl & SS & $M C$ & Sig. \\
\hline Sector & 9 & 448975,01 & 49886,11 & $* * *$ & 9 & 20923,3 & 2324,81 & $* * *$ & 9 & 4375583,75 & 486175,97 & *** \\
\hline Año & 3 & 1032701,6 & 344233,88 & $* * *$ & 3 & 24495,35 & 8165,12 & $* * *$ & 2 & 224250,83 & 112125,42 & ns \\
\hline Año*Sector & 27 & 327504,74 & 12129,8 & ns & 27 & 12843,9 & 475,7 & $* *$ & 18 & 2174107,5 & 120783,75 & * \\
\hline \multirow[t]{3}{*}{ Error } & 40 & 379344,5 & 9483,61 & & 40 & 8375 & 209,37 & & 30 & 1873262,5 & 62442,08 & \\
\hline & \multicolumn{4}{|c|}{ Ácido Tartárico } & & & & & & & & \\
\hline & gl & SS & MC & Sig. & & & & & & & & \\
\hline Sector & 9 & 2,53 & 0,28 & * & & & & & & & & \\
\hline Año & 2 & 17,65 & 8,83 & $* * *$ & & & & & & & & \\
\hline Año*Sector & 18 & 3,15 & 0,17 & ns & & & & & & & & \\
\hline Error & 30 & 3,31 & 0,11 & & & & & & & & & \\
\hline
\end{tabular}


De forma análoga al resultado del análisis de los componentes vegeto-productivos expuesto en el apartado anterior, es posible discriminar entre sectores en función de la composición de la uva cosechada en ellos. Así, la parcela Naval y los sectores R2 y R3 de Ricio presentan una tendencia hacia la producción de uvas más pesadas, menos dulces, más ácidas y de menor contenido polifenólico. Por el contrario, la parcela Campillo produce mostos con tendencia a un mayor contenido en azúcar, menor acidez y mayor contenido polifenólico, pero respecto al peso de las bayas, el sector C2 de esta finca produjo uvas más pesadas (similares a las producidas por el sector R2) así como una producción entre un 20\% y un 35\% superior a los otros dos sectores de Campillo (Tabla 32).

El efecto del clima sobre la composición de la uva se hizo notablemente presente el año 2013. Como ya se ha comentado, se trata de un año especialmente húmedo y fresco, clasificándose como templado (IH-1) y subhúmedo (IS-1) produciéndose mostos con menor contenido sacarimétrico, mayor acidez (tanto en ácido málico como en ácido tartárico) y menor contenido en polifenoles. Puesto que el año 2015 también se clasificó como IS-1, se vendimió aproximadamente 20 días antes que en 2013 (Tabla 17 del § 6.2) y sus mostos fueron similares a los de los años 2012 y 2014, se puede concluir que la temperatura (representada a través del $\mathrm{IH}$ ) durante el ciclo vegetativo es un factor decisivo en la determinación de la fecha de vendimia y en la composición de uva. Esta influencia del clima anual, particularmente del año 2013, coincide con los resultados encontrados por Ramos y Martínez de Toda (2019) en un estudio llevado a cabo en el ámbito de la DOCa Rioja entre los años 2.008 y 2.017.

En la Tabla 32 se presentan los resultados de laboratorio donde se cuantifican los parámetros relacionados con la uva. Los datos están separados por años (2012, 2013, 2014 y 2015) y cada año por sectores. Los valores de cada parámetro han sido agrupados mediante el test de Duncan, siempre que el análisis ANOVA mostró diferencias significativas, pudiendo así comparar los resultados de unos sectores frente a otros. De forma análoga, en la Tabla 33, se muestran los valores medios de los cuatro años para cada parámetro estudiado, agrupando los sectores también mediante el test de Duncan. Estos resultados se representan gráficamente en la Figura 50.

En la Tabla 34 se presentan los valores medios de cada parámetro durante los cuatro años de ensayo, de esta forma es posible analizar el efecto de la añada sobre las características estudiadas de la uva, de forma análoga a lo señalado respecto a los componentes vegeto-productivos (Tabla 30 del § 6.5.2). En la Figura 51 pueden observarse estos resultados de manera gráfica. 
Tabla 32. Valores separados por sectores de comparación de medias y sus agrupaciones mediante el test de Duncan, así como su significación ( $\mathrm{sg}$ ) para un nivel de probabilidad $\mathrm{p}<0,05\left(^{*}\right), \mathrm{p}<0,01\left(^{* *}\right)$ y $\mathrm{p}<0,001\left(^{* * *}\right.$ ) para: GAP (Grado de Alcohol Probable, \% volúmen), ATOTAL (Acidez Total, gr/l de Ácido Tartárico), MH2 (Ácido Málico, gr/l), IC (Índice de Color), IPT (Índice de Polifenoles Totales), ANTO (Antocianos, mg/l), P100B (peso de 100 bayas, gr), K (potasio, mg/l) y TH2 (Ácido Tartárico, gr/l). Resultados para cada uno de los cuatro años de estudio.

\begin{tabular}{|c|c|c|c|c|c|c|c|c|c|c|c|c|}
\hline AÑO & PARCELA & SECTOR & GAP & ATOTAL & $\mathrm{pH}$ & $\mathrm{MH} 2$ & IC & IPT & ANTO & P100B & K & $\mathrm{TH} 2$ \\
\hline \multirow{11}{*}{2012} & \multirow{3}{*}{ CAMPILLO } & C1 & 14,91 & $3,60 \mathrm{a}$ & $4,215 \mathrm{~cd}$ & $2,95 \mathrm{~d}$ & 16,3735 & 51 & 741,5 & 135 & & \\
\hline & & $C 2$ & 14,84 & $3,75 a b$ & $4,1 b c d$ & $2,25 b c$ & 18,8655 & 56,5 & 785,5 & 137,5 & & \\
\hline & & $C 3$ & 15,12 & $3,65 a$ & $4,305 d$ & $3,1 \mathrm{~d}$ & 18,1175 & 55,5 & 837,5 & 110,5 & & \\
\hline & \multirow{2}{*}{$\begin{array}{l}\text { MAJADA } \\
\text { HONDA }\end{array}$} & M1 & 14,44 & $3,7 a b$ & $3,975 a b$ & $1,75 a b$ & 14,298 & 48,5 & 599,5 & 151 & & \\
\hline & & M2 & 14,19 & $3,85 a b$ & $3,865 \mathrm{a}$ & $1,55 a$ & 14,7795 & 45 & 610,5 & 146,5 & & \\
\hline & \multirow{2}{*}{ NAVAL } & N1 & 14,70 & $4,7 c$ & $4,145 \mathrm{bcd}$ & $3,1 \mathrm{~d}$ & 14,345 & 49,5 & 630 & 140,5 & & \\
\hline & & N2 & 14,76 & $4,2 b c$ & $4,19 \mathrm{~cd}$ & $3,1 \mathrm{~d}$ & 12,8365 & 48 & 619 & 148,5 & & \\
\hline & \multirow{4}{*}{ RICIO } & R1 & 14,32 & $4,2 b c$ & $4,065 \mathrm{abc}$ & $2,85 d$ & 19,5525 & 58 & 907 & 116 & & \\
\hline & & R2 & 14,15 & $4,05 a b$ & $4,04 a b c$ & $2,9 d$ & 17,683 & 51 & 790 & 122 & & \\
\hline & & R3 & 15,09 & $3,95 a b$ & $4,1 \mathrm{bcd}$ & $2,7 \mathrm{~cd}$ & 20,3935 & 56,5 & 837 & 121 & & \\
\hline & & sig. & ns & $*$ & $*$ & $* * *$ & ns & ns & ns & ns & & \\
\hline \multirow{11}{*}{2013} & \multirow{3}{*}{ CAMPILLO } & C1 & 12,15 & 5,60 & $3,62 \mathrm{~cd}$ & 2,75 & 14,766 & $45,50 b c$ & 577,00 & $172,0 \mathrm{bcd}$ & $2090,0 a b c$ & $5,73 b$ \\
\hline & & C2 & 12,45 & 5,65 & $3,60 b c$ & 2,80 & 18,295 & $51,50 \mathrm{c}$ & 659,50 & 195,0def & $1955,0 \mathrm{ab}$ & $5,04 a$ \\
\hline & & C3 & 11,87 & 6,40 & $3,72 d$ & 4,00 & 18,731 & $52,00 \mathrm{c}$ & 698,00 & $163,5 a b$ & $2755,0 \mathrm{~d}$ & $5,94 b$ \\
\hline & \multirow{2}{*}{$\begin{array}{l}\text { MAJADA } \\
\text { HONDA }\end{array}$} & M1 & 10,83 & 6,25 & $3,51 a b$ & 3,05 & 13,303 & $38,50 a b$ & 498,50 & $166,5 \mathrm{abc}$ & $1825,0 a b$ & $5,62 b$ \\
\hline & & M2 & 10,70 & 5,80 & $3,44 a$ & 2,35 & 16,449 & $42,50 \mathrm{~b}$ & 565,50 & $145,5 \mathrm{a}$ & $1730,0 \mathrm{a}$ & $6,06 \mathrm{~b}$ \\
\hline & \multirow{2}{*}{ NAVAL } & N1 & 11,57 & 6,75 & $3,60 \mathrm{bc}$ & 3,95 & 14,193 & $43,50 \mathrm{~b}$ & 538,00 & $207,5 f$ & $2420,0 \mathrm{~cd}$ & $5,88 b$ \\
\hline & & N2 & 11,51 & 5,85 & $3,64 \mathrm{~cd}$ & 3,50 & 12,953 & $39,00 \mathrm{ab}$ & 501,00 & 197,5ef & $2210,0 b c$ & $5,73 b$ \\
\hline & \multirow{4}{*}{ RICIO } & R1 & 12,04 & 6,70 & $3,41 \mathrm{a}$ & 3,00 & 13,348 & $35,00 \mathrm{a}$ & 485,50 & 189,0cdef & $1830,0 \mathrm{ab}$ & $5,97 \mathrm{~b}$ \\
\hline & & R2 & 12,59 & 8,95 & $3,51 a b$ & 5,65 & 12,417 & $41,50 \mathrm{ab}$ & 470,50 & 189,5cdef & $2425,0 \mathrm{~cd}$ & $6,67 \mathrm{c}$ \\
\hline & & R3 & 12,32 & 7,50 & $3,51 a b$ & 4,05 & 13,295 & $41,00 a b$ & 501,00 & $181,5 b c d e$ & $2065,0 a b c$ & $6,52 c$ \\
\hline & & sig. & ns & ns & $* *$ & ns & ns & ** & ns & ** & ** & $* * *$ \\
\hline \multirow{11}{*}{2014} & \multirow{3}{*}{ CAMPILLO } & C1 & $14,895 \mathrm{~cd}$ & $3,1 a b$ & $4,03 a$ & 1,55 & 14,839 & $53,5 b c$ & 658,50 & $138,5 a b$ & 2165 & 5,3 \\
\hline & & C2 & $14,69 \mathrm{~cd}$ & $3,45 a b c$ & $3,935 a$ & 1,45 & 16,1135 & $58 \mathrm{c}$ & 654,50 & $142,0 a b$ & 2160 & 5,8 \\
\hline & & C3 & $16,015 d$ & $3,45 a b c$ & $4,215 b$ & 2,20 & 12,9315 & $49 a b c$ & 582,50 & 108,0a & 2740 & 5,8 \\
\hline & \multirow{2}{*}{$\begin{array}{l}\text { MAJADA } \\
\text { HONDA }\end{array}$} & M1 & $14,355 \mathrm{c}$ & $3,05 a b$ & 4,005a & 1,40 & 11,6755 & $42 a b c$ & 515,00 & 124,0a & 1955 & 5,2 \\
\hline & & M2 & $14,905 \mathrm{~cd}$ & $2,95 \mathrm{a}$ & $4,02 \mathrm{a}$ & 2,55 & 11,671 & $47 a b c$ & 596,00 & $112,0 \mathrm{a}$ & 1990 & 5,3 \\
\hline & \multirow{2}{*}{ NAVAL } & N1 & $12,865 a b$ & $3,7 \mathrm{~cd}$ & $3,95 \mathrm{a}$ & 2,10 & 7,762 & $34 a$ & 391,50 & $175,0 b c$ & 2285 & 5,5 \\
\hline & & N2 & $12,525 \mathrm{a}$ & $3,85 \mathrm{~cd}$ & $3,85 a$ & 2,05 & 7,819 & $32 a$ & 381,50 & $189,5 c$ & 2147,5 & 5,6 \\
\hline & \multirow{4}{*}{ RICIO } & R1 & $13,94 b c$ & $3,6 \mathrm{bcd}$ & $3,875 a$ & 1,95 & 12,7115 & $54 b c$ & 524,50 & $132,0 \mathrm{ab}$ & 2615 & 5,8 \\
\hline & & R2 & $14,9 \mathrm{~cd}$ & $4,1 d$ & $3,945 \mathrm{a}$ & 1,45 & 10,7335 & $38,5 a b$ & 490,00 & $170,5 b c$ & 2355 & 5,95 \\
\hline & & R3 & $14,11 b c$ & $3,6 b c d$ & $3,9 a$ & 1,80 & 10,774 & $37,5 \mathrm{ab}$ & 461,00 & $174,0 b c$ & 2070 & 5,7 \\
\hline & & sig. & ** & $*$ & $*$ & ns & ns & * & ns & ** & ns & ns \\
\hline \multirow{11}{*}{2015} & \multirow{3}{*}{ CAMPILLO } & C1 & $15,84 d$ & $3,25 a$ & $3,93 a b c d$ & $1,95 \mathrm{a}$ & $20,0855 \mathrm{~cd}$ & $67,85 \mathrm{ef}$ & $846,5 \mathrm{c}$ & $144,5 a$ & $2140 a b$ & $4,9 a$ \\
\hline & & $C 2$ & $15,63 \mathrm{~cd}$ & $3,7 a b c$ & $3,8 a b c$ & $1,35 \mathrm{a}$ & $23,3105 d$ & $59,9 \mathrm{de}$ & $835 \mathrm{~cd}$ & $161 a b$ & $1785 a$ & $4,3 a$ \\
\hline & & C3 & $16,04 d$ & $3,6 a b$ & $4,11 d$ & $2,4 \mathrm{a}$ & $22,8640 \mathrm{~d}$ & $72,6 f$ & $1032,5 e$ & 130a & $3240 c$ & $4,7 \mathrm{a}$ \\
\hline & \multirow{2}{*}{$\begin{array}{l}\text { MAJADA } \\
\text { HONDA }\end{array}$} & M1 & $15,09 \mathrm{bcd}$ & $4,25 c$ & $3,99 \mathrm{~cd}$ & $1,85 a$ & $19,2365 b c$ & $58,2 \mathrm{~cd}$ & $835,5 \mathrm{~cd}$ & $148 a$ & $2075 a b$ & $4,6 a$ \\
\hline & & M2 & $15,67 \mathrm{~cd}$ & $3,85 a b c$ & $3,97 \mathrm{bcd}$ & $2,25 a$ & $19,2740 \mathrm{bc}$ & $59,9 \mathrm{de}$ & $847,5 \mathrm{~d}$ & $150,5 \mathrm{a}$ & $2615 b$ & $4,8 \mathrm{a}$ \\
\hline & \multirow{2}{*}{ NAVAL } & N1 & $14,26 a b c$ & $4,25 c$ & $3,9 a b c$ & $2,75 a$ & $14,4460 \mathrm{a}$ & $47,4 a b$ & $689 a b c$ & 196b & $2630 \mathrm{~b}$ & $4,8 \mathrm{a}$ \\
\hline & & N2 & $14,52 \mathrm{abcd}$ & $3,85 a b c$ & $3,79 \mathrm{ab}$ & $2,15 a$ & $14,8075 a$ & $43,25 a b$ & $620 \mathrm{a}$ & 193b & 1945a & $4,4 \mathrm{a}$ \\
\hline & \multirow{4}{*}{ RICIO } & R1 & $13,52 \mathrm{a}$ & $3,85 a b c$ & $3,84 a b c$ & $1,55 a$ & $16,2510 \mathrm{ab}$ & $52,5 b c d$ & $777 \mathrm{bcd}$ & 140a & $2260 \mathrm{ab}$ & $4,5 \mathrm{a}$ \\
\hline & & R2 & $13,74 a b$ & $3,6 a b$ & $3,73 a$ & 2,35a & $16,0960 \mathrm{ab}$ & $40,9 a$ & $636 a b$ & $102 a b$ & 1990a & $4,6 a$ \\
\hline & & R3 & $14,56 a b c d$ & $3,9 b c$ & $3,8 a b c$ & $1,75 a$ & $18,4295 b c$ & $49,4 a b c$ & 747,5abcd & $142 a$ & $2015 \mathrm{a}$ & $4,8 \mathrm{a}$ \\
\hline & & sig. & * & ns & * & ns & $* *$ & $* * *$ & $* *$ & $*$ & $* *$ & ns \\
\hline
\end{tabular}


Tabla 33. Valores separados por sectores de comparación de medias y sus agrupaciones mediante el test de Duncan, así como su

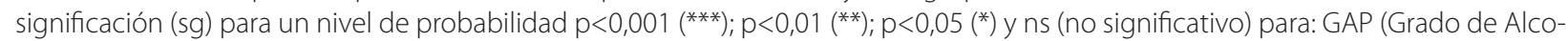
hol Probable, \% volúmen), ATOTAL (Acidez Total, gr/l de Ácido Tartárico), MH2 (Ácido Málico, gr/l), IC (Índice de Color), IPT (Índice de Polifenoles Totales), ANTO (Antocianos, mg/l), P100B (peso de 100 bayas, gr), K (potasio, mg/l) y TH2 (Ácido Tartárico, gr/l). Resultados para la media de los cuatro años de ensayo.

\begin{tabular}{|c|c|c|c|c|c|c|c|c|c|c|c|c|}
\hline AÑO & VIÑEDO & SECTOR & GAP & ATOTAL & pH & $\mathrm{MH} 2$ & IC & IPT & ANTO & P100B & K & TH2 \\
\hline \multirow{11}{*}{$\begin{array}{l}\text { MEDIA } \\
2012-2015\end{array}$} & \multirow{3}{*}{ CAMPILLO } & C1 & $14,45 b c$ & $3,89 a$ & $3,95 \mathrm{c}$ & $2,3 a b c$ & 16,52 cde & 54,46 ef & 705,87 cde & $147,5 b c$ & $2131,67 \mathrm{ab}$ & $5,31 a b c$ \\
\hline & & C2 & $14,40 \mathrm{bc}$ & $4,14 a b$ & $3,86 a b$ & $1,96 a$ & $19,15 \mathrm{e}$ & $56,47 f$ & 733,62 de & $158,87 \mathrm{c}$ & 1966,67 a & $5,05 \mathrm{a}$ \\
\hline & & C3 & $14,76 \mathrm{c}$ & $4,27 a b c$ & $4,09 d$ & $2,92 \mathrm{~cd}$ & 18,16 de & $57,27 f$ & 787,62 e & $128 a$ & 2911,67 c & $5,48 a b c$ \\
\hline & \multirow{2}{*}{$\begin{array}{l}\text { MAJADA } \\
\text { HONDA }\end{array}$} & M1 & $13,68 \mathrm{a}$ & $4,16 a b$ & $3,87 a b$ & $2,01 a b$ & $14,63 \mathrm{abc}$ & $46,8 \mathrm{bcd}$ & $612,12 a b c$ & $147,37 \mathrm{bc}$ & 1951,67 a & 5,14 a \\
\hline & & M2 & $13,86 a b$ & $4,12 a b$ & $3,82 \mathrm{ab}$ & $2,17 a b$ & $15,54 \mathrm{bcd}$ & $48,6 \mathrm{~cd}$ & $654,87 \mathrm{bcd}$ & $138,62 a b$ & $2111,67 \mathrm{a}$ & $5,39 a b c$ \\
\hline & \multirow{2}{*}{ NAVAL } & N1 & $13,35 \mathrm{a}$ & 4,85 de & $3,9 b c$ & $2,97 \mathrm{~cd}$ & $12,69 a b$ & $43,6 a b c$ & $562,12 \mathrm{ab}$ & $179,75 d$ & $2445 b$ & $5,39 a b c$ \\
\hline & & N2 & $13,40 \mathrm{a}$ & 4,44 abcd & $3,87 a b$ & $2,7 \mathrm{bcd}$ & $12,10 \mathrm{a}$ & $40,56 \mathrm{a}$ & $530,37 \mathrm{a}$ & $182,12 \mathrm{~d}$ & 2100,83 a & $5,24 a b$ \\
\hline & \multirow{4}{*}{$\mathrm{RIClO}$} & R1 & $13,45 a$ & $4,59 \mathrm{bcd}$ & $3,8 a$ & $2,34 a b c$ & $15,47 \mathrm{bcd}$ & 49,87 de & $673,5 \mathrm{~cd}$ & $144,25 b c$ & $2235 \mathrm{a}$ & $5,42 a b c$ \\
\hline & & R2 & $13,84 a b$ & $5,17 \mathrm{e}$ & $3,81 \mathrm{a}$ & $3,09 \mathrm{~d}$ & $14,23 \mathrm{abc}$ & $42,97 \mathrm{ab}$ & $596,62 a b c$ & $160,62 \mathrm{c}$ & $2256,67 \mathrm{ab}$ & $5,74 c$ \\
\hline & & R3 & $14,02 \mathrm{ab}$ & 4,74 cde & $3,83 a b$ & 2,57 abcd & $15,72 \mathrm{bcd}$ & $46,1 \mathrm{bcd}$ & $\begin{array}{r}636,62 \\
a b c d\end{array}$ & $154,62 b c$ & $2050 \mathrm{a}$ & $5,67 b c$ \\
\hline & & sig. & $* * *$ & $* * *$ & $* * *$ & $* *$ & ** & $* * *$ & $* * *$ & $* * *$ & $* * *$ & * \\
\hline
\end{tabular}

Tabla 34. Valores separados por años de comparación de medias y sus agrupaciones mediante el test de Duncan, así como su significación (sg) para un nivel de probabilidad $p<0,001\left(^{* * *}\right) ; p<0,01\left(^{* *}\right) ; p<0,05(*)$ y ns (no significativo) para: GAP (Grado de Alcohol Probable, \% volúmen), ATOTAL (Acidez Total, gr/l de Ácido Tartárico), MH2 (Ácido Málico, gr/l), IC (Índice de Color), IPT (Índice de Polifenoles Totales), ANTO (Antocianos, mg/l), P100B (peso de 100 bayas, gr), K (potasio, mg/l) y TH2 (Ácido Tartárico, gr/l).

\begin{tabular}{|r|r|r|r|r|r|r|r|r|r|r|r|}
\hline AÑO & GAP & A.TOTAL & PH & AMALICO & $\mathrm{IC}$ & IPT & ANTO & P100B & K & TH2 \\
\hline 2012 & $14,65 \mathrm{bc}$ & $3,96 \mathrm{~b}$ & $4,1 \mathrm{~d}$ & $2,62 \mathrm{~b}$ & $16,72 \mathrm{c}$ & $51,95 \mathrm{~b}$ & $735,75 \mathrm{~b}$ & $132,85 \mathrm{a}$ & & \\
\hline 2013 & $11,83 \mathrm{a}$ & $6,54 \mathrm{c}$ & $3,56 \mathrm{a}$ & $3,51 \mathrm{c}$ & $14,77 \mathrm{~b}$ & $43 \mathrm{a}$ & $549,45 \mathrm{a}$ & $180,75 \mathrm{~d}$ & 2130,5 & $5,92 \mathrm{c}$ \\
\hline 2014 & $14,32 \mathrm{~b}$ & $3,48 \mathrm{a}$ & $3,97 \mathrm{c}$ & $1,85 \mathrm{a}$ & $11,7 \mathrm{a}$ & $44,55 \mathrm{a}$ & $525,5 \mathrm{a}$ & $146,55 \mathrm{~b}$ & 2248,25 & $5,59 \mathrm{~b}$ \\
\hline 2015 & $14,89 \mathrm{c}$ & $3,75 \mathrm{ab}$ & $3,89 \mathrm{~b}$ & $2,03 \mathrm{a}$ & $18,48 \mathrm{c}$ & $55,19 \mathrm{c}$ & $786,65 \mathrm{~b}$ & $156,55 \mathrm{c}$ & 2269,5 & $4,64 \mathrm{a}$ \\
\hline & $* * *$ & $* * *$ & $* * *$ & $* * *$ & $* * *$ & $* * *$ & $* * *$ & $* * *$ & ns & $* * *$ \\
\hline
\end{tabular}

\subsubsection{Grado alcohólico probable}

El grado de alcohol probable (GAP) no mostró diferencias significativas entre los sectores durante los años 2012 y 2013, mientras que en el año 2015 las diferencias fueron moderadamente significativas y en 2014 significativas. Este último año, la parcela Naval, sectores N1 y N2, obtienen los niveles más bajos de GAP, mientras que el sector C3 de la finca Campillo el nivel sacarimétrico más elevado. Respecto al año 2015, en los sectores C1 y C3 se alcanzaron los niveles más elevados de GAP y en el sector R1 de Ricio los más bajos.

Comparando la media de los valores de los cuatro años, Tabla 33 y Figura 50, se aprecia cómo el sector C3 tiende a producir mayor grado alcohólico mientras que la parcela Naval, sectores N1 y N2, aportan menor GAP a las uvas que producen. 
Los resultados de la Tabla 34 muestran cómo el efecto añada afecta al contenido en azúcar de la cosecha. En el año 2013, caracterizado por una maduración con temperaturas más bajas de lo habitual y mayores precipitaciones anuales.

\subsubsection{Acidez total}

La acidez total mostró diferencias moderadamente significativas los años 2012 y 2014 (Tabla 32). Estos dos años los sectores N1 y N2 de Naval muestran valores elevados de acidez, además el año 2014 el sector R2 de Ricio también produjo uvas con elevada acidez.

Analizando los datos medios de los cuatro años (Tabla 33 y Figura 50) es el sector C1 de Campillo el que dio lugar a mostos de menor acidez y el sector R2 de Ricio el que produce mostos con el mayor contenido en acidez total.

Respecto a la diferencia entre añadas (Tabla 34) se puede observar como en el año 2013 la acidez total fue significativamente superior que en el resto de los años, particularmente frente al año 2014, añada en la que se obtuvieron los valores más bajos de acidez total (Figura 51).

\subsubsection{3. $\mathrm{pH}$}

El pH mostró diferencias moderadamente significativas los años 2012, 2014 y 2015, mientras que en el año 2013 las diferencias si fueron significativas.

Los sectores R1 y especialmente R2 de la parcela Ricio, mostraron una tendencia a producir uvas con un menor pH, mientras que el sector C3 se situó todos los años como el de mayores niveles de pH en el mosto (Tabla 32).

El año 2013 se obtiene el pH del mosto más bajo, siendo la añada 2012 la que produjo uvas con un elevado pH (Figura 51).

\subsubsection{4. Ácido málico}

Sólo se encontraron diferencias significativas respecto al ácido málico en la campaña 2012, apareciendo varios sectores con alto contenido del mismo y el sector M2 de Majadahonda con los niveles más bajos.

Atendiendo a los datos medios de los cuatro años (Tabla 33) el sector R2 destaca por producir uvas con mayor contenido en ácido málico, mientras que la finca Majadahonda, M1 y M2, y especialmente el sector C2 de Campillo se caracterizan por los niveles más bajos de ácido málico.

El año 2013 (Tabla 34) se presenta como el de mayor contenido de ácido málico en los mostos. 


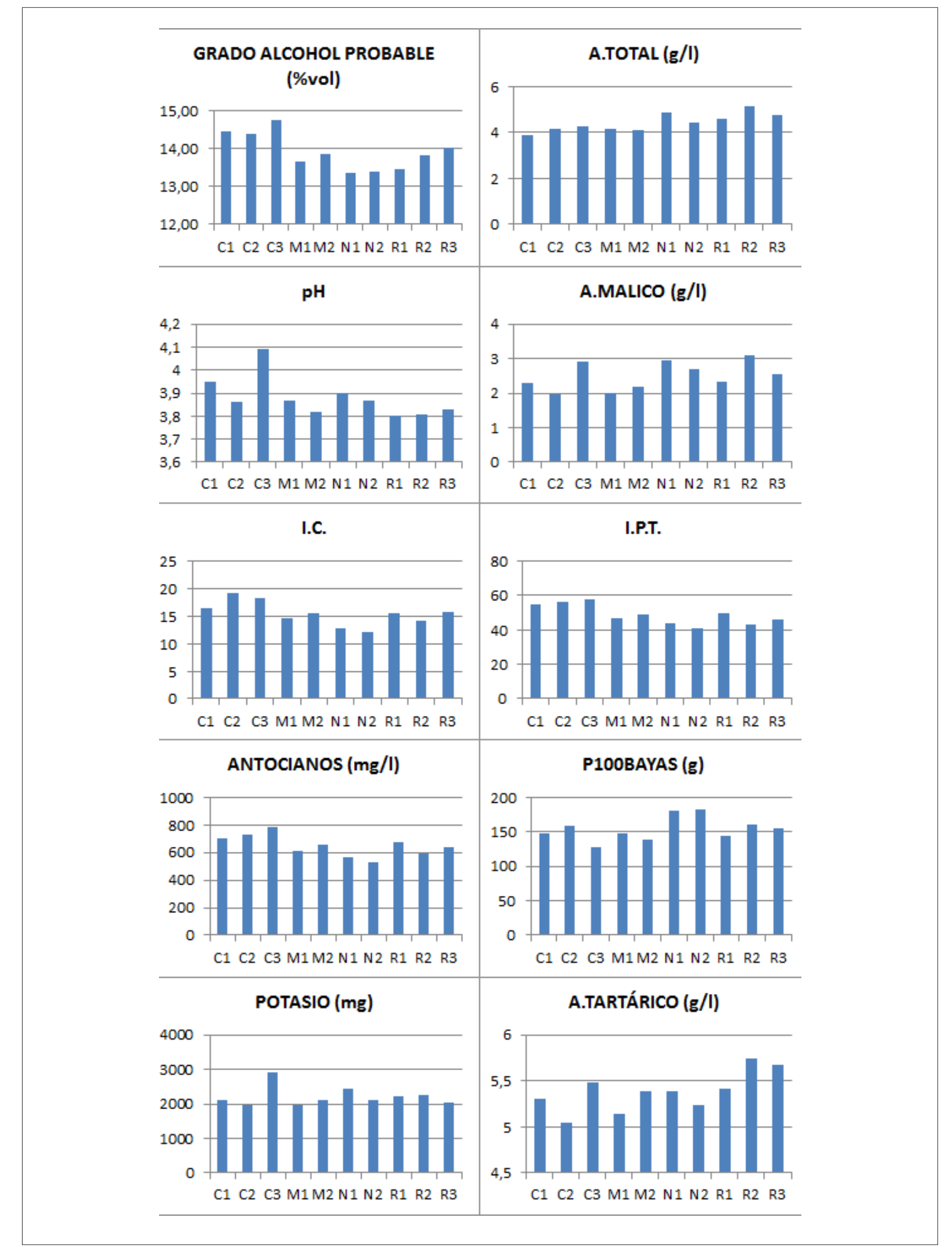

Figura 50. Representación de las variables relacionadas con la uva por sectores. 


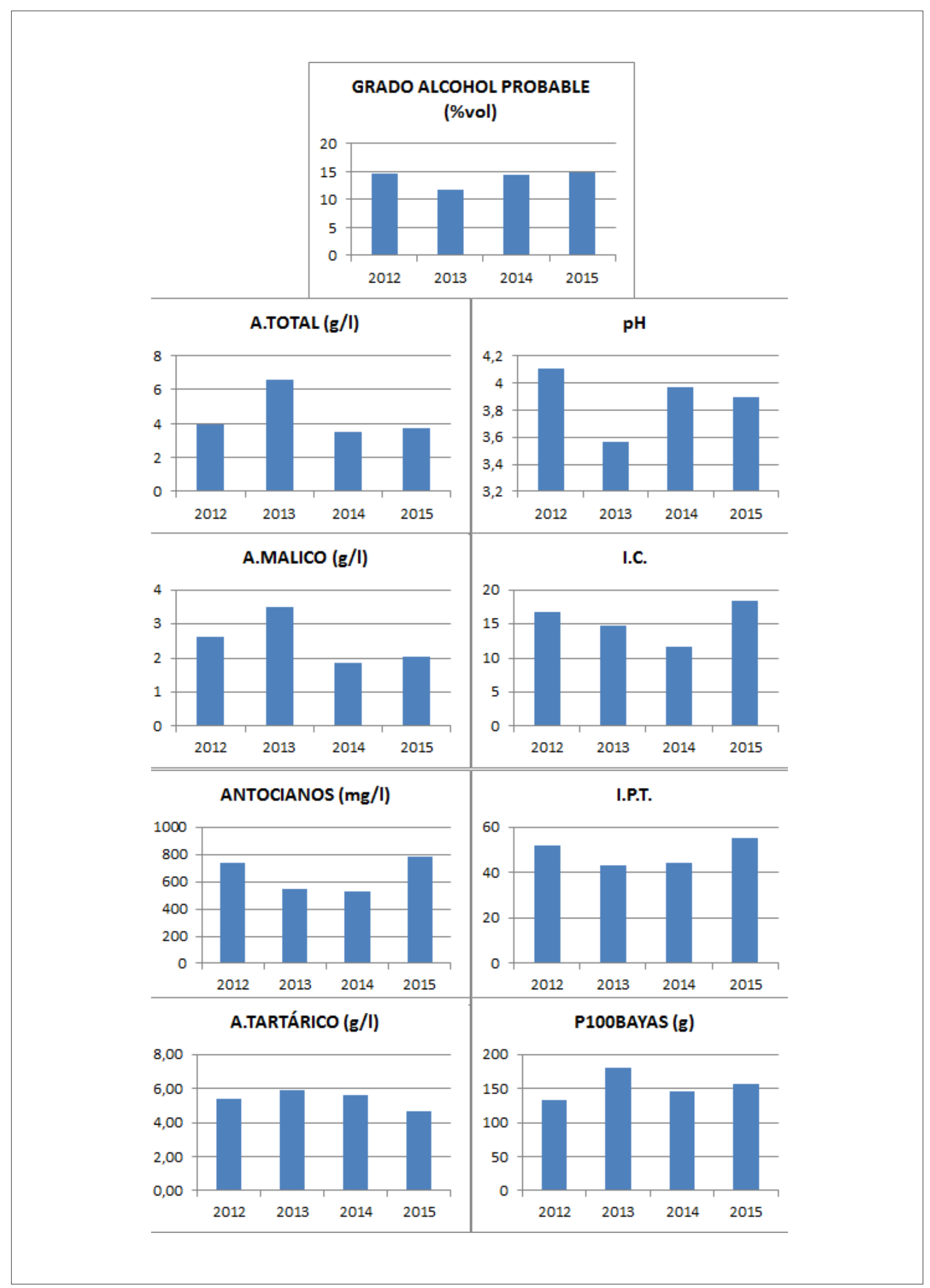

Figura 51. Representación de las variables relacionadas con la uva durante los cuatro años de ensayo, cuando hubo diferencias significativas en el análisis ANOVA. 


\subsubsection{Intensidad de color}

La Intensidad de Color (IC) de los mostos obtenidos sólo mostró diferencias significativas en la añada 2015, presentando la finca Naval los valores más bajos y los sectores C2 y C3 de Campillo los niveles más elevados (Tabla 32).

Analizando los datos medios de los cuatro años, aparecen, de nuevo, los sectores N1 y N2 de Naval como los de menor IC y los sectores C2 y C3 los de mayor IC (Figura 50).

Los mostos del año 2014 tienen los niveles de IC más bajos, significativamente inferiores a los de las añadas 2012 y 2015.

\subsubsection{6. Índice de polifenoles totales}

Respecto al Índice de Polifenoles Totales (IPT) se encontraron diferencias moderadamente significativas en el año 2014, significativas en 2013 y muy significativas en 2015. En la parcela Naval y en el sector R2 de Ricio se obtienen los mostos con menor contenido en IPT, lo contrario que sucede en la finca Campillo, especialmente en los sectores C2 y C3.

Analizando el contenido en IPT de los mostos según la añada, aparece la campaña 2015 como la de mayor concentración polifenólica, presentándose los niveles más bajos en las añadas 2014 y especialmente en 2013 (Tabla 34 y Figura 51). Una singularidad climática del año 2015 respecto al resto de años de ensayo es que se clasifica como de noches muy frías $(\mathrm{IF}+2)$ y esta es la razón por la que en esta añada haya tenido lugar una mayor síntesis de polifenoles.

\subsubsection{Antocianos}

Únicamente se encontraron diferencias significativas, respecto al contenido en antocianos, en la campaña 2015. Durante esta campaña, los sectores R2 y especialmente el sector N2 produjeron los mostos de menor contenido en antocianos, mientras que del sector C3 se obtuvo el mosto con mayor concentración en antocianos (Tabla 32).

En los resultados del análisis con los datos medios de los cuatro años (Tabla 33 y Figura 51) aparece la parcela Naval como la de menor contenido en antocianos y los sectores C2 y C3 de Campillo como los que producen mostos con las concentraciones más elevadas en antocianos.

Respecto al contenido de antocianos en función de la añada, se puede observar en la Tabla 34 como las campañas 2013 y 2014 producen mostos con menor concentración en antocianos que las campañas 2012 y 2105. 


\subsubsection{Potasio}

La concentración de potasio en la uva se midió en las campañas 2013, 2014 y 2015, encontrándose diferencias significativas, respecto a este parámetro, en los años 2013 y 2015 (Tabla 32). Observando los resultados de estos dos años parece que no existe una tendencia clara en la distribución del contenido en potasio según los sectores estudiados.

En relación a la añada sucede algo similar ya que las diferencias en la concentración de potasio en el mosto no mostraron diferencias significativas entre los tres años de estudio.

\subsubsection{9. Ácido tartárico}

El contenido en ácido tartárico de la uva se analizó, al igual que la concentración en potasio, durante las campañas 2013, 2014 y 2015. En la añada 2013, única en la que se encontraron diferencias significativas entre los sectores estudiados, el contenido en ácido tartárico de los mostos fue superior en los sectores R2 y R3 de la parcela Ricio e inferior en el sector C2 de Campillo.

El año 2013 se caracterizó por mostos con un mayor contenido en ácido tartárico mientras que la añada 2015, de las tres estudiadas, produjo unos mostos con la menor concentración en ácido tartárico.

\subsubsection{Peso de 100 bayas}

Las bayas más pesadas se encuentran en la finca Naval, sectores N1 y N2, también los sectores R2 y C2 muestran tendencia hacia la producción de uvas de mayor peso. Por el lado contrario, en el sector C3 se han recogido las bayas con menor peso.

En el año 2013 se han recogido las uvas de mayor peso, con respecto a los años 2014, 2015 y 2012, obteniéndose en esta última añada un menor peso medio de las bayas.

\subsubsection{Relación entre parámetros del suelo y vitícolas}

Respecto a las relaciones entre las variables estudiadas (Tabla 35), tanto relativas al viñedo como al suelo, se han encontrado varias correlaciones tanto entre parámetros vitícolas como entre estos y parámetros edáficos (Tablas 36 a 41 y Figuras 52 y 53). 
Tabla 35. Parámetros y simbología utilizada en este apartado y en los siguientes. Nótese que algunos tienen varios símbolos por exigencias de los programas informáticos utilizados

\begin{tabular}{|l|l|c|l|}
\hline SÍMBOLOS & PARÁMETRO & SíMBOLO & PARÁMETRO \\
\hline ANTO & Antocianos, mg/l & CAL & Calibre del sarmiento, cm \\
\hline ATOTAL & Acidez Total, gr/l de Ácido Tartárico & LONG & Longitud del sarmiento, cm \\
\hline GAP & Grado de Alcohol Probable, \% volúmen & PESOMAD & Peso de madera de poda, gr \\
\hline I.C., IC & Índice de Color & PRAC & Peso del racimo, gr \\
\hline I.P.T., IPT & Índice de Polifenoles Totales & Número de Racimos \\
\hline A.MALICO, MH2 & Ácido Málico, gr/l & PROD & Producción (NRAC*PRAC), gr \\
\hline P100B & peso de 100 bayas, gr & RAVAZ & Índice de Ravaz: (PESOMAD/PROD) \\
\hline K & potasio, mg/l & NPAMP & Número de Pámpanos \\
\hline A.TARTARICO, TH2 & Ácido Tartárico, gr/l & & \\
\hline
\end{tabular}

Sin embargo, aunque la relación es importante se plantea una cuestión, de difícil solución, relacionada con el número de muestras y la variabilidad de los parámetros que se pretenden relacionar. Se dispone de 80 observaciones (4 años * 20 muestras, incluidas las repeticiones en su caso) con datos de los parámetros vitícolas y sólo 20 observaciones de parámetros del suelo (20 perfiles) y se asume que éstas son invariables, cosa que no es cierta para muchas de estas variables. Estos parámetros edáficos son enfrentados con parámetros vitícolas con una variabilidad interanual importante, aunque con tendencias relativas estables temporalmente. En cualquier caso, además del ACP, según la sectorización inicial y según la ZIT definitiva, con los datos medios de los cuatro años (Tablas 36, Tabla 37, Figura 52 y Figura 53), se ha hecho un análisis por añadas (Tablas 38 a 41) en grupos de $20^{*} 20$ con la pretensión de, sino evitar el problema, al menos disminuirlo. Esta cuestión también se pone de manifiesto en el momento de la validación (§ 6.6). En la mayor parte de estos análisis se han encontrado correlaciones con tendencias similares y se exponen a continuación.

Atendiendo a las variables vitícolas, se observa correlación positiva entre el grupo de variables relacionadas con el contenido polifenólico del mosto (IC, IPT y contenido en antocianos) y el grado alcohólico probable y negativa con el peso de las bayas y del racimo (y con la producción), así como con la longitud y el calibre de los sarmientos (y con el peso de la madera de poda). 
Existe otro grupo de variables relacionadas con el rendimiento (peso de las bayas, peso y número de racimos y producción) que correlacionan positivamente entre sí y a la vez existe correlación positiva de este grupo con la longitud y el calibre de los sarmientos (y con el peso de la madera de poda) y con la acidez (especialmente con el número de racimos) y negativa con el contenido polifenólico y con el grado alcohólico (Tabla 36).

También existe un grupo de variables que correlacionan directamente entre sí y que están relacionadas con el crecimiento vegetativo: longitud y calibre de los sarmientos y peso de la madera de poda. Se han encontrado correlaciones positivas de este grupo con el rendimiento y la acidez del mosto e inversas con el contenido fenólico y el grado de alcohol probable (Tabla 36).

Resumiendo, y en términos generales, en las vides con alto crecimiento vegetativo se consiguieron los mayores rendimientos, así como mostos de menor graduación alcohólica, mayor acidez y menor contenido polifenólico. Estos resultados coinciden con los encontrados por Leibar et al. (2018) en la Rioja Alta durante tres años (2009, 2010 y 2011), situando los viñedos más vigorosos sobre los suelos con mayor capacidad de retención de agua. Bonilla et al. (2015) también encuentran resultados similares estudiando la variabilidad intraparcela en un viñedo situado en Laguardia (Álava) y amparado por la DOCa Rioja. En este último trabajo también se ha encontrado una relación positiva entre el NDVI y el crecimiento vegetativo (ver $\S$ 6.5.1), mientras que en el primero se empleó este índice de vegetación como estimador del crecimiento vegetativo.

Fuera del ámbito de la DOCa Rioja se han encontrado relaciones similares entre crecimiento vegetativo y composición de la uva en la región de Burdeos (van Leeuwen et al., 2004), en el valle del Ródano (Coipel et al., 2006) o en la Toscana (Filippetti et al., 2013). En este último trabajo se delimitan dos zonas en función del vigor dentro de un mismo viñedo, concluyendo que la zona menos vigorosa se corresponde con suelos con un menor contenido en nutrientes y con menor capacidad de retención de agua, y en ella se obtienen vinos con mejores atributos sensoriales. 
En relación con las variables edáficas, se encuentra un grupo (G1) de variables (ver § 6.4.2), que en el análisis según la sectorización inicial (Tabla 36) han correlacionado en positivo con el grado de alcohol probable, con el pH y con el contenido polifenólico del mosto y negativamente con el crecimiento vegetativo y el rendimiento. Sin embargo, al realizar el ACP según la ZIT propuesta tanto para los datos medios (2012-2015) como para cada añada (Tablas 37 a 41) se observa una tendencia de este grupo a correlacionar positivamente con el pH y en contenido en potasio. Los otros dos grupos de variables ( $G 2$ y G3) tienen un comportamiento similar, correlacionando positivamente con el crecimiento vegetativo, el rendimiento y la acidez e inversamente con el contenido polifenólico.

Atendiendo al gráfico Biplot (Figura 52) obtenido a partir del ACP sobre las 10 observaciones de la sectorización inicial y de las variables de la Tabla 36, se observa como el factor F1 queda definido positivamente por variables relacionadas con el contenido polifenólico, el GAP, el pH y por el G1 (grupo de variables relacionadas con el suelo) situándose en esta zona del gráfico las observaciones (sectores) C3, C1, C2 y M2, mientras que la parte negativa de este factor queda relacionada con el crecimiento vegetativo, el rendimiento y la acidez total encontrando en esta área los sectores N1, N2 y R2. En la zona central del factor F1 aparecen las observaciones R1, R3 y M1.

Respecto al factor F2, existen correlaciones positivas entre este factor y variables como el ácido tartárico, el ácido málico, la acidez total y los grupos de variables edáficas G2 y G3, y correlación negativa con el peso de los racimos y el calibre de los sarmientos. Se pueden realizar tres agrupaciones de las observaciones respecto a este factor, el primero correlacionado positivamente (sectores C3, R3 y R2), el segundo correlacionado negativamente (sectores N2 y C2) y un tercer grupo situado en torno al origen del eje (sectores N1, R1, M1, M2 y C1).

En función de la posición de los sectores en el plano factorial (Figura 52) aparecen observaciones, como C1 , C2, C3 y M2, con tendencia a producir mostos de mayor grado alcohólico, contenido polifenólico y $\mathrm{pH}$, con bajos rendimientos, menor crecimiento vegetativo y mostos menos ácidos. Existe un grupo con un comportamiento opuesto a este conjunto, formado por los sectores N1, N2 y R2. 
Tabla 36. Matriz de correlaciones (Pearson) de los parámetros analizados relacionados con la vid (datos medios 2012-2015) y con el suelo $(G 1, G 2, G 3)$, según la primera sectorización propuesta (10 sectores).

\begin{tabular}{|c|c|c|c|c|c|c|c|c|c|}
\hline Variables & GRADO & A.TOTAL & $\mathrm{pH}$ & $\mathrm{MH} 2$ & I.C. & I.P.T. & ANTO & P100B & K \\
\hline GRADO & 1 & & & & & & & & \\
\hline A.TOTAL & $-0,477$ & 1 & & & & & & & \\
\hline $\mathrm{pH}$ & 0,641 & $-0,376$ & 1 & & & & & & \\
\hline $\mathrm{MH} 2$ & $-0,119$ & 0,731 & 0,268 & 1 & & & & & \\
\hline I.C. & 0,863 & $-0,498$ & 0,364 & $-0,419$ & 1 & & & & \\
\hline I.P.T. & 0,838 & $-0,640$ & 0,550 & $-0,401$ & 0,936 & 1 & & & \\
\hline ANTO & 0,867 & $-0,517$ & 0,540 & $-0,286$ & 0,949 & 0,972 & 1 & & \\
\hline P100B & $-0,614$ & 0,451 & $-0,339$ & 0,309 & $-0,680$ & $-0,695$ & $-0,790$ & 1 & \\
\hline K & 0,315 & 0,184 & 0,739 & 0,672 & 0,132 & 0,272 & 0,365 & $-0,292$ & 1 \\
\hline $\mathrm{TH} 2$ & $-0,006$ & 0,709 & $-0,100$ & 0,699 & $-0,176$ & $-0,297$ & $-0,097$ & $-0,116$ & 0,373 \\
\hline NRAC & $-0,279$ & 0,924 & $-0,374$ & 0,665 & $-0,365$ & $-0,559$ & $-0,439$ & 0,453 & 0,030 \\
\hline PROD & $-0,713$ & 0,633 & $-0,291$ & 0,529 & $-0,796$ & $-0,798$ & $-0,830$ & 0,931 & $-0,065$ \\
\hline PRAC & $-0,712$ & 0,345 & $-0,186$ & 0,323 & $-0,770$ & $-0,696$ & $-0,789$ & 0,913 & $-0,110$ \\
\hline NPAMP & $-0,330$ & 0,436 & $-0,775$ & $-0,136$ & $-0,120$ & $-0,343$ & $-0,239$ & $-0,103$ & $-0,454$ \\
\hline LONG & $-0,690$ & 0,491 & $-0,365$ & 0,275 & $-0,722$ & $-0,775$ & $-0,847$ & 0,919 & $-0,276$ \\
\hline CALIBRE & $-0,704$ & 0,498 & $-0,483$ & 0,139 & $-0,575$ & $-0,616$ & $-0,711$ & 0,874 & $-0,338$ \\
\hline PESOMAD & $-0,560$ & 0,779 & $-0,465$ & 0,516 & $-0,651$ & $-0,807$ & $-0,782$ & 0,799 & $-0,195$ \\
\hline RAVAZ & $-0,409$ & 0,416 & $-0,060$ & 0,472 & $-0,423$ & $-0,290$ & $-0,261$ & 0,296 & 0,263 \\
\hline G1 & 0,828 & $-0,426$ & 0,743 & $-0,042$ & 0,698 & 0,707 & 0,783 & $-0,778$ & 0,527 \\
\hline $\mathrm{G} 2$ & 0,075 & 0,357 & $-0,083$ & 0,194 & $-0,077$ & $-0,251$ & $-0,118$ & $-0,241$ & $-0,035$ \\
\hline G3 & $-0,208$ & 0,566 & $-0,118$ & 0,475 & $-0,443$ & $-0,576$ & $-0,443$ & 0,054 & 0,069 \\
\hline
\end{tabular}

Los valores en negrita son diferentes de 0 con un nivel de significación alfa $=0,05$ 


\begin{tabular}{|c|c|c|c|c|c|c|c|c|c|c|}
\hline TH2 & NRAC & PROD & PRAC & NPAMP & LONG & CALIBRE & $\begin{array}{r}\text { PESO- } \\
\text { MAD } \\
\end{array}$ & RAVAZ & G1 & G2 \\
\hline & & & & & & & & & & \\
\hline & & & & & & & & & & \\
\hline & & & & & & & & & & \\
\hline & & & & & & & & & & \\
\hline & & & & & & & & & & \\
\hline & & & & & & & & & & \\
\hline & & & & & & & & & & \\
\hline & & & & & & & & & & \\
\hline 1 & & & & & & & & & & \\
\hline 0,711 & 1 & & & & & & & & & \\
\hline 0,114 & 0,563 & 1 & & & & & & & & \\
\hline$-0,196$ & 0,240 & 0,936 & 1 & & & & & & & \\
\hline 0,356 & 0,464 & $-0,079$ & $-0,280$ & 1 & & & & & & \\
\hline$-0,134$ & 0,417 & 0,881 & 0,874 & 0,023 & 1 & & & & & \\
\hline$-0,232$ & 0,431 & 0,806 & 0,786 & 0,164 & 0,896 & 1 & & & & \\
\hline 0,290 & 0,793 & 0,811 & 0,632 & 0,342 & 0,848 & 0,775 & 1 & & & \\
\hline 0,369 & 0,346 & 0,500 & 0,412 & $-0,139$ & 0,061 & 0,172 & 0,107 & 1 & & \\
\hline 0,028 & $-0,380$ & $-0,736$ & $-0,702$ & $-0,283$ & $-0,666$ & $-0,765$ & $-0,603$ & $-0,469$ & 1 & \\
\hline 0,534 & 0,426 & $-0,158$ & $-0,361$ & 0,511 & $-0,029$ & $-0,184$ & 0,233 & $-0,313$ & 0,285 & 1 \\
\hline 0,643 & 0,552 & 0,203 & $-0,002$ & 0,393 & 0,259 & 0,006 & 0,475 & $-0,097$ & 0,048 & 0,898 \\
\hline
\end{tabular}


Tabla 37. Matriz de correlaciones (Pearson) de los principales parámetros analizados relacionados con la vid (datos medios 20122015) y con el suelo (G1, G2, G3), según la ZIT definitiva (20 sectores).

\begin{tabular}{|c|c|c|c|c|c|c|c|c|}
\hline Variables & PESOMAD & LONG & NRAC & PROD & P100B & GAP & $\mathrm{pH}$ & ATOTAL \\
\hline PESOMAD & 1 & & & & & & & \\
\hline LONG & 0,818 & 1 & & & & & & \\
\hline NRAC & 0,680 & 0,362 & 1 & & & & & \\
\hline PROD & 0,799 & 0,868 & 0,633 & 1 & & & & \\
\hline P100B & 0,783 & 0,905 & 0,453 & 0,899 & 1 & & & \\
\hline GAP & $-0,486$ & $-0,640$ & $-0,295$ & $-0,676$ & $-0,598$ & 1 & & \\
\hline $\mathrm{pH}$ & $-0,445$ & $-0,349$ & $-0,433$ & $-0,367$ & $-0,376$ & 0,641 & 1 & \\
\hline ATOTAL & 0,790 & 0,528 & 0,807 & 0,634 & 0,501 & $-0,449$ & $-0,398$ & 1 \\
\hline $\mathrm{MH} 2$ & 0,586 & 0,358 & 0,576 & 0,505 & 0,352 & $-0,123$ & 0,126 & 0,788 \\
\hline IC & $-0,560$ & $-0,608$ & $-0,332$ & $-0,706$ & $-0,569$ & 0,702 & 0,347 & $-0,439$ \\
\hline IPT & $-0,704$ & $-0,685$ & $-0,499$ & $-0,788$ & $-0,625$ & 0,777 & 0,524 & $-0,511$ \\
\hline ANTO & $-0,666$ & $-0,712$ & $-0,375$ & $-0,741$ & $-0,651$ & 0,729 & 0,530 & $-0,450$ \\
\hline K & $-0,061$ & $-0,137$ & 0,078 & $-0,060$ & $-0,214$ & 0,312 & 0,628 & 0,273 \\
\hline $\mathrm{TH} 2$ & 0,281 & $-0,119$ & 0,576 & 0,142 & $-0,047$ & $-0,003$ & $-0,155$ & 0,600 \\
\hline G1 & $-0,140$ & $-0,108$ & $-0,026$ & $-0,059$ & $-0,146$ & 0,413 & 0,648 & $-0,020$ \\
\hline $\mathrm{G} 2$ & 0,404 & 0,268 & 0,578 & 0,414 & 0,243 & $-0,131$ & 0,054 & 0,513 \\
\hline G3 & 0,471 & 0,313 & 0,474 & 0,375 & 0,220 & $-0,254$ & $-0,048$ & 0,574 \\
\hline
\end{tabular}

Los valores en negrita son diferentes de 0 con un nivel de significación alfa $=0,05$ 


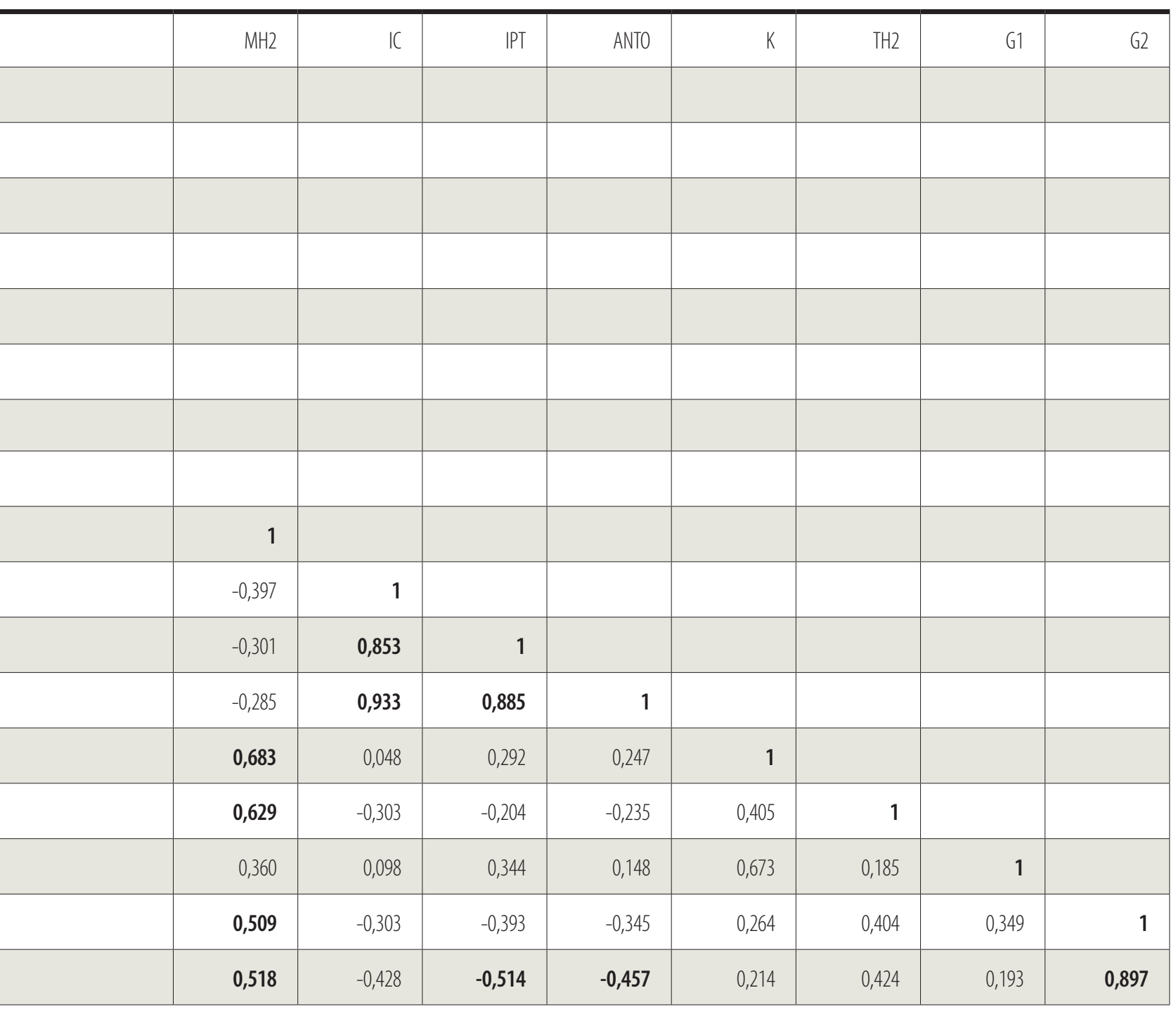


Tabla 38. Matriz de correlaciones (Pearson) de los principales parámetros analizados relacionados con la vid (año 2012) y con el suelo (G1, G2, G3), según la ZIT definitiva (20 sectores).

\begin{tabular}{|c|c|c|c|c|c|c|c|c|}
\hline Variables & PESOMAD & LONG & NRAC & PROD & P100B & GAP & $\mathrm{pH}$ & ATOTAL \\
\hline PESOMAD & 1 & & & & & & & \\
\hline LONG & 0,944 & 1 & & & & & & \\
\hline NRAC & $-0,270$ & $-0,324$ & 1 & & & & & \\
\hline PROD & 0,829 & 0,768 & 0,038 & 1 & & & & \\
\hline P100B & 0,793 & 0,821 & $-0,363$ & 0,773 & 1 & & & \\
\hline GAP & $-0,092$ & $-0,180$ & 0,089 & $-0,242$ & $-0,424$ & 1 & & \\
\hline $\mathrm{pH}$ & $-0,140$ & $-0,221$ & 0,342 & $-0,219$ & $-0,478$ & 0,703 & 1 & \\
\hline ATOTAL & 0,406 & 0,448 & 0,397 & 0,483 & 0,237 & $-0,329$ & $-0,133$ & 1 \\
\hline $\mathrm{MH} 2$ & $-0,173$ & $-0,209$ & 0,685 & $-0,064$ & $-0,470$ & 0,403 & 0,783 & 0,360 \\
\hline IC & $-0,549$ & $-0,650$ & 0,419 & $-0,431$ & $-0,699$ & 0,479 & 0,221 & $-0,209$ \\
\hline IPT & $-0,425$ & $-0,568$ & 0,383 & $-0,381$ & $-0,705$ & 0,584 & 0,452 & $-0,116$ \\
\hline ANTO & $-0,646$ & $-0,731$ & 0,532 & $-0,517$ & $-0,786$ & 0,421 & 0,384 & $-0,167$ \\
\hline G1 & $-0,048$ & $-0,090$ & 0,195 & 0,043 & $-0,261$ & 0,425 & 0,604 & $-0,038$ \\
\hline$G 2$ & $-0,050$ & $-0,035$ & 0,398 & 0,020 & $-0,255$ & 0,301 & 0,207 & 0,322 \\
\hline G3 & 0,053 & 0,129 & 0,269 & 0,139 & $-0,029$ & 0,089 & $-0,046$ & 0,322 \\
\hline
\end{tabular}

Los valores en negrita son diferentes de 0 con un nivel de significación alfa $=0,05$ 


\begin{tabular}{|r|r|r|r|r|r|r|}
\hline & MH2 & $I C$ & IPT & ANT0 & G1 & G2 \\
\hline & & & & & & \\
\hline & & & & & & \\
\hline \\
\hline
\end{tabular}


Tabla 39. Matriz de correlaciones (Pearson) de los principales parámetros analizados relacionados con la vid (año 2013) y con el suelo (G1, G2, G3), según la ZIT definitiva (20 sectores).

\begin{tabular}{|c|c|c|c|c|c|c|c|c|}
\hline Variables & PESOMAD & LONG & NRAC & PROD & P100B & GAP & pH & ATOTAL \\
\hline PESOMAD & 1 & & & & & & & \\
\hline LONG & 0,900 & 1 & & & & & & \\
\hline NRAC & $-0,134$ & $-0,144$ & 1 & & & & & \\
\hline PROD & 0,668 & 0,740 & $-0,002$ & 1 & & & & \\
\hline P100B & 0,568 & 0,570 & $-0,378$ & 0,605 & 1 & & & \\
\hline GAP & 0,251 & 0,149 & $-0,311$ & $-0,044$ & 0,453 & 1 & & \\
\hline pH & $-0,020$ & 0,004 & $-0,088$ & 0,021 & 0,172 & 0,318 & 1 & \\
\hline ATOTAL & 0,651 & 0,423 & $-0,102$ & 0,185 & 0,231 & 0,124 & $-0,255$ & 1 \\
\hline $\mathrm{MH} 2$ & 0,709 & 0,463 & $-0,062$ & 0,290 & 0,300 & 0,165 & 0,103 & 0,910 \\
\hline IC & $-0,415$ & $-0,336$ & 0,239 & $-0,378$ & $-0,318$ & 0,161 & 0,256 & $-0,470$ \\
\hline IPT & $-0,197$ & $-0,222$ & 0,277 & $-0,404$ & $-0,153$ & 0,293 & 0,641 & $-0,211$ \\
\hline ANTO & $-0,448$ & $-0,373$ & 0,220 & $-0,385$ & $-0,265$ & 0,232 & 0,438 & $-0,510$ \\
\hline K & 0,305 & 0,163 & $-0,100$ & 0,147 & 0,259 & 0,260 & 0,690 & 0,436 \\
\hline $\mathrm{TH} 2$ & 0,358 & 0,157 & $-0,144$ & 0,129 & $-0,095$ & 0,028 & $-0,317$ & 0,766 \\
\hline G1 & $-0,173$ & $-0,202$ & 0,062 & $-0,065$ & 0,006 & 0,073 & 0,590 & $-0,007$ \\
\hline $\mathrm{G} 2$ & 0,376 & 0,379 & $-0,117$ & 0,465 & 0,367 & 0,122 & 0,090 & 0,506 \\
\hline G3 & 0,411 & 0,447 & $-0,086$ & 0,406 & 0,165 & $-0,150$ & $-0,082$ & 0,616 \\
\hline
\end{tabular}

Los valores en negrita son diferentes de 0 con un nivel de significación alfa $=0,05$ 


\begin{tabular}{|c|c|c|c|c|c|c|c|}
\hline $\mathrm{MH} 2$ & IC & IPT & ANTO & K & $\mathrm{TH} 2$ & G1 & $G 2$ \\
\hline & & & & & & & \\
\hline & & & & & & & \\
\hline & & & & & & & \\
\hline & & & & & & & \\
\hline & & & & & & & \\
\hline & & & & & & & \\
\hline & & & & & & & \\
\hline & & & & & & & \\
\hline 1 & & & & & & & \\
\hline$-0,402$ & 1 & & & & & & \\
\hline$-0,019$ & 0,632 & 1 & & & & & \\
\hline$-0,383$ & 0,975 & 0,721 & 1 & & & & \\
\hline 0,697 & $-0,077$ & 0,437 & 0,055 & 1 & & & \\
\hline 0,657 & $-0,450$ & $-0,331$ & $-0,498$ & 0,313 & 1 & & \\
\hline 0,202 & 0,147 & 0,574 & 0,274 & 0,659 & $-0,041$ & 1 & \\
\hline 0,561 & $-0,362$ & $-0,104$ & $-0,311$ & 0,457 & 0,532 & 0,349 & 1 \\
\hline 0,611 & $-0,501$ & $-0,265$ & $-0,495$ & 0,368 & 0,653 & 0,193 & 0,897 \\
\hline
\end{tabular}


Tabla 40. Matriz de correlaciones (Pearson) de los principales parámetros analizados relacionados con la vid (año 2014) y con el suelo (G1, G2, G3), según la ZIT definitiva (20 sectores).

\begin{tabular}{|c|c|c|c|c|c|c|c|c|}
\hline Variables & PESOMAD & LONG & NRAC & PROD & P100B & GAP & pH & ATOTAL \\
\hline PESOMAD & 1 & & & & & & & \\
\hline LONG & 0,590 & 1 & & & & & & \\
\hline NRAC & 0,845 & 0,651 & 1 & & & & & \\
\hline PROD & 0,621 & 0,708 & 0,763 & 1 & & & & \\
\hline P100B & 0,711 & 0,701 & 0,762 & 0,832 & 1 & & & \\
\hline GAP & $-0,221$ & $-0,464$ & $-0,423$ & $-0,799$ & $-0,561$ & 1 & & \\
\hline $\mathrm{pH}$ & $-0,496$ & $-0,645$ & $-0,492$ & $-0,693$ & $-0,697$ & 0,691 & 1 & \\
\hline ATOTAL & 0,837 & 0,730 & 0,754 & 0,675 & 0,748 & $-0,266$ & $-0,498$ & 1 \\
\hline $\mathrm{MH} 2$ & $-0,254$ & $-0,038$ & $-0,179$ & $-0,050$ & $-0,054$ & 0,062 & 0,036 & 0,061 \\
\hline IC & $-0,211$ & $-0,206$ & $-0,382$ & $-0,489$ & $-0,306$ & 0,489 & 0,181 & $-0,267$ \\
\hline IPT & $-0,357$ & $-0,139$ & $-0,536$ & $-0,628$ & $-0,418$ & 0,608 & 0,231 & $-0,307$ \\
\hline ANTO & $-0,308$ & $-0,380$ & $-0,485$ & $-0,602$ & $-0,407$ & 0,567 & 0,306 & $-0,380$ \\
\hline K & 0,061 & 0,309 & $-0,004$ & $-0,140$ & $-0,012$ & 0,432 & 0,306 & 0,339 \\
\hline $\mathrm{TH} 2$ & 0,539 & 0,474 & 0,417 & 0,241 & 0,308 & 0,142 & $-0,252$ & 0,741 \\
\hline G1 & $-0,109$ & $-0,016$ & 0,019 & $-0,096$ & $-0,134$ & 0,234 & 0,537 & 0,105 \\
\hline $\mathrm{G} 2$ & 0,381 & 0,250 & 0,588 & 0,275 & 0,386 & $-0,129$ & 0,042 & 0,413 \\
\hline G3 & 0,351 & 0,135 & 0,445 & 0,211 & 0,341 & $-0,098$ & 0,041 & 0,328 \\
\hline
\end{tabular}

Los valores en negrita son diferentes de 0 con un nivel de significación alfa $=0,05$ 


\begin{tabular}{|c|c|c|c|c|c|c|c|}
\hline $\mathrm{MH} 2$ & IC & IPT & ANTO & K & TH2 & G1 & $G 2$ \\
\hline & & & & & & & \\
\hline & & & & & & & \\
\hline & & & & & & & \\
\hline & & & & & & & \\
\hline & & & & & & & \\
\hline & & & & & & & \\
\hline & & & & & & & \\
\hline & & & & & & & \\
\hline 1 & & & & & & & \\
\hline$-0,414$ & 1 & & & & & & \\
\hline$-0,064$ & 0,837 & 1 & & & & & \\
\hline$-0,234$ & 0,953 & 0,833 & 1 & & & & \\
\hline 0,282 & 0,128 & 0,426 & 0,116 & 1 & & & \\
\hline 0,129 & 0,011 & 0,080 & $-0,113$ & 0,447 & 1 & & \\
\hline 0,099 & $-0,161$ & $-0,052$ & $-0,164$ & 0,409 & 0,331 & 1 & \\
\hline$-0,155$ & $-0,422$ & $-0,530$ & $-0,504$ & 0,086 & 0,176 & 0,349 & 1 \\
\hline$-0,163$ & $-0,452$ & $-0,593$ & $-0,503$ & $-0,027$ & 0,035 & 0,193 & 0,897 \\
\hline
\end{tabular}


Tabla 41. Matriz de correlaciones (Pearson) de los principales parámetros analizados relacionados con la vid (año 2015) y con el suelo (G1, G2, G3), según la ZIT definitiva (20 sectores).

\begin{tabular}{|c|c|c|c|c|c|c|c|c|}
\hline Variables & PESOMAD & LONG & NRAC & PROD & P100B & GAP & $\mathrm{pH}$ & ATOTAL \\
\hline PESOMAD & 1 & & & & & & & \\
\hline LONG & 0,554 & 1 & & & & & & \\
\hline NRAC & 0,711 & 0,207 & 1 & & & & & \\
\hline PROD & 0,672 & 0,532 & 0,826 & 1 & & & & \\
\hline P100B & 0,455 & 0,861 & 0,122 & 0,496 & 1 & & & \\
\hline GAP & $-0,492$ & $-0,272$ & $-0,743$ & $-0,802$ & $-0,303$ & 1 & & \\
\hline $\mathrm{pH}$ & $-0,428$ & $-0,395$ & $-0,691$ & $-0,666$ & $-0,346$ & 0,581 & 1 & \\
\hline ATOTAL & 0,313 & 0,580 & 0,218 & 0,440 & 0,459 & $-0,346$ & $-0,232$ & 1 \\
\hline $\mathrm{MH} 2$ & 0,566 & 0,432 & $-0,014$ & 0,154 & 0,305 & 0,039 & 0,313 & 0,302 \\
\hline IC & $-0,556$ & $-0,420$ & $-0,541$ & $-0,746$ & $-0,631$ & 0,695 & 0,395 & $-0,388$ \\
\hline IPT & $-0,733$ & $-0,591$ & $-0,750$ & $-0,835$ & $-0,563$ & 0,814 & 0,736 & $-0,432$ \\
\hline ANTO & $-0,659$ & $-0,592$ & $-0,611$ & $-0,755$ & $-0,575$ & 0,668 & 0,760 & $-0,326$ \\
\hline K & $-0,085$ & $-0,137$ & $-0,321$ & $-0,236$ & $-0,187$ & 0,384 & 0,763 & 0,113 \\
\hline $\mathrm{TH} 2$ & 0,024 & $-0,127$ & $-0,049$ & $-0,117$ & 0,018 & 0,348 & 0,149 & 0,147 \\
\hline G1 & $-0,095$ & 0,030 & $-0,154$ & $-0,024$ & $-0,084$ & 0,326 & 0,294 & $-0,181$ \\
\hline $\mathrm{G} 2$ & 0,524 & 0,308 & 0,501 & 0,531 & 0,096 & $-0,377$ & $-0,177$ & 0,176 \\
\hline G3 & 0,645 & 0,253 & 0,455 & 0,469 & 0,093 & $-0,337$ & $-0,064$ & 0,222 \\
\hline
\end{tabular}

Los valores en negrita son diferentes de 0 con un nivel de significación alfa $=0,05$ 


\begin{tabular}{|c|c|c|c|c|c|c|c|}
\hline $\mathrm{MH} 2$ & IC & IPT & ANTO & K & TH2 & G1 & $G 2$ \\
\hline & & & & & & & \\
\hline & & & & & & & \\
\hline & & & & & & & \\
\hline & & & & & & & \\
\hline & & & & & & & \\
\hline & & & & & & & \\
\hline & & & & & & & \\
\hline & & & & & & & \\
\hline 1 & & & & & & & \\
\hline$-0,197$ & 1 & & & & & & \\
\hline$-0,128$ & 0,758 & 1 & & & & & \\
\hline$-0,141$ & 0,696 & 0,910 & 1 & & & & \\
\hline 0,531 & 0,187 & 0,507 & 0,517 & 1 & & & \\
\hline 0,127 & $-0,111$ & 0,275 & 0,158 & 0,327 & 1 & & \\
\hline 0,228 & 0,314 & 0,364 & 0,229 & 0,519 & 0,163 & 1 & \\
\hline 0,311 & $-0,250$ & $-0,384$ & $-0,376$ & 0,113 & 0,062 & 0,349 & 1 \\
\hline 0,463 & $-0,292$ & $-0,404$ & $-0,373$ & 0,163 & 0,075 & 0,193 & 0,897 \\
\hline
\end{tabular}




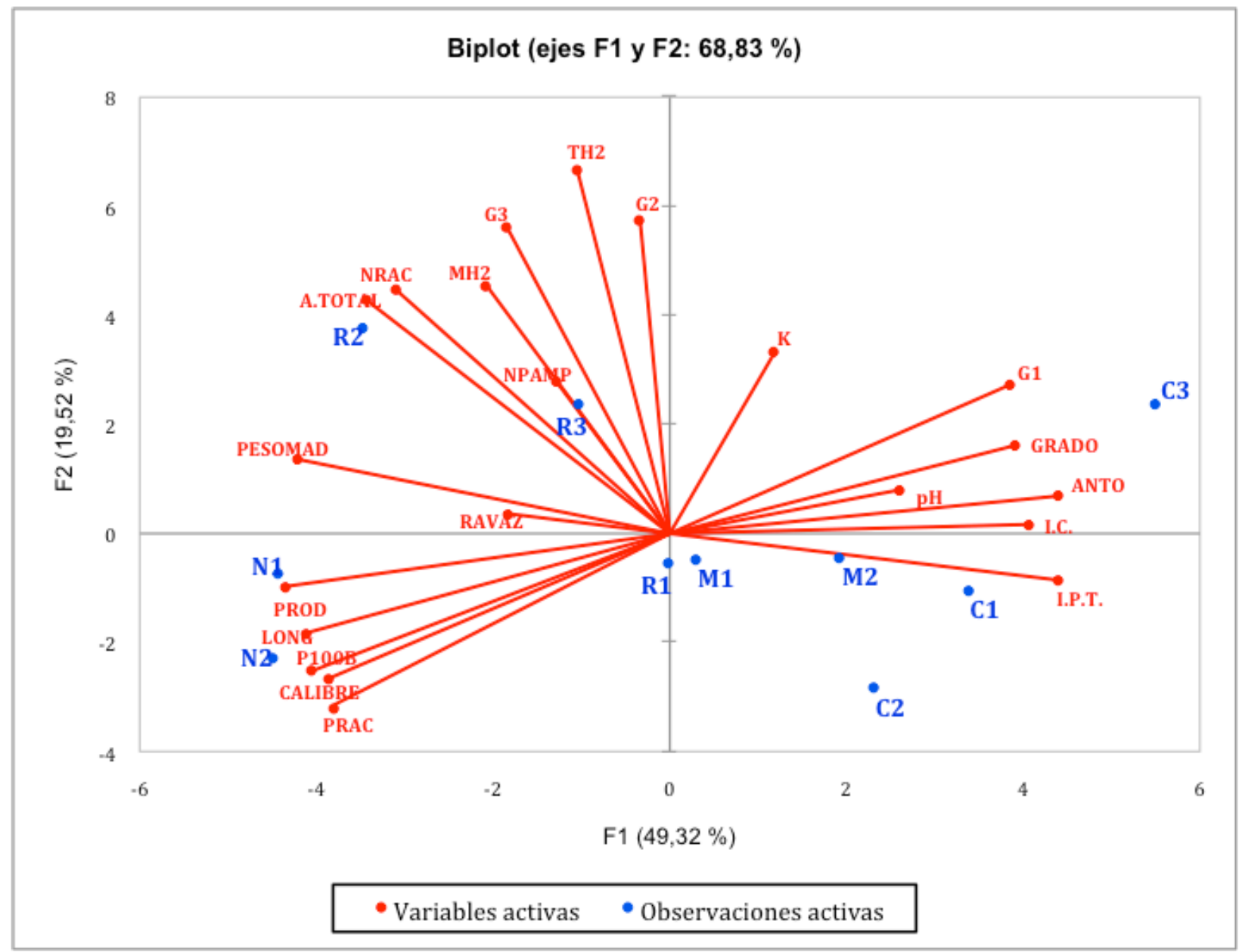

Figura 52. Gráfico Biplot con la distribución de observaciones (10 sectores) y variables (Tabla 36) del Análisis de Componentes Principales según los factores 1 (eje F1: abscisas) y 2 (eje F2: ordenadas). 


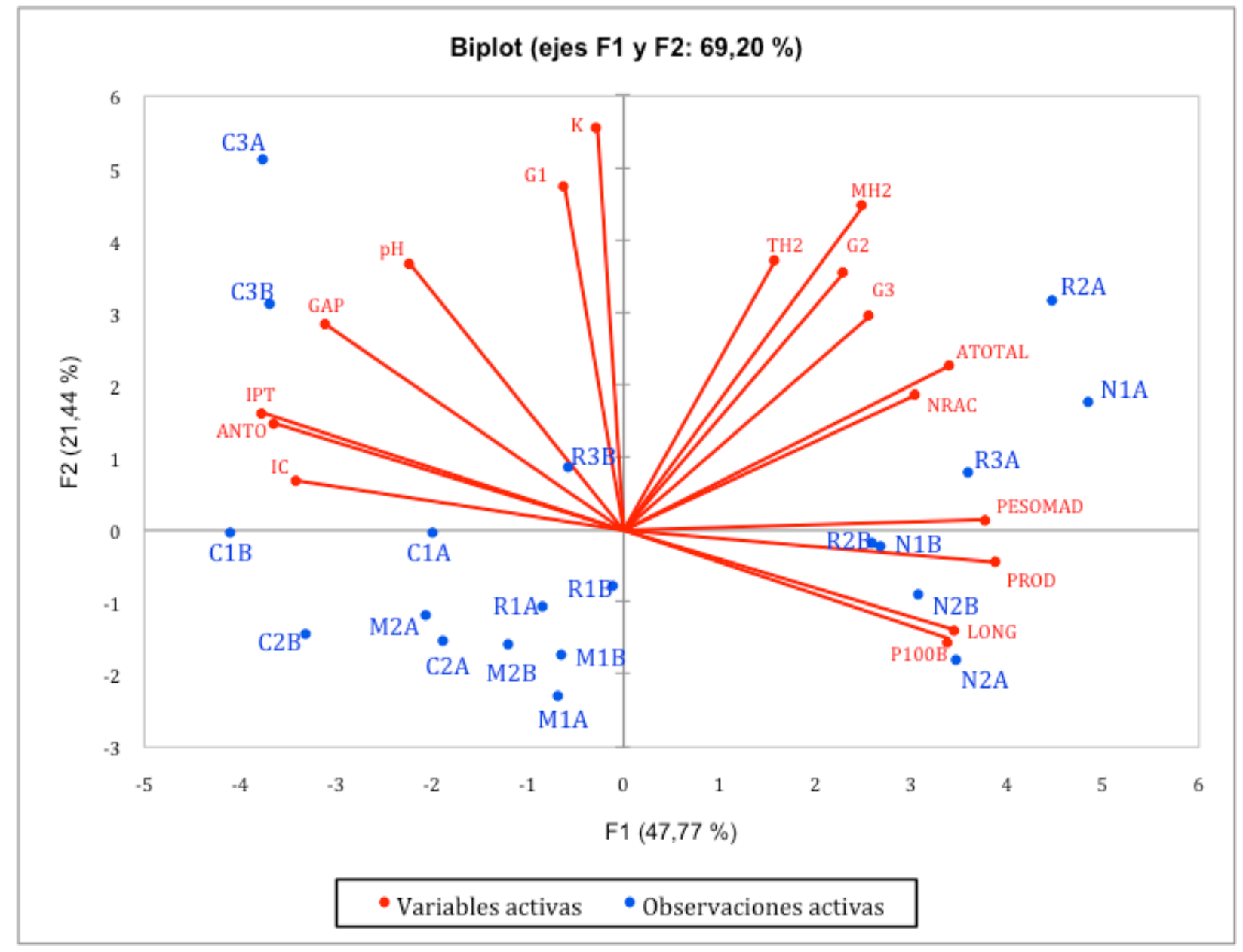

Figura 53. Gráfico Biplot con la distribución de observaciones (20 sectores) y variables (Tabla 37) del Análisis de Componentes Principales según los factores 1 (eje F1: abscisas) y 2 (eje F2: ordenadas). 
A pesar de que los factores del gráfico Biplot (Figura 53), del ACP de las variables según la ZIT propuesta, quedan definidos de manera muy distinta a la obtenida según se ha expuesto en los párrafos anteriores, el resultado de este análisis mantiene las correlaciones encontradas en la sectorización inicial. Así, aparecen un primer grupo de observaciones (R2A, R2B, R3A, N1A, N1B, N2A y N2B) con tendencia a ser vigorosos y productivos y a producir mostos con bajo contenido en GAP y compuestos polifenólicos y más acidos. En contraposición encontramos las observaciones C3A, C3B, C1A, C1B, C2A, C2B y M2A. Este análisis permite establecer la distancia entre las observaciones R3A Y R3B, algo que hace recomendable no incluir en la misma unidad las dos observaciones realizadas en el sector R3.

\subsection{MAPA DE ZONIFICACIÓN INTEGRADA DEL TERROIR (ZIT)}

Como se ha dicho en el capítulo metodológico, la realización de la ZIT se efectúa en dos etapas bien diferenciadas: la integración de los resultados y la validación. En la primera utilizamos un modelo paramétrico (Gómez-Miguel \& Sotés, 1990-2017) y en la validación los resultados de los elementos vegeto-productivos y de composición de la uva.

En las parcelas del ensayo, el análisis de los componentes del clima no da como resultado diferentes clases por su menor variabilidad geográfica (aunque la variabilidad interanual sea importante), quedando restringido a una sola de ellas (§ 6.2). De forma similar, en relación con la litología y la geomorfología, aunque con mayor variabilidad geográfica que el clima, las clases consideradas se reducen a dos unidades: W y F ( $\S$ 6.3).

Sin duda, como se ha visto, los elementos que producen mayor variabilidad en las parcelas del ensayo son el suelo y el propio cultivo, en sentido amplio. Por lo demás, variables como las que permiten el tratamiento del modelo digital del terreno (Figura 30; altitud, exposición y longitud e inclinación de la pendiente) junto con las citadas, litología y geomorfología del relieve, son integradas en el modelo a través del concepto de serie de suelos, en la propia STU.

Esto justifica que en la evaluación de las STU pueda ser utilizado como elemento de zonificación el modelo paramétrico citado más arriba y cuyo resultado es el índice de calidad (ICA). Los parámetros utilizados en este modelo son la textura de los horizontes A y B, la pendiente, la litología, la caliza activa de los horizontes A y B, la materia orgánica, la profundidad efectiva, la CIC, la acidez de cambio, el Al de cambio, el $\mathrm{K}$ y el PKI, el Mg y el PMI, las relaciones K/Mg y Ca/Mg, el PSI, la CE, el material original y las condiciones sequía-humedad (edafoclima).

Las variables consideradas para caracterizar cada taxón han sido las disponibles (de las cuantitativas) con significado agronómico y algunas otras elaboradas a partir de ellas y de especial interés vitícola (relación K/Mg, Ca/Mg, etc.). También se han considerado otras variables que, como la materia orgánica del horizonte C, evitan indefiniciones (entre Xerorthent típico y Xerofluvent típico, por ejemplo) y en suma, las que incorporan información referente a las propiedades más relevantes del siguiente horizonte, información que se perdería en el caso de utilizar únicamente los dos horizontes previamente considerados. Los resultados del ICA, según la ZIT propuesta para la parcelas de ensayo, se incluyen en la Tabla 42 y su representación en la Figura 54. 
Tabla 42. ZIT: índice de calidad (ICA) y clasificación de los sectores según la ZIT propuesta (Figura 47).

\begin{tabular}{|c|c|c|c|c|c|c|}
\hline NOMBRE & SUPERFICIE (ha) & PERFIL1 & CÓDIGO & SECTOR & ICA & CLASES1 \\
\hline CAMPILLO & 0,1686 & 352,302 & $\mathrm{C} 1 \mathrm{~A}$ & C1 & 20,5 & Clase 2 \\
\hline CAMPILLO & 0,766 & 352,307 & $C 2 A$ & $\mathrm{C2}$ & 21,4 & Clase 2 \\
\hline CAMPILLO & 0,2817 & 352,305 & C $3 B$ & C3 & 21,35 & Clase 2 \\
\hline CAMPILLO & 0,217 & 352,308 & $C 2 B$ & C4 & 17,4 & Clase 3 \\
\hline CAMPILLO & 0,1181 & 352,306 & $\mathrm{C} 1 \mathrm{~B}$ & $C 5$ & 18,39 & Clase 3 \\
\hline CAMPILLO & 0,4567 & 352,306 & $\mathrm{C} 1 \mathrm{~B}$ & C6 & 18,39 & Clase 3 \\
\hline CAMPILLO & 0,1616 & 352,301 & C $3 A$ & $C 7$ & 21,7 & Clase 2 \\
\hline MAJADAHONDA & 0,4397 & 353,303 & $M 2 B$ & M1 & 10,4 & Clase 3 \\
\hline MAJADAHONDA & 0,3021 & 353,302 & M2A & M2 & 25,5 & Clase 2 \\
\hline MAJADAHONDA & 0,2618 & 353,304 & M1B & M3 & 20,1 & Clase 3 \\
\hline MAJADAHONDA & 0,4592 & 353,301 & M1A & M4 & 19,69 & Clase 3 \\
\hline MAJADAHONDA & 0,0479 & 353,306 & R3B & M5 & 36,77 & Clase 1 \\
\hline MAJADAHONDA & 0,168 & 353,306 & R3B & M5 & 36,77 & Clase 1 \\
\hline MAJADAHONDA & 0,1412 & 353,308 & R1B & M6 & 24,8 & Clase 2 \\
\hline MAJADAHONDA & 0,1514 & 353,308 & R1B & M6 & 24,8 & Clase 2 \\
\hline NAVAL & 0,1896 & 352,31 & $\mathrm{~N} 1 \mathrm{~B}$ & N1 & 25,4 & Clase 2 \\
\hline NAVAL & 0,2655 & 352,31 & N1B & N1 & 25,4 & Clase 2 \\
\hline NAVAL & 0,2964 & 352,304 & $\mathrm{~N} 2 \mathrm{~A}$ & N2 & 28,6 & Clase 2 \\
\hline NAVAL & 0,2037 & 352,303 & N1A & N3 & 22,5 & Clase 2 \\
\hline NAVAL & 0,3191 & 352,309 & $\mathrm{~N} 2 \mathrm{~B}$ & N4 & 21,94 & Clase 2 \\
\hline NAVAL & 0,1114 & 353,306 & R3B & N4 & 36,77 & Clase 1 \\
\hline $\mathrm{RIClO}$ & 0,3087 & 353,308 & R1B & $\mathrm{R} 1$ & 24,8 & Clase 2 \\
\hline $\mathrm{RIClO}$ & 0,1326 & 353,31 & R1A & $\mathrm{R} 1$ & 30,06 & Clase 2 \\
\hline $\mathrm{RIClO}$ & 0,2869 & 353,305 & R2A & R2 & 47,8 & Clase 1 \\
\hline $\mathrm{RIClO}$ & 0,1344 & 353,307 & $R 2 B$ & R3 & 50,3 & Clase 1 \\
\hline $\mathrm{RIClO}$ & 0,3889 & 353,309 & R3A & R3 & 31,44 & Clase 1 \\
\hline $\mathrm{RIClO}$ & 0,4435 & 353,306 & R3B & R3 & 36,77 & Clase 1 \\
\hline $\mathrm{RIClO}$ & 0,092 & 353,309 & R3A & R4 & 31,44 & Clase 1 \\
\hline $\mathrm{RIClO}$ & 0,0113 & 353,308 & R1B & R5 & 24,8 & Clase 2 \\
\hline $\mathrm{RIClO}$ & 0,0466 & 353,308 & $\mathrm{R} 1 \mathrm{~B}$ & R5 & 24,8 & Clase 2 \\
\hline $\mathrm{RIClO}$ & 0,0545 & 353,308 & R1B & R5 & 24,8 & Clase 2 \\
\hline $\mathrm{RIClO}$ & 0,0519 & 353,306 & R3B & R5 & 36,77 & Clase 1 \\
\hline $\mathrm{RIClO}$ & 0,0478 & 353,306 & R3B & R5 & 36,77 & Clase 1 \\
\hline
\end{tabular}


En la Tabla 42 también se incluye la referencia de las STU de la DOCa Rioja procedente de la correlación realizada previamente (Tabla 25). No se incluye su ICA puesto que no son comparables por haberse reducido sus valores a 100 en el universo de toda la DO y, por ello, han sido variados respecto al resultado original. Una referencia al ICA de la SMU (no el de la STU), realizado como media ponderada de las STU que contiene, se incluye en la Tabla 5.

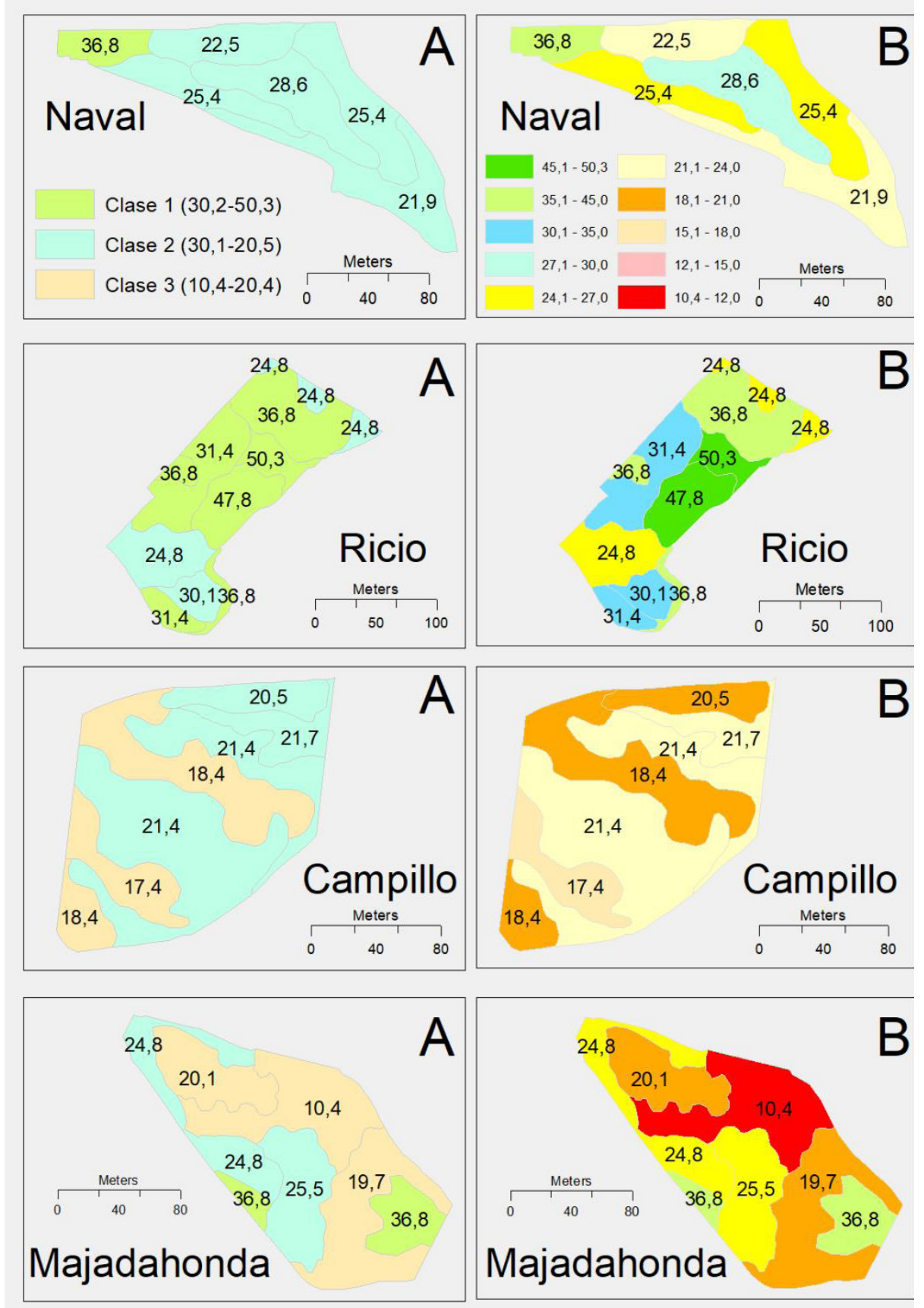

Figura 54. Zonificación Integrada del Terroir (ZIT): en la columna A se representa la agrupación del índice de calidad (ICA) por clases y en la columna B su distribución en porcentajes distribuidos de forma aleatoria en 10 clases. 
La definición de las clases en el mapa de gestión de partida se realizó siguiendo el mismo planteamiento de todas las zonificaciones realizadas en España por el equipo de la UPM (Gómez-Miguel \& Sotés, 1990-2017), es decir, partiendo de la agrupación del ICA en cinco clases. Además, el resultado de las clases se realiza principalmente en términos porcentuales, de 0 a 100, y por lo tanto, las referencias se deben entender como los mejores y los peores terroir, según la clasificación obtenida bajo este criterio. Como se observa en la división en 10 clases en las parcelas de ensayo (Figura 54), el ICA comienza en 10,4\% y termina en 50,3\% por lo que en la ZIT sólo aparecen las tres clases superiores de las identificadas para toda la DOCa Rioja, con una distribución geográfica dispar (Figura 55).

La validación del método se hace a partir del resultado de los parámetros determinantes del medio (ICA) en relación con los que se han denominado vegeto-productivos y de composición de la uva. El análisis estadístico, a través del ACP, ha permitido demostrar la relación significativa con un nivel de confianza del 95 \% entre algunos de ellos como el peso de la madera de poda, el número de racimos o la acidez total, el ácido tartárico y el IPT del mosto (Tabla 43).

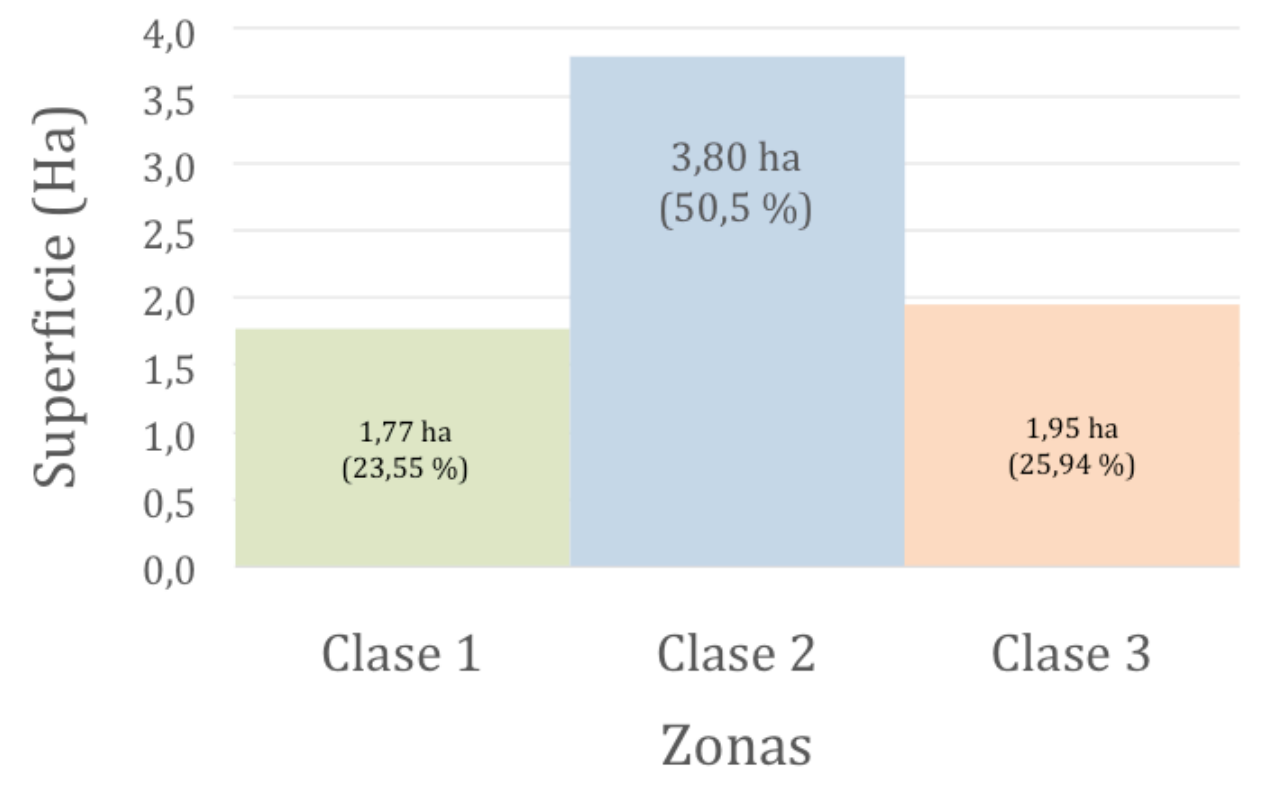

Figura 55. Superficie (ha, \%) por clases como resultado de la Zonificación Integrada del Terroir (ZIT) en las parcelas del ensayo. 
Tabla 43. Matriz de correlación (Pearson) de los parámetros relacionados con la vid (componentes vegeto-productivos y composición de la uva) de la media de años 2012-2015 y el Índice de Calidad (ICA), según la ZIT definitiva (20 sectores).

\begin{tabular}{|c|c|c|c|c|c|c|c|c|}
\hline Variables & PESOMAD & LONG & NRAC & PROD & P100B & GAP & pH & ATOTAL \\
\hline PESOMAD & 1 & & & & & & & \\
\hline LONG & 0,818 & 1 & & & & & & \\
\hline NRAC & 0,680 & 0,362 & 1 & & & & & \\
\hline PROD & 0,799 & 0,868 & 0,633 & 1 & & & & \\
\hline P100B & 0,783 & 0,905 & 0,453 & 0,899 & 1 & & & \\
\hline GAP & $-0,486$ & $-0,640$ & $-0,295$ & $-0,676$ & $-0,598$ & 1 & & \\
\hline pH & $-0,445$ & $-0,349$ & $-0,433$ & $-0,367$ & $-0,376$ & 0,641 & 1 & \\
\hline ATOTAL & 0,790 & 0,528 & 0,807 & 0,634 & 0,501 & $-0,449$ & $-0,398$ & 1 \\
\hline $\mathrm{MH} 2$ & 0,586 & 0,358 & 0,576 & 0,505 & 0,352 & $-0,123$ & 0,126 & 0,788 \\
\hline IC & $-0,560$ & $-0,608$ & $-0,332$ & $-0,706$ & $-0,569$ & 0,702 & 0,347 & $-0,439$ \\
\hline IPT & $-0,704$ & $-0,685$ & $-0,499$ & $-0,788$ & $-0,625$ & 0,777 & 0,524 & $-0,511$ \\
\hline ANTO & $-0,666$ & $-0,712$ & $-0,375$ & $-0,741$ & $-0,651$ & 0,729 & 0,530 & $-0,450$ \\
\hline K & $-0,061$ & $-0,137$ & 0,078 & $-0,060$ & $-0,214$ & 0,312 & 0,628 & 0,273 \\
\hline $\mathrm{TH} 2$ & 0,281 & $-0,119$ & 0,576 & 0,142 & $-0,047$ & $-0,003$ & $-0,155$ & 0,600 \\
\hline ICA & 0,585 & 0,155 & 0,825 & 0,399 & 0,200 & $-0,154$ & $-0,295$ & 0,631 \\
\hline
\end{tabular}

Los valores en negrita son diferentes de 0 con un nivel de significación alfa $=0,05$ 


\begin{tabular}{|r|r|r|r|r|r|r|}
\hline & MH2 & $I C$ & IPT & ANT0 & K & TH2 \\
\hline & & & & & & \\
\hline & & & & & & \\
\hline \\
\hline
\end{tabular}


La relación más interesante para que la validación del método sea positiva es la que permite relacionar el ICA con las variables de composición de la uva, especialmente con aquellas propiedades que están relacionadas con los parámetros descriptivos de la vendimia que tienen mayor importancia desde un punto de vista enológico.

En el plano Biplot obtenido del ACP de las STU propuestas en la ZIT (Tabla 37) y las variables de la Tabla 38 se observa un grupo de STU (N1A, N1B, N2A, N2B, R2A, R2B y R3A) caracterizados por su alto vigor, altos rendimientos, mayor acidez (tanto en ácido tartárico como málico) y menores niveles en el contenido polifenólico (antocianos, IC e IPT), en el grado de alcohol probable y en el pH. En el extremo opuesto se encuentran las observaciones C3A, C3B, C1B, C2B, C1A y M2A. El primer grupo de individuos correlaciona positivamente con el ICA.

Analizando estos resultados junto con los de la Figura 52 (Biplot del ACP según la sectorización inicial) se observa como las STU R3A y R3B se comportan de manera muy diferente $y$, como ya se ha comentado en $\S 6.5 .4$, no es recomendable incluir ambas observaciones en un mismo sector. También se puede apreciar como el sector C3 así como sus STU (C3A y C3B) se sitúa entre los sectores poco vigorosos y de alto contenido polifenólico pero tiene la particularidad de producir mostos con buena acidez, lo que redundará en un mayor equilibrio de la cosecha.

Como se ha comentado, el ICA tiene una correlación con distintas variables, pero no debe olvidarse el problema descrito en el apartado anterior sobre la variabilidad interanual de los parámetros vitícolas frente a la supuesta estabilidad de los parámetros edáficos, por lo que se realiza el análisis ACP para cada una de las cuatro añadas del ensayo (Tablas 44 a 47), obteniéndose resultados similares al ACP de los datos medios: el ICA tiene correlaciones directas con la acidez, el ácido málico y el ácido tartárico e inversas con el GAP, el pH y los compuestos polifenólicos (Tablas 43-47). En las Figuras 57-59 se incluye una representación gráfica de algunas de estas variables enfrentadas al ICA. También es reseñable la importancia del manejo del cultivo en los resultados vegeto-productivos y en la composición de la uva, aspecto que no está integrado en el ICA y que, por lo tanto, podría modificar el resultado de la validación al variar las condiciones del cultivo. 


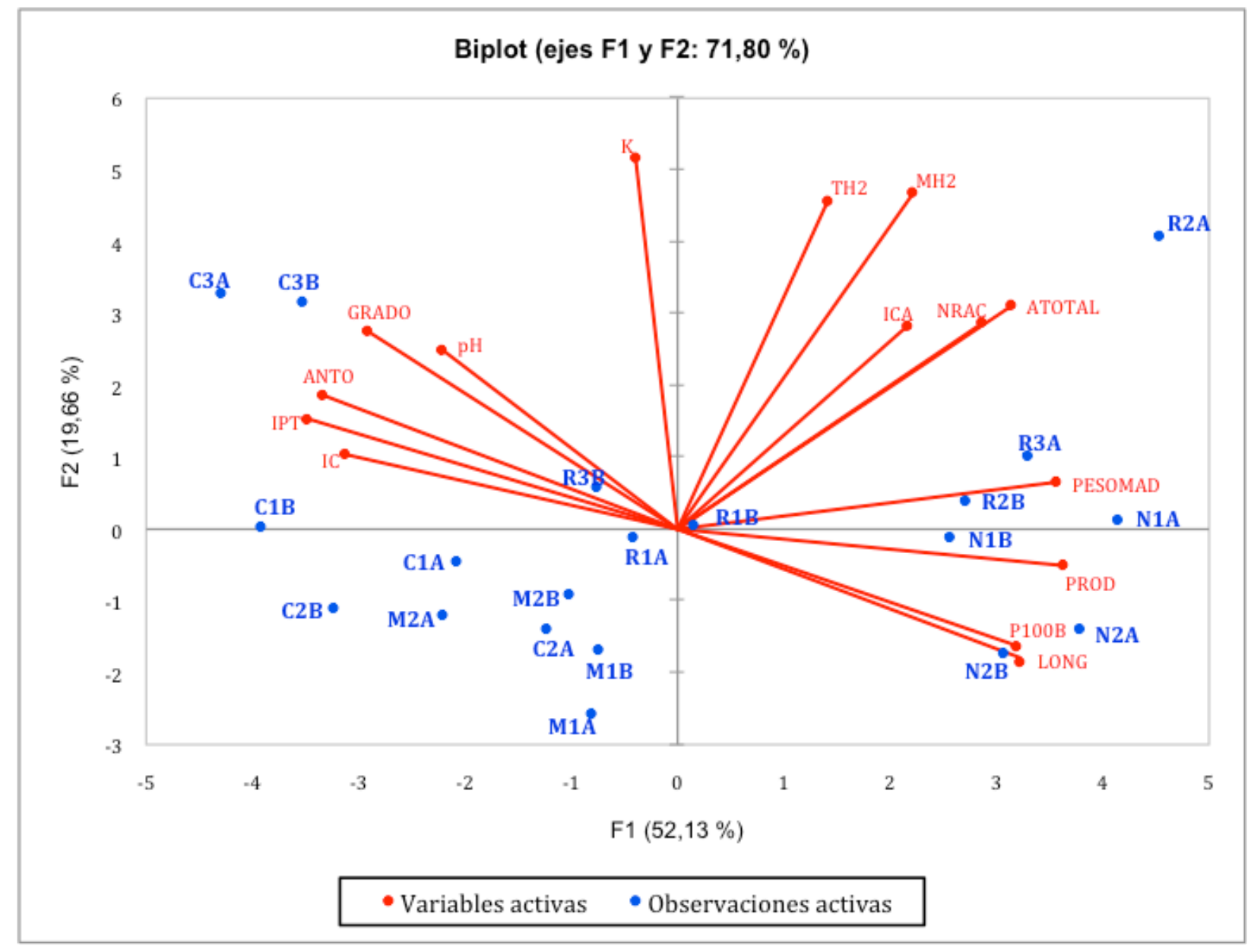

Figura 56. Gráfico Biplot con la distribución de observaciones (20 sectores) y variables (Tabla 43) del Análisis de Componentes Principales según los factores 1 (eje F1: abscisas) y 2 (eje F2: ordenadas) 
Tabla 44. Matriz de correlación (Pearson) de los principales parámetros relacionados con la vid (componentes vegeto-productivos y composición de la uva) del año 2012 y el Índice de Calidad (ICA), según la ZIT definitiva (20 sectores).

\begin{tabular}{|c|c|c|c|c|c|c|c|c|}
\hline Variables & PESOMAD & LONG & NRAC & PROD & P100B & GAP & pH & ATOTAL \\
\hline PESOMAD & 1 & & & & & & & \\
\hline LONG & 0,944 & 1 & & & & & & \\
\hline NRAC & $-0,270$ & $-0,324$ & 1 & & & & & \\
\hline PROD & 0,829 & 0,768 & 0,038 & 1 & & & & \\
\hline P100B & 0,793 & 0,821 & $-0,363$ & 0,773 & 1 & & & \\
\hline GAP & $-0,092$ & $-0,180$ & 0,089 & $-0,242$ & $-0,424$ & 1 & & \\
\hline $\mathrm{pH}$ & $-0,140$ & $-0,221$ & 0,342 & $-0,219$ & $-0,478$ & 0,703 & 1 & \\
\hline ATOTAL & 0,406 & 0,448 & 0,397 & 0,483 & 0,237 & $-0,329$ & $-0,133$ & 1 \\
\hline MH2 & $-0,173$ & $-0,209$ & 0,685 & $-0,064$ & $-0,470$ & 0,403 & 0,783 & 0,360 \\
\hline $\mathrm{IC}$ & $-0,549$ & $-0,650$ & 0,419 & $-0,431$ & $-0,699$ & 0,479 & 0,221 & $-0,209$ \\
\hline $\mathbb{P P T}$ & $-0,425$ & $-0,568$ & 0,383 & $-0,381$ & $-0,705$ & 0,584 & 0,452 & $-0,116$ \\
\hline ANTO & $-0,646$ & $-0,731$ & 0,532 & $-0,517$ & $-0,786$ & 0,421 & 0,384 & $-0,167$ \\
\hline ICA & $-0,346$ & $-0,333$ & 0,422 & $-0,215$ & $-0,409$ & $-0,118$ & 0,006 & 0,211 \\
\hline
\end{tabular}

Los valores en negrita son diferentes de 0 con un nivel de significación alfa $=0,05$ 


\begin{tabular}{|r|r|r|r|r|}
\hline & MH2 & IC & IPT & ANT0 \\
\hline & & & & \\
\hline & & & & \\
\hline & & & & \\
\hline & 1 & & & \\
\hline & 0,245 & 1 & & \\
\hline & 0,425 & 0,836 & & \\
\hline & 0,449 & 0,929 & 0,842 & 1 \\
\hline & 0,368 & 0,363 & 0,188 & 0,407 \\
\hline
\end{tabular}


Tabla 45. Matriz de correlación (Pearson) de los principales parámetros relacionados con la vid (componentes vegeto-productivos y composición de la uva) del año 2013 y el Índice de Calidad (ICA).

\begin{tabular}{|c|c|c|c|c|c|c|c|c|}
\hline Variables & PESOMAD & LONG & NRAC & PROD & P100B & GAP & pH & ATOTAL \\
\hline PESOMAD & 1 & & & & & & & \\
\hline LONG & 0,900 & 1 & & & & & & \\
\hline NRAC & $-0,134$ & $-0,144$ & 1 & & & & & \\
\hline PROD & 0,668 & 0,740 & $-0,002$ & 1 & & & & \\
\hline P100B & 0,568 & 0,570 & $-0,378$ & 0,605 & 1 & & & \\
\hline GAP & 0,251 & 0,149 & $-0,311$ & $-0,044$ & 0,453 & 1 & & \\
\hline $\mathrm{pH}$ & $-0,020$ & 0,004 & $-0,088$ & 0,021 & 0,172 & 0,318 & 1 & \\
\hline ATOTAL & 0,651 & 0,423 & $-0,102$ & 0,185 & 0,231 & 0,124 & $-0,255$ & 1 \\
\hline $\mathrm{MH} 2$ & 0,709 & 0,463 & $-0,062$ & 0,290 & 0,300 & 0,165 & 0,103 & 0,910 \\
\hline IC & $-0,415$ & $-0,336$ & 0,239 & $-0,378$ & $-0,318$ & 0,161 & 0,256 & $-0,470$ \\
\hline IPT & $-0,197$ & $-0,222$ & 0,277 & $-0,404$ & $-0,153$ & 0,293 & 0,641 & $-0,211$ \\
\hline ANTO & $-0,448$ & $-0,373$ & 0,220 & $-0,385$ & $-0,265$ & 0,232 & 0,438 & $-0,510$ \\
\hline K & 0,305 & 0,163 & $-0,100$ & 0,147 & 0,259 & 0,260 & 0,690 & 0,436 \\
\hline $\mathrm{TH} 2$ & 0,358 & 0,157 & $-0,144$ & 0,129 & $-0,095$ & 0,028 & $-0,317$ & 0,766 \\
\hline ICA & 0,608 & 0,437 & $-0,329$ & 0,215 & 0,351 & 0,542 & $-0,168$ & 0,722 \\
\hline
\end{tabular}

Los valores en negrita son diferentes de 0 con un nivel de significación alfa $=0,05$ 


\begin{tabular}{|c|c|c|c|c|c|}
\hline MH2 & IC & IPT & ANTO & K & TH2 \\
\hline & & & & & \\
\hline & & & & & \\
\hline & & & & & \\
\hline & & & & & \\
\hline & & & & & \\
\hline & & & & & \\
\hline & & & & & \\
\hline & & & & & \\
\hline 1 & & & & & \\
\hline$-0,402$ & 1 & & & & \\
\hline$-0,019$ & 0,632 & 1 & & & \\
\hline$-0,383$ & 0,975 & 0,721 & 1 & & \\
\hline 0,697 & $-0,077$ & 0,437 & 0,055 & 1 & \\
\hline 0,657 & $-0,450$ & $-0,331$ & $-0,498$ & 0,313 & 1 \\
\hline 0,670 & $-0,336$ & $-0,216$ & $-0,362$ & 0,296 & 0,699 \\
\hline
\end{tabular}


Tabla 46. Matriz de correlación (Pearson) de los principales parámetros relacionados con la vid (componentes vegeto-productivos y composición de la uva) del año 2014 y el Índice de Calidad (ICA).

\begin{tabular}{|c|c|c|c|c|c|c|c|c|}
\hline Variables & PESOMAD & LONG & NRAC & PROD & P100B & GAP & pH & ATOTAL \\
\hline PESOMAD & 1 & & & & & & & \\
\hline LONG & 0,590 & 1 & & & & & & \\
\hline NRAC & 0,845 & 0,651 & 1 & & & & & \\
\hline PROD & 0,621 & 0,708 & 0,763 & 1 & & & & \\
\hline P100B & 0,711 & 0,701 & 0,762 & 0,832 & 1 & & & \\
\hline GAP & $-0,221$ & $-0,464$ & $-0,423$ & $-0,799$ & $-0,561$ & 1 & & \\
\hline $\mathrm{pH}$ & $-0,496$ & $-0,645$ & $-0,492$ & $-0,693$ & $-0,697$ & 0,691 & 1 & \\
\hline ATOTAL & 0,837 & 0,730 & 0,754 & 0,675 & 0,748 & $-0,266$ & $-0,498$ & 1 \\
\hline $\mathrm{MH} 2$ & $-0,254$ & $-0,038$ & $-0,179$ & $-0,050$ & $-0,054$ & 0,062 & 0,036 & 0,061 \\
\hline IC & $-0,211$ & $-0,206$ & $-0,382$ & $-0,489$ & $-0,306$ & 0,489 & 0,181 & $-0,267$ \\
\hline IPT & $-0,357$ & $-0,139$ & $-0,536$ & $-0,628$ & $-0,418$ & 0,608 & 0,231 & $-0,307$ \\
\hline ANTO & $-0,308$ & $-0,380$ & $-0,485$ & $-0,602$ & $-0,407$ & 0,567 & 0,306 & $-0,380$ \\
\hline K & 0,061 & 0,309 & $-0,004$ & $-0,140$ & $-0,012$ & 0,432 & 0,306 & 0,339 \\
\hline $\mathrm{TH} 2$ & 0,539 & 0,474 & 0,417 & 0,241 & 0,308 & 0,142 & $-0,252$ & 0,741 \\
\hline ICA & 0,791 & 0,344 & 0,788 & 0,432 & 0,439 & $-0,092$ & $-0,267$ & 0,587 \\
\hline
\end{tabular}

Los valores en negrita son diferentes de 0 con un nivel de significación alfa $=0,05$ 


\begin{tabular}{|r|r|r|r|r|r|r|}
\hline & MH2 & $I C$ & IPT & ANTO & $K$ & TH2 \\
\hline & & & & & & \\
\hline & & & & & & \\
\hline \\
\hline
\end{tabular}


Tabla 47. Matriz de correlación (Pearson) de los principales parámetros relacionados con la vid (componentes vegeto-productivos y composición de la uva) del año 2015 y el Índice de Calidad (ICA).

\begin{tabular}{|c|c|c|c|c|c|c|c|c|}
\hline Variables & PESOMAD & LONG & NRAC & PROD & P100B & GAP & $\mathrm{pH}$ & ATOTAL \\
\hline PESOMAD & 1 & & & & & & & \\
\hline LONG & 0,554 & 1 & & & & & & \\
\hline NRAC & 0,711 & 0,207 & 1 & & & & & \\
\hline PROD & 0,672 & 0,532 & 0,826 & 1 & & & & \\
\hline P100B & 0,455 & 0,861 & 0,122 & 0,496 & 1 & & & \\
\hline GAP & $-0,492$ & $-0,272$ & $-0,743$ & $-0,802$ & $-0,303$ & 1 & & \\
\hline $\mathrm{pH}$ & $-0,428$ & $-0,395$ & $-0,691$ & $-0,666$ & $-0,346$ & 0,581 & 1 & \\
\hline ATOTAL & 0,313 & 0,580 & 0,218 & 0,440 & 0,459 & $-0,346$ & $-0,232$ & 1 \\
\hline $\mathrm{MH} 2$ & 0,566 & 0,432 & $-0,014$ & 0,154 & 0,305 & 0,039 & 0,313 & 0,302 \\
\hline $\mathrm{IC}$ & $-0,556$ & $-0,420$ & $-0,541$ & $-0,746$ & $-0,631$ & 0,695 & 0,395 & $-0,388$ \\
\hline IPT & $-0,733$ & $-0,591$ & $-0,750$ & $-0,835$ & $-0,563$ & 0,814 & 0,736 & $-0,432$ \\
\hline ANTO & $-0,659$ & $-0,592$ & $-0,611$ & $-0,755$ & $-0,575$ & 0,668 & 0,760 & $-0,326$ \\
\hline K & $-0,085$ & $-0,137$ & $-0,321$ & $-0,236$ & $-0,187$ & 0,384 & 0,763 & 0,113 \\
\hline $\mathrm{TH} 2$ & 0,024 & $-0,127$ & $-0,049$ & $-0,117$ & 0,018 & 0,348 & 0,149 & 0,147 \\
\hline ICA & 0,678 & 0,108 & 0,872 & 0,650 & 0,021 & $-0,608$ & $-0,498$ & $-0,050$ \\
\hline
\end{tabular}

Los valores en negrita son diferentes de 0 con un nivel de significación alfa $=0,05$ 


\begin{tabular}{|r|r|r|r|r|r|r|}
\hline & MH2 & $I C$ & IPT & ANT0 & $K$ & TH2 \\
\hline & & & & & & \\
\hline & & & & & & \\
\hline \\
\hline
\end{tabular}




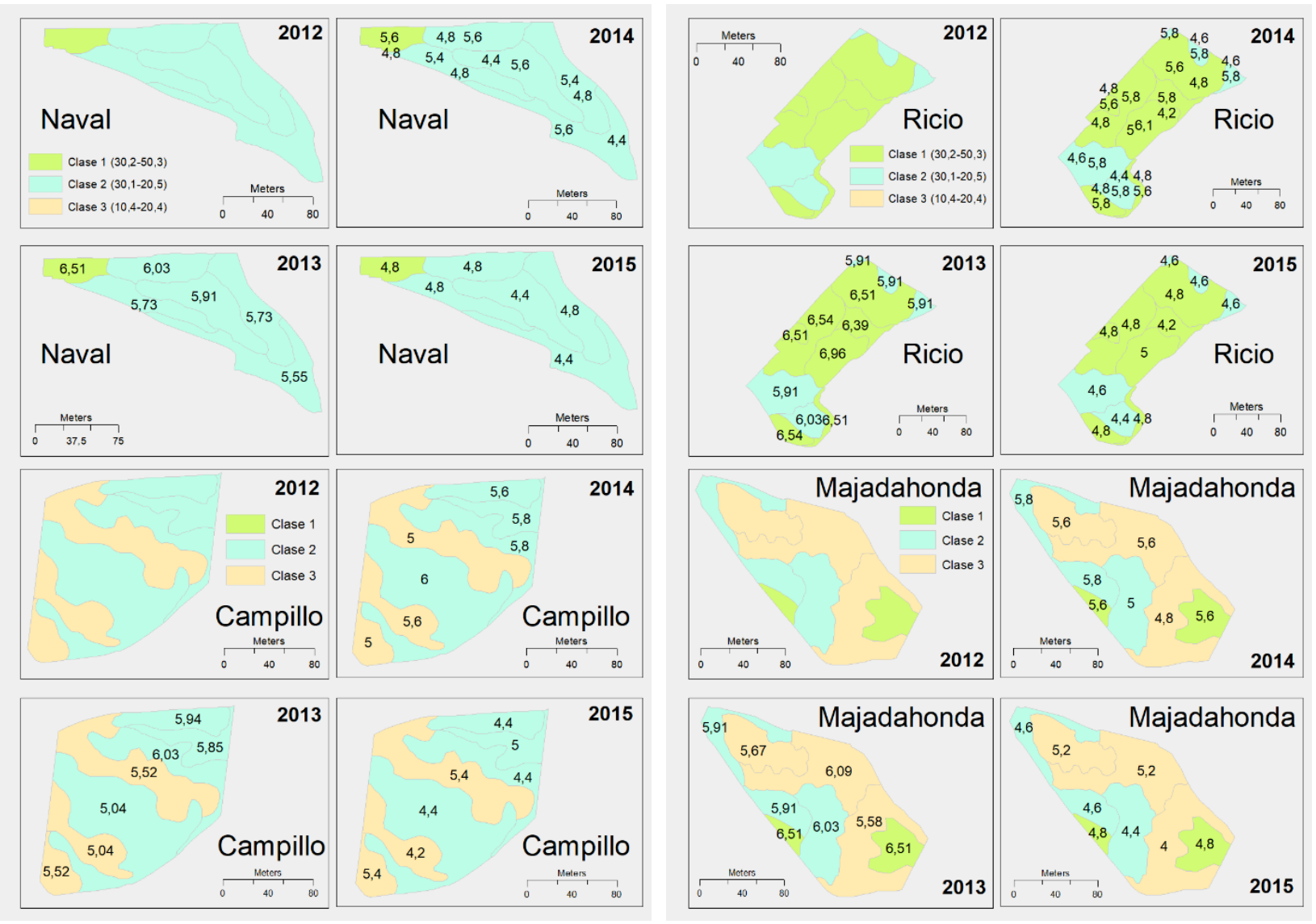

Figura 58. Distribución geográfica del ácido tartárico (TH2, g/l) en las cuatro parcelas del ensayo y durante los cuatro años (etiquetas) en relación con las clases (colores) procedentes de la ZIT (compárese con la Figura 54). 


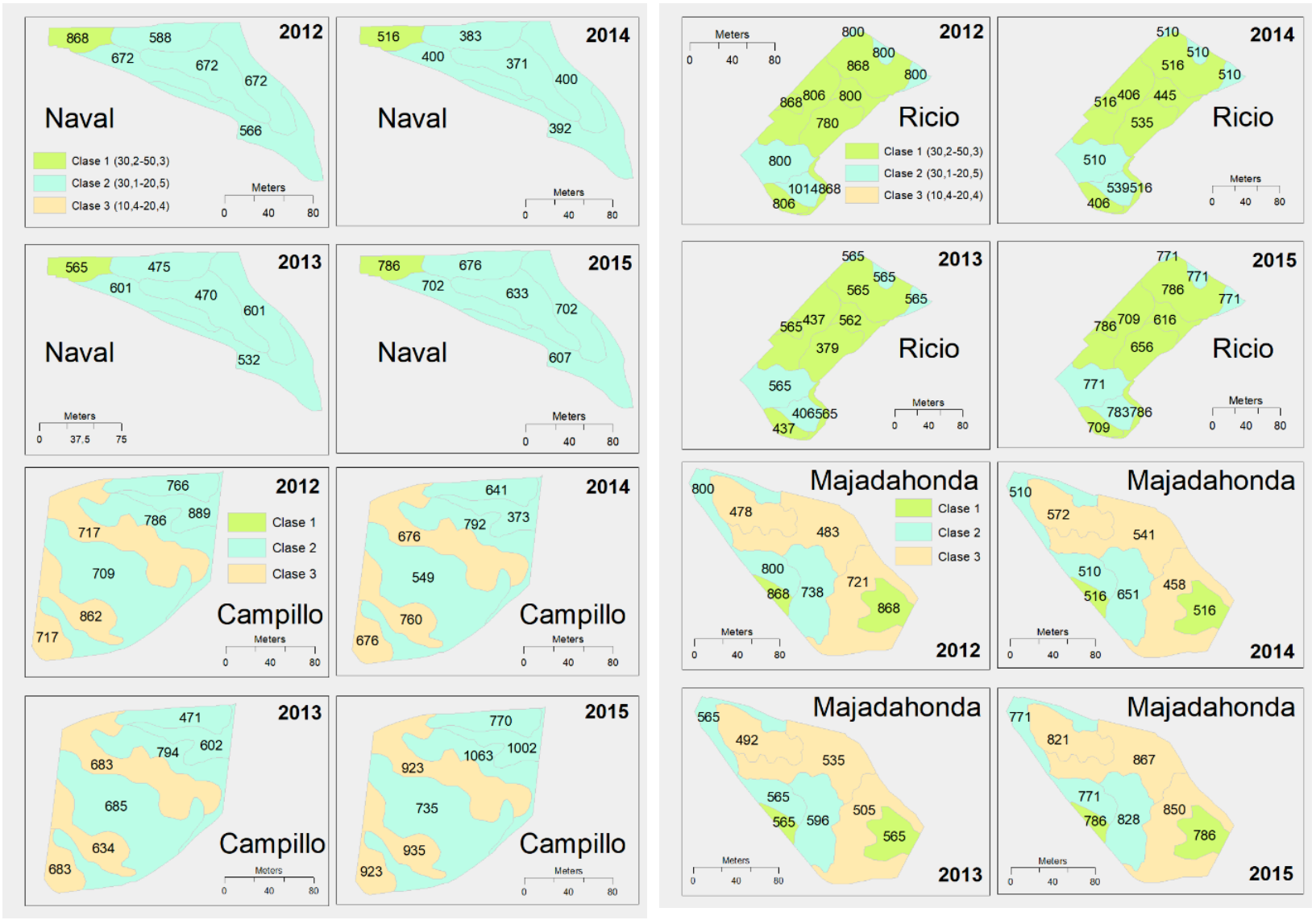

Figura 59. Distribución geográfica del ácido tartárico $(\mathrm{TH} 2, \mathrm{~g} / \mathrm{l})$ en las cuatro parcelas del ensayo y durante los cuatro años (etiquetas) en relación con las clases (colores) procedentes de la ZIT (compárese con la Figura 54). 


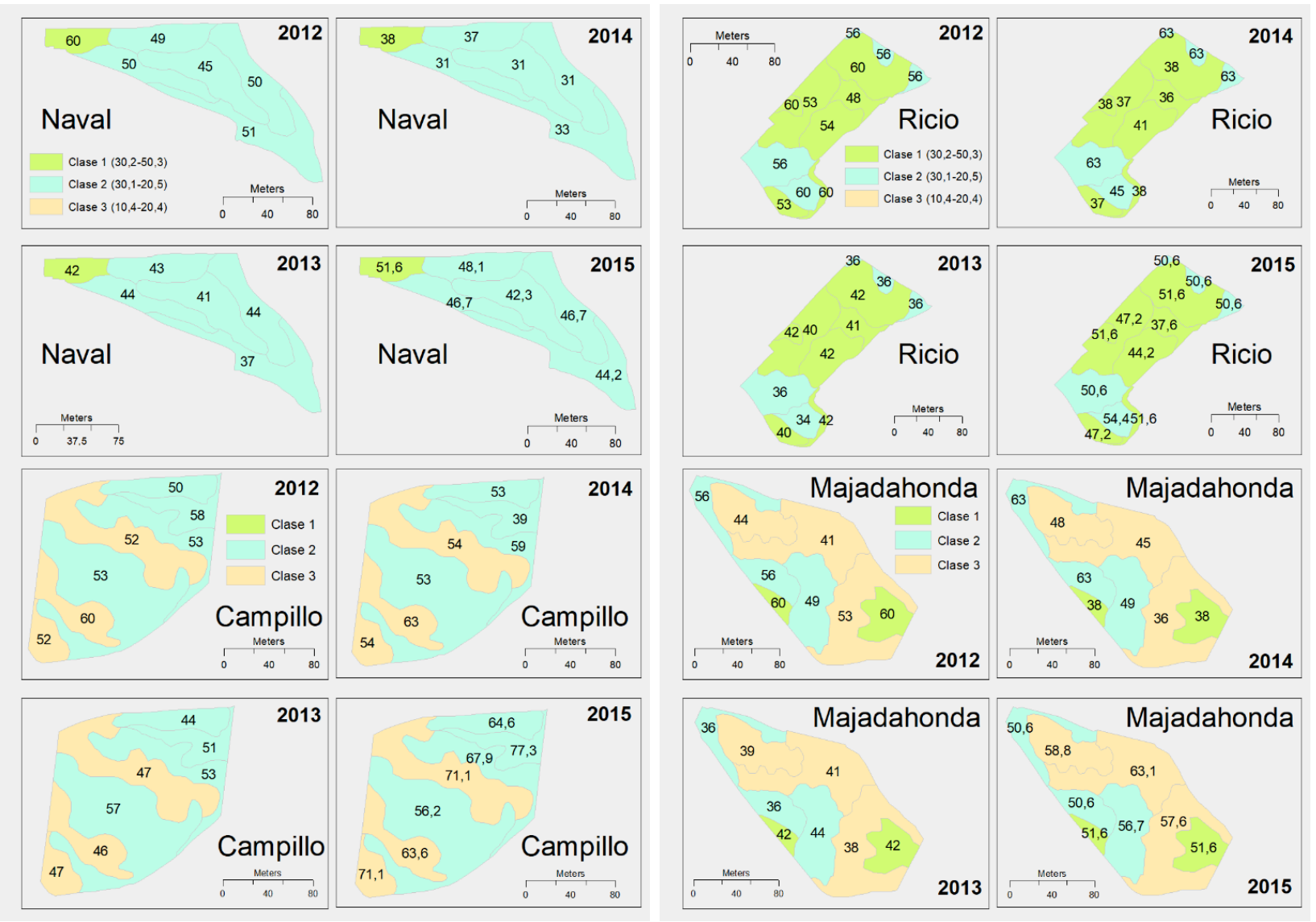

Figura 57. Distribución geográfica del ácido tartárico (TH2, g/l) en las cuatro parcelas del ensayo y durante los cuatro años (etiquetas) en relación con las clases (colores) procedentes de la ZIT (compárese con la Figura 54). 


\subsection{EXTRAPOLACIÓN A LA DO CA RIOJA}

La extrapolación de los resultados de las parcelas del ensayo a toda la DOCa Rioja tiene algunas limitaciones, como las características técnicas del propio mapa de referencia: escala, SMU politáxicas e índice de calidad (ICA) normalizado de 0 a 100. Además, el ICA incluido en el informe final se refiere al de la SMU como media ponderada y no a cada STU (Tabla 5). Por estos motivos, los resultados del ICA de los perfiles de este ensayo no permiten la identificación de sus STU en la cartografía de las SMU de la DO.

La única opción que permite la extrapolación es la comparación de los datos homogéneos e idénticos en los dos conjuntos geográficos, la DO y el ensayo, para lo que se propone la utilización de imágenes multiesprectales. Para realizar esta comparación es necesario efectuar las acotaciones geográficas pertinentes. En concreto, se cartografían las unidades a las que está restringido el ensayo: la zona climática (\$ 6.2), las unidades litogeomórficas (Figura 28; § 6.3) y las SMU (§ 6.4) de la DO en las que se encuentran las STU del ensayo. El resultado de estas acotaciones se representa en la Figura 60.

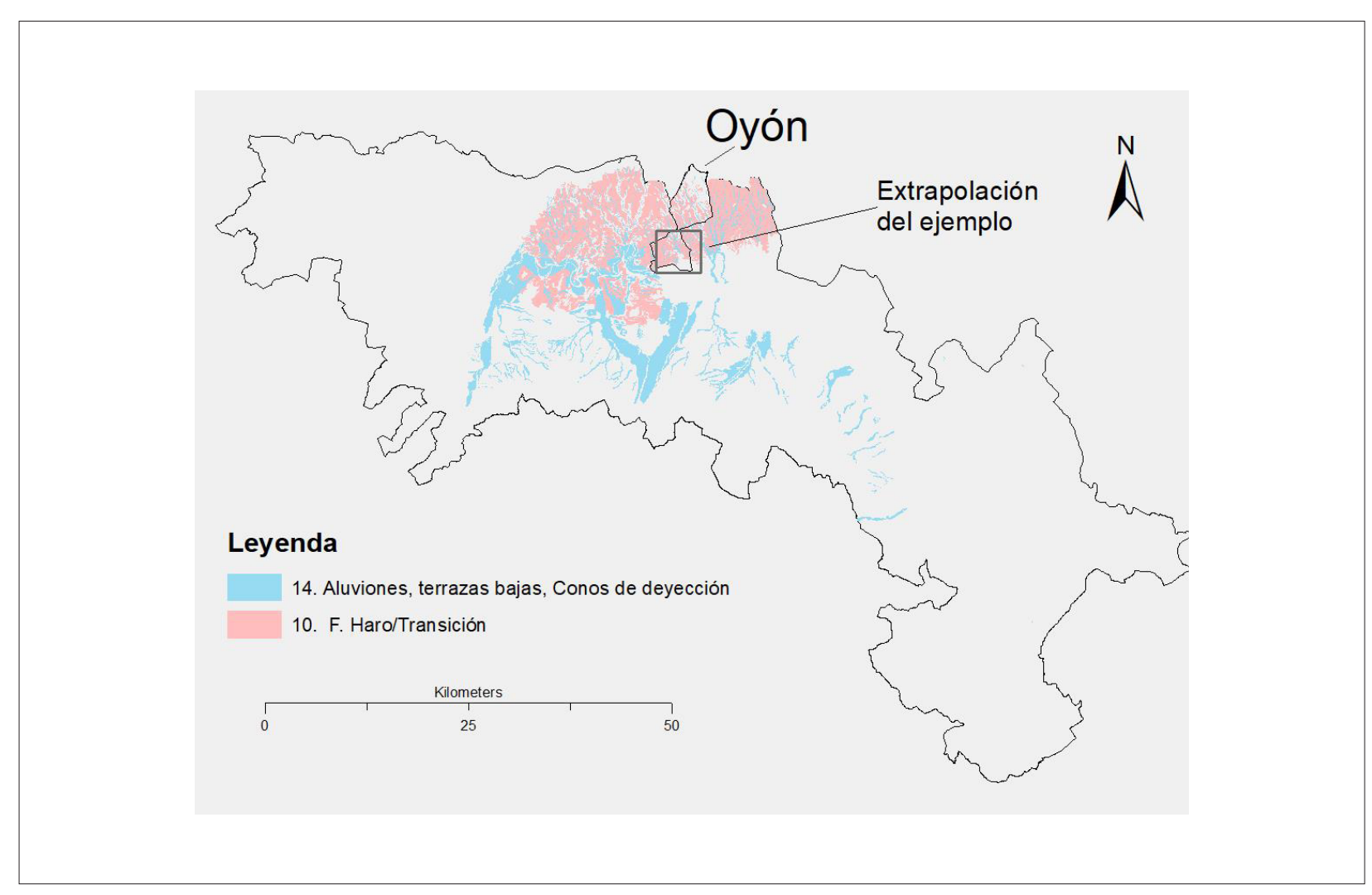

Figura 60. Distribución geográfica de las unidades de la DOCa Rioja a las que es posible realizar la extrapolación de los resultados del ensayo. Se destaca la zona extrapolada en la Figura 61. Elaboración propia a partir de Gómez-Miguel y Sotés (1997).

La extrapolación se ha realizado a partir del NDVI procedente de la imagen del año 2015 utilizada en las parcelas de ensayo. Primero se procedió a calcular los valores máximo y mínimo del NDVI de cada sector limitado en la Figura 47; en segundo lugar, se definieron los límites del NDVI de los sectores con idéntica clasificación (3 clases del ICA) según la ZIT y finalmente, se identificaron estos valores de NDVI en la escena de la DOCa Rioja previamente acotada. Un detalle de esta extrapolación se muestra en la Figura 61.

En la Figura 62 se compara este resultado con el original del estudio de la DOCa Rioja, siendo evidente la mejora en la definición de unidades. 


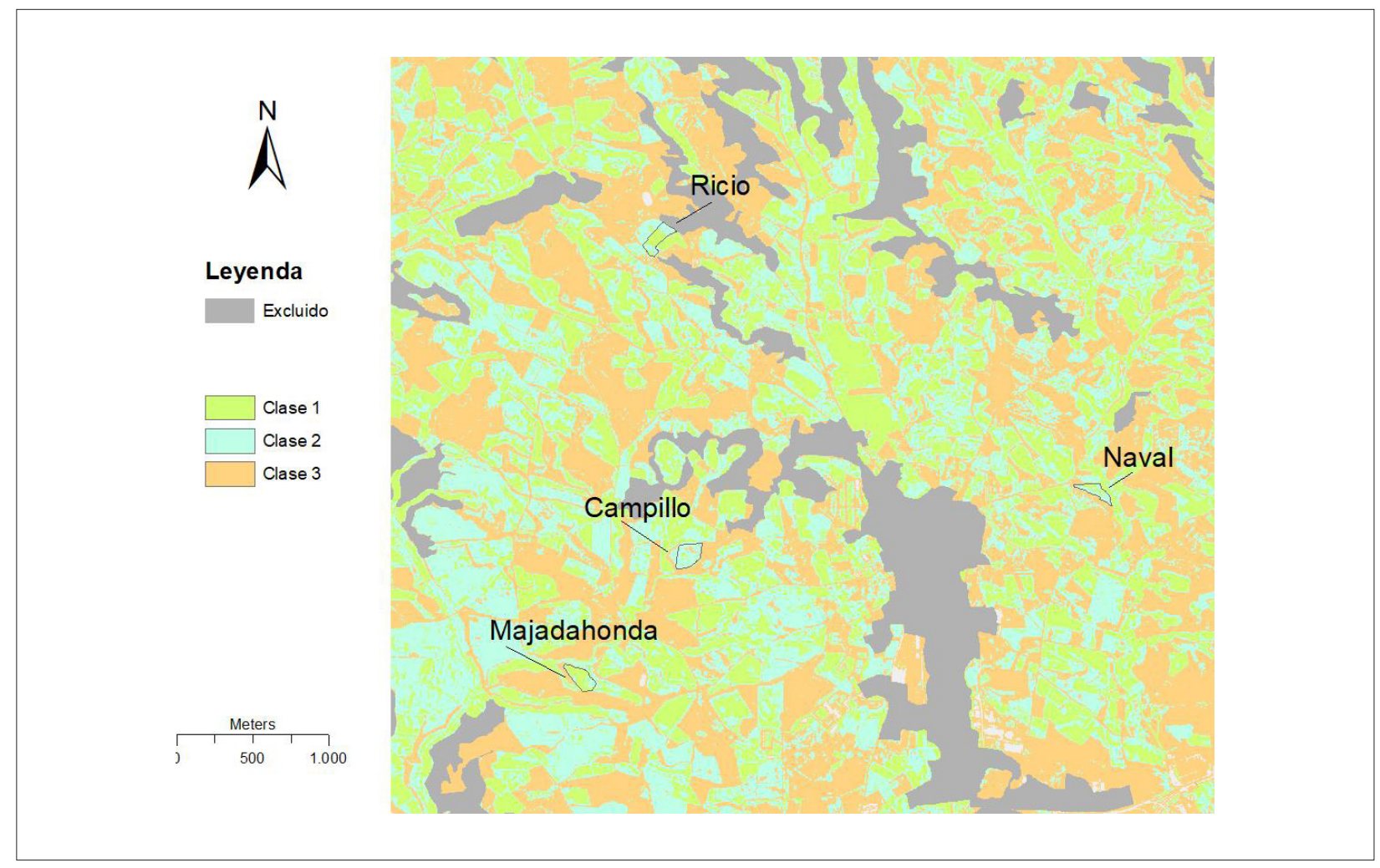

Figura 61. ZIT de la zona geográfica de la DOCa Rioja a la que se han extrapolado los resultados del ensayo: ver la Figura 60. Se incluye la situación de las parcelas de ensayo.

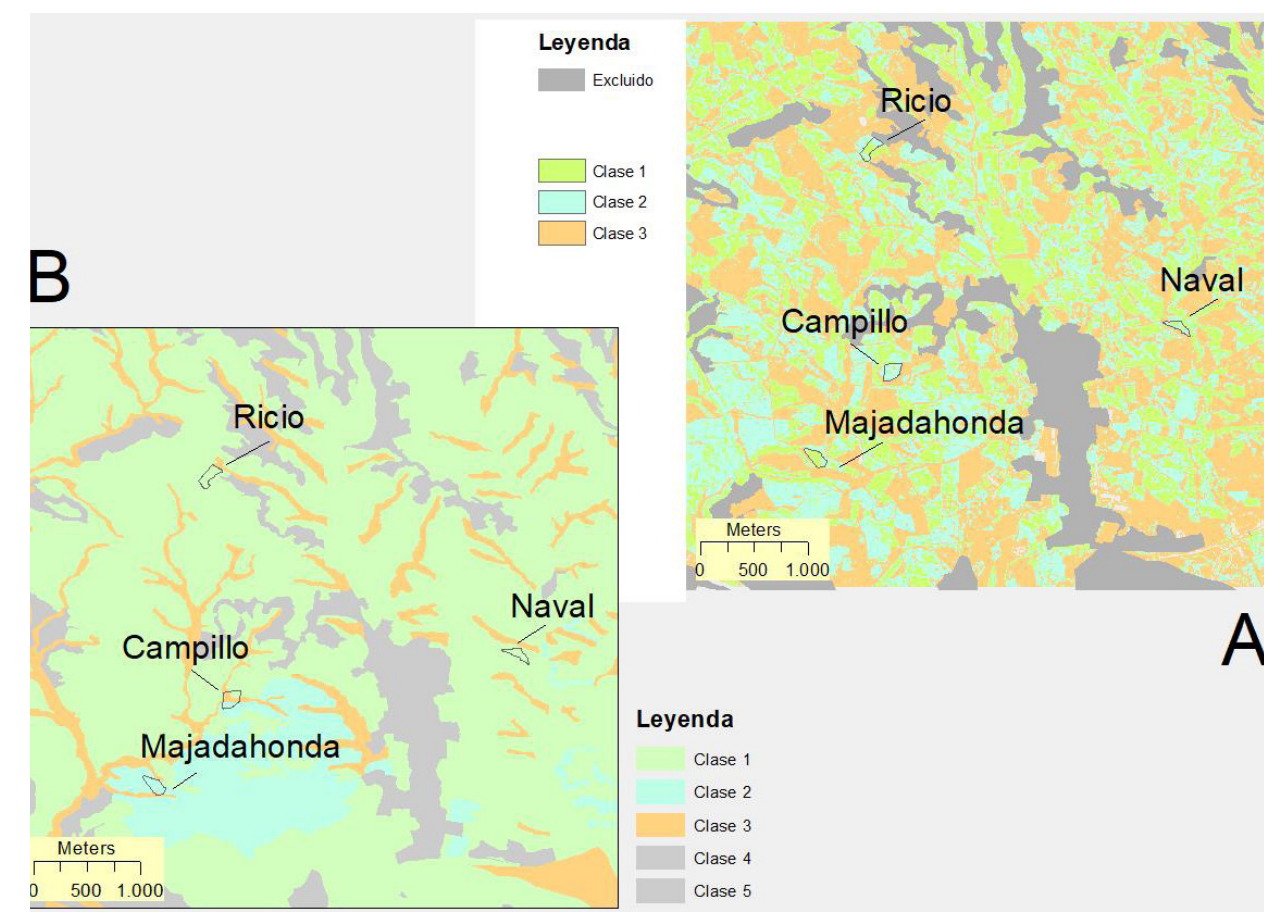

Figura 62. Comparación de la ZIT de la zona geográfica de la DOCa Rioja procedente del resultado de la extrapolación de los datos del ensayo (A) con del estudio a escala original 1:50.000 (B). 


\subsection{CONCLUSIÓN}

Se han encontrado notables diferencias en el clima anual durante los cuatro años de estudio, manifestándose en hasta 20 días de diferencia en la fecha de vendimia, aunque los períodos de tiempo entre los distintos estados fenológicos se mantienen más o menos constantes, por ejemplo, de aproximadamente 108 días entre floración y madurez. También se ha podido comprobar la influencia del clima (principalmente a través del régimen termopluviométrico) sobre el comportamiento de la vid, aumentando el crecimiento vegetativo y el vigor con la disponibilidad hídrica, así como incrementando la acidez y disminuyendo el grado de alcohol probable y el contenido polifenólico en las añadas de temperaturas más suaves, por ejemplo en un año clasificado como templado frente a otro templado cálido (según el MCCS). A nivel intraparcela, la representación gráfica del NDVI se vio modificada por la extrema sequía del año 2012 en la parcela Ricio, invirtiéndose la clasificación de los sectores, pasando los de niveles altos y muy altos el resto de los años a bajos y muy bajos, y viceversa.

Los sectores R2 y R3 de la parcela Ricio y la parcela Naval (suelos profundamente modificados por el agricultor) presentan tanto un carácter vigoroso como elevados rendimientos respecto a las características vegeto-productivas, y producen mostos más ácidos y de menor contenido sacarimétrico y polifenólico. Por el contario, sobre los sectores C1 y C3 de Campillo y los sectores M1 y M2 de Majadahonda se obtienen uvas con mayor contenido en azúcar y polifenoles y menor acidez, y las vides aquí cultivadas son menos vigorosas y menos productivas. El sector C2 (Calcixerept típico, arcillosa pesada, mésica, mixta) de Campillo se caracterizó por producir un rendimiento entre un 20\% y un 35\% superior al de los sectores C1 y C3 de la misma parcela, pero con características del mosto similares a las de estos sectores, evidenciando la importancia de la STU en la producción y composición de la cosecha. Se ha constatado la relación entre el NDVI y el crecimiento vegetativo (longitud y calibre de los sarmientos y peso de la madera de poda) y se ha puesto de relieve la similitud entre la distribución gráfica del NDVI y de la FIA, permitiendo emplear aquella para mejorar la precisión de los límites de la zonificación, una vez comprobada su estabilidad temporal, independientemente de la resolución espacial de la escena multiespectral utilizada (al menos entre 0,5 y 2,5 m/pixel).

De las variables vitícolas analizadas se diferencian tres grupos, relacionados: con el rendimiento (número y peso del racimo, peso de las bayas y producción de la cepa), con el crecimiento vegetativo (longitud y calibre de los sarmientos y peso de la madera de poda) y con el contenido polifenólico (I.C., I.P.T. y contenido en antocianos). Generalizando, las viñas de alto crecimiento vegetativo han generado altos rendimientos y uvas con bajo contenido polifenólico, además de menores contenidos sacarimétricos y de mayor acidez. Por ejemplo, suelos que proporcionan este tipo de respuesta de la planta han sido los del subgrupo Xerofluvent típico, aunque este resultado también puede deberse a la situación topográfica particular, como puede ser la vaguada en la que se sitúa el punto de muestreo R2A, que recoge agua y, por lo tanto, aumenta la disponibilidad hídrica para la planta. Además dentro de este subgrupo se han encontrado respuestas muy distintas, por ejemplo entre R3B y R2A, lo que hace necesario clasificar los perfiles con mayor detalle para conocer su influencia sobre el viñedo.

En la ZIT propuesta se ha utilizado un modelo paramétrico (el mismo que se utilizó en el mapa de gestión de referencia) basado en el ICA para la integración de resultados, así como los resultados vegeto-productivos y de composición de la uva para la validación de la zonificación. Esta validación ha sido positiva encontrando relaciones significativas entre los parámetros determinantes del medio y variables relacionadas con el mosto como el GAP, la acidez y el contenido polifenólico.

Se ha propuesto una metodología de extrapolación de resultados apoyada en la teledetección, en particular en el NDVI, que ha mejorado significativamente la definición de las unidades del estudio original. 


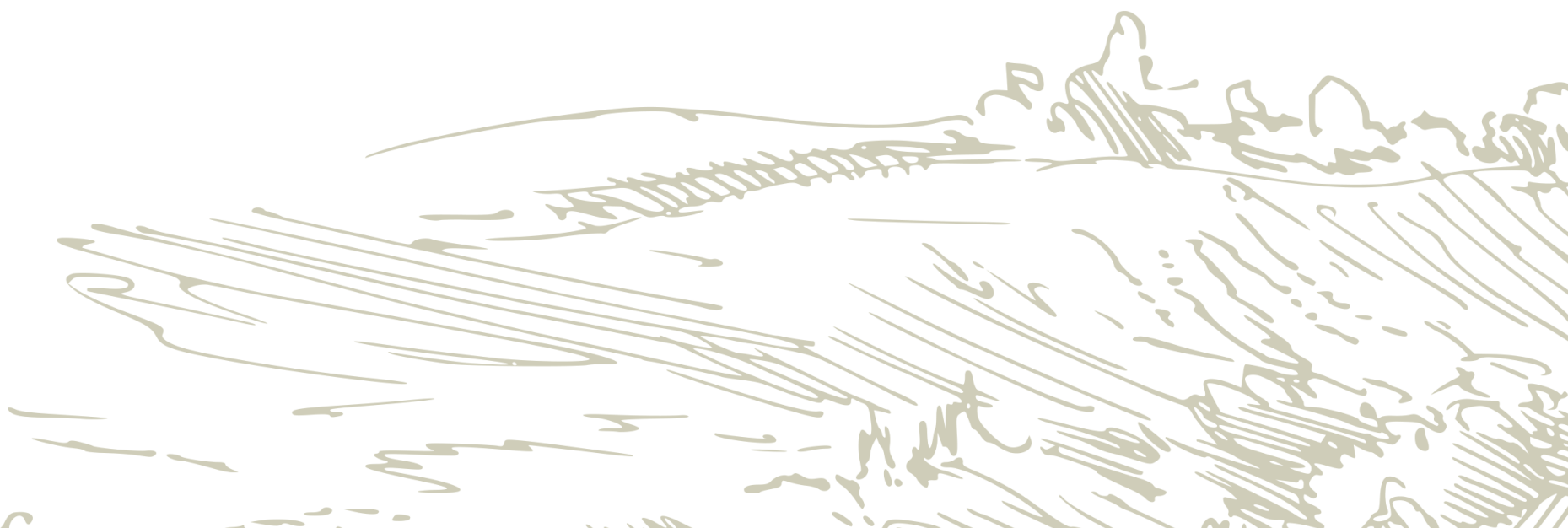

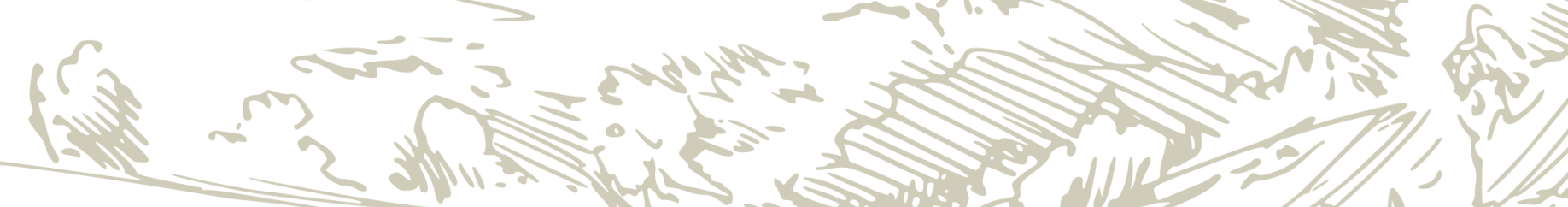




\section{CAPÍTULO 7 \\ Conclusiones}

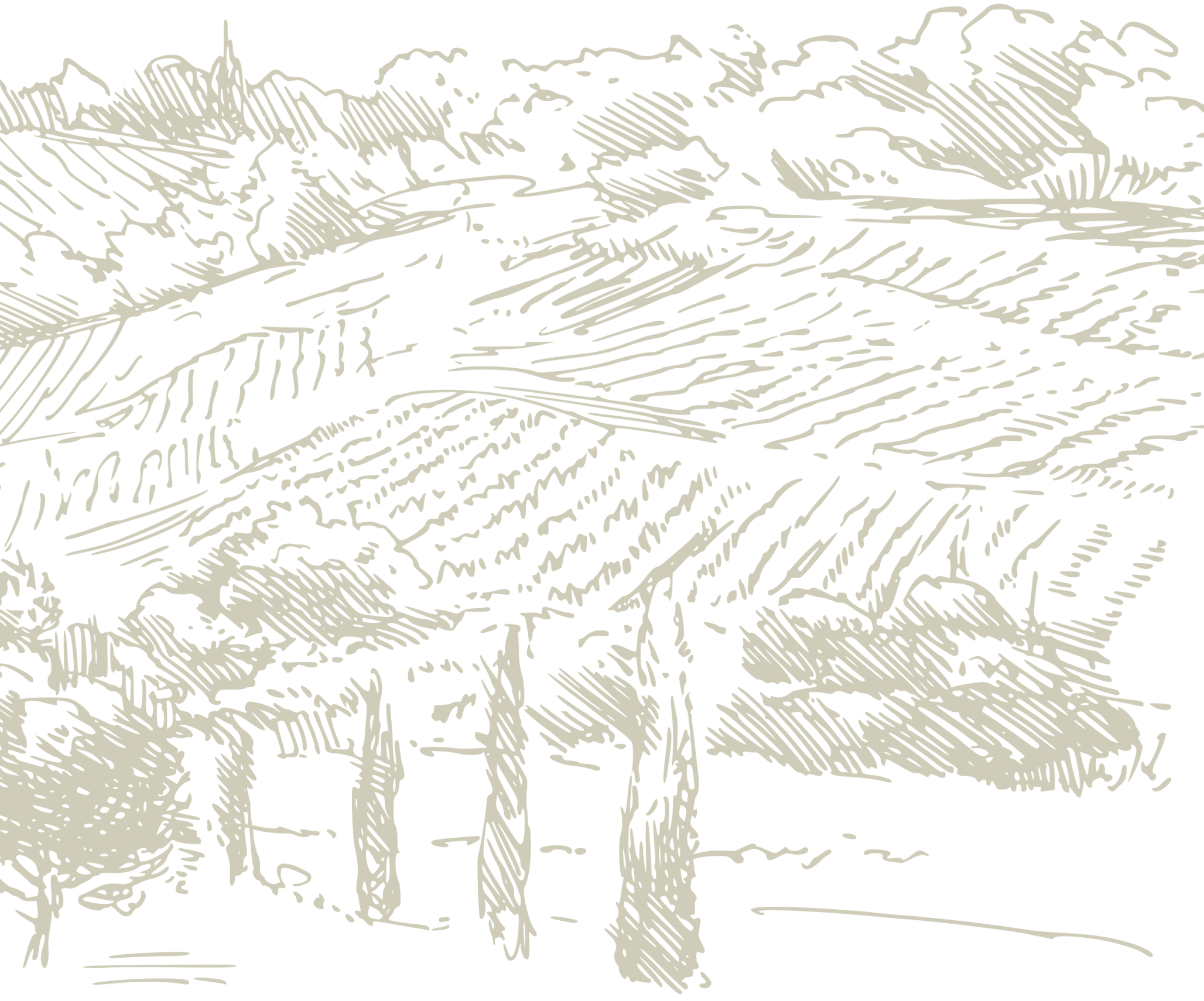



Este estudio se lleva a cabo sobre cuatro parcelas situadas en el municipio de Oyón, en el ámbito de la DOCa Rioja. El clima de la zona, según el MCCS (Tonietto, 1999; Tonietto \& Carbonneau, 2004), es templado cálido, de noches frescas y moderadamente seco, aunque se ha encontrado una alta variabilidad climática interanual durante los cuatro años de estudio. El 85\% del viñedo existente en el municipio de Oyón, se encuentra sobre la formación Facies de Haro-Transición (Martínez \& Gómez-Miguel, 2017), situándose los viñedos del ensayo sobre esta misma formación, bien sobre su origen terciario, bien sobre material cuaternario asociado. Las parcelas se encuentran a una altitud comprendida entre 415 (parcela MAJADAHONDA) y 508 (parcela RICIO) msnm, con desniveles intraparcela de hasta el $15 \%$ (RICIO).

Respecto a los suelos encontrados, se han descrito perfiles incluidos en los órdenes (USDA, 2014) entisol (p.e. Xerorthent típico), inceptisol (p.e. Calcixerept típico) y alfisol (p.e. Haploxeralf típico). En general, los horizontes de los suelos del ensayo tienen $\mathrm{pH}$ alcalino (entre 8,1 y 8,9), están saturados en bases ( $V=100 \%$, principalmente por calcio), sin problemas de salinidad (CE1:5 entre 0,2 y 0,8 dS/m), ni alcalinidad (PSI<10\%) y niveles altos de caliza activa (por encima del $10 \%$ y hasta 17,6 \%) que no deberían suponer un problema habiendo empleado el 41B como portainjerto. En todos los horizontes analizados se encontraron niveles bajos de arena (por debajo del 25\%), y niveles variables de limo (entre 35 y 70\%) y arcilla (entre 20 y 60) con clases texturales (USDA, 2014) variadas: arcilloso, arcillo limoso, franco arcilloso, franco arcillo limoso, franco y franco limoso. Respecto a la fertilidad potencial, cuantificada como CIC, son suelos con niveles bajos o medios (Garrido Valero, 1993) y semejantes a los epipedones de DOCa Rioja citados en la bibliografía por Gómez-Miguel en 2002 (n 592: media 1,4%, DS 0,58) y por Peregrina et al. en 2010 (n 120). Se ha observado cómo la MO aporta una gran parte de CIC, posiblemente por la naturaleza de las arcillas (bajos valores de ALFA), lo que es la causa de la alta correlación entre esta CIC y la MO.

La reserva de agua varía considerablemente de unos perfiles a otros (incluso dentro de un mismo viñedo), desde 54,8 mm (perfil N2B) hasta 195,5 mm (perfil R2B) y se ha podido comprobar la trascendencia de la capacidad de retención de agua del suelo, pudiendo ser determinante este parámetro en la aparición, o no, de estrés hídrico en momentos clave del ciclo vegetativo en función de las características climáticas de una añada particular. Sobre este aspecto, siempre hay que tener en consideración la situación topográfica del punto de muestreo, puesto que localizaciones en lugares dónde se recoge agua afectaran considerablemente a la disponibilidad hídrica para la planta.

Además, son precisamente los suelos con alta capacidad de retención de agua los que se han relacionado, en comparación con los de baja capacidad, con valores altos de NDVI y, a su vez, con propiedades vigorosas del viñedo: alto rendimiento, alto peso de madera de poda, bajo grado de alcohol probable, alta acidez y niveles bajos de IPT y de contenido en antocianos. Una excepción a esta relación se ha presentado en el perfil N2B de la parcela NAVAL, que tiene una reserva de agua de 54,8 mm (la más baja de las encontradas) $y$, sin embargo, el comportamiento del viñedo se asemeja al de los perfiles con mayor capacidad retención de agua. Este perfil se ha clasificado como Haploxerept aquico francofina, pesada, mésica, carbonatada, tratándose, por tanto, de un suelo hídrico y esta es la posible razón de la anomalía observada. Analizando los resultados a escala intraparcela en el viñedo Ricio, se observa un comportamiento anómalo el año 2012 en el sector R2, que el resto de los años se mostró productivo y vigoroso y en este año el crecimiento vegetativo se vio limitado respecto a R1 y R3. El año 2012 fue extremadamente seco, siendo posible que el excesivo déficit hídrico unido a la modificación antrópica del terreno altere las diferencias encontradas entre sectores, aunque se mantenga la estabilidad temporal de la zonificación. Además, el NDVI también ha recogido esta anomalía. 
El efecto del clima sobre las características vitícolas se hizo especialmente presente el año 2013, año atípicamente húmedo y fresco, clasificándose como templado (HI-1) y subhúmedo (DI-1). Este año se obtuvieron mostos con menor contenido sacarimétrico, mayor acidez (tanto en ácido málico como en ácido tartárico) y menor contenido en polifenoles. También el año 2015 se clasificó como Dl-1 pero la vendimia tuvo lugar aproximadamente 20 días antes que en 2013 y además, sus mostos fueron similares a los de los años 2012 y 2014, por lo tanto, se puede concluir que la temperatura (representada a través del HI) durante el ciclo vegetativo es un factor decisivo en la determinación de la fecha de vendimia y en la composición de uva.

Se ha constatado la relación entre el NDVI y el crecimiento vegetativo (longitud y calibre de los sarmientos y peso de la madera de poda) y se ha puesto de relieve la similitud entre la distribución gráfica del NDVI y de la FIA. Al utilizar imágenes multiespectrales de distinta resolución espacial (0,5 y 2,5 m/pixel) se ha podido comprobar la uniformidad en el patrón espacial del NDVI independientemente de dicha resolución y además, la distribución del NDVI no se ve modificada significativamente al realizar segmentaciones o cálculos del NDVI como media de varios píxeles contiguos, siendo suficiente el cálculo pixel a pixel.

La propuesta de ZIT planteada incluye, como aportación metodológica, el uso del NDVI en la cartografía de los límites de los sectores definidos en la etapa inicial a partir de la FIA. En dicha zonificación se ha utilizado un modelo paramétrico (el mismo que se utilizó en el mapa de gestión de referencia) basado en el ICA para la integración de resultados, así como los resultados vegeto-productivos y de composición de la uva para la validación de la zonificación. Esta validación ha sido positiva encontrando relaciones significativas entre los parámetros determinantes del medio y variables relacionadas con el mosto como el GAP, la acidez y el contenido polifenólico. Además, el uso del NDVI a partir de imágenes multiesprectales permitió reducir en un $80 \%$ el número de observaciones necesarias para realizar la zonificación, viéndose lógicamente disminuido el coste total de la zonificación frente a metodologías recomendadas como la de la OIV (2012).

La extrapolación de los resultados a la DOCa Rioja, realizada a través del NDVI, representa una evidente mejora en la definición de las unidades del mapa de gestión de referencia, permitiendo de este modo el uso del mapa original como un mapa de mayor detalle susceptible de ser utilizado en Viticultura de Precisión. 


\section{CAPÍTULO 8 \\ Bibliografía}

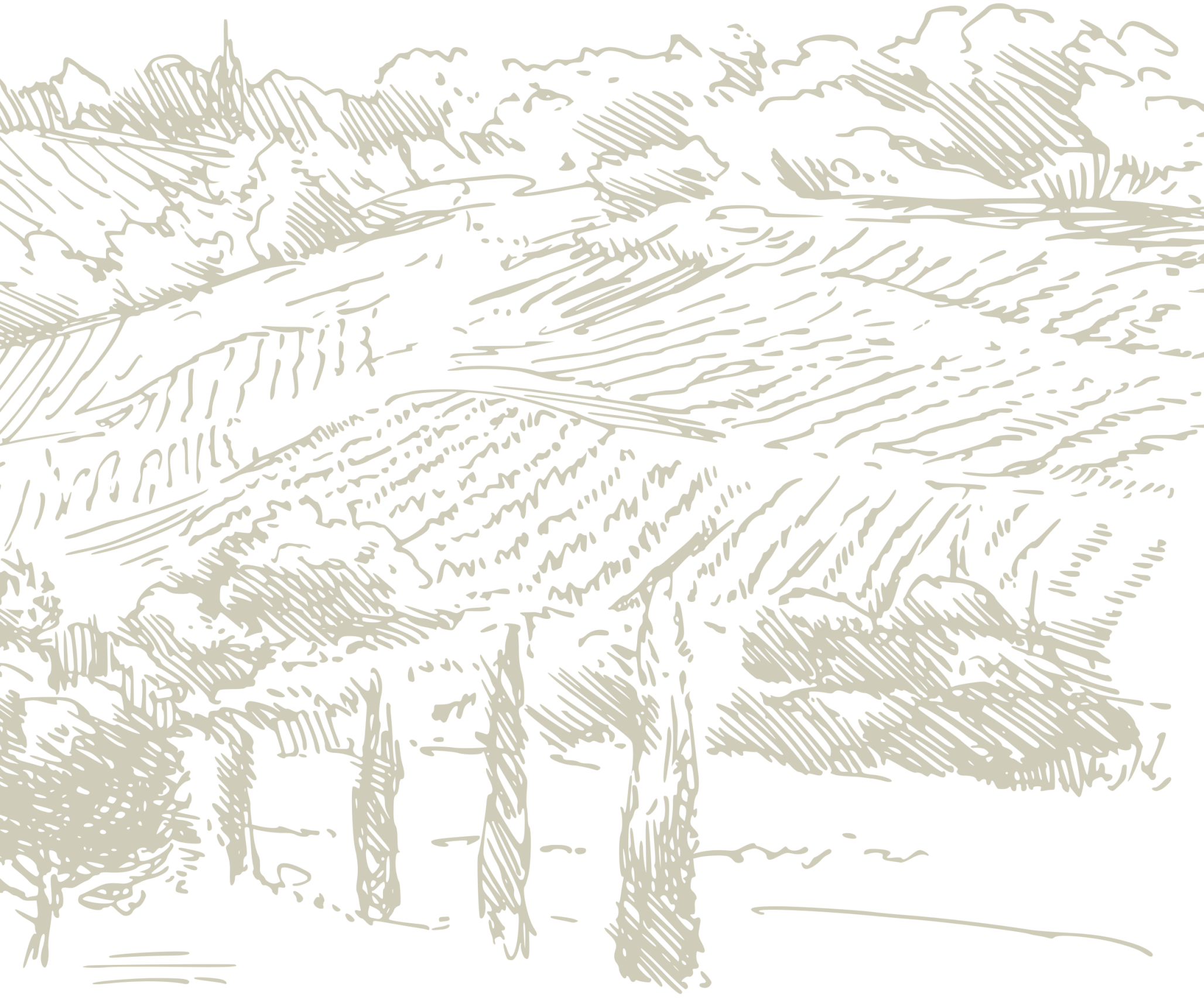





\section{Referencias.}

Abela, E. (1885). El libro del viticultor:Breve resumen de las prácticas más útiles para cultivar las viñas y fabricar buenos vinos: Producción y comercio vinícola: Clasificación y sinonimia de las vides (Ed. facs ed.). Madrid : (): Manuel G. Hernández,.

Acevedo-Opazo, C., Tisseyre, B., Guillaume, S., \& Ojeda, H. (2008). The potential of high spatial resolution information to define within-vineyard zones related to vine water status. Precision Agriculture, 9(5), 285-302.

aemet. (2019). El blog de la agencia estatal de meteorología. Retrieved from https://aemetblog.es/

Amerine, M. A., \& Winkler, A. J. (1944). Composition and quality of must and wines of california grapes. California(USA): Hildargia.

Andrenelli, M. C., Magini, S., Pellegrini, S., Perria, R., Vignozzi, N., \& Costantini, E. A. C. (2013). The use of the ARP৫ system to reduce the costs of soil survey for precision viticulture

Baeza, P. (1994). Caracterización ecofisiológica y evaluación agronómica de diferentes sistemas de conducción del viñedo (vitis vinifera L.) en regadío

Bavaresco, L., Gatti, M., \& Fregoni, M. (2010). Nutritional deficiencies. In S. Delrot (Ed.), Methodologies and results in grapevine researchNutri (pp. 165-191). Dordrecht etc.: Springer.

Becker, N. J. (1977). Experimental research on the influence of microclimate on grape constituents and on quality of the crop. Proceedings of the OIV Symposium on Quality and Vintage. Cape Town. South Africa, 181-188.

Bennet, J. S. (2002). Relationships between carbohydrate supply and reserves and the reproductive growth of grapevines (vitis vinifera L.)

Blanco-Ward, D., Garcia Queijeiro, J. M., \& Jones, G. V. (2007). Spatial climate variability and viticulture in the Miño river valley of Spain. Vitis, 46(2), 63-70.

Bodin, F., \& Morlat, R. (2006). Characterization of viticultural terroirs using a simple field model based on soil depth I. validation of the water supply regime, phenology and vine vigour, in the anjou vineyard (france). Plant and Soil, 281(1-2), 37-54.

Bonilla, I., Martinez de Toda, F., \& Martinez-Casasnovas, J. A. (2015). Vine vigor, yield and grape quality assessment by airborne remote sensing over three years: Analysis of unexpected relationships in CV. Tempranillo. Spanish Journal of Agricultural Research, 13(2), e0903. 
Bramley, R. G. V. (2005). Understanding variability in winegrape production systems - 2. within vineyard variation in quality over several vintages. Australian Journal of Grape and Wine Research, 11(1), 33-42.

Bramley, R. G. V. (2010). Precision viticulture: Managing vineyard variability for improved quality outcomes. In A. G. (. G. Reynolds (Ed.), Managing wine quality (pp. 445-479). Oxford : Boca Raton : (uk): Woodhead ; CRC Press,

Bramley, R. G. V., \& Hamilton, R. P. (2007). Terroir and precision viticulture: Are they compatible? Journal International Des Sciences De La Vigne Et Du Vin, 41(1), 1-8.

Bramley, R. G. V., \& Hamilton, R. (2004). Understanding variability in winegrape production systems 1. within vineyard variation in yield over several vintages. Australian Journal of Grape and Wine Research, 10(1), 32-45.

Bramley, R. G. V., Ouzman, J., \& Thornton, C. (2011). Selective harvesting is a feasible and profitable strategy even when grape and wine production is geared towards large fermentation volumes. Australian Journal of Grape and Wine Research, 17(3), 298-305.

Branas, J. (1946). In Bernon G., Levadoux L. (Eds.), Éléments de viticulture générale. Montpellier. A l'Ecole Nationale d'Agriculture.

Buttrose, M. (1968). Some effects of light intensity and temperature on dry weight and shoot growth of grape-vine. Annals of Botany, 32(128), 753-\&.

Cadet de Vaux, A. (1803). Arte de hacer el vino. Valladolid. Maxtor, edición facsímil de la edición original.

Cambardella, C. A., \& Karlen, D. L. (1999). Spatial analysis of soil fertility parameters.1(1)

Cambardella, C. A., Moorman, T. B., Novak, J. M., Parkin, T. B., Karlen, D. L., Turco, R. F., \& Konopka, A. E. (1994). Field-scale variability of soil properties in central iowa soils. Soil Science Society of America Journal, 58(5), 1501-1511.

Carey, V. A., Saayman, D., Archer, E., Barbeau, G., \& Wallace, M. (2008). Viticultural terroirs in stellenbosch, south africa. I. the identification of natural terroir units. Journal International Des Sciences De La Vigne Et Du Vin, 42(4), 169-183.

Carey, V. A., Bonnardot, V. M., \& Knight, F. (2003). The zoning of terroirs for wine production: South africa. In M. Fregoni, D. Schuster \& A. Paoletta (Eds.), Terroir zonazione viticoltura :Tratatto internazionale (pp. 227-244). Rivoli Veronese: Phytoline.

Carmona, M. J., Chaib, J., Martínez-Zapater, J. M., \& Thomas, M. R. (2008). A molecular genetic perspective of reproductive development in grapevine. Journal of Experimental Botany, 59(10), 2579-2596. 
Chone, X., Lavigne-Cruege, V., Tominaga, T., van Leeuwen, C., Castagnede, C., Saucier, C., \& Dubourdieu, D. (2006). Effect of vine nitrogen status on grape aromatic potential: Flavor precursors (S-cysteine conjugates), glutathione and phenolic content in vitis vinifera L. CV. sauvignon blanc grape juice. Journal International Des Sciences De La Vigne Et Du Vin, 40(1), 1-6.

Chone, X., van Leeuwen, C., Chery, P., \& Ribereau-Gayon, P. (2001). Terroir inluence on water status and nitrogen status of non-irrigated cabernet sauvignon (vitis vinifera)vegetative development, must and wine composition (example of a medoc top estate vineyard, sain julien area, bordeaux, 1997). South African Journal for Enology and Viticulture, 22, 8-15.

Chuine, I., Yiou, P., Viovy, N., Seguin, B., Daux, V., \& Ladurie, E. (2004). Historical phenology: Grape ripening as a past climate indicator. Nature, 432(7015), 289-290.

Clingeleffer, P. (2014). Terroir: The application of an old concept in modern viticulture. In N. K. V. Alfen (Ed.), Encyclopedia of agriculture and food systems (pp. 277-288). Oxford: Academic Press.

Clingeleffer, P., Martin, S. R., Krstic, M., \& Dunn, G. M. (2001). Crop development, crop estimation and crop control to secure quality and production of major wine grape varieties: A national approach. Paper presented at the Final Report to Grape and Wine Research and Development Corporation. CSIRO Plant Industry, Australia.

Coipel, J., Rodriguez Lovelle, B., Sipp, C., \& van Leeuwen, C. (2006). "Terroir" effect, as a result of environmental stress, depends more on soil depth than on soil type (vitis vinifera L. Cv. grenache noir, cotes du rhone, france, 2000). Journal International Des Sciences De La Vigne Et Du Vin, 40(4), 177-185.

Columela, L. J. M. (2008). In Álvarez de Sotomayor y Rubio,Juan María (Ed.), Los doce libros de agricultura. Mairena de Aljarafe (Sevilla). Extramuros.

Constantinescu, G. (1967, Méthodes et principes de détermination des aptitudes viticoles d'une région et du choix des cépages appropriés. Bulletin De L'O.I.V., 441, 1179-1205.

Cook, B. I., \& Wolkovich, E. M. (2016). Climate change decouples drought from early wine grape harvests in france. Nature Climate Change, 6(7), 715-+.

Coombe, B. G. (1995). Growth stages of the grapevine: Adoption of a system for identifying grapevine growth stages. Australian Journal of Grape and Wine Research, 1(2), 104-110.

Cortiula, C., Gautier, F., Slate, A., Salomao, M., Foss, C., Quénol, H., \& Marangon, M. (2018). Intra-site climate variation in an english vineyard. Paper presented at the XIIth International Terroir Congress

CRDOCa Rioja. (2016). Memoria 2015. Logroño: Consejo Regulador de la Denominación de Origen Calificada Rioja. 
Delgado, R., Martin, P., del Alamo, M., \& Gonzalez, M. (2004). Changes in the phenolic composition of grape berries during ripening in relation to vineyard nitrogen and potassium fertilisation rates. Journal of the Science of Food and Agriculture, 84(7), 623-630.

Deloire, A., Carbonneau, A., Wang, Z., \& Ojeda, H. (2004). Vine and water a short review. Journal International Des Sciences De La Vigne Et Du Vin, 38(1), 1-13.

Dobrowski, S., Ustin, S., \& Wolpert, J. (2003). Grapevine dormant pruning weight prediction using remotely sensed data. Australian Journal of Grape and Wine Research, 9(3), 177-182.

Fernández, L. (1999). Caracterización, integración y análisis espacial de variables edafo-climáticas. metodología y aplicación al cultivo del viñedo en la DOCa Rioja

Filippetti, I., Allegro, G., Valentini, G., Pastore, C., Colucci, E., \& Intrieri, C. (2013). Influence of vigour on vine performance and berry composition of cv. Sangiovese (Vitis vinifera L.). Journal International Des Sciences De La Vigne Et Du Vin, 47(1), 21-33.

García de Lujan, A. (2003). Factores para la delimitación de la denominación de origen "Jerez-Xérès-Sherry". In M. Fregoni, D. Schuster \& A. Paoletta (Eds.), Terroir zonazione viticoltura :Tratatto internazionale (pp. 305-312). Rivoli Veronese: Phytoline.

García-Escudero, D. (2007). Experiencias de riego en la DOCa Rioja. In P. Baeza Trujillo, J. R. Lissarrague \& P. Sánchez de Miguel (Eds.), Fundamentos aplicación y consecuencias del riego en la vid (pp. 201-230). Madrid: Editorial Agrícola Española.

Garrido Valero, M. S. (1993). In Ministerio de Agricultura, Pesca y Alimentación (Ed.), Interpretación de análisis de suelos. Madrid. España.

Gladstones, J. (1992). Viticulture and environtment. Australia: Winetitles.

Gladstones, J. (2011). Wine, terroir and climate change [recurso electrónico].]. Adelaide : (at): Wakefield Press,.

Gobierno de Navarra. (2019). Meteorología y climatología de Navarra. Retrieved from www.meteo.navarra.es

Gómez Sánchez, P. J. (1996). Desarrollo de una metodología edafoclimática para zonificación vitícola: Aplicación a la denominación de origen ribera del duero

Gómez-Miguel, V. (2006). Edafología. Atlas nacional de España. Geología, geomorfología y edafología (pp. 7.17.50). Madrid: Centro Nacional de Información Geográfica.

Gómez-Miguel, V. (2011). Terroir. In J. Böhm (Ed.), Atlas das castas da península ibérica :História, terroir, ampelografia (pp. 104-153). Lisboa, Portugal: Dinalivro. 
Gómez-Miguel, V., \& Sotés, V. (1990-2017). Mapa de suelos para la delimitación de zonas vitícolas en la DO Ribera del Duero, en la DO Ca.Rrioja, en la DO Rueda, en la DO Toro, en la DO Bierzo, en la DO Somontano, en la DO Cigales, en la DO Arribes, en la RD Douro y en la DO Campo de Borja. Informes Técnicos ETSIA-ETSIAAB. Universidad Politécnica de Madrid.

Gómez-Miguel, V., Sotés, V., Martínez, A., \& Gonzalez-SanJose, M. L. (2016). Use of remote sensing in zoning's studies for terroir and precision viticulture: Implementation in DO Ca Rioja (Spain). 39th World Congress of Vine and Wine, 7, UNSP 01025.

Hall, A., \& Jones, G. V. (2010). Spatial analysis of climate in winegrape-growing regions in australia. Australian Journal of Grape and Wine Research, 16(3), 389-404.

Hall, A., Lamb, D. W., Holzapfel, B. P., \& Louis, J. P. (2011). Within-season temporal variation in correlations between vineyard canopy and winegrape composition and yield. Precision Agriculture, 12(1), 103117.

Hall, A., Louis, J., \& Lamb, D. (2003). Characterising and mapping vineyard canopy using high-spatial-resolution aerial multispectral images. Computers \& Geosciences, 29(7), 813-822.

Hancock, J. M. (2005). Geology of wine. In R. C. S. R. M. C. R. Plimer (Ed.), Encyclopedia of geology (pp. 85-89). Oxford: Elsevier.

Huggett, J. (2006). Geology and wine: A review. Proceedings of the Geologists Association, 117, 239-247.

Huglin, P. (1978). Nouveau mode d'évaluation des possibilités héliothermiques d'un milieu viticole. Comptes Rendus De L'Académie D'Agriculture De France, 64, 1117-1126.

Huglin, P., \& Schneider, C. (1998). Biologie et écologie de la vigne. Paris: Lavoisier.

Ibáñez, S. (2013). Gestión del suelo en viñedo mediante cubiertas vegetales. incidencia sobre el control del rendimiento y del vigor. astectos ecofisiológicos, nutricionales, microclimáticos y de calidad del mosto y del vino

IGME. (1976). Mapa geológico de españa (1:50.000). cartografía y memoria de la hoja no 204. Madrid: Instituto Geológico y Minero de España.

IGME. (1987). Mapa geológico de españa (1:50.000). cartografía y memoria de la hoja no 171. Madrid: Instituto Geológico y Minero de España.

IGN. (2012). Modelo digital del terreno (MDT05)

Instituto Geográfico Nacional. (2006). Atlas nacional de españa geología, geomorfología y edafología. Madrid: Centro Nacional de Información Geográfica. 
Instituto Geográfico Nacional. (2009). Plan nacional de ortofotografía

Instituto dos Vinhos do Douro e do Porto. (2019). Retrieved from https://www.ivdp.pt/consumidor/historia

Intrigliolo, D. S., \& Ramon Castel, J. (2010). Response of grapevine Cv. 'tempranillo' to timing and amount of irrigation: Water relations, vine growth, yield and berry and wine composition. Irrigation Science, 28(2), 113-125.

IPCC. (2014). In Field, C.B., V.R. Barros, D.J. Dokken, K.J. Mach, M.D. Mastrandrea, T.E. Bilir, M. Chatterjee, K.L. Ebi, Y.O. Estrada, R.C. Genova, B. Girma, E.S. Kissel, A.N. Levy, S. MacCracken, P.R. Mastrandrea y L.L. White (Ed.), Cambio climático 2014: Impactos, adaptación y vulnerabilildad - resumen para responsables de políticas. Ginebra, Suiza: Organización Meteorológica Mundial.

Jackson, D., \& Lombard, P. (1993). Environmental and management-practices affecting grape composition and wine quality - a review. American Journal of Enology and Viticulture, 44(4), 409-430.

Johnson, L., Roczen, D., Youkhana, S., Nemani, R., \& Bosch, D. (2003). Mapping vineyard leaf area with multispectral satellite imagery. Computers and Electronics in Agriculture, 38(1), 33-44.

Jones, G. V. (2006). Climate and terroir: Impacts of climate variability and change on wine. In R. W. Macqueen, L. D. Meinert \& Geological Association of Canada (Eds.), Fine wine and terroir :The geoscience perspective (). St. John's, Canada: Geological Association of Canada.

Jones, G. V., \& Davis, R. E. (2000). Climate influences on grapevine phenology, grape composition, and wine production and quality for bordeaux, france. American Journal of Enology and Viticulture, 51(3), 249-261.

Jones, G. V., Duff, A. A., Hall, A., \& Myers, J. W. (2010). Spatial analysis of climate in winegrape growing regions in the western united states. American Journal of Enology and Viticulture, 61 (3), 313-326.

Jones, G. V., Duff, A. A., \& Myers, J. W. (2006). Modeling viticultural landscapes: A GIS analisys of the viticultural potential in the rogue valley of oregon. Paper presented at the VIth International Terroir Congress, 256-261.

Jones, G. V., Fraga, H., Malheiro, A. C., Moutinho-Pereira, J., Alves, F., Pinto, J. G., \& Santos, J. A. (2014). High resolution climatic zoning of the portugueseviticultural regions. Paper presented at the $X$ th International Terroir Congress,

Jones, G. V., Reid, R., \& Vilks, A. (2012). Climate, grapes, and wine: Structure and suitability in a variable and changing climate. In P. H. Dougherty (Ed.), The geography of wine: Regions, terroir and techniques (pp. 109-133)

Jones, G. V., Snead, N., \& Nelson, P. (2004). Geology and wine 8. modeling viticultural landscapes: A GIS analysis of the terroir potential in the umpqua valley of oregon. Geoscience Canada, 31(4), 167-178. 
Junquera, P. (2011). Influencia de la distancia entre filas y de la densidad de pámpanos en el aprovechamiento de los recursos ambientales y en la respuesta del cv. tempranillo (vitis vinifera L.) conducido en espaldera con riego deficitario

Kliewer, W., \&Torres, R. (1972). Effect of controlled day and night temperatures on grape coloration. American Journal of Enology and Viticulture, 23(2), 71-77.

Lamb, D., Mitchell, A., \& Hyde, G. (2005). Vineyard trellising with steel posts distorts data from EM soil surveys. Australian Journal of Grape and Wine Research, 11(1), 24-32.

Lamb, D., Weedon, M., \& Bramley, R. G. V. (2004). Using remote sensing to predict grape phenolics and colour at harvest in a cabernet sauvignon vineyard: Timing observations against vine phenology and optimising image resolution. Australian Journal of Grape and Wine Research, 10(1), 46-54.

Larrea Redondo, A. (1979). In Instituto de Estudios Riojanos e., La Rioja (Provincia). Diputación Provincial,ed and Patronato José María Quadrado e. (Eds.), Vides de Rioja en su entorno. Logroño: Instituto de Estudios Riojanos: Servicio de Cultura de la Excma. Diputación Provincial.

Leibar, U., Unamunzaga, O., Jose Fernandez-Gomez, M., Galindo-Villardon, P., Castro, C., \& Aizpurua, A. (2018). Benefit of ancillary data acquired at the cooperative level to study soil type and climatic zone influence on berry composition: A case study in Rioja appellation. Oeno One, 52(2), 119-133.

Mackenzie, D., \& Christy, A. (2005). The role of soil chemistry in wine grape quality and sustainable soil management in vineyards. Water Science and Technology, 51(1), 27-37.

MAGRAMA. (2015). Ministerio de agricultura, alimentación y medio ambiente. plataforma de conocimiento para el medio rural y pesquero. Observatorio de tecnologías probadas. Material vegetal.

Martínez de Toda, F. (2011). Claves de la viticultura de calidad: Nuevas técnicas de estimación y control de la calidad de la uva en el viñedo. Madrid: Mundi-Prensa.

Martínez, A., \& Gómez-Miguel, V. (2019). Terroir zoning: Influence on grapevine response (vitis vinifera L.) at whitin-vineyard and between-vineyard scale. In M. Oliveira, \& A. A. Fernandes-Silva (Eds.), Plant Phenology and Vegetation. London: Intecopen.

Martínez, A., \& Gómez-Miguel, V. D. (2017). Vegetation index cartography as a methodology complement to the terroir zoning for its use in precision viticulture. OENO One, 51(3)

Martínez, A., Cámara, J., \& Gómez-Miguel, V. (2014). Vegetation index variability in vinneyards of rioja alta (DOCa Rioja) in different dates. Paper presented at the Xth International Terroir Congress.

Martínez, A., \& Gómez-Miguel, V. (2018). Caracterización del terroir: Influencia en la composición de la uva y relación con el NDVI dentro de la DOCa.Rioja. Paper presented at the XIIth International Terroir Congres. 
Medrano, H., Escalona, J. M., \& Flexas, J. (2007). Indicadores integradores del estado hídrico de la planta. In P. Baeza Trujillo, J. R. Lissarrague \& P. Sánchez de Miguel (Eds.), Fundamentos aplicación y consecuencias del riego en la vid (pp. 15-34). Madrid: Editorial Agrícola Española.

Morlat, R., \& Bodin, F. (2006). Characterization of viticultural terroirs using a simple field model based on oil depth - II. validation of the grape yield and berry quality in the anjou vineyard (france). Plant and Soil, 281(1-2), 55-69.

Morlat, R. (1989). In Université de Bordeaux II. Institut d'Oenologie (Ed.), Le terroir viticole: Contribution a l'etude de sa caracterisation et de son influence sur les vins, application aux vignobles rouges de moyenne vallée de la loire.Tesis Doctoral.

Munsell Color Company. (1990). Munsel soil color charts. Baltimore, Maryland: Macbeth División of Kollmorgen corporation.

OIV (2010). Resolución OIVNITI333/2010. definición de terroir vitivinícola. OIV.

OIV (2012). Resolución OIVNITI 423-2012. Líneas directrices de la OIV sobre metodologías de zonificación vitivinícola a nivel del suelo y del clima. OIV.

Ojeda, H., Carillo, N., Deis, L., Tisseyre, B., Heywang, M., \& Carbonneau, A. (2005). Viticulture de précision et état hydrique. II : Comportement quantitatif et qualitatif de zones intra-parcellaires définies à partir de la cartographie des potentiels hydriques. Paper presented at the XIV Ėmes Journées GESCO, Geisenheim, Allemagne.

Ojeda, H., Deloire, A., \& Carbonneau, A. (2001). Influence of water deficits on grape berry growth. Vitis, 40(3), $141-145$.

Orio, P. (2010). Efectos del deshojado precoz, durante cuatro años, sobre las características de la producción en las variedades tempranillo, mazuelo y graciano (vitis vinifera L.)

Pan-Montojo, J. (2005). La vitivinicultura en el siglo XX: Una perspectiva desde el mediterráneo. In J. Nadal, \& A. Parejo (Eds.), Mediterráneo e historia económica (). Almería: Caja Rural Intermediterránea. Cajamar.

Papadakis, J. (1980). El clima : con especial referencia a los climas de América Latina, Península Ibérica, Ex-colonias Ibéricas y sus potencialidades agropecuarias. Buenos Aires : (ag): Albatros,.

Peregrina, F., López, D., Zaballa, O., Villar, M. T., González, G., \& García-Escudero, E. (2010). Calidad de los suelos de viñedo en la denominación de origen rioja: Indice de riesgo de encostramiento (FAOPNUMA), contenido de carbono orgánico y relación con la fertilidad del suelo. Revista De Ciências Agrárias, 33(1), 338-345.

Pérez, A. (2002). Densidad de plantación y riego: Aspectos ecofisiológicos, agronómicos y calidad de la uva en cV. tempranillo (vitis vinifera L.) 
Pringle, M. J., McBratney, A. B., Whelan, B. M., \& Taylor, J. A. (2003). A preliminary approach to assessing the opportunity for site-specific crop management in a field, using yield monitor data. Agricultural Systems, 76(1), 273-292.

Ramos, M. C., \& Martinez de Toda, F. (2019). Variability of Tempranillo grape composition in the Rioja DOCa (Spain) related to soil and climatic characteristics. Journal of the Science of Food and Agriculture, 99(3), 1153-1165.

Resco, P. (2015). Viticultura y cambio climático en españa: Vulnerabilidad en las distintas regiones y estrategias de adaptación frente a nuevas políticas. (Unpublished Escuela Técnica Superior de Ingenieros Agrónomos. Universdiad Politécnica de Madrid, Madrid.

Reynier, A. (2012). Manual de viticultura. Guía técnica de viticultura. Mundiprensa. Madrid.

Riou, C., Becker, N., Sotés, V., Gómez-Miguel, V., Carbonneau, A., Panagiotou, M., Calo,A., Costacurta,A., de Castro,R., Pinto,A.; Lopes,C., Carneiro,L., Climaco, P. (1994). Le determinisme climatique de la maturation du raisin :Application au zonage de la teneru en sucre dans la communaute europeenne $=$ the effect of climate on grape rigening: Application to the zoning of sugar content in the european community. Luxembourg: Office des Publications Officielles des Communautés Européennes.

Rossi, R., Pollice, A., Diago, M., Oliveira, M., Millan, B., Bitella, G., .. Tardaguila, J. (2013). Using an automatic resistivity profiler soil sensor on-the-go in precision viticulture. Sensors, 13(1), 1121-1136.

Rouse, J. W. J., Haas, R. H., Schell, J. A., \& Deering, D. W. (1973). Monitoring vegetation systems in the great plains with ERTS. Proceedings of the 3rd ERTS Symposium, NASA SP-351 1, 309-17.

Rubio, J. A. (2002). Riego y aclareo de racimos: Efectos en la actividad fisiológica, en el control del rendimienty en la calidad de la uva del cv. Tempranillo (Vitis vinifera L.. )Tesis Doctoral.

Ruhl, E. (2000). Effect of rootstocks and K+ supply on pH and acidity of grape juice. Proceedings of the XxV International Horticultural Congress, Pt 2, (512), 31-37.

Sánchez de Miguel, P. (2007). Producción y distribución de fotoasimilados en la vid (vitis vinifera L.) durante el período de maduración: Cambios en la respuesta fotosintética a la luz de las hojas por factores biológicos, ambientales y culturales.

Sanchez, L., \& Dokoozlian, N. (2005). Bud microclimate and fruitfulness in vitis vinifera L. American Journal of Enology and Viticulture, 56(4), 319-329.

Santesteban, L. G., Guillaume, S., Royo, J. B., \& Tisseyre, B. (2013). Are precision agriculture tools and methods relevant at the whole-vineyard scale? Precision Agriculture, 14(1), 2-17.

Seguin, G. (1986). Terroirs and pedology of wine growing. Experientia, 42(8), 861-873.

Selley, R. C. (2004). The winelands of britain: Past, present and prospective. Dorking: Petravin Press. 
Smart, R. E. (1998). Canopy managment. In B. G. Coombe, \& P. R. Dry (Eds.), Viticulture (1st ed., pp. 85-103). Adelaide, Australia: Winetitles.

Steele, M. R., Gitelson, A. A., Rundquist, D. C., \& Merzlyak, M. N. (2009). Nondestructive estimation of anthocyanin content in grapevine leaves. American Journal of Enology and Viticulture, 60(1), 87-92.

Steele, M., Gitelson, A. A., \& Rundquist, D. (2008). Nondestructive estimation of leaf chlorophyll content in grapes. American Journal of Enology and Viticulture, 59(3), 299-305.

Steenwerth, K. L., Drenovsky, R. E., Lambert, J. -., Kluepfel, D. A., Scow, K. M., \& Smart, D. R. (2008). Soil morphology, depth and grapevine root frequency influence microbial communities in a pinot noir vineyard. Soil Biology \& Biochemistry, 40(6), 1330-1340.

Taylor, J. A. (2004). Digital terroirs and precision viticulture: Investigations into the application of information technology in australian vineyards

Tisseyre, B., \& McBratney, A. B. (2008). A technical opportunity index based on mathematical morphology for site-specific management: An application to viticulture. Precision Agriculture, 9(1-2), 101-113.

Tisseyre, B., Ojeda, H., \& Taylor, J. (2007). New technologies and methodologies for site-specific viticulture. Journal International Des Sciences De La Vigne Et Du Vin, 41(2), 63-76.

Tonietto, J. (1999). Les macroclimats viticoles mondiaux et l'infl uence du mésoclimat sur la typicité de la syrah et du muscat de hambourg dans le sud de la france: Méthodologie de caractérisation.

Tonietto, J. (2017). Geoviticulture MCC system. Retrieved from http://www.cnpuv.embrapa.br/tecnologias/ $\mathrm{ccm} / \mathrm{ccm} \cdot \mathrm{en} \cdot \mathrm{html}$

Tonietto, J., \& Carbonneau, A. (2004). A multicriteria climatic classification system for grape-growing regions worldwide. Agricultural and Forest Meteorology, 124(1-2), 81-97.

Unamunzaga, O. (2010). Zonificación de un viñedo de Rioja Alavesa según las propiedades del suelo y su influencia sobre producción y calidad

USDA. (1975). Soil taxonomy. Soil Survey Staff. Washington, D.C.: USDA. Natural Resources Conservation Service.

USDA. (1993). Soil survey manual. Soil Conservation Service. U.S. Dept. of Agriculture Handbook 18.

USDA. (1994). Keys to soil taxonomy, 6thed. Soil Survey Staff. Washington, D.C.: USDA. Soil Conservation Service.

USDA. (2012). Field book for describing and sampling soils, version 3.0. Soil Survey Staff. Lincoln, NE: Natural Resources Conservation Service. 
USDA. (2014). Keys to soil taxonomy, 12th ed. Soil Survey Staff. Washington, D.C.: USDA. Natural Resources Conservation Service.

USDA. (2017). Soil survey manual Soil Survey Division Staff. U.S. Dept. of Agriculture. Handbook N. 18.

van Leeuwen, C., \& Seguin, G. (2006). The concept of terroir in viticulture. Journal of Wine Research, 17(1), 1-10.

van Leeuwen, C., Bois, B., Roby, J., \& Resseguier, L. (2012). Towards a unified terroir zoning methodology in viticulture. Paper presented at the IXe International Terroir Congress, 81-84.

van Leeuwen, C., Friant, P., Chone, X., Tregoat, O., Koundouras, S., \& Dubourdieu, D. (2004). Influence of climate, soil, and cultivar on terroir. American Journal of Enology and Viticulture, 55(3), 207-217.

van Leeuwen, C., Roby, J., Pernet, D., \& Bois, B. (2012, Methodology of soil-based zoning for viticultural terroirs. Bulletin De L'O.I.V., 83, 947-949.

van Leeuwen, C., Tregoat, O., Chone, X., Bois, B., Pernet, D., \& Gaudillere, J. -. (2009). Vine water status is a key factor in grape ripening and vintage quality for red bordeaux wine. how can it be assessed for vineyard management purposes? Journal International Des Sciences De La Vigne Et Du Vin, 43(3), 121-134.

van Leeuwen, C. (2010). Terroir: The effect of the physical environment on vine growth, grape ripening and wine sensory attributes. In A. G. Reynolds (Ed.), Managing wine quality. V1: Viticulture and wine quality (pp. 273-315). Oxford: Woodhead.

Vasconcelos, M. C., Greven, M., Winefield, C. S., Trought, M. C. T., \& Raw, V. (2009). The flowering process of vitis vinifera: A review. American Journal of Enology and Viticulture, 60(4), 411-434.

Vaudour, E. (2010). Los terroirs vitícolas : Definiciones, caracterización y protección. Zaragoza: Acribia, D.L.

Wagner, P. (1974). Wines, grape vines and climate. Scientific American, 230(6), 107-115.

White, R. E. (2009). Understanding vineyard soils. Oxford ; New York: (xxk): Oxford University Press,.

Wilson, J. E. (1998). Terroir: The role of geology, climate, and culture in the making of french wines. San Francisco: University of California Press.

Wilson, J. E. (2001). Geology and wine 4. the origin and odyssey of terroir. Geoscience Canada, 28(3), 139-141.

Witze, A. (2005). The grapes of rock. Nature, 438(7071), 1073-1074.

Zarco-Tejada, P. J., Catalina, A., Gonzalez, M. R., \& Martin, P. (2013). Relationships between net photosynthesis and steady-state chlorophyll fluorescence retrieved from airborne hyperspectral imagery. Remote Sensing of Environment, 136, 247-258. 


